Office of

ENERGY EFFICIENCY \&

RENEWABLE ENERGY

\title{
Solid-State Joining of Magnesium Sheet to High-Strength Steel
}

February 2021

Piyush Upadhyay (PNNL)

Hrishikesh Das (PNNL)

Jian Chen (ORNL)

Zhili Feng (ORNL)

Hui Huang (ORNL)

Yong Chae Lim (ORNL)

Yuan Li (ORNL)

Donovan Leonard (ORNL)

Xin Sun (ORNL)

Lianghua Xiong (ANL)

Chihpin Andrew Chuang (ANL)

Dileep Singh (ANL)

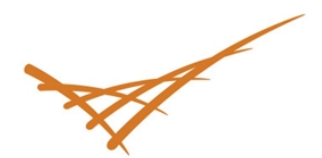

Pacific Northwest

NATIONAL LABORATORY
OAK RIDGE

Argonne

NATIONAL LABORATORY 


\title{
DISCLAIMER
}

This report was prepared as an account of work sponsored by an agency of the United States Government. Neither the United States Government nor any agency thereof, nor Battelle Memorial Institute, nor any of their employees, makes any warranty, express or implied, or assumes any legal liability or responsibility for the accuracy, completeness, or usefulness of any information, apparatus, product, or process disclosed, or represents that its use would not infringe privately owned rights. Reference herein to any specific commercial product, process, or service by trade name, trademark, manufacturer, or otherwise does not necessarily constitute or imply its endorsement, recommendation, or favoring by the United States Government or any agency thereof, or Battelle Memorial Institute. The views and opinions of authors expressed herein do not necessarily state or reflect those of the United States Government or any agency thereof.

\author{
PACIFIC NORTHWEST NATIONAL LABORATORY \\ operated by \\ BATTELLE \\ for the \\ UNITED STATES DEPARTMENT OF ENERGY \\ under Contract DE-AC05-76RL01830
}

Printed in the United States of America
Available to DOE and DOE contractors from the
Office of Scientific and Technical Information,
P.O. Box 62, Oak Ridge, TN 37831-0062;
ph: (865) 576-8401
fax: (865) 576-5728
email: reports@adonis.osti.gov

\author{
Available to the public from the National Technical Information Service \\ 5301 Shawnee Rd., Alexandria, VA 22312 \\ ph: (800) 553-NTIS (6847) \\ email: orders@ntis.gov <https://www.ntis.gov/about $>$ \\ Online ordering: $\underline{\text { http://www.ntis.gov }}$
}




\section{Solid-State Joining of Magnesium Sheet to High-Strength Steel}

February 2021

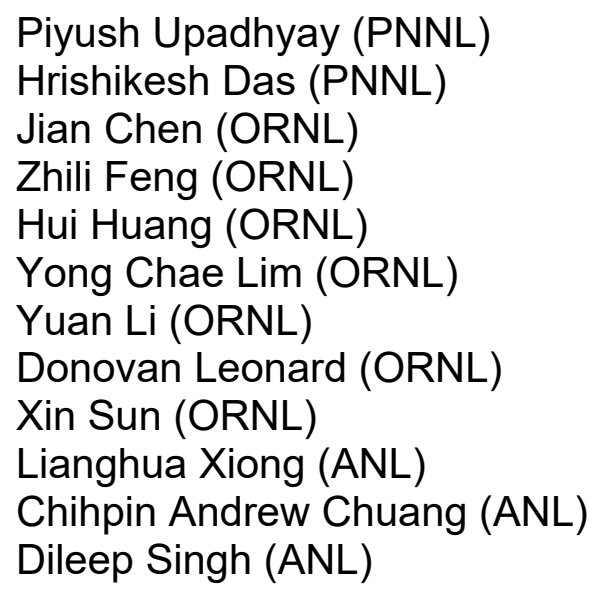

Pacific Northwest National Laboratory Richland, Washington 99354 
PNNL-30945

ORNL/SPR-2021/1836

ANL-21/07

Oak Ridge National Laboratory

Oak Ridge, Tennessee 37830

Argonne National Laboratory

Lemont, Illinois 60439 


\section{Abstract}

Increasing the use of lightweight materials and implementing enabling manufacturing technologies are the two primary paths toward automotive weight reduction. In many situations, the ability to substitute light weight material requires a need to attach and join light weight material to existing steel substructures requiring dissimilar joining technologies. Dissimilar joining methods currently available in cost range for high volume automotive manufacturing face multiple challenges. The problem is exacerbated in the case of Magnesium alloy to steel joints because of their highly dissimilar nature and lack of mutual miscibility. Additionally, Magnesium's poor room temperature ductility complicates the use of point fastening technologies.

Two emerging solid-state joining technologies Friction Stir assisted Scribe welding (FaST) and Ultrasonic Welding (USW) that employ large amount of plastic deformation at the interface were used to investigate, develop, and understand dissimilar joints between Magnesium Alloy to DP590 Steel. Various process responses including interface temperatures, process forces, strain fields were captured during the development of the welding process. Variety of welded samples were tested and characterized to understand the relationship between welding conditions and joints microstructure and mechanical properties. 


\section{Summary}

This document provides a comprehensive report on a collaborative research work in dissimilar joining of Magnesium to Steel. The research work was conducted at Oak Ridge National Laboratory (ORNL), Pacific Northwest National Laboratory (PNNL) and Argonne National Laboratory (ANL) within the Joining Core 1.0 Program. Dissimilar joints between $2.0 \mathrm{~mm}$ AZ31 sheet and $1.0 \mathrm{~mm}$ DP590 were fabricated using FaST at PNNL and USW at ORNL. Fabricated joints were tested and characterized using progressively advanced characterization techniques at all the three labs. The primary goal of this project was to shed light on fundamental joining mechanism at play that results in intimate bonding at the interface of the two immiscible systems of $\mathrm{Mg}$ and $\mathrm{Fe}$. Welds with and without $\mathrm{Zn}$ layers made at various welding conditions were characterized and tested to correlate the welding conditions to joint performance.

The reports first provide a brief overview of current state of the art in dissimilar joining of Mg/Steel by surveying salient prior works. A brief introduction of the two solid state joining technologies is then provided. Experimental details concerning materials, process setup and equipment used is provided with explanations of in-situ process measurements. Subsequently, Section 2.0 provides a comprehensive treatment of experimental results in that includes process responses, microstructural characterization, and various mechanical testing.

Overall accomplishments and understanding gathered as a direct result of this project work are summarized as follows.

1) Viable joints between AZ31 Mg Alloy and DP590 steel considered immiscible systems was demonstrated using Friction stir assisted scribe and Ultrasonic welding methods. With $\mathrm{Zn}$ coating, joint strength is derived from several microns thick $\mathrm{Mg} / \mathrm{Zn}$ eutectic compounds acting as a bridging layer at the interface. Steel - Mg-Zn eutectic layer is the weak-link of the joint.

2) Viable joints in AZ31-uncoated steel, Pure Mg-Steel and Pure Mg-Pure Fe were also fabricated. Upon advanced characterization various elements including $\mathrm{Al}, \mathrm{Fe}$ and complex Oxide were found at the interface. When $\mathrm{Al}$ is present joint strength is derived from nano scale $\mathrm{Al} / \mathrm{Fe} \mathrm{IMC}$. When $\mathrm{Al}$ is absent, we see nano layered Oxygen at the interface in both USW and FSW processes.

3) In both the above cases, viable joints were only possible when both the $\mathrm{Mg}$ and steel interface contained highly refined sub-micron sized grains.

4) While FaST hook provides mechanical strength to the joint, metallurgical bonding in between the hook mediated by either $\mathrm{Mg} / \mathrm{Zn}$ eutectic or oxide layer also contribute significantly. Morphology of the hook feature can aid in overall joint's ductility. Excessive hook size results in premature fracture via Mg sheet.

5) Mechanical testing results obtained in this project enabled Interface by Design (IbD) sister project team to establish and validate cohesive zone model (CZM) enabling joint fracture prediction.

6) The approach established to test and characterize vastly dissimilar joint in lap shear, T peel, $U$ peel and cross tension testing can be used for other dissimilar pairs and to scale up for dissimilar joining from coupon to component level. 
7) For FaST maximum lap shear strength achieved for both coated and uncoated DP 590 steel are almost similar ( 205 N/mm) for a hook size of $\sim 150 \mathrm{um}$. When the hook size is reduced to $<30 \mu \mathrm{m}$ a lap shear strength of $\sim 250 \mathrm{~N} / \mathrm{mm}$ is obtained for uncoated DP590 while for coated DP 590 the joints strength decreased to $\sim 175 \mathrm{~N} / \mathrm{mm}$.

8) For USW, Mg - Zn coated DP590 steel shows the highest average lap shear strength 8 $\mathrm{kN}$, whereas, uncoated DP 590 steel and different Mg alloys (i.e., AZ31B, AZ61, and $\mathrm{AZ} 80$ ) ranged from $3.5 \mathrm{kN}$ to $5 \mathrm{kN}$. 


\section{Acknowledgments}

At PNNL, welding and data analysis activities were supported by $\mathrm{H}$. Das in association with $\mathrm{T}$. Wang. Mechanical testing and characterizations were performed by T. Roosendaal, E. Nickerson, and O. Angel. A. Guzman performed sample preparation. Advanced characterization work was supported by X. Ma and B. At ORNL Gwalani. J. Chen and Y. C. Lim performed and characterized the USW. 


\title{
Acronyms and Abbreviations
}

\author{
APT: Atom probe tomography \\ AS: Advancing side \\ CMOS: Complementary metal oxide \\ semiconductor \\ CPM: Concentration profile map \\ CT: Cross-tension \\ CZM: Cohesive Zone model \\ DIC: Digital image correlation \\ EBSD: Electron back scattered diffraction \\ EDM: Electron discharge machining \\ EDS: Energy dispersive spectroscopy \\ FaST: Friction stir Assisted Scribe Technique \\ FIB: Field Ion Beam \\ HAZ: Heat affected zone \\ HCP: Hexagonal closed pack \\ HDG: Hot dip galvanized \\ IbD: Interface by Design \\ IMC: Intermetallic compound \\ KAM: Kernel Average Misorientation \\ LWW: Longitudinal Whole Weld \\ NDE: Non-destructive evolution \\ PDFs: Powder diffraction files \\ RS: Retreating side \\ RSW: Resistance spot welding \\ SADP: Selected Area Diffraction Pattern \\ SEM: Scanning electron microscopy \\ SPD: Severe Plastic Deformation \\ SR: Swept Radius \\ TC: Thermocouple \\ TEM: Transmission electron microscopy \\ TIG: Tungsten inert gas \\ TWI: The welding Institute \\ TWW: Transverse Whole Weld \\ UFG: Ultra fine grains \\ USW: Ultrasonic welding \\ WCL: Weld Centre Longitudinal \\ XPS: X-Ray Photoelectron Spectroscopy
}




\section{Contents}

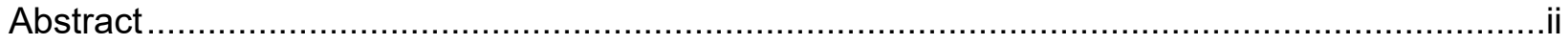

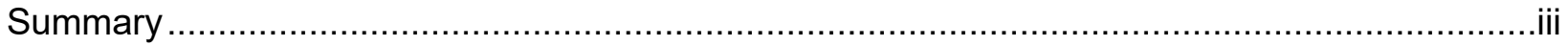

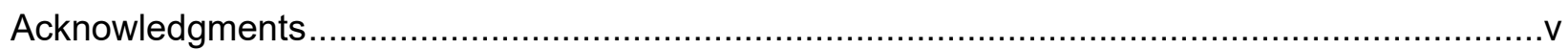

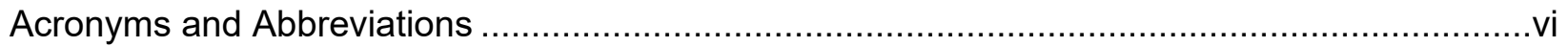

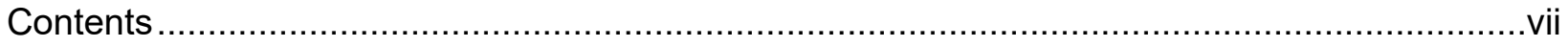

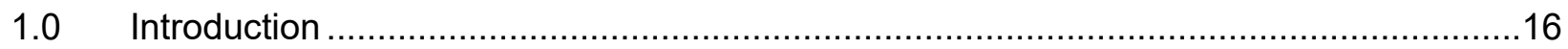

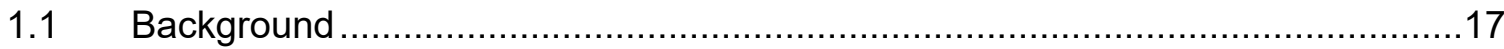

1.1.1 Friction stir assisted scribe technique (FaST) ...............................19

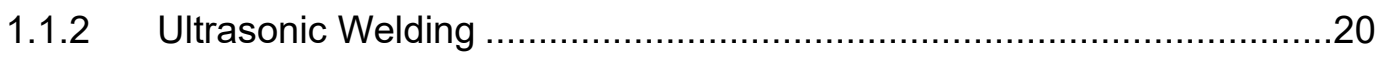

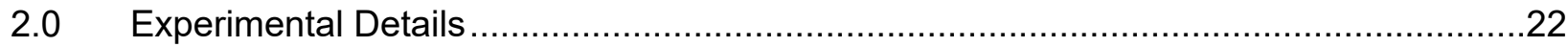

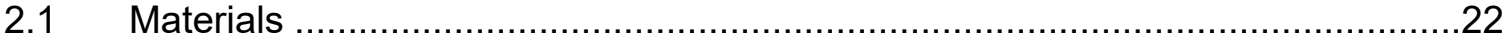

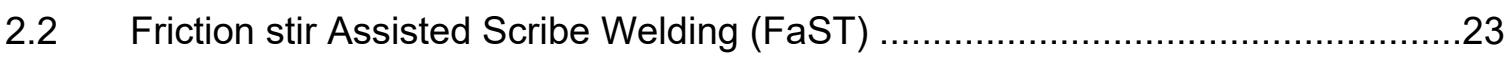

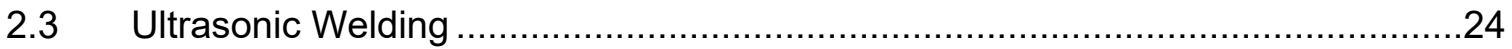

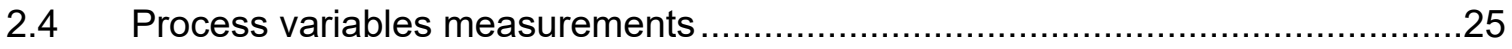

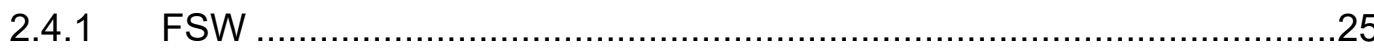

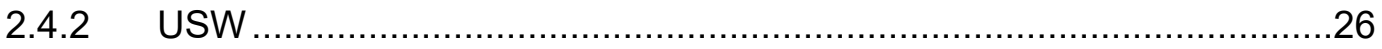

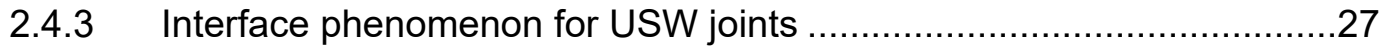

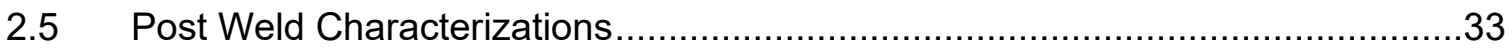

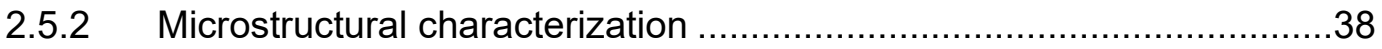

2.5.1 Preliminary corrosion test......................................................... 40

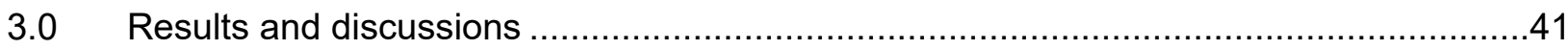

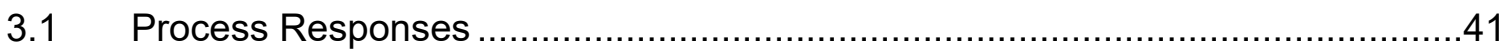

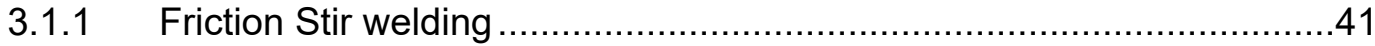

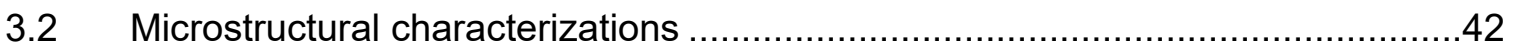

3.2.1 Scanning Electron Microscopy ….............................................. 42

3.2.2 Synchrotron X- Ray Diffraction and Tomography...............................53

3.2.3 EBSD of Pure Mg-Pure Fe joint by FaST ..........................................60

3.2.4 XPS of Pure Mg-Pure Fe joint by USW ..........................................60

3.2.5 Transmission Electron Microscopy................................................63

3.2.6 Atom Probe Tomography .................................................... 70

3.2.7 Micro and Nano Indentation .......................................................

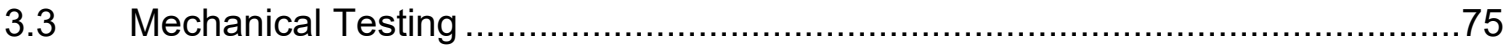

3.3.1 Lap shear testing for AZ31 - coated and uncoated DP 590 steel joint, Pure Mg - DP 590 steel joint and Pure Mg - Pure Fe joints by FaST ................................................................................ 75

3.3.2 T Peel, Cross tension, and U Peel for FaST joints..............................79

3.3.1 Lap shear and U-peel for USW samples........................................81 
3.3.2 Fatigue Testing for USW joints................................................ 82

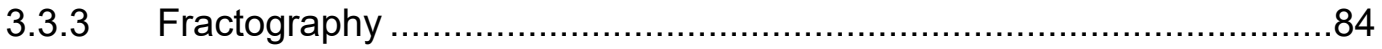

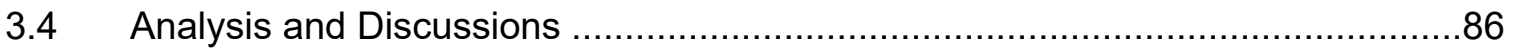

3.4.1 Abnormal Zn flow during FaST process .........................................86

3.4.2 DIC Analysis .................................................................... 88

3.4.3 Preliminary corrosion test of joined samples ...................................90

3.4.4 Cu interface layer reaction for AZ31 - uncoated DP 590 joint by

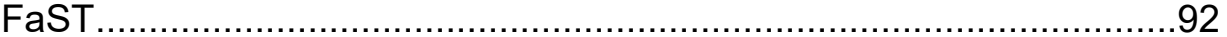

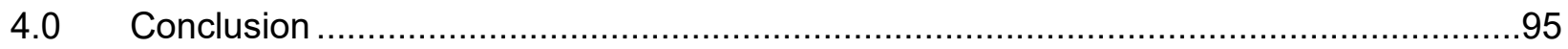

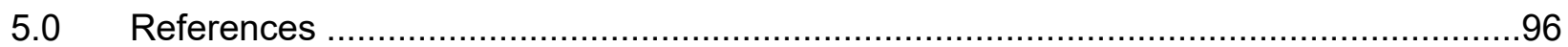

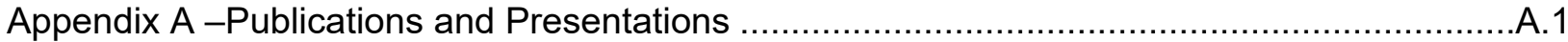

\section{Figures}

Figure $1 \mathrm{Mg}$-Fe Phase Diagram (Source: Literature Review / PNNL).

Figure 2 Schematic of friction stir lap, butt, and spot welding; laser lap and butt welding; hybrid laser and TIG lap and butt welding, USW, RSW, laser-brazing lap welding, and diffusion bonding. (Source: Literature Review / PNNL) .....

Figure 3 Cross sections of $\mathrm{Mg} / \mathrm{steel}$ joints in different configurations made with different welding methods. Source references are shown in brackets (Source: Literature Review / PNNL)

Figure 4 Friction stir scribe technology: Schematic of the process (a) Mg $-\mathrm{Zn}$ coated DP 590 steel, (b) Mg - uncoated DP 590 steel, and (c) weld cross sections illustrating hooking features (Source: PNNL)

Figure 5 Schematic of Friction Stir Welding. (Source: TWI) ............................................20

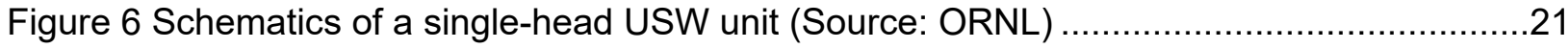

Figure 7 Schematics of a dual-head USW unit (Source: ORNL) .....................................21

Figure 8 EDS analysis on the surface of Zn-removed DP590 indicating no Zn left on the surface (Source: ORNL)

Figure 9 Gantry FSW machine system at PNNL used in this project to produce dissimilar joints, Welding setup ready to make sample for T peel testing. Note that the FaST joining is being performed on the edge of the sample to produce T peel joints. (Source: PNNL).

Figure 10 Long weld for Lap Shear Sample and T-Peel sample (Source: PNNL) ...................23

Figure 11 Different kind of Stitch welds (Source: PNNL).

Figure 12 Wire EDM cut samples shows cut out location from where whole weld longitudinal, weld center longitudinal and regular trasnverse sections for tensile tests were extracted. (Source: PNNL)

Figure 13 Experimental setup to produce USW joint coupons using a single-head welding machine. (Source: ORNL)

Figure 14 FaST process response (Source: PNNL) 
Figure 15 Schematic of (a) experimental setup to measure interfacial relative motion and heat generation and (b) dimension of the joint samples (Source: ORNL) ...........26

Figure 16 Schematic of experimental setup to observe the phenomenon of acoustic softening (Source: ORNL).

Figure 17 Tangential displacement measured at six locations across the interfaces (AZ31B-AZ31B USW joint). (Source: ORNL)...

Figure 18 Overall principal strain measured on the cross-sections of each metal sheet (AZ31B-AZ31B USW joint). (Source: ORNL).

Figure 19 Relative velocity curves across each interface showing sliding (high amplitude) and sticking (low amplitude) motion, as well as the temperature distribution when sticking relative motion was observed (AZ31B-AZ31B USW joint). (Source: ORNL)

Figure 20 Relative velocity curves across each interface showing sliding (high amplitude) and sticking (low amplitude) motion, as well as the temperature distribution when sticking relative motion was observed ( $\mathrm{Zn}$ coated DP590-AZ31B USW joint). (Source: ORNL)

Figure 21 Relative velocity curves across each interface showing sliding (high amplitude) and sticking (low amplitude) motion (bare DP590-AZ31B USW joint). (Source: ORNL)

Figure 22 Temperature history at the center of the joint interface of the USW joints made with different metal pairs (Source: ORNL)

Figure 23 Ultrasonic C-scan NDE analysis (top) of the AZ31B-AZ31B USW weld samples (bottom). Note: FSH, full screen height. (Source: ORNL)

Figure 24 Vertical strain (عyy) and temperature distributions when a short pulse $(0.2 \mathrm{~s})$ of ultrasonic energy was applied indicating the occurrence of acoustic softening (Source: ORNL)....

Figure 25 (a) Different sample preparation from welded plate, (b) Dimensions of crosstension specimen (all dimensions are in $\mathrm{mm}$ ) and image of cross-tension specimen. (Source: PNNL)

Figure 26 (a) T-peel specimen geometry (all dimensions are in $\mathrm{mm}$ ). Blue color represents the AZ31 sheet and orange color represents the DP590 steel sheet, (b) A picture of T-peel sample. (Source: PNNL)

Figure 27 (a) U-peel specimen geometry (all dimensions are in $\mathrm{mm}$ ) and (b) A picture of

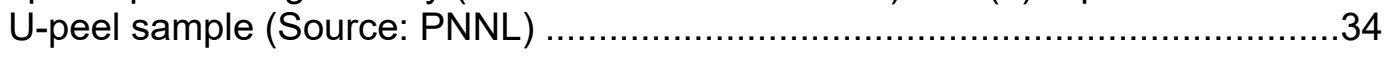

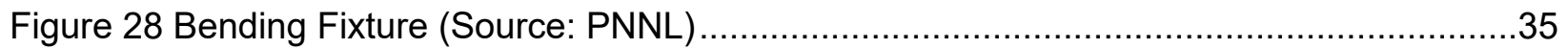

Figure 29 CT sample and U Peel Testing Fixture (Source: PNNL) ......................................36

Figure 30 Stitch weld T Peel samples before testing (Source: PNNL) ...................................36

Figure 31 CT Samples before testing and Problems associated with preparation of CT samples (Source: PNNL)

Figure 32 Different kind of lap shear samples: transverse, whole weld longitudinal,

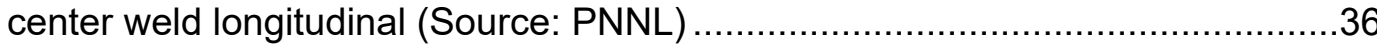

Figure 33 DIC set-up and painted samples before lap shear tests (Source: PNNL) .................37

Figure 34 Schematic of (a) lap shear and fatigue samples and (b) U-peel samples for USW joints (Source: ORNL) 
Figure 35 Joint strength characterizations: (a) lap shear and fatigue testing and (b) Upeel testing (Source: ORNL) ......................................................................

Figure 36 FIB Location at the joint interface (Source: PNNL) ..............................................38

Figure 37 Atom probe tomography of the interface between AZ31 and Steel. (a) APT results when the interface of $\mathrm{Mg}$ rich side and steel was vertical, the all ion density map show a non-uniform density of ions, (b) rotation of the lifted out micro slab using the omni probe manipulator in the FIB and aligned the interface at 45 degree to the field ionization axis, (c) smooth transition from Fe rich side to the Mg rich side. (Source: PNNL) .......................39

Figure 38 Preliminary corrosion testing in the salt spray chamber (Source: ORNL)... 40

Figure 39 Summary of the measured temperature for different joints by FaST process (Source: PNNL).

Figure 40 Thermal cycle at the interface for AZ31-Coated and uncoated DP 590 steel, Pure Mg-Uncoated DP 590 steel and Pure Mg-Pure Fe joints (Source: PNNL)

Figure 41 SEM with EDS mapping at the joint interface for two different temperature conditions (Source: PNNL)

Figure $42 \mathrm{Zn}$ diffusion away from the joint line (Source: PNNL)

Figure 43 FaST processed AZ31 Mg to coated and uncoated DP 590 steel at different temperature (Source: PNNL)

Figure 44 SEM images of the cross-sections of AZ31/HDG-DP590 (Source: PNNL) .44

Figure 45 EDS analysis on interface of AZ31/HDG-DP590 conducted via FAST: (a) SEM of interface of run 1, (b) SEM of selected region with red rectangle in (a), (b1-4) EDS mapping analysis on region shown in (b). Note that MgO layer is marked with white double side (Source: PNNL).

Figure 46 EDS analysis on the interface of AZ31/bare MS270 conducted via FAST: (a) SEM of interface of run 4, (b) SEM of selected region with red rectangle in (a), (b1-4) EDS mapping analysis on region shown in (b), (c) EDS linear scan analysis on red line (Source: PNNL).

Figure 47 Progressively smaller hook size due to reduced scribe engagement (Source: PNNL)

Figure 48 SEM with EDS of AZ31Mg-uncoated DP 590 joint. (a) Joint interface, EDS mapping of (b) Mg, (b1) Fe, (b2) Al; (b3) O. (Source: PNNL)

Figure 49 Morphology and chemical composition at the center of the joint interface on Zn-coated DP590-AZ31B welds produced with low welding energy (1000W for $0.5 \mathrm{~s}$ using the dual-head machine). The inserted line plots represent the quantification of each composition (Source: ORNL).

Figure 50 Interfacial morphology though the joint line of the Zn-coated DP590-AZ31B welds produced with low welding energy (1000W for $0.5 \mathrm{~s}$ using the dualhead machine). (Source: ORNL)

Figure 51 A typical Zn-coated DP590-AZ31B USW lap shear coupon (produced with the single-head machine at $3500 \mathrm{~W}$ for $4 \mathrm{~s}$ ) (Source: ORNL)

Figure 52 Morphology and chemical composition at the center of the joint interface on Zn-coated DP590-AZ31B welds produced with high welding energy ( $3500 \mathrm{~W}$ for $4 \mathrm{~s}$ using the single-head machine). The inserted line plots 
represent the quantification of each composition along the dashed line.

The unit of the horizontal axis is in count. (Source: ORNL)

Figure 53. Morphology near the edge of the joint interface on Zn-coated DP590-AZ31B welds produced with high welding energy ( $3500 \mathrm{~W}$ for $4 \mathrm{~s}$ using the singlehead machine). (Source: ORNL)

Figure 54 Joining bare DP590-AZ31B pairs with varying welding power and time at a constant 280lbs clamping force, and the resultant joint integrity. (Source: ORNL)

Figure 55 Joining bare DP590-AZ31B pairs with varying clamping force and welding time at a constant $3000 \mathrm{~W}$ welding power, and the resultant joint integrity. (Source: ORNL)

Figure 56 Joining bare DP590-AZ31B pairs with varying surface roughness and welding time at a constant $3500 \mathrm{~W}$ welding power, and the resultant lap shear strength. (Source: ORNL) .....

Figure 57 A typical bare DP590-AZ31B USW lap shear coupon (produced with the single-head machine at $3500 \mathrm{~W}$ for $4 \mathrm{~s}$ ) (Source: ORNL)

Figure 58 Cross-section of bare DP590-AZ31B USW joint (a) optical macrograph and (b) SEM image at the center of the joint interface (Source: ORNL).

Figure 59 SEM with EDS of Pure Mg-uncoated DP 590 joint. (a) Joint interface, EDS mapping of $\mathrm{Mg}, \mathrm{Fe}$ and $\mathrm{O}$. (Source: PNNL)

Figure 60 SEM image showing morphology at the center of a bare DP590-pure Mg USW joint (produced with the single-head machine at 3500W for 4s) (Source: ORNL)

Figure 61 Diffraction line scan across Mg-steel interface without $\mathrm{Zn}$ coating layer. Left, schematic illustration of diffraction line scan. Middle, contour plot of diffraction patterns. Right, principal peaks of diffraction patterns evolve across the interface. (Source: ANL)

Figure 62 Diffraction line scan across Mg-steel interface with Zn coating layer. Left, schematic illustration of diffraction line scan. Middle, contour plot of diffraction patterns. Right, principal peaks of diffraction patterns evolve across the interface. (Source: ANL).....

Figure 63 Evolution of intermetallic compound phases across Mg-steel interface. Steel side labels in negative value to the interface while $\mathrm{Mg}$ side is in positive value. Two major phases of $M g Z n_{2}$ and $M_{51} Z_{20}$ are highlighted and phase fraction is tracked by Rietveld refinement (Source: ANL)

Figure 64 Bonded Mg-steel joint without and with $\mathrm{Zn}$ coating. Fe-rich particles can be found deep in Mg side. Crack is susceptible to initiate at the interface and propagate into Mg side. Scale bars are $100 \mathrm{~mm}$ (Source: ANL)

Figure 65 Diffraction patterns of Mg-steel interface under two conditions: without and with $\mathrm{MgO}$ layer. The oxidation peak is identified at the condition with $\mathrm{MgO}$ layer. (Source: ANL)

Figure 66 Series of line-scan diffraction data across bare DP590-pure Mg joint interface. The reciprocal lattice vector $q\left(\AA^{-1}\right)$ is on the $\mathrm{x}$-axis and the distance from interface at which each diffraction pattern recorded is on the $y$-axis. The position of the interface is defined as 0 , where positive direction is magnesium and negative direction is steel. (Source: ANL) 
Figure 67. Evolution of integrated intensity of Mg-HCP peaks along the distance from bare DP590-pure Mg USW joint interface. Intensity of magnesium phase, HCP-100, HCP-002 and HCP-101 peaks, is integrated and plotted against the depth at which the diffraction pattern was recorded (Source: ANL)

Figure 68 Series of line-scan diffraction data across Zn-coated DP590-pure Mg joint interface. The reciprocal lattice vector $q\left(\AA^{-1}\right)$ is on the $\mathrm{x}$-axis and the distance from interface at which each diffraction pattern recorded is on the $y$-axis. The position of the interface is defined as 0 , where positive direction is magnesium and negative direction is steel. (Source: ANL)

Figure 69 Evolution of integrated intensity of Mg-HCP peaks along the distance from $\mathrm{Zn}$ coated DP590-pure Mg USW joint interface. Intensity of magnesium phase, HCP-100, HCP-002 and HCP-101 peaks, is integrated and plotted against the depth at which the diffraction pattern was recorded (Source: ANL)

Figure 70 Phase fraction evolution of crystalline phases detected at different depth from recorded diffraction patterns (Zn coated DP590-pure Mg USW sample): (a) iron and magnesium phases; (b) $\mathrm{Zn}$ and $\mathrm{Mg}_{51} \mathrm{Zn}_{20}$; (c) $\mathrm{MgZn}_{2}$ (Source: ANL)

Figure 71 Macro-cross section and EBSD. (a) SEM macro for joint interface (b: red rectangular section for EBSD), (b1) IPF map, (b2) KAM and (b3) grain boundary orientation map. (Source: PNNL).

Figure 72 XPS depth profile of a pure Fe-pure Mg joint welded in air (Source: ORNL)

Figure 73 XPS depth profile of a pure Fe-pure Mg joint welded in oxygen (Source: ORNL)

Figure 74 XPS depth profile of a pure Fe-pure Mg joint welded in nitrogen (Source: ORNL)

Figure 75 TEM with EDS of AZ31Mg-DP 590 joint. (a) Joint interface; (b) nano steel grains (inset: dislocations marked by red arrows); (c) S/TEM image, EDS mapping of (c1) Fe and Mg, (c2) Al (inset: high magnification view), (c3) $O$; (d) location of two EDS line scans; EDS line scan elemental analysis plots (d1) and (d2), for AZ31Mg-DP 590. (Source: PNNL)

Figure 76 TEM with EDS of pure Mg-DP 590 joint. (a) Joint interface (inset: highcontrast, high-angle annular dark field image with oxide layer at the interface); (b) nanosized steel grains (inset: dislocations, marked by red arrows), (c) S/TEM image with location of EDS line scan; EDS mapping of (c1) Fe and Mg, (c2) O (inset: high magnification view), (d1) line scan elemental analysis plot for pure Mg-DP 590. (Source: PNNL).

Figure 77 Morphology and chemical composition of a FIB sample extracted near the edge of the joint interface on Zn-coated DP590-AZ31B welds produced with high welding energy ( $3500 \mathrm{~W}$ for $4 \mathrm{~s}$ using the single-head machine). (Source: ORNL)

Figure 78 High-angle annular dark field (HAADF) image showing the interfacial morphology and EDS maps showing the chemical composition at the center of a bare DP590-AZ80 USW sample (produced with the singlehead machine at $3500 \mathrm{~W}$ for $4 \mathrm{~s}$ ) (Source: ORNL) 
Figure 79 Chemical composition analysis on a FIB-lifted thin slice extracted from the center of the bare DP590-pure Mg USW joint (produced with the singlehead machine at $3500 \mathrm{~W}$ for $4 \mathrm{~s}$ ) (Source: ORNL)

Figure 80 TEM analysis of Pure Mg-Pure Fe (Source: PNNL)

Figure 81. STEM/EDS analysis of USW joints made with pure Fe and pure $\mathrm{Mg}$ in oxygen rich environment (>99vol\% oxygen). (Source: ORNL).

Figure 82 APT results from the interfacial region of the FaST joint between AZ31 and DP590. (a) schematic showing the region of interest for the APT analysis (notation b, c and d indicates corresponding figures) ; (b) reconstruction showing the Mg ion map from Mg alloy side; (c) reconstructions showing the $\mathrm{Mg}, \mathrm{Fe}, \mathrm{Al}$, and $\mathrm{O}$ maps including the interface between the two alloys; (d) DP 590 steel side. (Source: PNNL). .70

Figure 83 Elemental distribution across the interfacial region of the FaST joint between AZ31 and DP590. (a) Two-dimensional compositional map of the Fe, Mg, $\mathrm{O}, \mathrm{Al}$ and $\mathrm{Zn}$; (b) one-dimensional composition change along a cylinder $10 \mathrm{~nm}$ in diameter and $60 \mathrm{~nm}$ long. (Source: PNNL)

Figure 84. APT chemical analysis of USW joints made with pure Fe and pure $\mathrm{Mg}$ in oxygen rich environment (>99vol\% oxygen). (Source: ORNL)

Figure 85. APT chemical analysis of USW joints made with pure Fe and pure $\mathrm{Mg}$ in in nitrogen shielding gas (<1vol\% oxygen). (Source: ORNL)

Figure 86. Vickers hardness distribution map of top Mg sheet (a), hardness distribution map of bottom steel (b) (Source: PNNL).

Figure 87. Discretized welded zones based on hardness measurements (Source: PNNL) ........74

Figure 88 Representative load vs. displacement curves obtained during nano indentation weld interface (left). Snapshot of joint cross-section at various magnification shows nano indents at AZ31 weld nugget near the interface, IM layer at the interface and steel near the interface. (Source: PNNL)

Figure 89 Comparison of hardness and elastic modulus calculated from nano indentation tests near the weld interface and base material. For IMC, the base represents IMC layer found outside of hooks. (Source: PNNL).

Figure 90 Lap shear tensile test results of welded AZ31/HDG-DP590, AZ31/bare DP590, AZ31/EG-MS270 and AZ31/bare MS270. Pictures of fractured AZ31/bare DP590 and AZ31/bare MS270 are also shown to display the difference in fracture mode: AZ31/HDG-DP590 and AZ31/EG-MS270 fractured the base steel (Source: PNNL) ...

Figure 91 Paint Bake effect lap shear test for AZ341-Coated DP 590 and AZ31-uncoated DP 590 (Source: PNNL) ................................................................76

Figure 92 Lap shear Stitch Vs. Cut welds (Source: PNNL) .76

Figure 93 Process parameters and response during plunging for stitch welds (Source: PNNL)

Figure 94 Lap shear strength comparison for longitudinal and transverse samples

(Source: PNNL).

Figure 95 Comparison of lap shear strength for AZ31-uncoated DP 590 steel, Pure Mguncoated DP 590 steel and pure Mg-Pure Fe (Source: PNNL). 
Figure 96 Different swept radius of scribe and effect on joint strength (Source: PNNL)

Figure $97 \mathrm{~T}$ peel strength for scribe length of (a) $0.3 \mathrm{~mm}$ and (b) $0.35 \mathrm{~mm} \mathrm{AZ31-coated}$

DP 590 steel and AZ31-uncoated DP 590 steel (Source: PNNL).

Figure $98 \mathrm{~T}$ peel results and summary for different conditions and different scribe length welds of AZ31-coated DP 590 steel and AZ31-uncoated DP 590 steel (Source: $P N N L$ ).

Figure 99 Cross tension result for AZ31-coated DP 590 steel and AZ31-uncoated DP 590 steel joints (Source: PNNL).

Figure 100 U Peel results for AZ31-Coated DP 590 steel (Source: PNNL)

Figure 101. Lap shear and U-peel test results of USW joints made with AZ31B and DP590 (Zn coated versus non-coated, both welded with $3500 \mathrm{~W}$ for $4 \mathrm{~s}$ using the single-head machine) (Source: ORNL)

Figure 102. Lap shear and U-peel test results of USW joints made with AZ31B and DP590 (Zn coated versus uncoated) (Source: ORNL)

Figure 103. (a) Results of high cycle fatigue testing on Mg-Steel USW samples with fracture modes and test samples illustrating an interfacial fracture and a Mg fracture (Source: ORNL)

Figure 104. Schematic of DIC strain measurement during fatigue testing (Source: ORNL) .......83

Figure 105. Strain evolution (AZ31B) side during fatigue testing (Source: ORNL) .84

Figure 106 Fractography of broken AZ31/HDG-DP590: (a1) SEM of fractured Mg side and (b1, c1, d1) EDS analysis of Mg side shown in (a1); (b1) SEM of fractured steel side and (b2, c2, d2) EDS analysis of steel side shown in (a2) (Source: PNNL) ....

Figure 107 Fracture location with EDS analysis (Source: PNNL)

Figure 108 Fractographs of longitudinal lap shear samples for AZ31-Uncoated DP 590

(Source: PNNL). .85

Figure 109 Interfacial Fracture after T Peel test (Source: PNNL).....

Figure 110 Surface pictures of different welds. Zinc diffusing upward to top magnesium surface are labelled by red arrows. (Source: PNNL) .......................................86

Figure $111 \mathrm{OM}$ and SEM of cross-sections (Source: PNNL) .87

Figure 112 EDS mapping for Zn flow (Source: PNNL)

Figure 113 DIC analysis snapshots showing the fracture process of AZ31-HDG DP 590 (Source: PNNL).

Figure 114 Strain distribution analysis through the section from DIC (Source: PNNL) .89

Figure 115 Fracture mode through DIC for (a) Longitudinal Whole Weld, (b) Weld Centre Longitudinal (Source: PNNL)

Figure 116 Comparison of lap shear tests for Az31-uncoated DP 590, AZ31-coated DP 590, AZ31-cu interlayer-uncoated DP 590 (Source: PNNL)

Figure 117 AZ31-Zn coated DP 590 steel joint by FaST; After Salt-fog corrosion: front and back side of the joints after $24 \mathrm{hrs}$., $48 \mathrm{hrs}$. and $72 \mathrm{hrs}$. (Source: PNNL)

Figure 118 Lap shear samples before and after fog test AZ31-Zn coated DP 590 steel joint by FaST (Source: PNNL) 
Figure $119 \mathrm{Mg} / \mathrm{Zn}$ coated steel FaST joint cross-section that was exposed to 72 hours inside a salt fog chamber per ASTM B117 showing areas with different extents of corrosion. (Source: PNNL)

Figure 120 Fracture surface and post-corrosion lap shear failure load as a function of salt-exposure time for AZ31-Zn coated DP 590 joints by USW (Source: ORNL)

Figure 121 (a) SEM Cross section of AZ31-Uncoated DP 590 steel joint with Cu interlayer, Cu particles outside the joint regions (b) and EDS mapping (b1); Different magnification images close to the interface (c)-(c2), (d) Cu layer and $\mathrm{Mg}$ side with a thin interlayer at the interface, EDS elemental mapping of section $\mathrm{d},(\mathrm{d} 1) \mathrm{Mg}$ and $\mathrm{Cu},(\mathrm{d} 2) \mathrm{Al},(\mathrm{d} 3) \mathrm{O}$.

Figure 122 (a) SEM Cross section of another location of AZ31-Uncoated DP 590 steel, (b) high mag. image of section $b$ (marked red in (a)), (c) Eutectic formation at the interface, EDS elemental mapping at section c, (c1) $\mathrm{Cu}$ and $\mathrm{Al},(\mathrm{c} 2) \mathrm{Mg}$ and $\mathrm{O}$, (c3) Fe.

Figure 123 (a) SEM image showing line scan through Mg-Cu interlayer and Steel, (b) EDS line scan elemental profile.

Figure 124 EDS point analysis at different locations towards the $\mathrm{Mg}$ side and at the interface (corresponding formation of probable IMC's mentioned in the table)

\section{Tables}

Table 1. Chemical composition of DP590, unit in wt\% (no Zn coating)..... .23

Table 2. Chemical composition of AZ31B, AZ61, AZ80, Pure Mg unit in wt\% 


\subsection{Introduction}

Decreasing the weight of automobiles can directly contribute to the goal of reducing fuel consumption and emission. Increasing the use of lightweight materials and implementing manufacturing technologies that enable the use of lightweight materials are the two primary paths toward weight reduction. In some situations, lightweight materials can be directly substituted for higher density materials, but in most situations, barriers exist to direct substitution. In a modern multi-material vehicle, lightweight materials, such as $\mathrm{Al}$ and $\mathrm{Mg}$ alloys can be a challenge to join and attach to the underlying substructure, usually composed of steel. Even in Al- and Mg-intensive designs where entire substructures may be constructed of lightweight metals, there remains a need to join the substructure with other parts of the vehicle, such as the steel passenger safety cage. Joining methods currently available in the cost range relevant to high volume automotive manufacturing include resistance spot welding, adhesives, linear fusion welding, hemming, clinching, bolting, and riveting. However, because of the highly dissimilar natures of the materials, Mg to steel joints are extremely problematic. Mg to steel joints simply cannot be fusion-welded due to the extreme differences in their melting temperatures. Additionally, no intermediate phases exist between a $\mathrm{Mg}$ and Fe system. Joining methods that require a large amount of plastic strain in the Mg component suffer from Mg's poor ductility at room temperature.

Friction stir welding (FSW) and ultrasonic welding (USW) methods provide joining options that may be able to overcome some of the technical barriers preventing more robust and reliable joining of $\mathrm{Mg}$ to steel (1), (2), (3). Both methods involve creating a large degree of plastic deformation at the interface while at the same time delivering heat from frictional and plastic work. Both methods are solid-state, warm deformation technologies, and take advantage of the enhanced ductility of $\mathrm{Mg}$ and steel at elevated temperatures. If properly developed these methods hold potential in effective joining of vastly dissimilar material set. There are several identified technical barriers towards this goal:

* Lack of understanding of processing and interface conditions required to achieve robust joints.

* Lack of comprehensive performance information on joints fabricated by FSW/USW methods

* Insufficient understanding of the feasible joint geometries.

* For USW, lack of fundamental understanding of the response of materials and joint geometry to process variables

This project was designed to overcome many of these technical barriers by conducting experimental work on Mg-steel joints in three broad tasks 1) Fabrication of Mg-Fe joints in different processing conditions, interface conditions, material composition, and loading conditions 2) Characterization of joined interface using progressively advanced techniques including scanning electron microscopy (SEM), transmission electron microscopy (TEM), X-ray tomography, atom probe tomography (APT) and 3) Mechanical testing in different loading conditions. In collaboration with other sister projects within the joining core program that focuses on modeling and corrosion of the joints, the project seeks to obtain an applied understanding of 
- the localized metal forming and potential metallurgical bonding that develops during Friction Stir and Ultrasonic Welding methods

- the intermetallic formation and approaches to control this during each process, in order to tailor the joint interface that maximizes strength, ductility, and corrosion resistance.

- how the process parameters influence the joint strength and performance of the joints and assemblies produced, and

- how both processes interact with existing corrosion protection methods (coatings) and how they affect the overall corrosion performance of hybrid magnesium/steel assemblies

The overall goal of this project is to mature two types of solid-phase joining techniques- FSW and USW-by developing an understanding of the methods and processing conditions required to achieve robust joints between $\mathrm{Mg}$ and steel, thus integrating lightweight materials for multimaterial vehicles.

\subsection{Background}

Efforts of dissimilar joining of Mg-Steel outline in the literature can be broadly divided into four categories viz: mechanical joining, chemical joining, fusion welding, and solid-state welding methods (4). Mechanical joining methods include conventional rivets, threaded fasteners, bolted joints, flow drill screws (5), clinching (6), friction-stir blind riveting (7), self-piercing riveting (8), hemming (9), etc. Chemical joining approach refers to adhesive joining (10). Fusion and solid stated based joints are categorized based on welding temperatures. Fusions joints made with welding temperature above $\sim 650{ }^{\circ} \mathrm{C}$, while solid-state welding occurs at temperature below $\left.\sim 650^{\circ} \mathrm{C}\right)($

). Various fusion welding methods have been applied for joining of $\mathrm{Mg}$ alloys and steel, such as laser welding, hybrid laser and tungsten inert gas (TIG) welding, laser-brazing welding, and resistance spot welding (RSW). Among solid-state joining methods, friction stir welding (FSW), friction stir spot welding (FSSW), ultrasonic spot welding (USW) and impact welding have been applied.

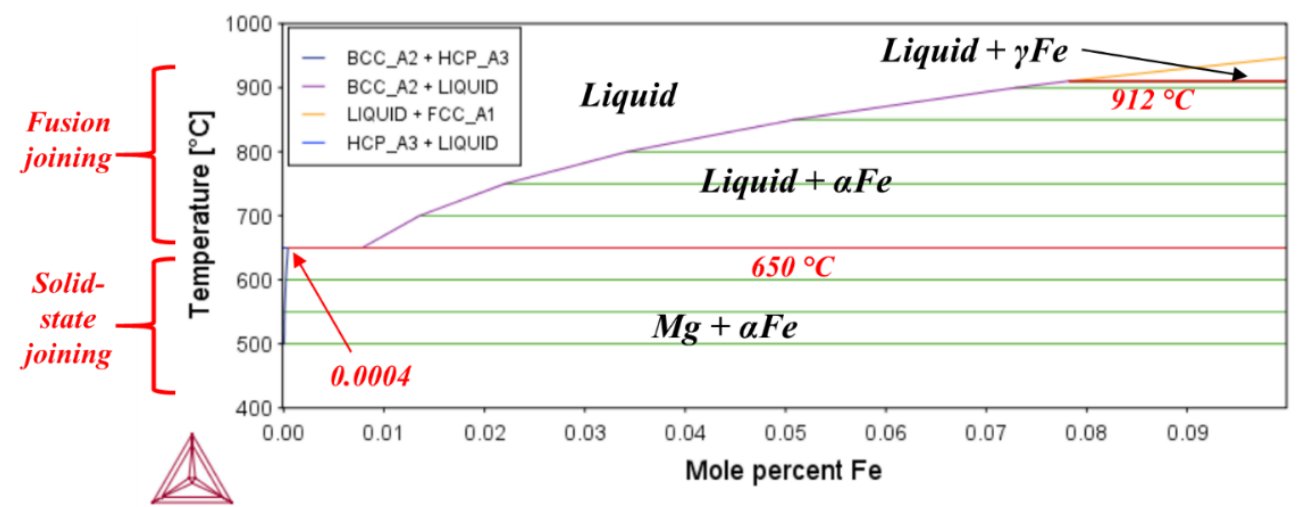

Figure 1 Mg-Fe Phase Diagram (Source: Literature Review / PNNL)

Joint configurations reported in the literature can be divided into three broad categories: linear lap welding, linear butt welding, and spot welding. A schematic of various welding methods with different joint configurations published in detail in a review paper (11) is shown in Figure 2. Relevant literature includes the following: lap-laser and lap-hybrid laser-TIG [ (12), (13)], lap-laserbrazing (14), lap-FSW (3), butt-laser and butt-hybrid laser-TIG (15), butt-FSW (16), spot-RSW (17), spot-FSW (18), and spot-USW (19). Diffusion bonding has also been used to join magnesium alloys and steel (20). The schematics in Figure 2 represent the typical welding 
configurations discussed in the literature. Note that some articles describe atypical setups. For example, steel sheet was put on top of magnesium sheet for laser lap welding and a laser beam was applied on the steel side for laser-butt welding.

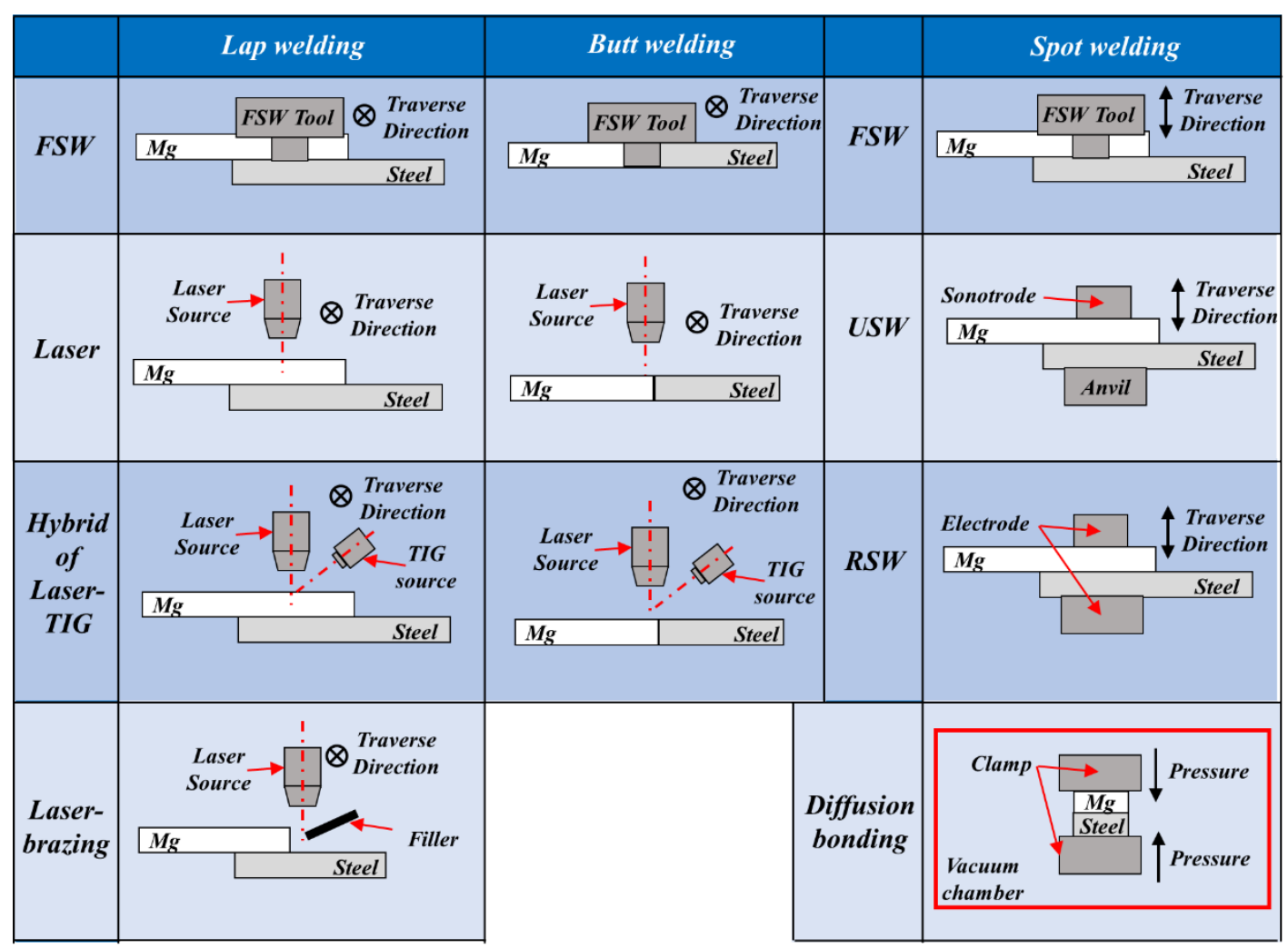

Figure 2 Schematic of friction stir lap, butt, and spot welding; laser lap and butt welding; hybrid laser and TIG lap and butt welding, USW, RSW, laser-brazing lap welding, and diffusion bonding. (Source: Literature Review / PNNL)

For lap welding softer Mg sheers are placed on the top of the steel sheet. In the case of Laser and Friction stir welding, power source is typically applied from the Mg side while for USW the vibrating horn in present on the steel side.

As indicated in the introduction, joining $\mathrm{Mg}$ to steel in absence of interlayers or coating is difficult due to the immiscibility of the two systems. Additionally, oxide and hydroxide layers that invariably form on the Mg surface can prevent reaction during welding. It is not feasible to remove Oxide layer prior to joining. Additionally, it is unwelded gaps are often observed during fusion welding of Mg-Steel. Several interfacial products have been reported in dissimilar Mg-Steel joint. A summary interfacial product and some illustrative joint cross sections and microstructures are shown in Figure 3 below. Interfacial products in all the cases are due to the presence of intentional interfacial layers. Oxidation around the interface is most striking for fusion welding. IMCs were also observed at the interface due the migration and reaction of alloying elements towards the interface. Al, Y and $\mathrm{Nd}$ in $\mathrm{Mg}$ alloys have been reported to have formed IMC at the surface [38]. Since $\mathrm{Zn}$ coating is readily available in steels for corrosion prevention they have been widely used as primary interlayer for $\mathrm{Mg}$-steel joining. A Mg-Zn eutectic structure typically forms at the 
interface that has been ascribed to promote bonding. IMCs such as $M g Z n_{2}, A_{5} M_{11} Z_{4}, M_{7} Z_{3}$, $\mathrm{Mg}_{2} \mathrm{Zn}_{11}$ were also observed for coatings in certain conditions.

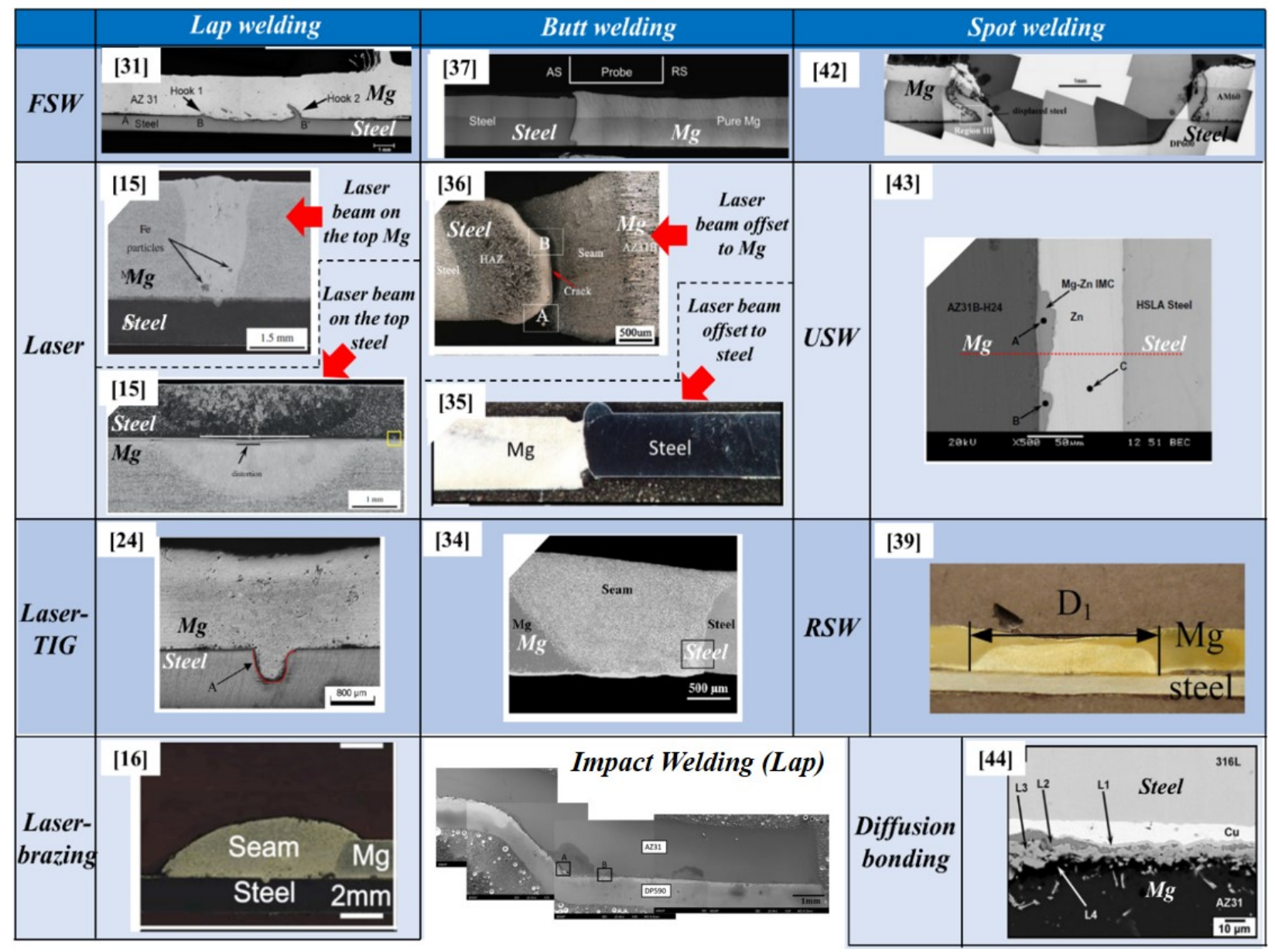

Figure 3 Cross sections of Mg/steel joints in different configurations made with different welding methods. Source references are shown in brackets (Source: Literature Review / PNNL)

\subsubsection{Friction stir assisted scribe technique (FaST)}

Friction stir assisted scribe technology (FaST) conceived and developed at PNNL is a derivative of Friction stir welding (FSW) (Figure 4). In a conventional FSW (Figure 5), a non- consumable rotating tool consisting of a large diameter shoulder and a small diameter pin is plunged into abutting or overlapping faces of materials to be joined. A forge force is applied to the tool such that rotating pin penetrates into the work piece. Once the shoulder comes in contact with the workpiece and enough local heat has been generated due to rotation and forge force causing the material around the workpiece to plastically deform, the tool is translated along the joint line such that plasticized material is swept around the front to the back of the tool forming a joint. Workpieces are held together by clamping. In contrast to typical FSW setups used in conventional FSW of dissimilar metals, material pairs in FaST are set up such that lower melting point material is on top. (Figure 4). A cutter scribe is attached to the tip of a conventional FSW tool while the conventional portion of the FSW tool (shoulder and tool pin) plastically deforms and "stirs" the lower melting-point top workpiece, the cutter scribe makes a small continuous cut on the surface 
of the higher melting point material at the bottom. As the tool rotates and traverses the machining action of the scribe in concert with FSW on the top layer results in intimate bonding between the two layers. Often a mechanical hook-like interlocking feature is observed in joint cross section at the material interface. A consistently maintained clearance between the pin and surface of the bottom sheet ensures that pin never interacts with the high melting point material (the bottom layer). This aspect-unique to FaST as opposed to conventional FSW- results in bottom layer being only machined being "plowed" through. Thus, the propensity of bulk melting and associated defect/ void formations typically observed in conventional FSW of the dissimilar pair is avoided. A video containing animation of this process can be found here (21)
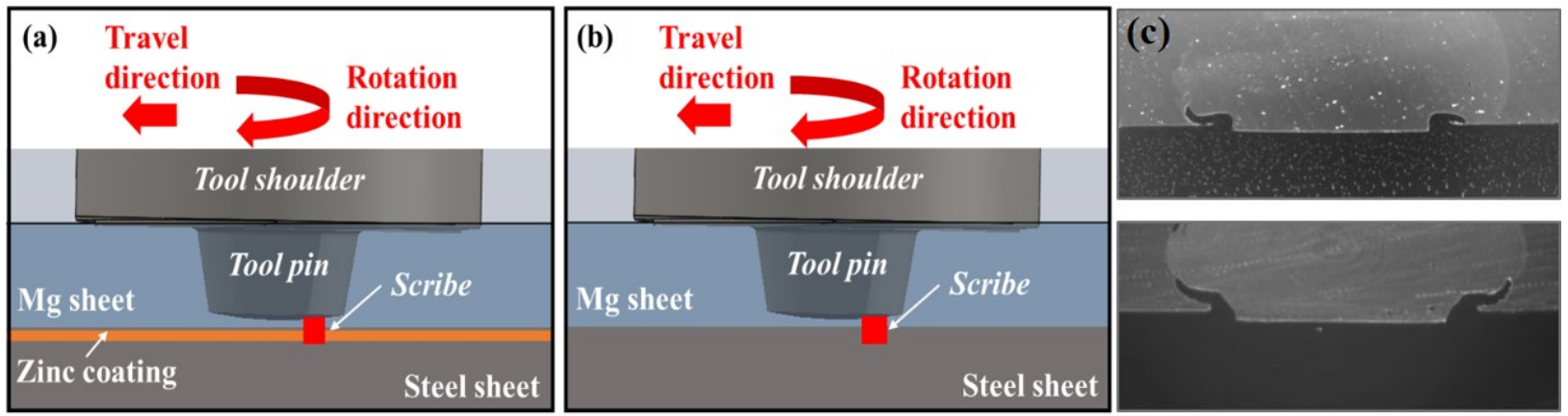

Figure 4 Friction stir scribe technology: Schematic of the process (a) Mg - Zn coated DP 590 steel, (b) Mg - uncoated DP 590 steel, and (c) weld cross sections illustrating hooking features (Source: PNNL)

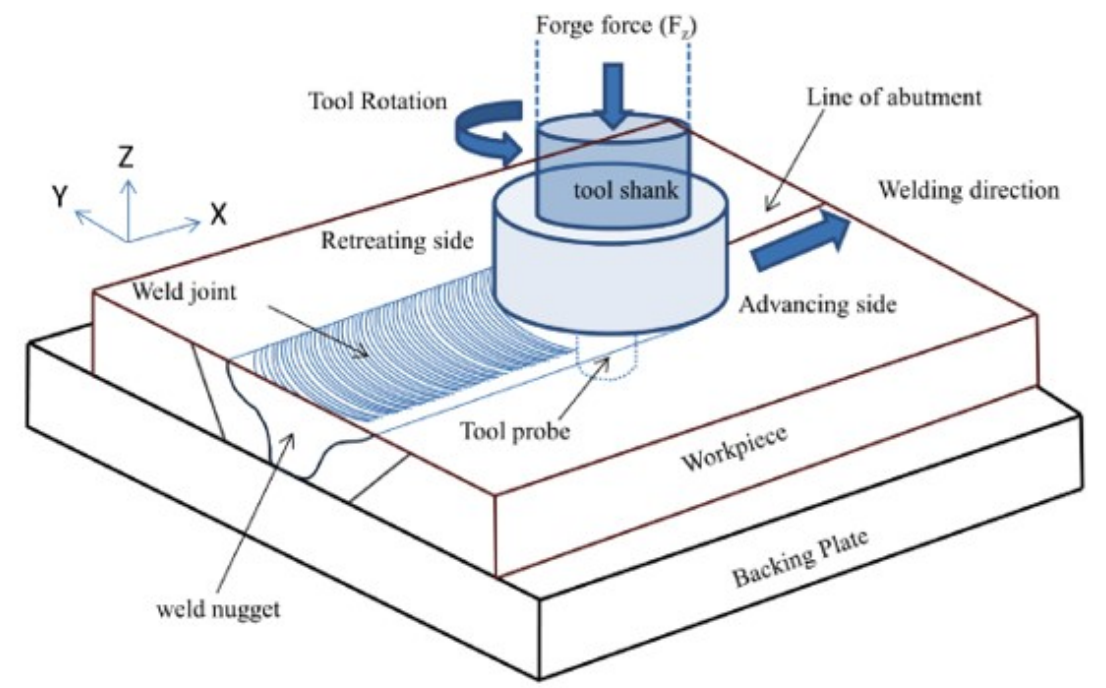

Figure 5 Schematic of Friction Stir Welding. (Source: TWI)

\subsubsection{Ultrasonic Welding}

Ultrasonic spot welding (USW) is a solid-state joining method that can be used to join dissimilar materials. In automotive industry, USW has been successfully applied to join dissimilar metal components such as aluminum and copper in the battery assemblies of electric vehicles 
(22).Figure 6 shows a schematic of a typical single-head USW unit for joining metal sheets. During USW processes, metal sheets are clamped between the Sonotrode and an anvil with a moderate clamping force. A lateral ultrasonic vibration (typically $15 \mathrm{k}-40 \mathrm{k} \mathrm{Hz}$ ) is generated by an ultrasonic transducer and delivered to the interface of the metal. The welding heat is generated through interfacial friction, as well as plastic deformation and elastic hysteresis (22). The heating and the interfacial pressure induce rapid diffusion and the resulting reaction at the interface forms the joint (23) (24) . To improve the efficiency of heat generation, a dual-head USW can also be used as shown in Error! Reference source not found. in which the bottom anvil is replaced with another Sonotrode that vibrates at the same frequency with a $180^{\circ}$ phase difference with respect to the top Sonotrode.

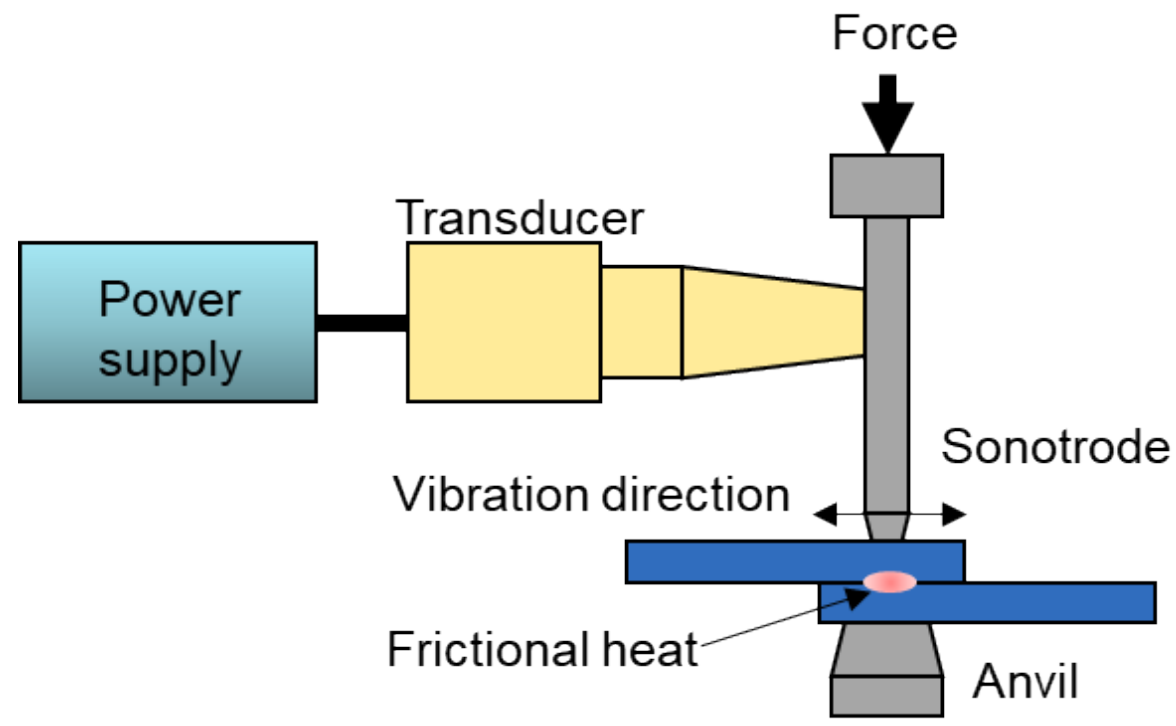

Figure 6 Schematics of a single-head USW unit (Source: ORNL) 


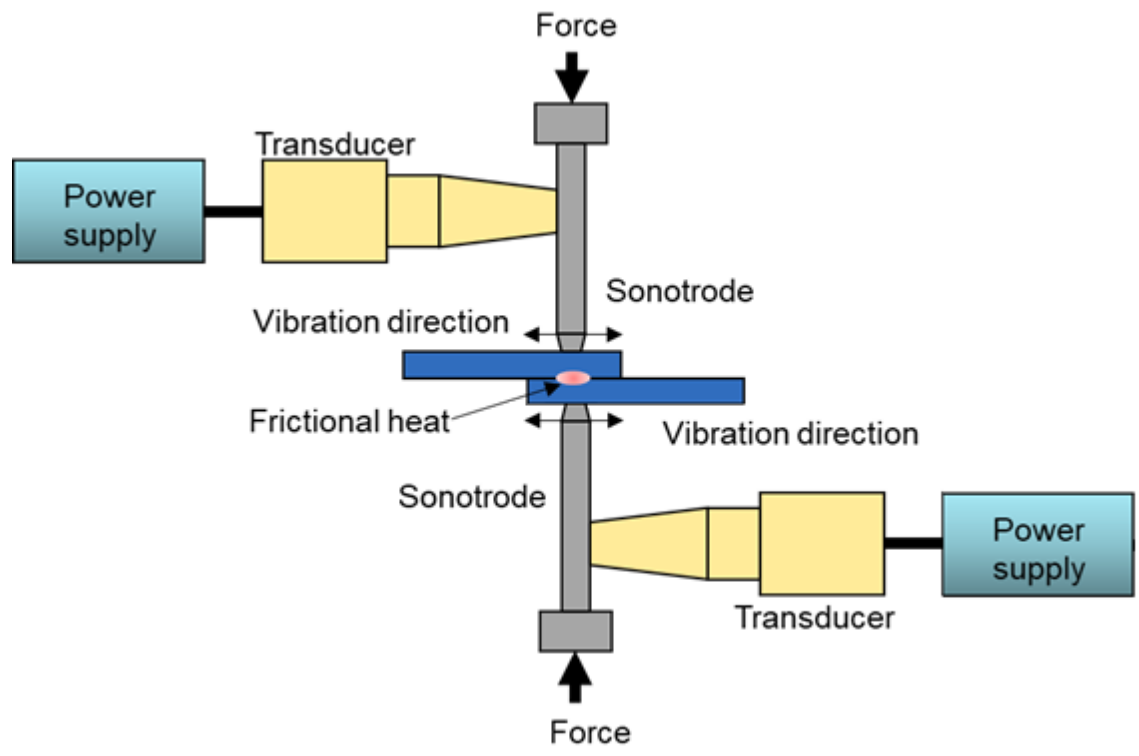

Figure 7 Schematics of a dual-head USW unit (Source: ORNL)

\section{Appendix A Experimental Details}

\subsection{Materials}

The materials used in this study primarily included 2-mm-thick AZ31B Mg alloy (POSCO) and 1mm-thick hot dipped galvanized (HDG) DP590 steel (US steel) with protective Zn coating (50 $\mu \mathrm{m}$ to $70 \mu \mathrm{m})$. The chemical analysis of the AZ61, AZ80 and pure $\mathrm{Mg}$ sheets are listed in

Table 2.

Table 1. Chemical composition of DP590, unit in wt\% (no Zn coating)

\begin{tabular}{|c|c|c|c|c|c|}
\hline $\mathrm{C}$ & $\mathrm{Mn}$ & $\mathrm{Si}$ & $\mathrm{Al}$ & $\mathrm{Cr}$ & $\mathrm{Fe}$ \\
\hline 0.07 & 2.19 & 0.01 & 0.04 & 0.05 & Bal. \\
\hline
\end{tabular}

Table 2. Chemical composition of AZ31B, AZ61, AZ80, Pure Mg unit in wt\%

\begin{tabular}{|c|c|c|c|c|c|c|}
\hline Alloy & Al & $\mathrm{Si}$ & $\mathrm{Zn}$ & $\mathrm{Mn}$ & $\mathrm{Zr}$ & $\mathrm{Mg}$ \\
\hline AZ31 & 3.0 & 0.023 & 0.80 & 0.35 & 0.018 & Bal. \\
\hline AZ61 & 6.07 & 0.01 & 0.6 & 0.42 & - & Bal. \\
\hline AZ80 & 8.34 & 0.01 & 0.69 & 0.26 & - & Bal. \\
\hline Pure Mg & 0.01 & - & - & - & - & Bal. \\
\hline
\end{tabular}

Joints with and without the Zn coating on steel were studied. For FaST joints, the galvanized steel was dipped in $5 \% \mathrm{HCl}$ acid solution for 30 minutes dissolving any trace of $\mathrm{Zn}$ coating from the steel surface. This ensured that no $\mathrm{Zn}$ was present in the steel prior to welding. For USW case Zn coating were removed mechanically. EDS analysis on the Zn-removed DP590 (Figure 8) showed no $\mathrm{Zn}$ element on the surface indicating the $\mathrm{Zn}$ coating was completely removed. 


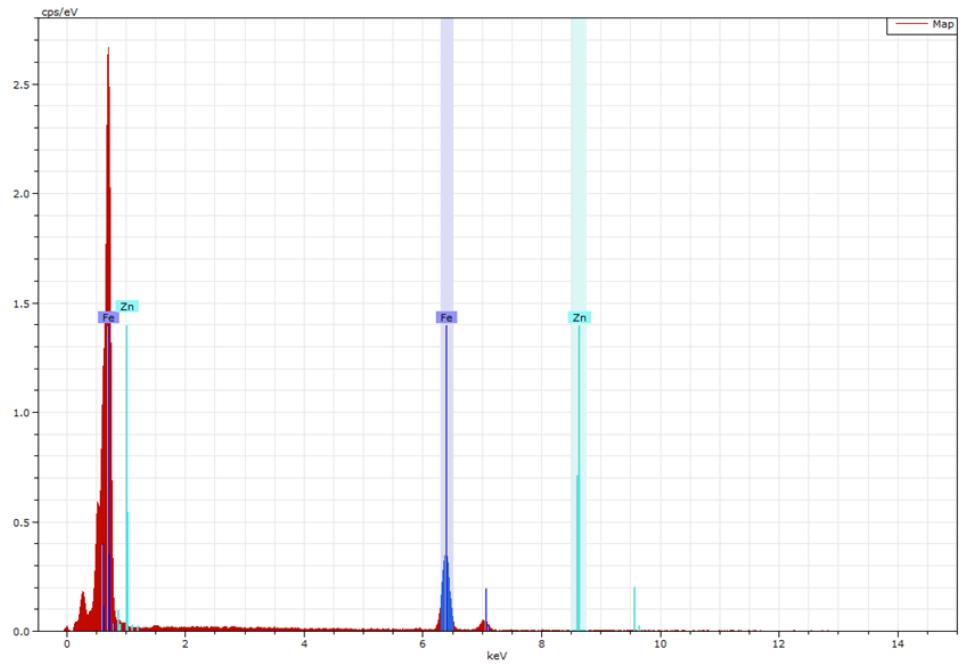

Figure 8 EDS analysis on the surface of Zn-removed DP590 indicating no Zn left on the surface (Source: ORNL)

\subsection{Friction stir Assisted Scribe Welding (FaST)}

FSW and USW joints were fabricated in various conditions for characterization and testing. Figure 9 - Figure 12 and Figure 13 show various elements of joining including the setup, joined sample, and cross-sections for FaST and USW, respectively.
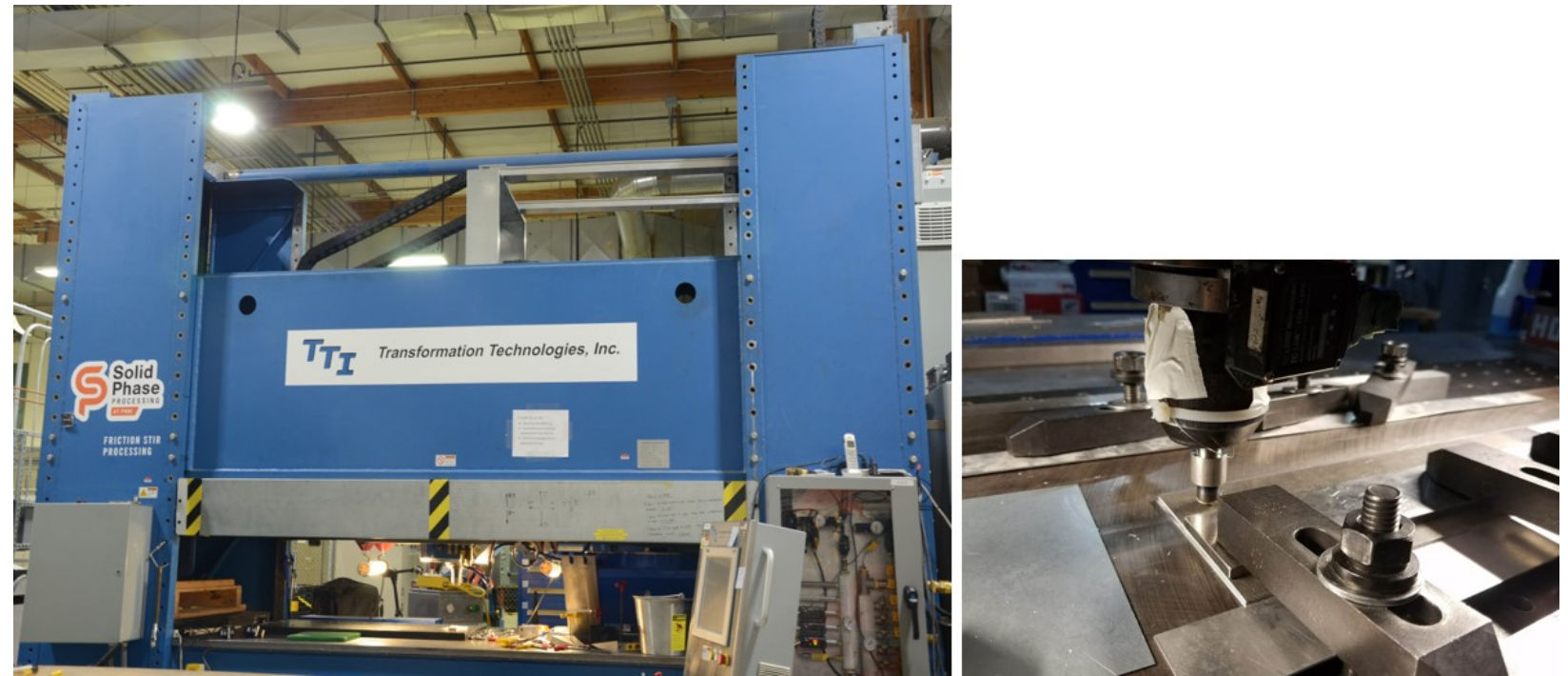

Figure 9 Gantry FSW machine system at PNNL used in this project to produce dissimilar joints, Welding setup ready to make sample for $\mathrm{T}$ peel testing. Note that the FaST joining is being performed on the edge of the sample to produce T peel joints. (Source: PNNL) 

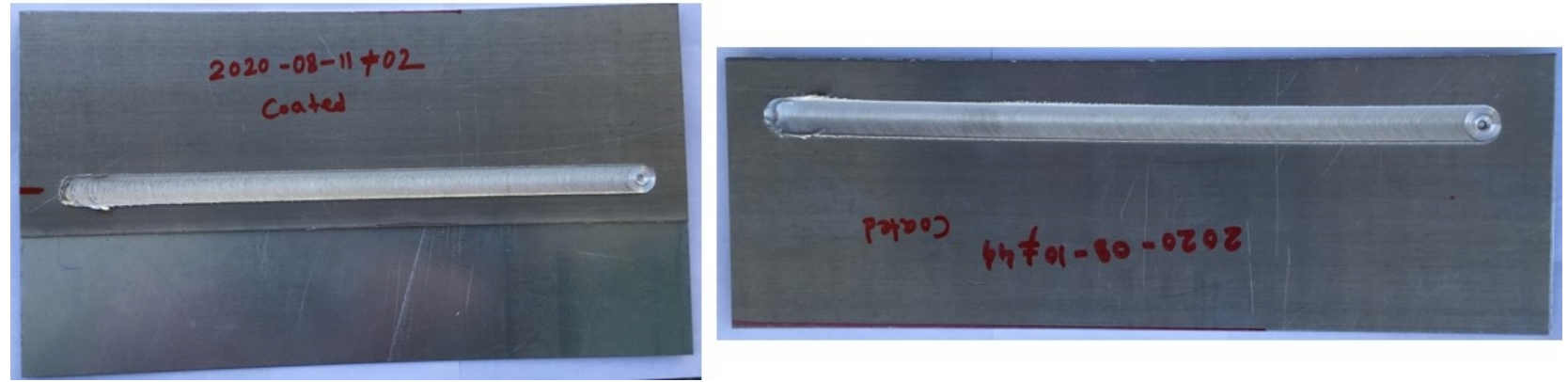

Figure 10 Long weld for Lap Shear Sample and T-Peel sample (Source: PNNL)

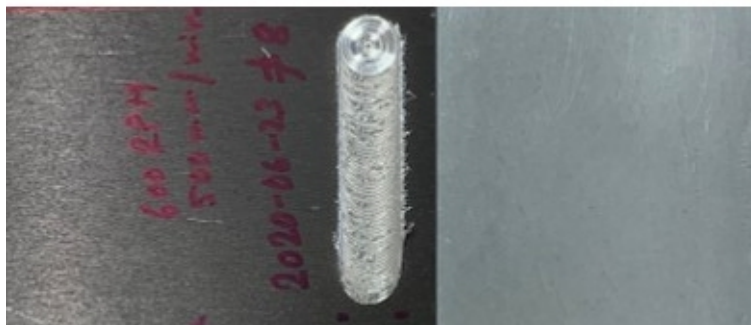

Figure 11 Different kind of Stitch welds (Source: PNNL)

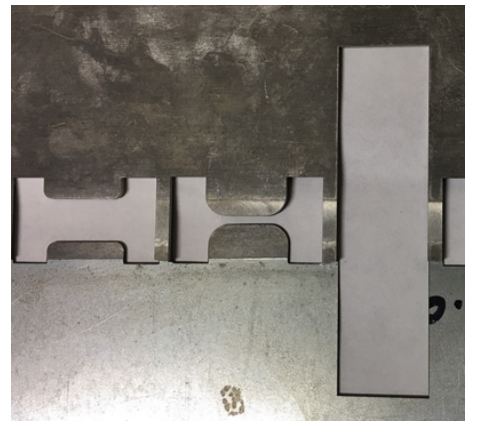

Figure 12 Wire EDM cut samples shows cut out location from where whole weld longitudinal, weld center longitudinal and regular trasnverse sections for tensile tests were extracted. (Source: PNNL)

\subsection{Ultrasonic Welding}

The UW process development, optimization and sample preparations were mainly conducted on the single-head welding unit (Error! Reference source not found.). The influence of the welding conditions including welding power, time, clamping force, etc. on the resultant joint performance was studied. Post-weld microstructural characterizations and joint strength testing (lap shear, fatigue, and U-peel tests) were also performed. The dimension of the lap shear and fatigue samples is shown in Error! Reference source not found.a and the dimension of the U-peel sample is shown in Error! Reference source not found.b. A variety of welding conditions (welding power, time, clamping force, etc.) was applied to help understand the USW process, bonding mechanisms, and the resultant joint quality. 
PNNL-30945

ORNL/SPR-2021/1836

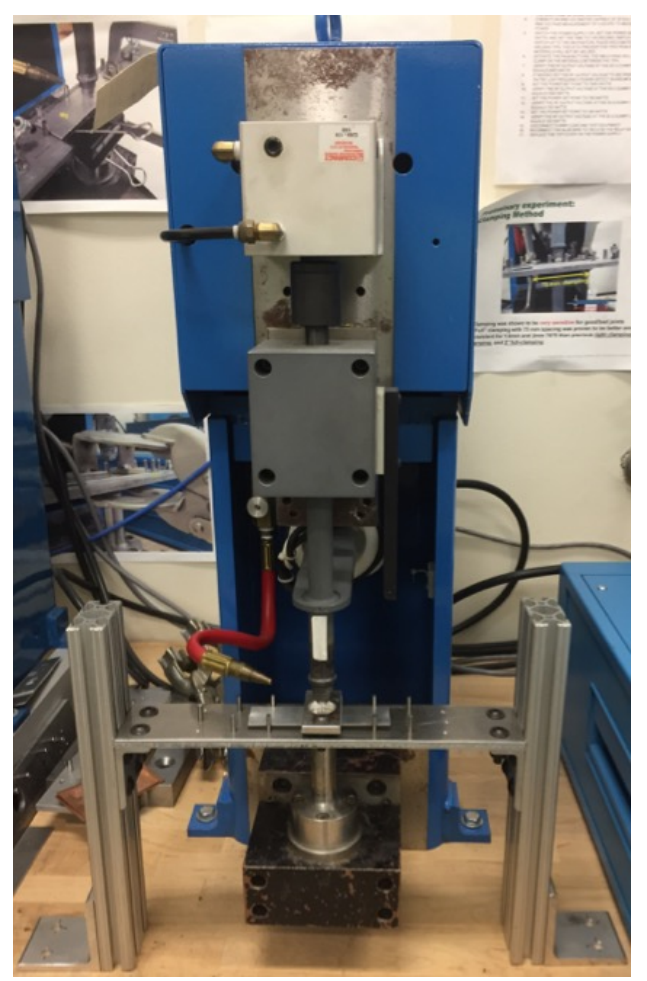

ANL-21/07

Figure 13 Experimental setup to produce USW joint coupons using a single-head welding machine. (Source: ORNL) 


\subsection{Process variables measurements}

\subsubsection{FSW}
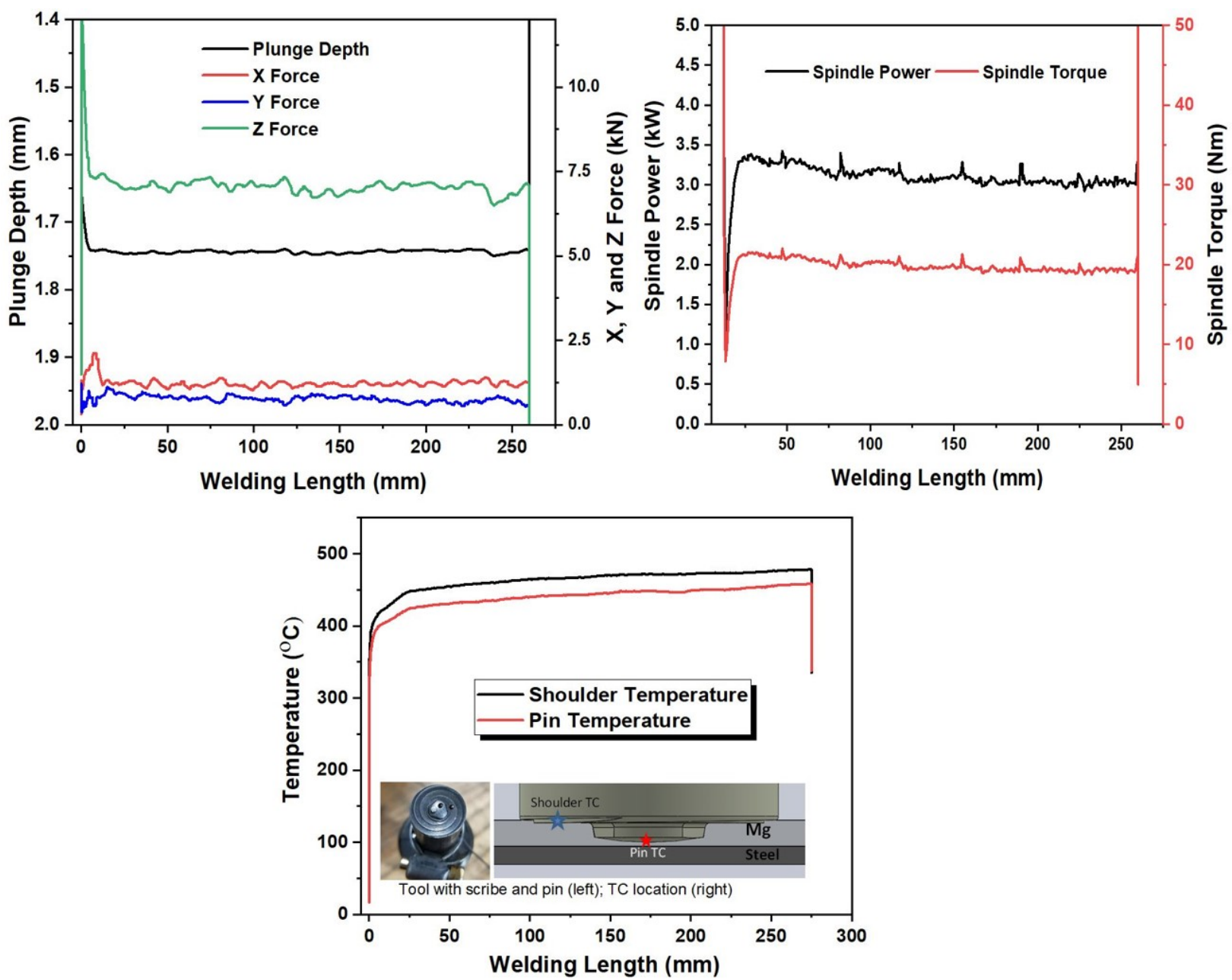

Figure 14 FaST process response (Source: PNNL)

Process response variables during FSW process including the tool forces in $\mathrm{X}, \mathrm{Y}$ and $\mathrm{Z}$ directions, welding power and torque and welding temperature were measured. Tool forces and torque trends can provide an important aspect to understand the FaST process. Analysis of the tool forces and torques provides insights into the simultaneous process of thermally activated softening, strain and strain rate hardening, and material process deformation. Since torque is a measure of the shear stress and since shear stress on the work piece is responsible for heat generation and plastic flow, force and torque data can be helpful to qualify welding conditions. All the lap welds were made under displacement control mode. The planar forces measured in $X$ and $Y$ direction is a metric of workpiece material response. As an example, the measured temperature and the process response experienced during FaST are plotted in Figure 14. K type Thermo-couples (TCs) of $0.8 \mathrm{~mm}$ diameter were used to measure the weld inter-face and tool shoulder temperature during the welding. The TC wires were inserted into the tool at tip of the FSW pin and at the shoulder as shown in Figure 14. The TC tip was made flush with the tool surface so that the TC tip is in direct contact with the material during the welding process. The TC wires were connected to a wireless transmitter attached to the tool holder. All of these datasets 
can serve function as input parameters into the process/structure property modeling, nondestructive evaluation, and process control applications.

\subsubsection{USW}

Instrumentation for in situ process measurements were also performed for USW. The dual head welding unit was used to quantitatively study the interfacial motion and heat generation mechanisms. As shown in Figure 15 (a), an infrared camera and a high-speed digital image correlation (DIC) were coupled to measure the in-situ interfacial temperature and deformation behaviors. To track the motion of the interfaces by DIC, a high-contrast (in visible wavelength) speckle pattern capable of sustaining a temperature exposure up to $1100^{\circ} \mathrm{C}$ was coated on the edge of $\mathrm{Mg}$ and steel sheets. By tracking the displacements of the six subsets ( $\mathrm{p} 1-\mathrm{p} 6$ marked by the white boxes on the Sonotrode teeth and the metal surfaces adjacent to the contact interfaces in Figure 15 (a)) using Digital Image Correlation (DIC) algorithm, the tangential vibratory velocity of each material point across the contact interfaces was calculated. Another important reason to apply such a coating was that the emissivity (in infrared wavelength) was uniformly high ( 0.95). As such, the influence of surface emissivity on temperature measurement by the IR camera was negligible. The infrared camera recorded the temperature evolution at a speed of $200 \mathrm{frames} / \mathrm{s}$. While, the high-speed camera recorded the vibratory motion of both Sonotrode tips and both metal sheets at a speed of 120,000 frames/s. The pixel resolution of the high-speed images was $18 \mu \mathrm{m} /$ pixel. The size of the metal sheets was $25.4 \mathrm{~mm} \times 25.4 \mathrm{~mm}$ square shape as shown in Figure 15 (b). The welding region was positioned on one edge of the sheet stack to monitor the interfacial motion and heat generation. The clamping force between the Sonotrodes was $1.1 \mathrm{kN}$. Both Sonotrode tips had an identical $7 \mathrm{~mm} \times 7 \mathrm{~mm}$ nominal contact area with six parallel teeth perpendicular to the vibration direction. The ultrasonic welder had a fixed vibration frequency of $20 \mathrm{kHz}$ on both Sonotrodes with $180^{\circ}$ phase shift from each other. Moderate welding energy input (1000W, up to $0.5 \mathrm{~s}$ ) was applied.

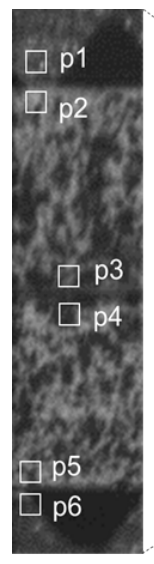

$1 \mathrm{~mm}$

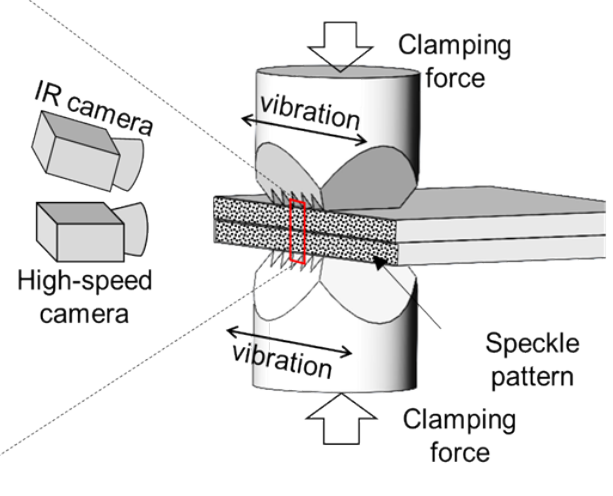

(a)

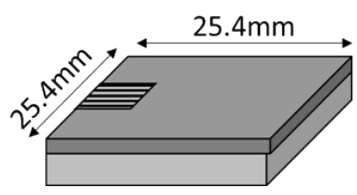

(b)

Figure 15 Schematic of (a) experimental setup to measure interfacial relative motion and heat generation and (b) dimension of the joint samples (Source: ORNL) 


\subsubsection{Observation of Acoustic Softening in USW process}

The single-head machine was also used to study the phenomenon of acoustic softening when material undergoes ultrasonic vibration (22) (23). When acoustic softening occurs, materials plastic flow stress drastically reduces. Investigations have revealed that the ultrasonic energy required to produce an identical amount of flow stress reduction is $10^{7}$ less than the required thermal energy (22). Additionally, such a flow stress reduction recovers once the ultrasonic vibration stops, indicating an extremely limited microstructural degradation compared to the thermal-induced material softening. The schematic of the experimental setup is shown in Figure 16. A miniature sample was used in the experiment. The bottom surface was fixed on the anvil, and the top surface was in contact with the top Sonotrode and vibrated horizontally with the Sonotrode at $20 \mathrm{kHz}$. A monochrome CMOS camera (500 fps) coupled with an infrared camera (200 fps) was placed to record the evolution of the strain and temperature fields on one side of the sample. A similar speckle pattern as described in Error! Reference source not found. was applied on the sample surface to enable the strain measurement by DIC algorithms and the accurate temperature measurement via infrared intensity.

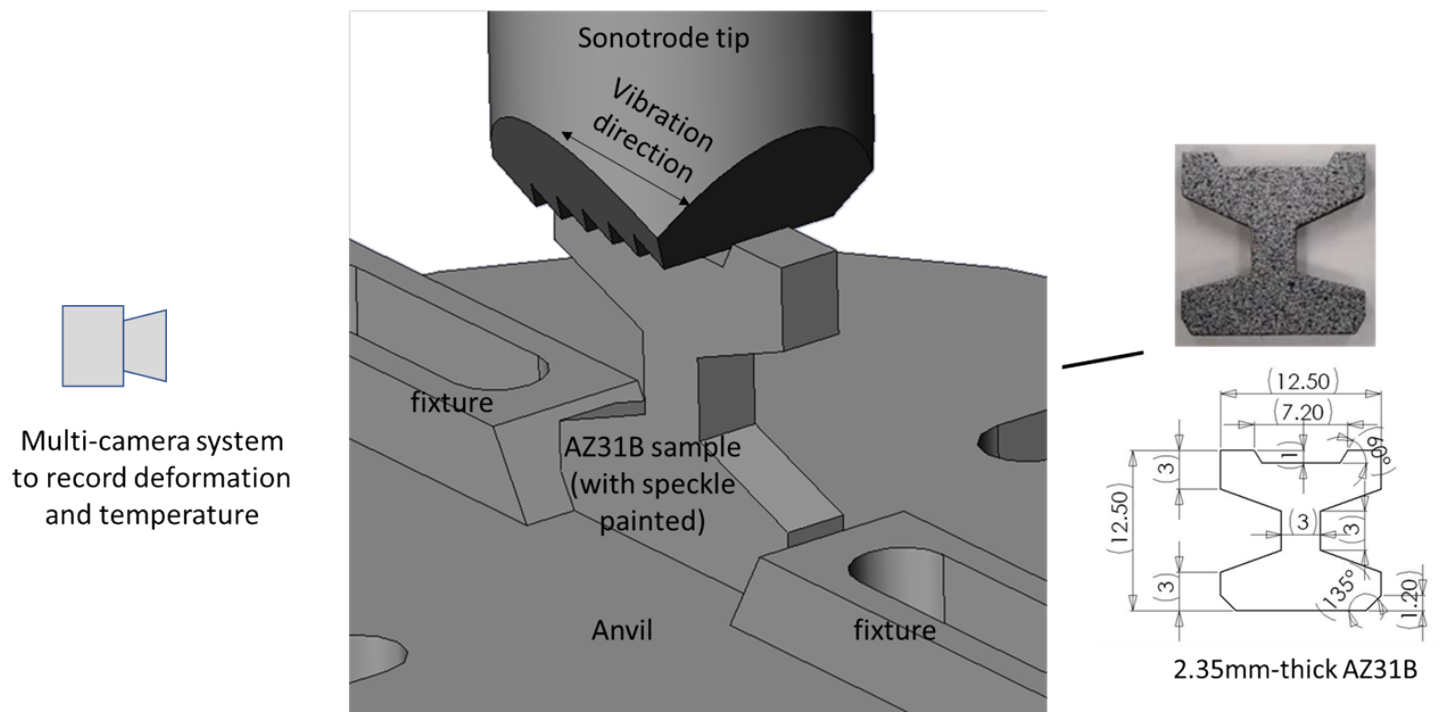

Figure 16 Schematic of experimental setup to observe the phenomenon of acoustic softening (Source: ORNL)

\subsubsection{Interface phenomenon for USW joints}

In-situ interfacial measurement setup shown in Figure 15 was applied to study the interfacial relative motion and the heat generation of USW joints made with different metal pairs: (1) AZ31B and AZ31B similar metal pair, (2) Zn-coated DP590 and AZ31B dissimilar joint pair and (3) bare DP590 and AZ31B dissimilar pair.

Figure 178 shows the tangential displacement along the vibrational direction measured at six locations (though $\mathrm{p} 1$ to $\mathrm{p} 6$ ) across the interfaces during welding AZ31B-AZ31B joints using the dual head welding machine (1000W for $0.5 \mathrm{~s}$ ). The results were measured by tracking the displacement of the subsets in the high-speed image sequence using the DIC algorithms. The positive value means that the tangential displacement was towards the right side of the image and the negative was towards the left. Results show that both Sonotrodes (measured on p1 and p6) had an overall displacement during welding. The top Sonotrode moved to the right (up to 60 
$\mu \mathrm{m}$ ) first and then to the left (up to $-55 \mu \mathrm{m}$ ) and the bottom one moved to the left first (up to -60 $\mu \mathrm{m}$ ) and then to the right (up to $55 \mu \mathrm{m}$ ). The displacement of the two surfaces of the top Mg sheet (p2 and p3) had a consistent value up to about $80 \mu \mathrm{m}$ before $0.17 \mathrm{~s}$. After $0.17 \mathrm{~s}$, the displacement at $\mathrm{p} 2$ and $\mathrm{p} 3$ started to deviate indicating an increase of shear deformation. The displacement measured at $\mathrm{p} 4$ and $\mathrm{p} 5$ on the bottom Mg sheet had the similar behavior. Large shear deformation started at $0.17 \mathrm{~s}$. The increase of shear deformation after $0.17 \mathrm{~s}$ on both $\mathrm{Mg}$ sheets is also confirmed by the principal strain evolution curves as plotted in Figure 19.

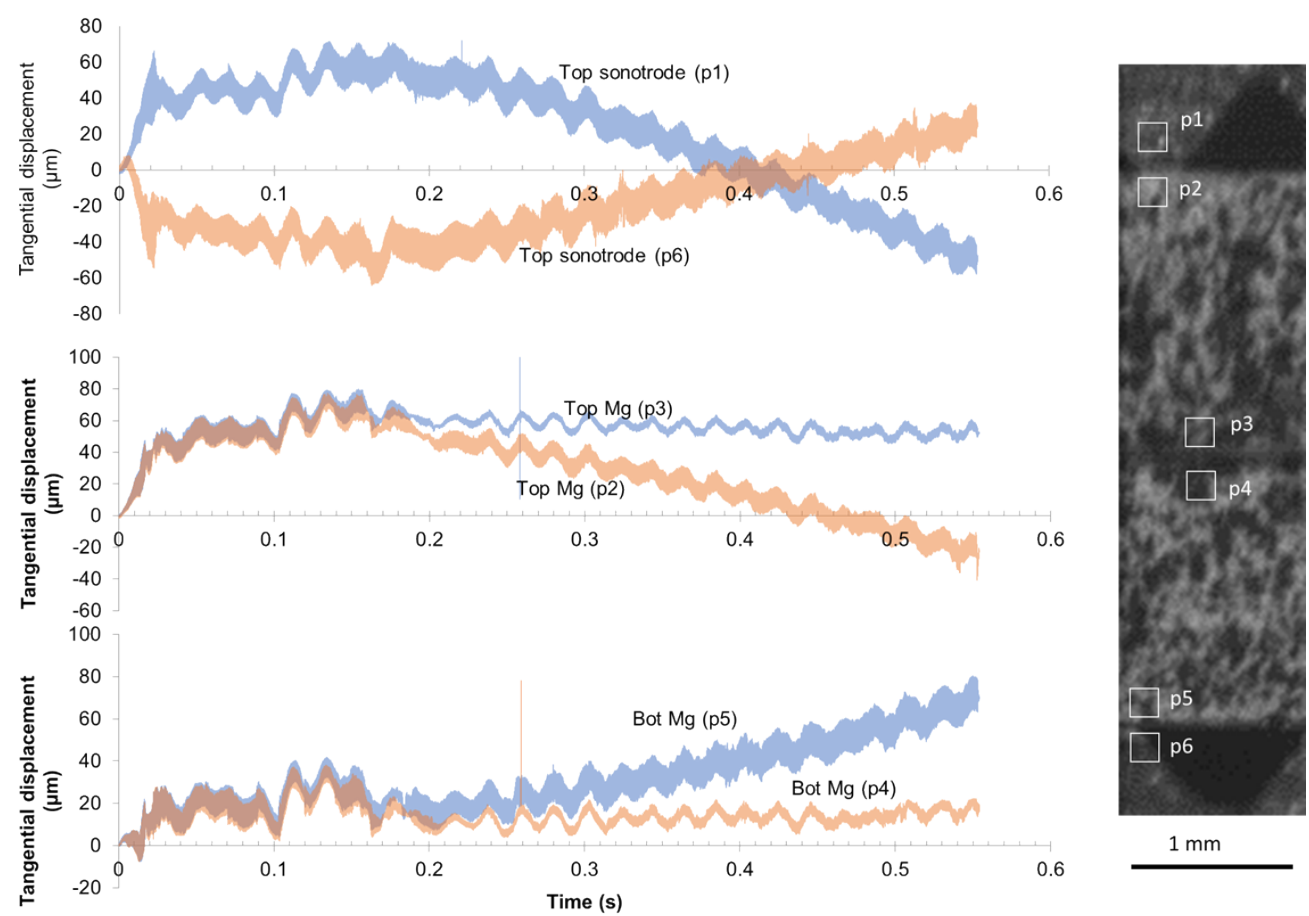

Figure 17 Tangential displacement measured at six locations across the interfaces (AZ31BAZ31B USW joint). (Source: ORNL)

Figure 20 shows the relative velocity across each interface derived from Figure 17. By examining the high-speed image frames, the high relative velocity (above $0.5 \mathrm{~m} / \mathrm{s}$ ) regions in the curves appear to correspond to the moments in time when interfacial sliding was observed. In contrast, when the materials across the interface stuck or bonded together, the relative velocity amplitude was low. It is worth noting that the relative velocity at the interface should be zero when two materials are stuck or joined, but the measured amplitude was nonzero. This is because the measurement was derived by tracking the motion of two subsets adjacent to each interface (refer to Figure 15), and the center of these subsets were about $0.2 \mathrm{~mm}$ apart from the interface. Thus, the relative velocity between the two subsets across each interface would not be zero even though there was no sliding at the interface during the shear motion of the two Sonotrodes. Further examination of the inserted IR images in Figure 19 reveals that the transient interfacial heat generation shifted from interface to interface, and it could be associated with the reciprocal interfacial sliding (relatively high amplitude of interfacial velocity) occurring at the corresponding interfaces. As demonstrated in Error! Reference source not found., at $t=0.010 \mathrm{~s}$, the first sliding occurred at the $\mathrm{Mg}-\mathrm{Mg}$ faying surface. Correspondingly, the highest temperature rise was also observed at the same interface in the IR image. The line plot along the cross-sectional centerline shows that the peak temperature at the $\mathrm{Mg}-\mathrm{Mg}$ faying surface was $50^{\circ} \mathrm{C}$, and 
temperature near the two Sonotrodes was $46^{\circ} \mathrm{C}$. At $\mathrm{t}=0.020 \mathrm{~s}$, the bottom $\mathrm{Mg}$-Sonotrode interface was sliding. The location of maximum temperature rise shifted to the bottom of the $\mathrm{Mg}$ sheet stack (from $46^{\circ} \mathrm{C}$ to $68^{\circ} \mathrm{C}$ ). Between $0.028 \mathrm{~s}$ and $0.030 \mathrm{~s}$, sliding was observed at the top $\mathrm{Mg}-$ Sonotrode interface, and the temperature distribution measured at $0.030 \mathrm{~s}$ confirmed that the top $\mathrm{Mg}-$ Sonotrode interface was experiencing faster heat generation. The peak temperature rose from $55^{\circ} \mathrm{C}$ to $90^{\circ} \mathrm{C}$.

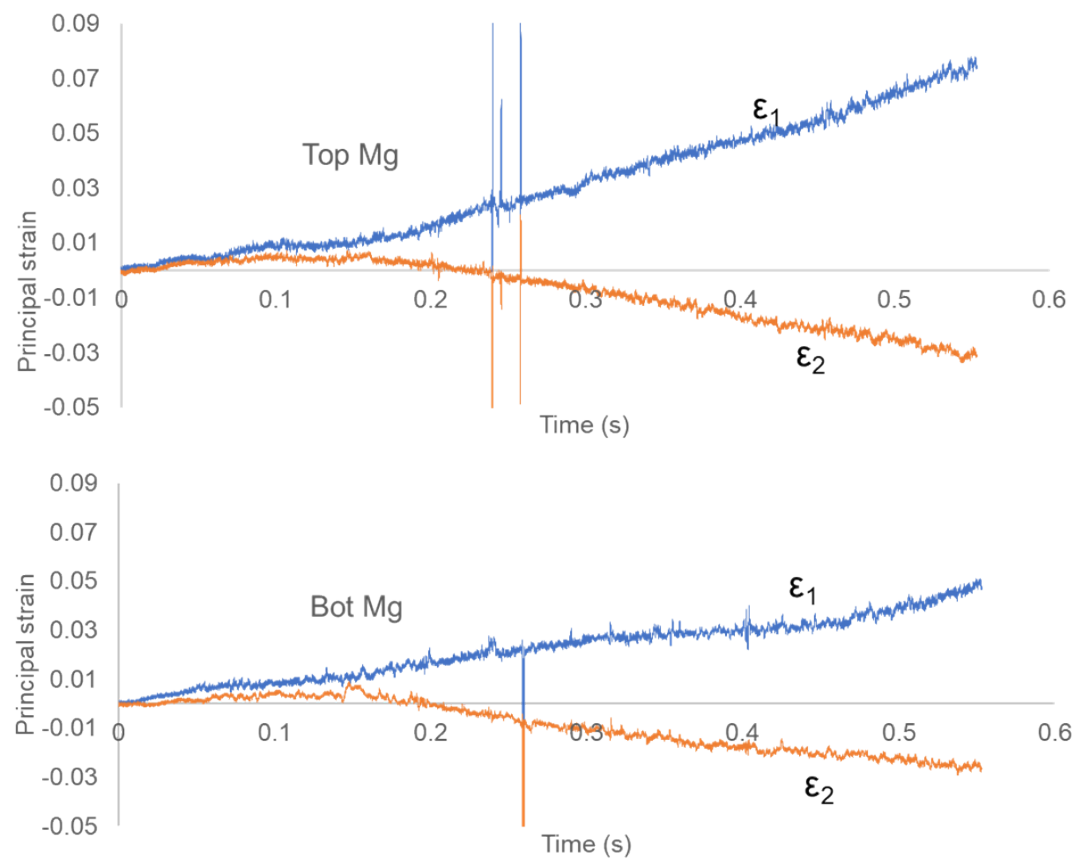

Figure 18 Overall principal strain measured on the cross-sections of each metal sheet (AZ31BAZ31B USW joint). (Source: ORNL)

Thus, the sliding phenomenon as well as the frictional heat generation observed in Error! Reference source not found. occurred alternatively among the three contact interfaces from $t=$ $0 \mathrm{~s}$ to $\mathrm{t}=0.21 \mathrm{~s}$. Such an alternation might be related to the following factors. (1) Dynamic change in friction coefficient at each interface-sliding occurred preferentially at the interface with the lowest friction. (2) The formation and destruction of localized microscale bonds at the $\mathrm{Mg}-\mathrm{Mg}$ faying surface due to the fretting mechanism (22), (24). After $0.16 \mathrm{~s}$, no more sliding occurred at the $\mathrm{Mg}-\mathrm{Mg}$ interface, suggesting that a macroscale weld joint started to form. Further analysis of weld formation will be discussed subsequently. Sliding between Mg sheets and both Sonotrodes still occurred after $0.16 \mathrm{~s}$, but eventually after $0.21 \mathrm{~s}$, no more sliding was observed at any of the interfaces. This could be associated with the increasing surface indentation on $\mathrm{Mg}$ that prevented both Mg-Sonotrode interfaces from sliding. Similar interfacial phenomena were also observed in welding Zn coated DP590 - AZ31B USW joints using the same welding condition (1000W for $0.5 \mathrm{~s}$ ) as shown in Figure 20. The interfacial sliding was first observed at the DP590 - AZ31B joint interface, and it then switched back and forth among all three interfaces within the first 0.17s, although most sliding occurred at the AZ31B - bottom Sonotrode interface. The transient interfacial heat generation also shifted from interface to interface, and it could be associated with the reciprocating interfacial sliding (high amplitude of interfacial velocity) occurring at the corresponding interfaces. 
For joint samples made with bare DP590 and AZ31B using the same welding condition (1000W for $0.5 \mathrm{~s}$ ), the interfacial relative motion was different from what was observed in AZ31B-AZ31B pair and Zn coated DP590-AZ31B USW joints. As shown in Figure 21, sliding mainly occurred at the DP590-AZ31B joint interface throughout the entire welding process.

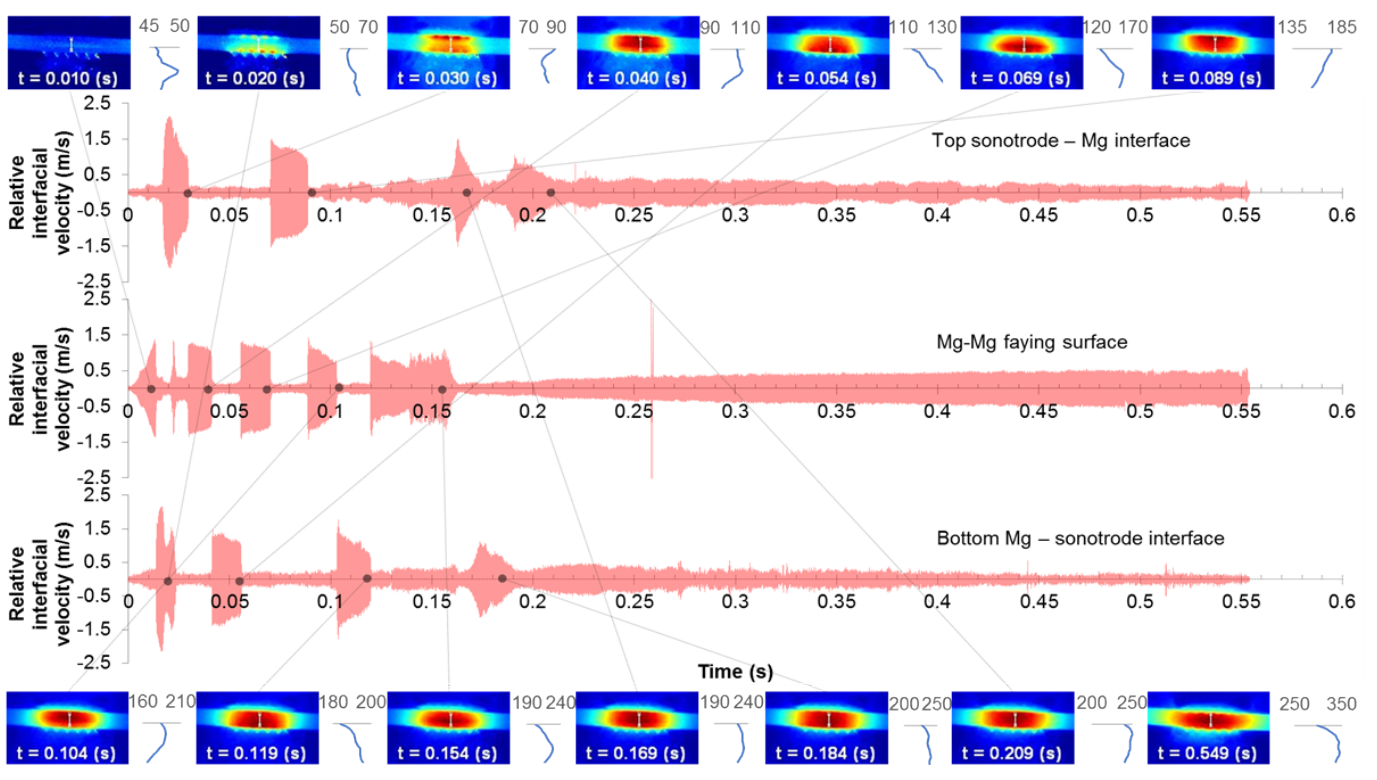

Figure 19 Relative velocity curves across each interface showing sliding (high amplitude) and sticking (low amplitude) motion, as well as the temperature distribution when sticking relative motion was observed (AZ31B-AZ31B USW joint). (Source: ORNL)

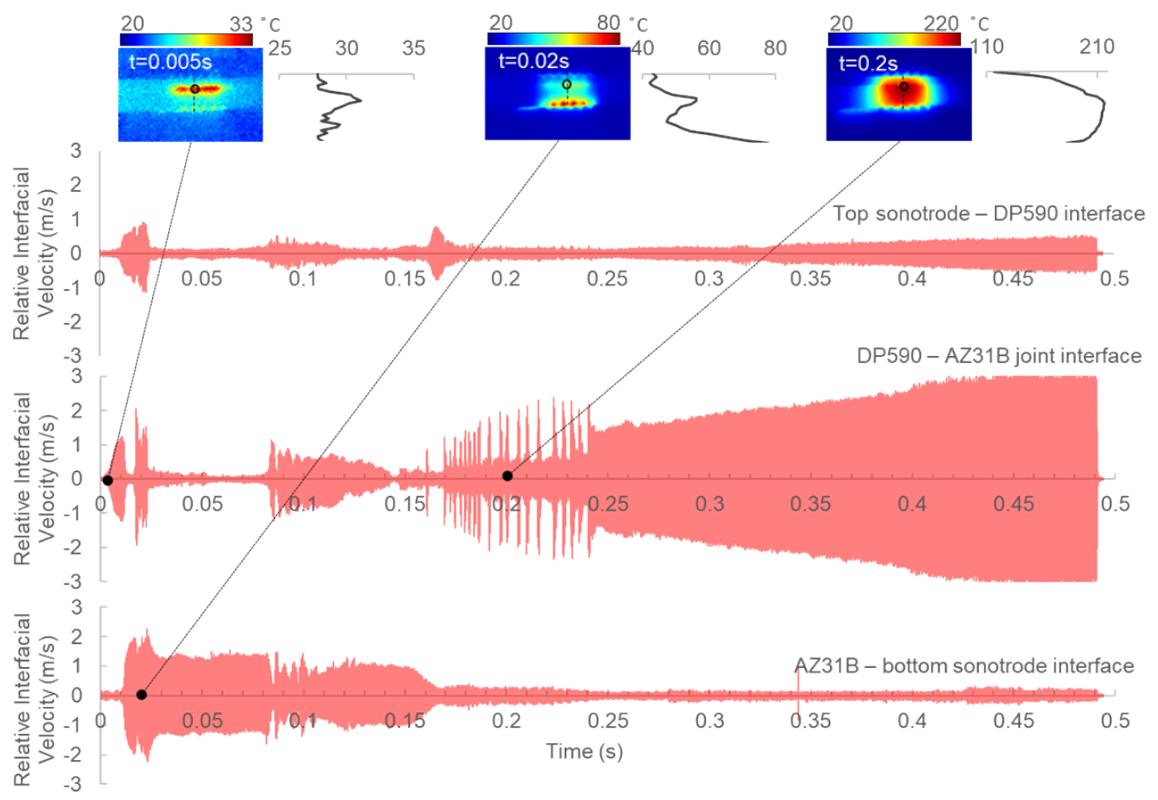

Figure 20 Relative velocity curves across each interface showing sliding (high amplitude) and sticking (low amplitude) motion, as well as the temperature distribution when sticking relative motion was observed (Zn coated DP590-AZ31B USW joint). (Source: ORNL) 
Figure 22 displays the temperature histories at the center of the joint interfaces of the three types of USW joint pairs welded using the same welding conditions (1000W for 0.5). Among them, the temperature curve of the bare DP590-AZ31B joint interface had a fastest increase rate and a peak value. This is consistent to the fact that the relative velocity of bare DP590-AZ31B joint interface had a highest and most stable vibration as can be seen from Figure 19, Figure 20 and Figure 21. After welding, metallurgical bonds were formed between AZ31B-AZ31B and Zn-coated DP590-AZ31B joint interface. However, no bond was formed at the bare DP590-AZ31B interface. This is because that $\mathrm{Mg}$ and Fe are immiscible and there is no intermetallic compounds (IMCs) in the $\mathrm{Mg} / \mathrm{Fe}$ system. The solubility between $\mathrm{Mg}$ and $\mathrm{Fe}$ is exceptionally low. Thus, joining steel to Mg alloy without the coating materials (such $\mathrm{Zn}$ ) is challenging.

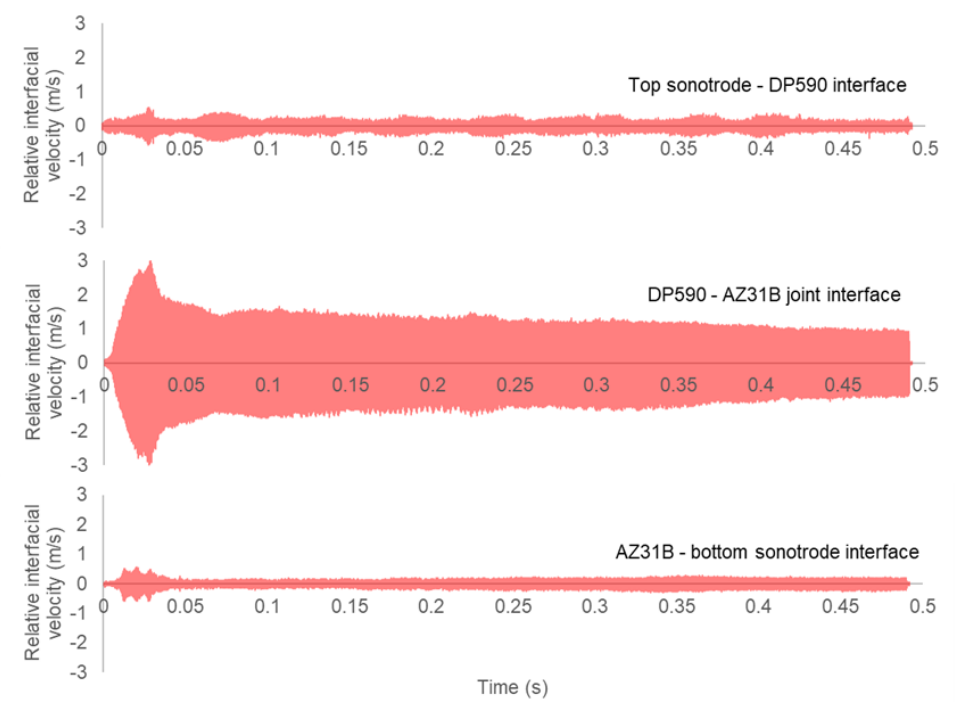

Figure 21 Relative velocity curves across each interface showing sliding (high amplitude) and sticking (low amplitude) motion (bare DP590-AZ31B USW joint). (Source: ORNL)

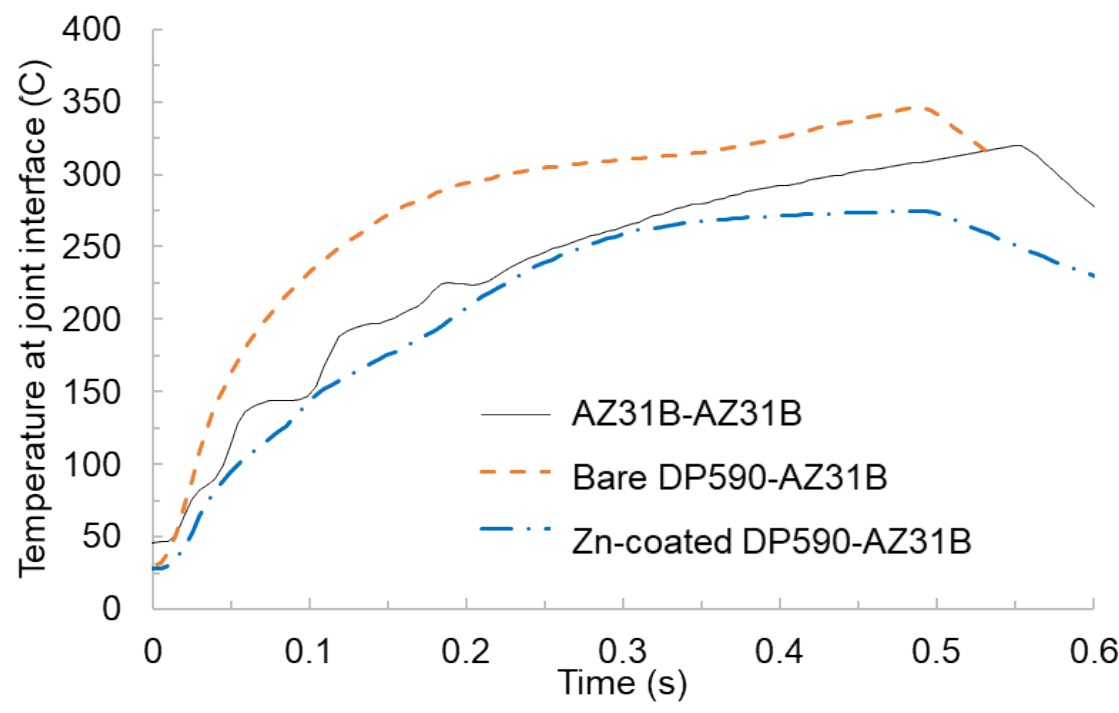

Figure 22 Temperature history at the center of the joint interface of the USW joints made with different metal pairs (Source: ORNL) 


\subsubsection{Progressive weld formation of USW joints}

To study progressive weld formation, additional AZ31B-AZ31B USW joint was produced using the dual-head machine. The dimension of the joint samples and the location of the weld were identical to those used for measuring the interfacial phenomena (Figure 15). The welding power was also set at $1000 \mathrm{~W}$ with varying welding times $(0.10 \mathrm{~s}, 0.15 \mathrm{~s}, 0.20 \mathrm{~s}, 0.30 \mathrm{~s} 0.40 \mathrm{~s}, 0.50 \mathrm{~s}$, and $0.55 \mathrm{~s}$, respectively). As shown in Figure 23, no joints were formed in the first two samples that were welded with $0.10 \mathrm{~s}$ and $0.15 \mathrm{~s}$ time duration. Other welded samples were all nondestructively analyzed using the ultrasonic C-scan NDE technique with a $14 \mathrm{~mm}$ by $14 \mathrm{~mm}$ scan area and the results are also shown in Figure 16. The black area on the left side of the Cscan images represents the off-sample scan region. The color map represents the reflection intensity measured within the gate as discussed previously, in which the reflection from the Mg$\mathrm{Mg}$ interface was expected. The unit of the reflection intensity is described as a percentage of full screen height (FSH) (22). High intensity of the reflection signal indicates a discontinuity or weak localized bond, and low intensity suggests a good,localized bond. As can be seen in Figure 23, the progressive bond formation as a function of welding time was clearly visualized. Referring to the relative motion at the $\mathrm{Mg}-\mathrm{Mg}$ faying surface in Figure 19, reciprocal sliding was observed from the beginning to $0.17 \mathrm{~s}$. As suggested by previous research (25), (24) the formation and destruction of localized microscale bonds were competing processes. Thus, no macroscale bond was formed in the first two weld coupons ( $0.10 \mathrm{~s}$ and $0.15 \mathrm{~s}$ welding duration). After $0.17 \mathrm{~s}$ on the relative velocity curves (refer to Figure 19), no more sliding at the Mg-Mg interface was observed, suggesting a macroscale bond was formed which was strong enough to survive subsequent highfrequency vibrations.

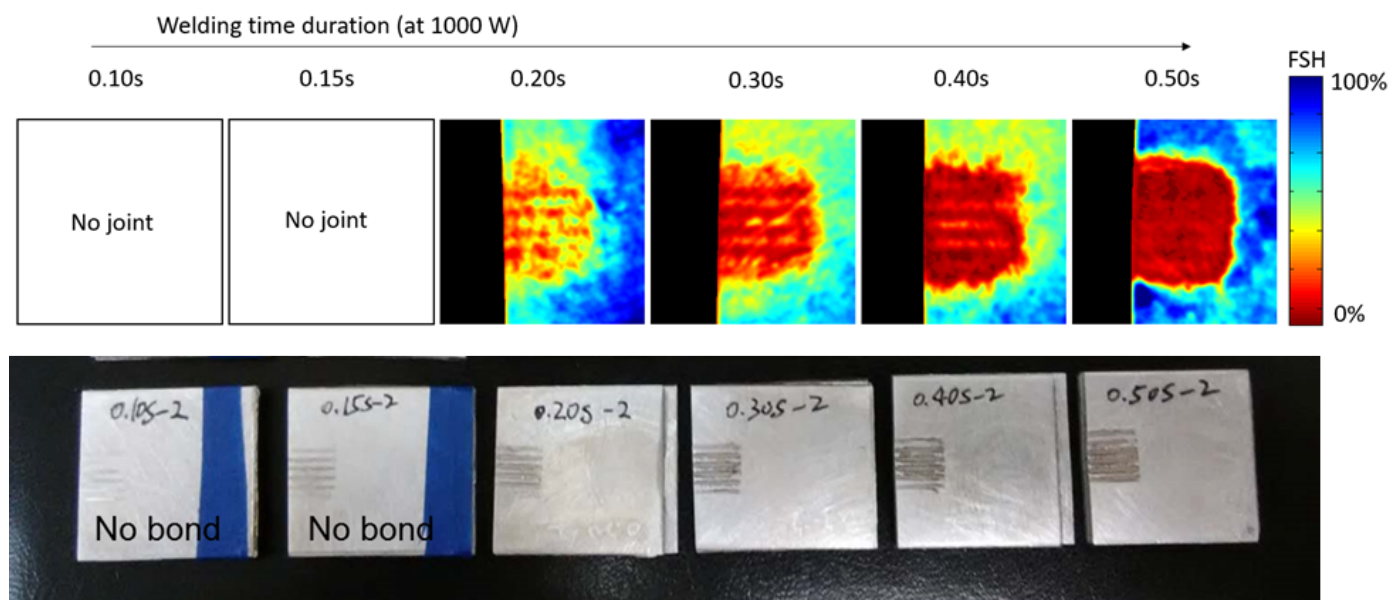

Figure 23 Ultrasonic C-scan NDE analysis (top) of the AZ31B-AZ31B USW weld samples (bottom). Note: FSH, full screen height. (Source: ORNL)

\subsubsection{Acoustic Softening}

Figure 24 shows the evolution of vertical strain and temperature distributions in the experiment that was designed to study the acoustic softening phenomenon (Figure 16). The experiment was conducted on the single-head USW machine. As shown in Figure 24, the vertical strain was initially zero. At about $0.75 \mathrm{~s}$, the Sonotrode started engaging and delivering a constant $250 \mathrm{lbs}$. force to the specimen. In this period, the strain middle section of the sample (indicated by a black box in Figure 24) increased and maintained at a constant value of -0.025 (negative means 
compressive strain). At $2 \mathrm{~s}$, ultrasonic vibration started and a sudden increase of the compressive strain to -0.04 was observed. This was a result of acoustic softening. Although the ultrasonic vibration lasted for $0.2 \mathrm{~s}$, the strain maintained at -0.04 through the end of the ultrasonic vibration till 2.2s. The clamping force still maintained for additional $0.5 \mathrm{~s}$ after ultrasonic vibration stopped. In this period, the strain kept at -0.045 . At $2.7 \mathrm{~s}$, the Sonotrode started disengaging. The compressive strain decreased to -0.035 . Through the entire experiment, the temperature within the same middle section of the specimen was also recorded as shown in Figure 24. The result indicates that the maximum temperature change was less than ${ }^{2} \mathrm{C}$. This means that the change in strain curve was either force or acoustic softening induced and was not caused by temperature change.

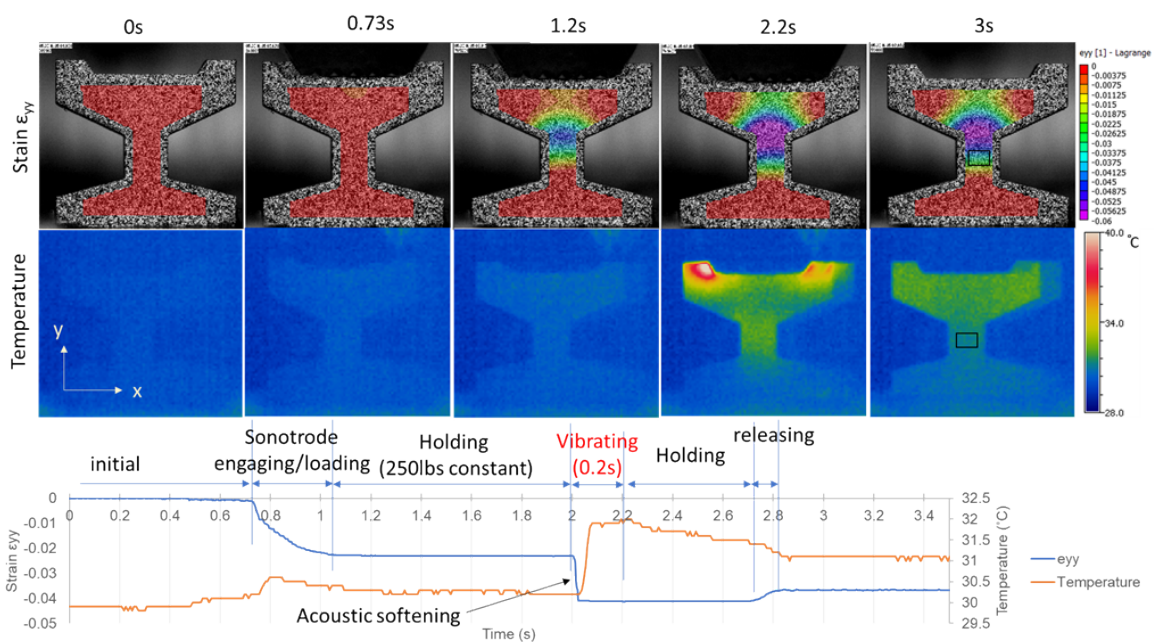

Figure 24 Vertical strain (عyy) and temperature distributions when a short pulse $(0.2 \mathrm{~s})$ of ultrasonic energy was applied indicating the occurrence of acoustic softening (Source: ORNL)

\subsection{Post Weld Characterizations}

Post welding characterization were performed to understand the effects of welding conditions the produced joints. This included mechanical testing and microstructural characterizations of the joints in various configurations.
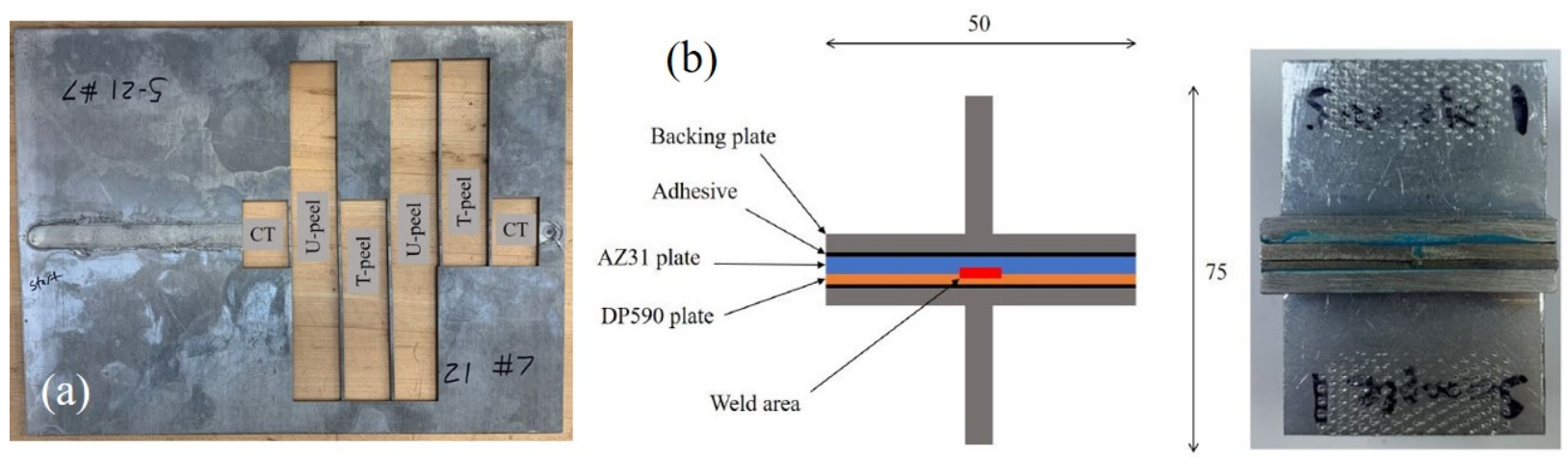

Figure 25 (a) Different sample preparation from welded plate, (b) Dimensions of cross-tension specimen (all dimensions are in $\mathrm{mm}$ ) and image of cross-tension specimen. (Source: PNNL) 


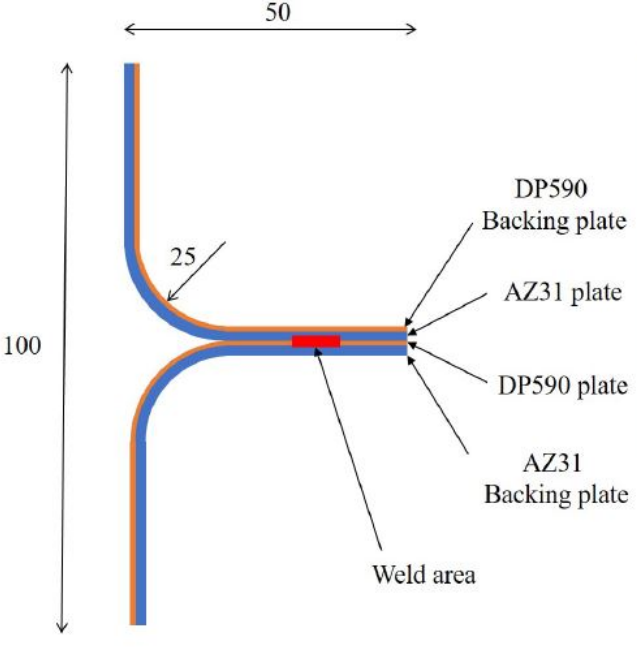

(a)

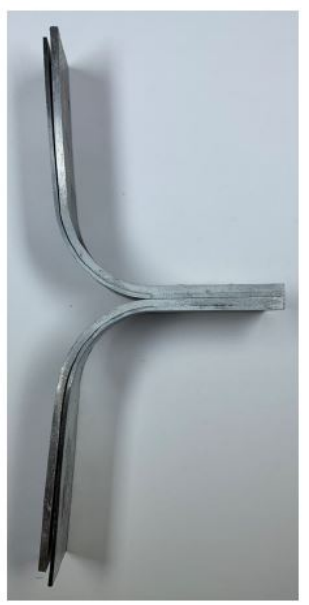

(b)

Figure 26 (a) T-peel specimen geometry (all dimensions are in $\mathrm{mm}$ ). Blue color represents the AZ31 sheet and orange color represents the DP590 steel sheet, (b) A picture of T-peel sample. (Source: PNNL)

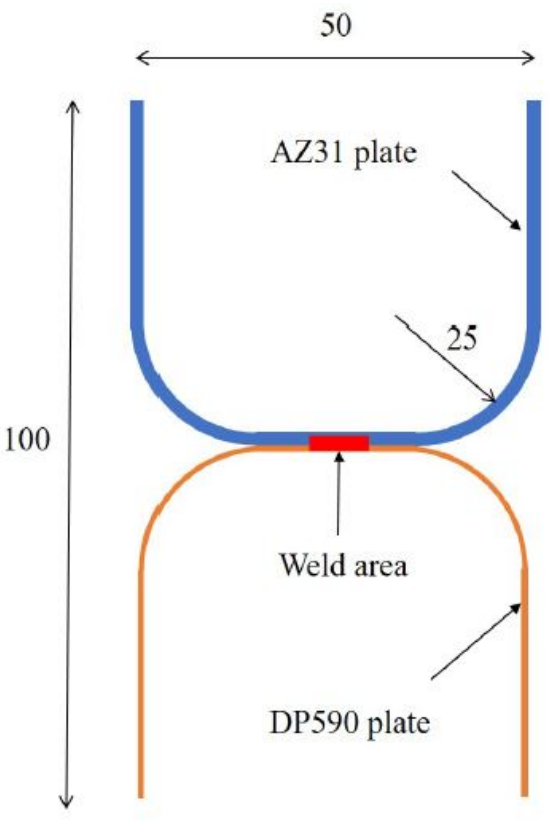

(a)

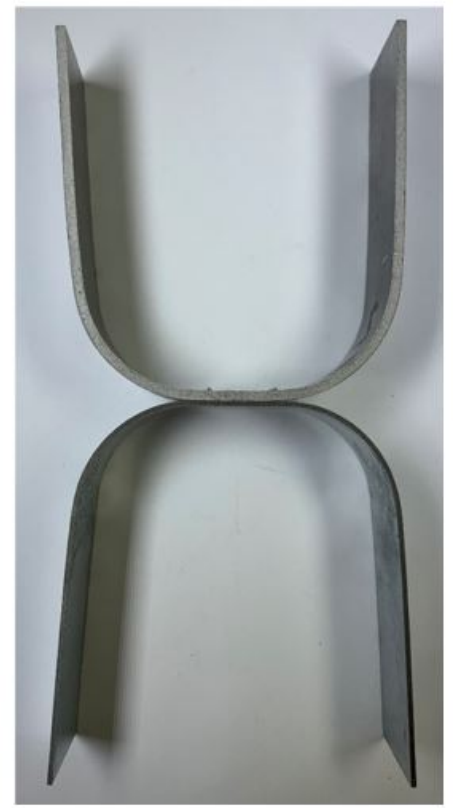

(b)

Figure 27 (a) U-peel specimen geometry (all dimensions are in $\mathrm{mm}$ ) and (b) A picture of U-peel sample (Source: PNNL)

Friction stir welded sheets were cut as shown in Figure 25 (a) to extract samples for cross-tension, T-peel, and U-peel tests. The linear FaST weld can be seen in the center, made with the tool advancing from left to right. In order to reduce the heat exposure and stress during sample preparation, the welded $\mathrm{Mg} / \mathrm{steel}$ sheet was cut by electrical discharge machining. Geometry of the cross-tension specimen with its dimensions is shown in Figure 25 (b). To ensure that 
interfacial strength is accurately measured and to impart uniform stress across the interface the entire weld area should be under uniform stress. To achieve this, we adhesively bonded backing plates on both sides of the weld. Sandpaper grinding was done on the bonding surface of the backing plate and weld sample. The backing plates were made by welding two steel plates in T configuration. The surfaces were cleaned with a cloth to remove any sandpaper residues. BETAMATE structural adhesive (Dow Automotive system, The Dow Chemical Company, USA) was used to bond the backing plate and sample. $0.225 \mathrm{~mL}$ of adhesive was applied on both the facing surfaces of the backing plates. An additional $0.005 \mathrm{~mL}$ of adhesive was applied to the faying surface of the weld to avoid any gap between the sample and the backing plate. Finally, the cut weld specimen was sandwiched between two backing plates as shown in Figure 25 (b) with even clamping force. Two consecutive heating steps were used for adhesive curing: (a) 10 minutes at $50^{\circ} \mathrm{C}$ and (b) 45 minutes at $150^{\circ} \mathrm{C}$. After curing, the side faces of the samples were polished lightly to remove excess adhesive. Figure 25 (b) shows an example of a cross-tension sample. The geometry of a T-peel specimen along with dimensions is shown in Figure 26a. To avoid any asymmetric bending and to ensure interfacial fracture, the stiffness on the either side was balanced by adhesively bonding the $\mathrm{Mg}$ sheet to the steel side and the steel sheet to the Mg side (See Figure 26). Both arms of the T-peel specimen are effectively bimaterials beams with matching flexural strength. Bonding process described in the last paragraph for Cross tension tests was followed for $T$ peel samples. Test results from flexurally matched $T$ peel samples were used for modeling work. Normal T Peel samples with no flexural matching were also tested for industry bench marking.

Pairing of brittle Mg with ductile DP590 steel complicated sample preparation. Several trial runs were used to ensure that post weld bending of the samples produced repeatable coupon geometry. After trial and error an optimum bend radius of $25 \mathrm{~mm}$ was used. Figure 26 (b) shows an example of T-peel sample. Geometry and representative U-peel specimen are shown in Figure 27 (a) and (b). Figure 28, Figure 29 and Figure 30 show fixtures used for bending and testing of T Peel, U Peel and CT samples. Lap shear tensile test samples were prepared according to ASTMD1002-10 with $30 \mathrm{~mm}$ width. Unguided lap shear tensile tests were done with a cross head speed of $76.2 \mathrm{~mm} / \mathrm{sec}$. Tabs with a corresponding thickness of $\mathrm{Mg}$ and steel sheets were glued to the grip region to align the sample. Lap shear, T peel, CT, longitudinal samples were prepared with coated and uncoated DP 590 steel as shown in Figure 30, Figure 31 and Figure 32. DIC set up used is shown in Figure 33.

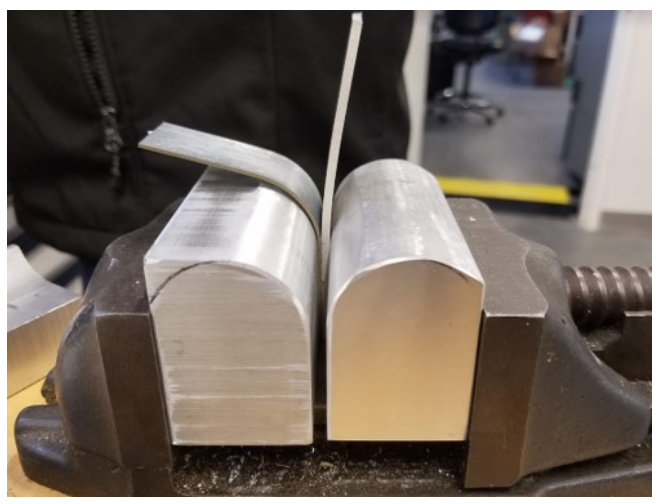

Figure 28 Bending Fixture (Source: PNNL) 
PNNL-30945

ORNL/SPR-2021/1836

ANL-21/07

Fixture For CT Sample

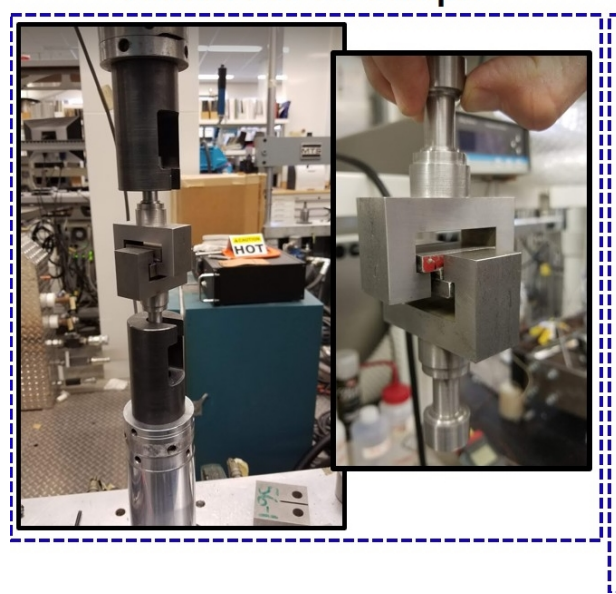

Fixture For U Peel Testing

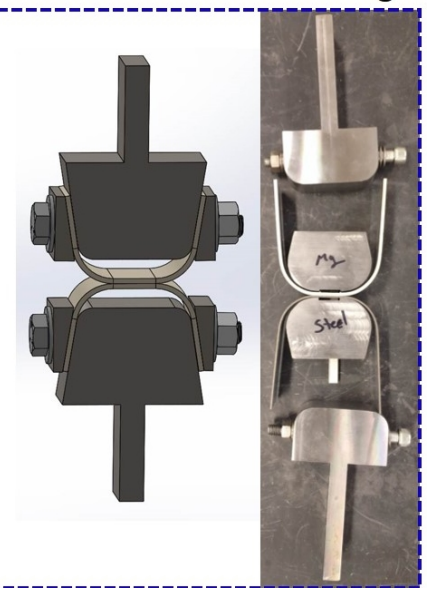

Figure 29 CT sample and U Peel Testing Fixture (Source: PNNL)

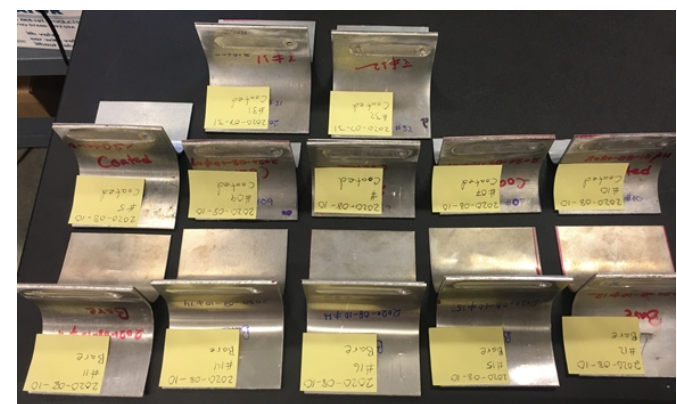

Figure 30 Stitch weld T Peel samples before testing (Source: PNNL)
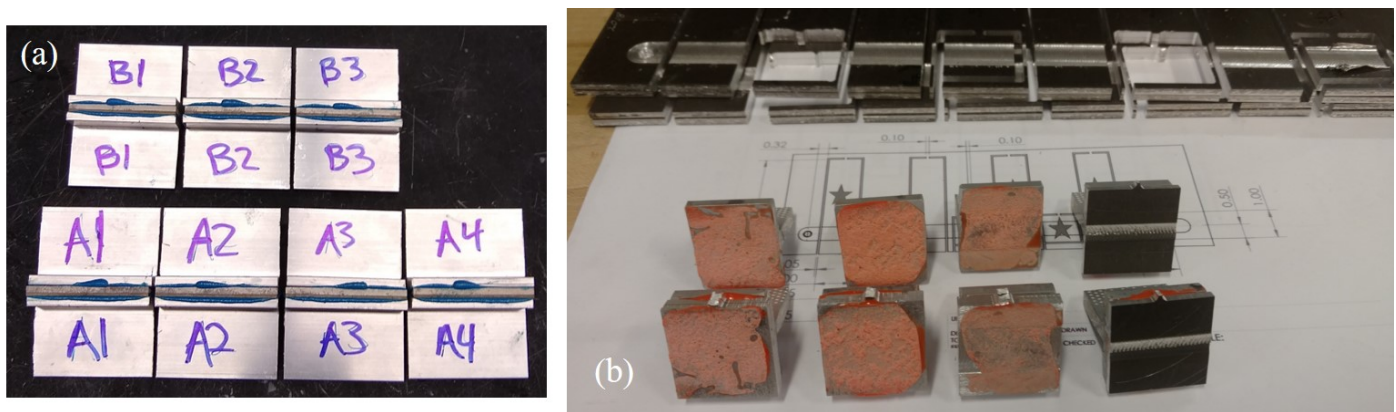

Figure 31 CT Samples before testing and Problems associated with preparation of CT samples (Source: PNNL) 
PNNL-30945

ORNL/SPR-2021/1836

ANL-21/07
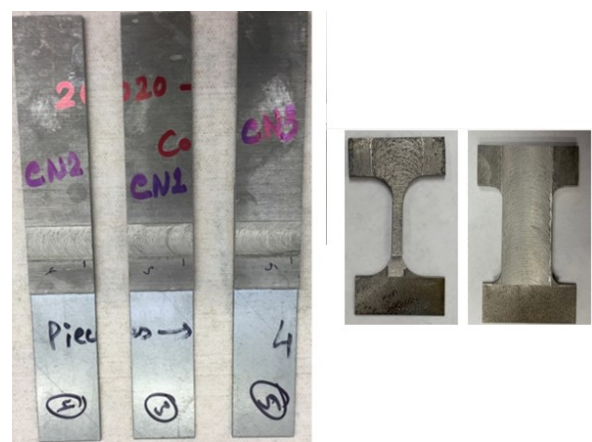

Figure 32 Different kind of lap shear samples: transverse, whole weld longitudinal, center weld longitudinal (Source: PNNL)
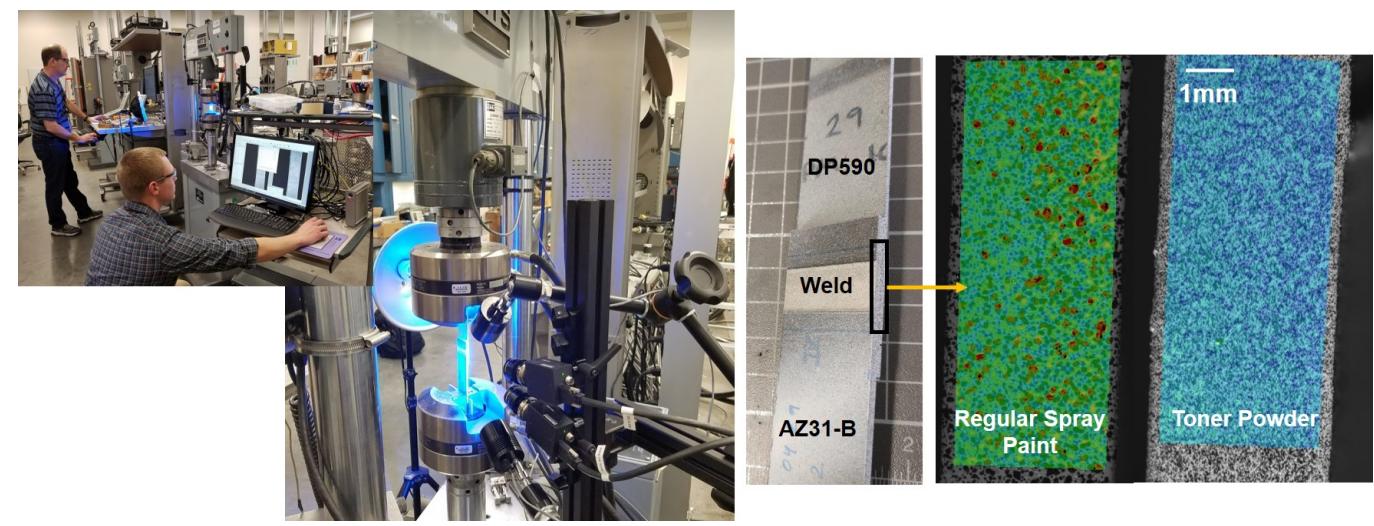

Figure 33 DIC set-up and painted samples before lap shear tests (Source: PNNL)

Lap shear, fatigue and U-peel testing methods were applied to study the strength of the USW joints made with different metal pairs and welding conditions (Figure 34). The tests were performed using a hydraulic system as shown in Figure 35.

(a)

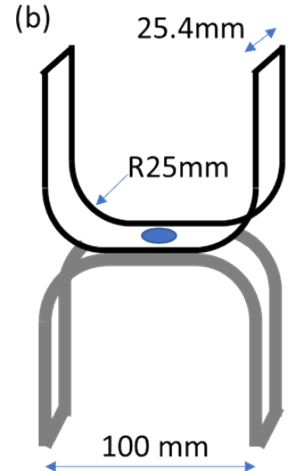

Figure 34 Schematic of (a) lap shear and fatigue samples and (b) U-peel samples for USW joints (Source: ORNL) 

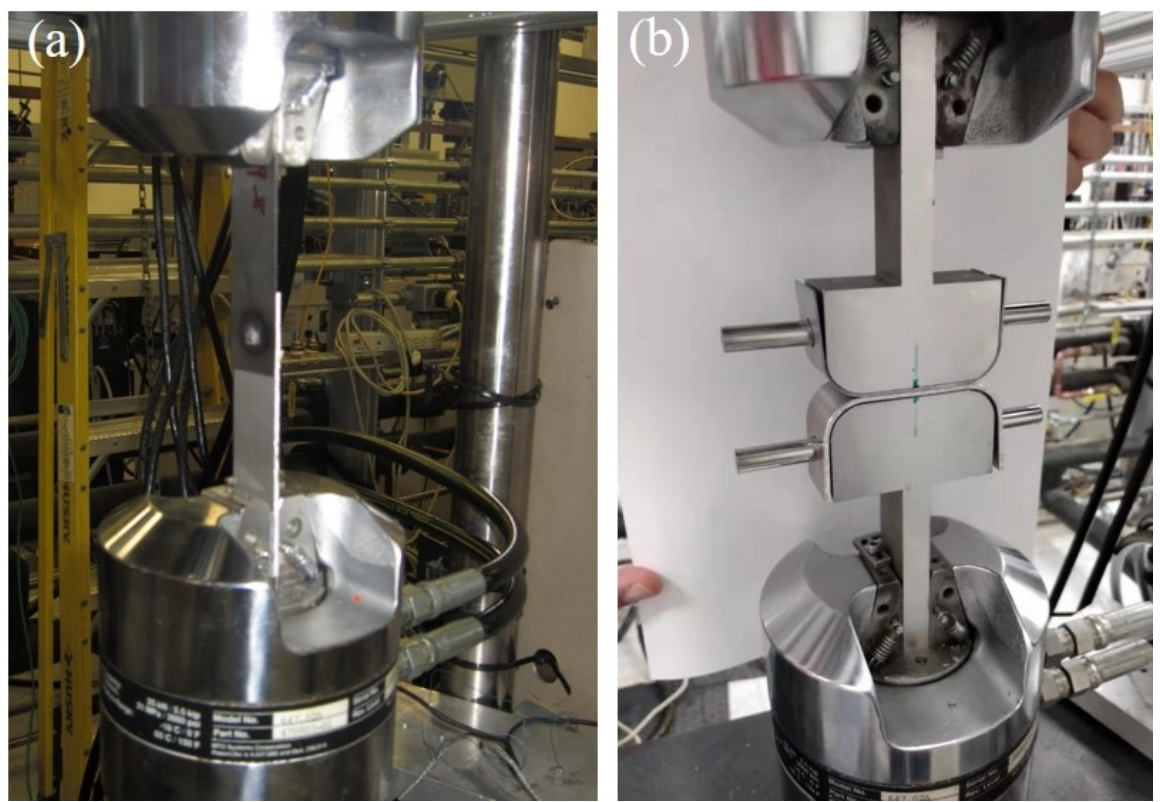

ANL-21/07

Figure 35 Joint strength characterizations: (a) lap shear and fatigue testing and (b) U-peel testing (Source: ORNL)

\section{- C-Scan nondestructive testing}

Ultrasonic C-scan nondestructive examination (NDE) technique was used to study the progressive weld formation of some selected samples produced with varying welding conditions. The welded samples were submerged in a water tank and scanned with a spherically focused ultrasonic transducer $(20 \mathrm{MHz}, 25.4-\mathrm{mm}$ focal distance and 6.35-mm diameter) in pulsed echo mode at a spatial resolution of $50 \mu \mathrm{m}$. In the C-scan experiment, a signal gate or threshold was set to cover the range where the reflection from the joint interface was expected. Within the gate, the intensity of the ultrasonic signal was recorded. A strong signal suggested a discontinuity between joint interface and hence no or weak localized bond. On the contrary, a weak signal suggested a good localized bond. It is noted that the surface waviness (imprinted during the welding process), particularly on the side facing towards the transducer, could disturb the ultrasound signal. Thus, before the C-scan analysis, this side of the metal surface was carefully grinded flat to remove the Sonotrode imprints.

\subsubsection{Microstructural characterization}

Microstructural characterizations of welded joints were conducted using progressively advanced techniques ranging from simple optical characterization to high magnification TEM imaging. Specifically, Scanning Electron Microscopy (SEM), Energy dispersive spectroscopy (EDS), Electron Back Scattered Diffraction (EBSD), Transmission Electron Microscopy (TEM), Atom Probe Tomography (APT), X-ray photoelectron spectroscopy (XPS), synchrotron diffraction. were used to study the morphology and composition of the joint interfaces and fracture surfaces. 


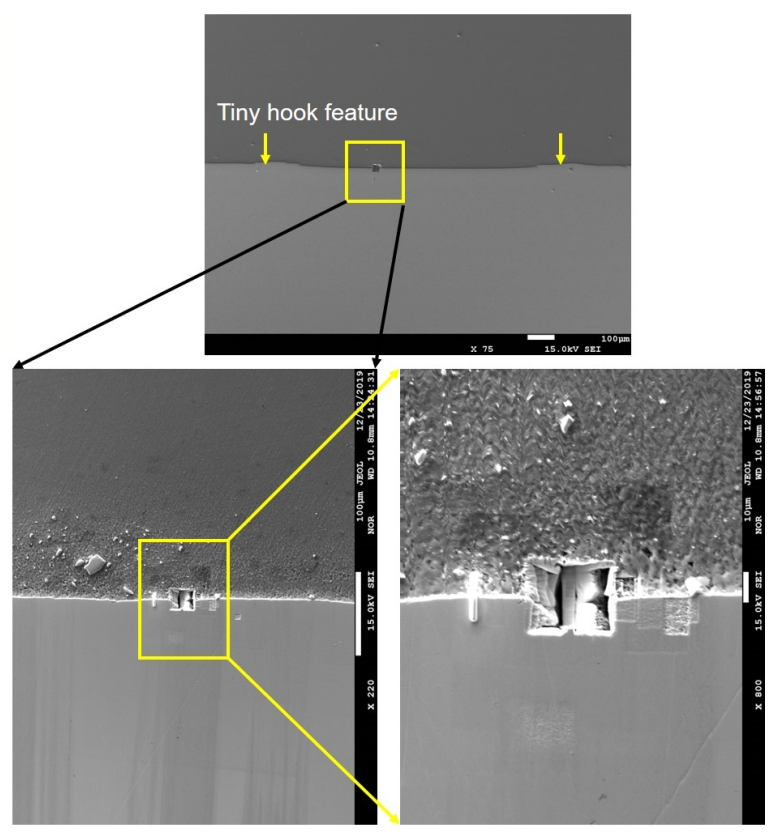

Figure 36 FIB Location at the joint interface (Source: PNNL)

The SEM imaging and the sample preparation for S/TEM and APT (using the FIB lift-out technique) were performed using a Thermo Fisher Scientific Quanta 200 FIB-SEM outfitted with an Oxford Instruments X-ray Energy Dispersive Spectroscopy (EDS) system for compositional analysis. A FEI Titan 80-300 operated at $300 \mathrm{kV}$ and a JEOL ARM200F operated at $200 \mathrm{kV}$ were used for S/TEM. TEM foils were extracted from the vicinity of the interface region (Figure 36) for AZ31-DP 590, pure Mg-DP 590 and pure Mg-pure Fe welds, using a focused ion beam (FIB) liftout technique. Cautions were taken to thin the heterojunction interface to make both sides electron transparent while retaining the interface integrity. 
Density map of all ions
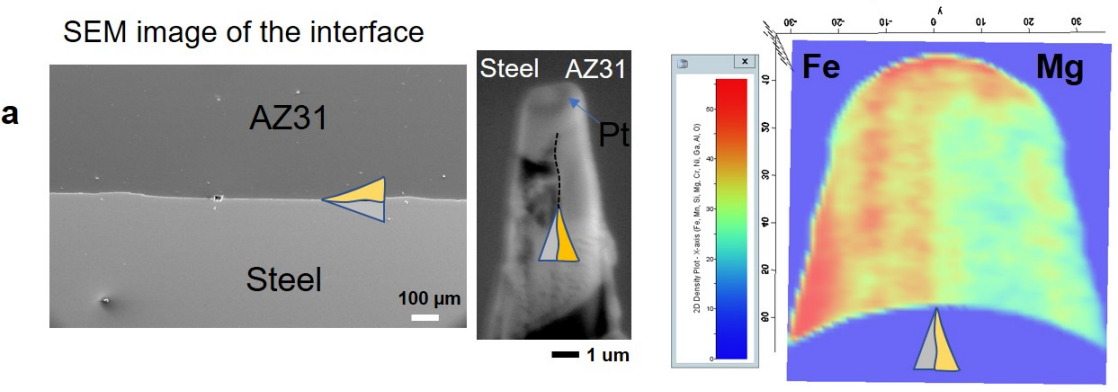

High density of ions on the Fe side and very low on the $\mathrm{Mg}$ side

b

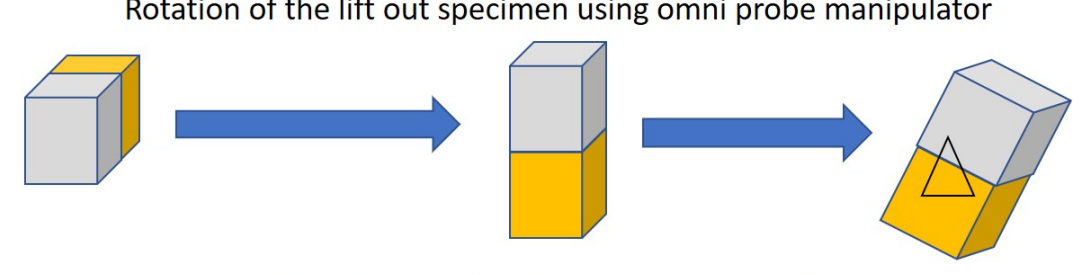

C

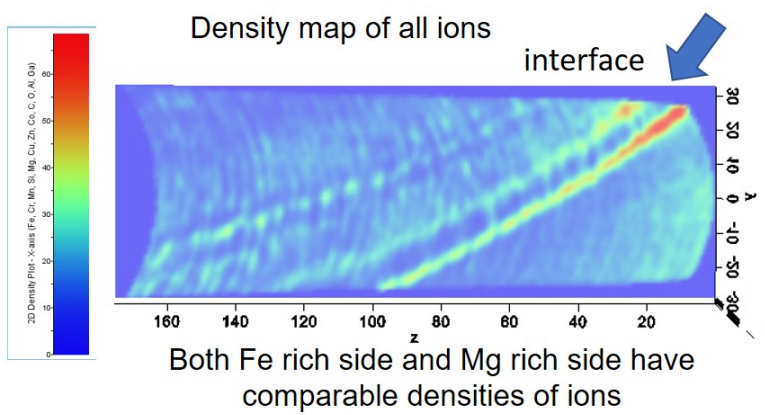

Figure 37 Atom probe tomography of the interface between AZ31 and Steel. (a) APT results when the interface of $\mathrm{Mg}$ rich side and steel was vertical, the all ion density map show a non-uniform density of ions, (b) rotation of the lifted out micro slab using the omni probe manipulator in the FIB and aligned the interface at 45 degree to the field ionization axis, (c) smooth transition from $\mathrm{Fe}$ rich side to the Mg rich side. (Source: PNNL)

A CAMECA LEAP 4000X HR APT was used in pulsed voltage mode at $200 \mathrm{kHz}$ pulse frequency, with $20 \%$ pulse fraction, and a specimen temperature of $50-60 \mathrm{~K}$, while the detection rate was maintained at 0.005 atoms/pulse. For the successful field evaporation of the needles in APT, the FIB lifted samples were rotated, 90 degrees out of plane and then 45 degree in plane in the FIB before making the needle specimen. As the field evaporation energies of $\mathrm{Fe}(33 \mathrm{~V} / \mathrm{nm})$ and $\mathrm{Mg}$ $(21 \mathrm{~V} / \mathrm{nm})$ are far apart, the plane by plane field ionization of both $\mathrm{Mg}$ rich side and Fe rich side was viable with the interface in the vertical direction. Hence, the we rotated the lifted out micro slab using the omni probe manipulator in the FIB and aligned the interface at 45 degree to the field ionization axis (Figure 37 (a) and (b)). This allowed a smooth transition from Fe rich side to the Mg rich side. 


\section{- Preliminary corrosion test}

Preliminary corrosion tests were performed in the salt spray chamber ( $5 \mathrm{wt} \% \mathrm{NaCl}$ ). Samples exposed in the chamber (Figure 38) for various of time durations were taken out for lap shear tensile tests to evaluate the degradation of the joints. A separate corrosion task was established later in the project. This project provided samples to support this task. Comprehensive and detailed corrosion characterization on the dissimilar joints can be found in other report.

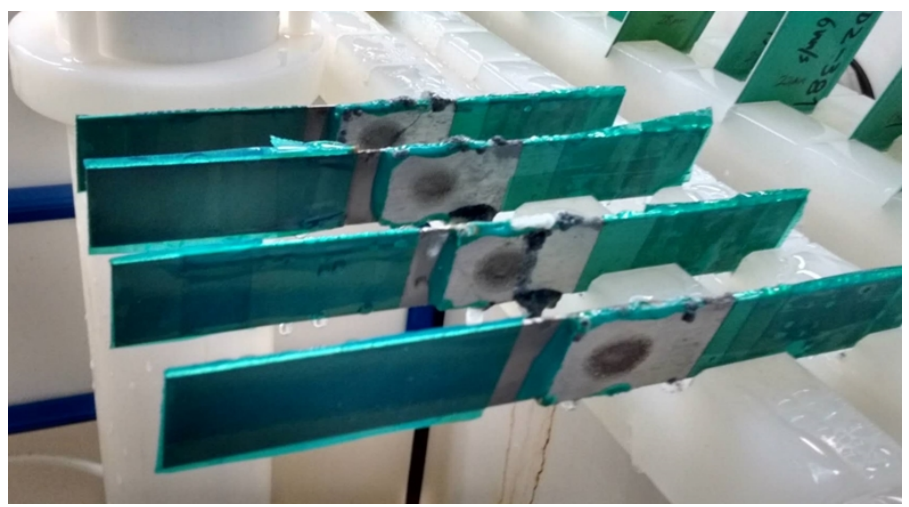

Figure 38 Preliminary corrosion testing in the salt spray chamber (Source: ORNL) 


\subsection{Results and discussions}

\subsection{Process Responses}

\subsubsection{Friction Stir welding}

\subsubsection{Interface Temperature Measurement during FaST process}

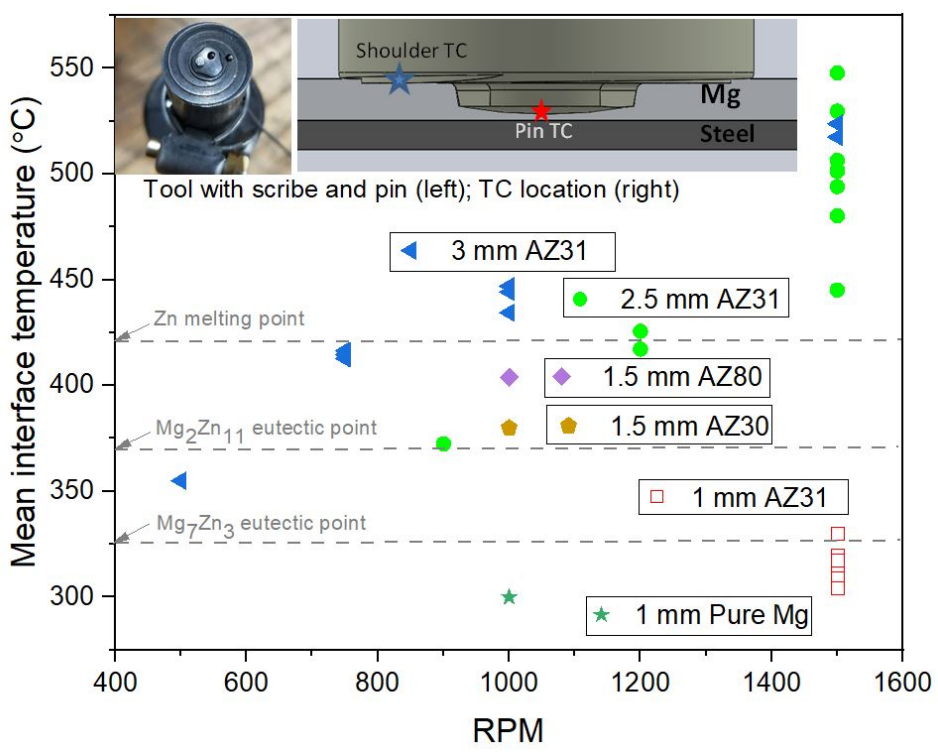

Figure 39 Summary of the measured temperature for different joints by FaST process (Source: PNNL)

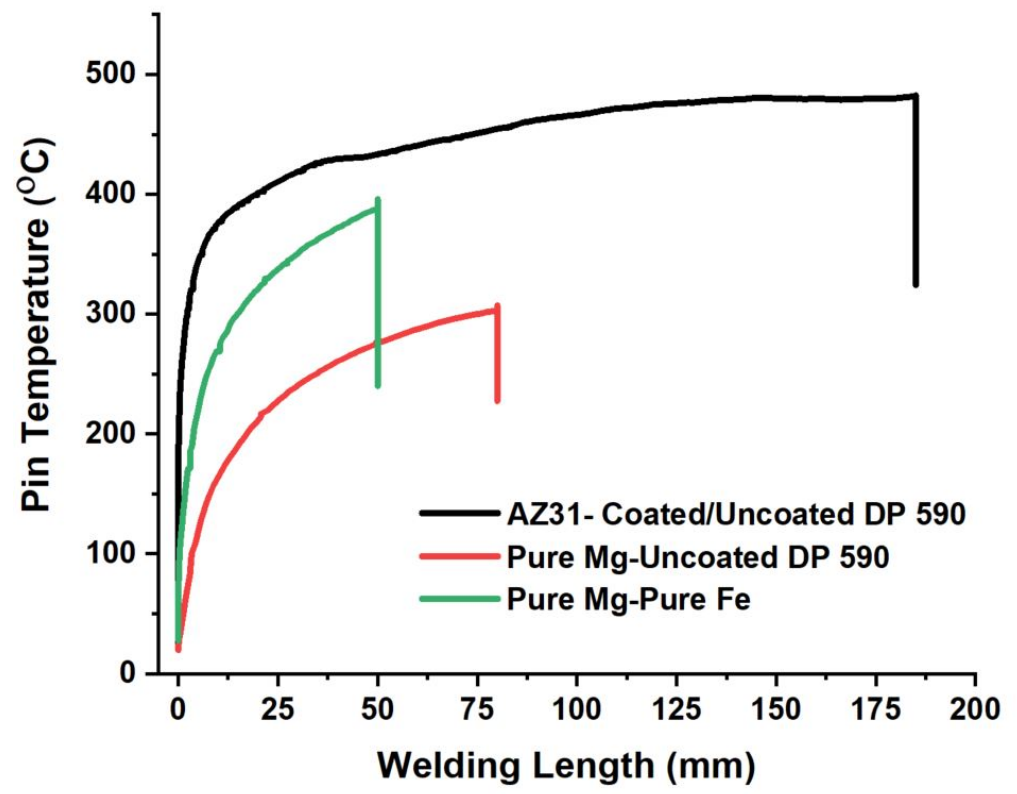

Figure 40 Thermal cycle at the interface for AZ31-Coated and uncoated DP 590 steel, Pure MgUncoated DP 590 steel and Pure Mg-Pure Fe joints (Source: PNNL) 


\subsection{Microstructural characterizations}

\subsubsection{Scanning Electron Microscopy}

\subsubsection{Interface characterization for FSW ed AZ31-coated DP 590 weld without Scribe}

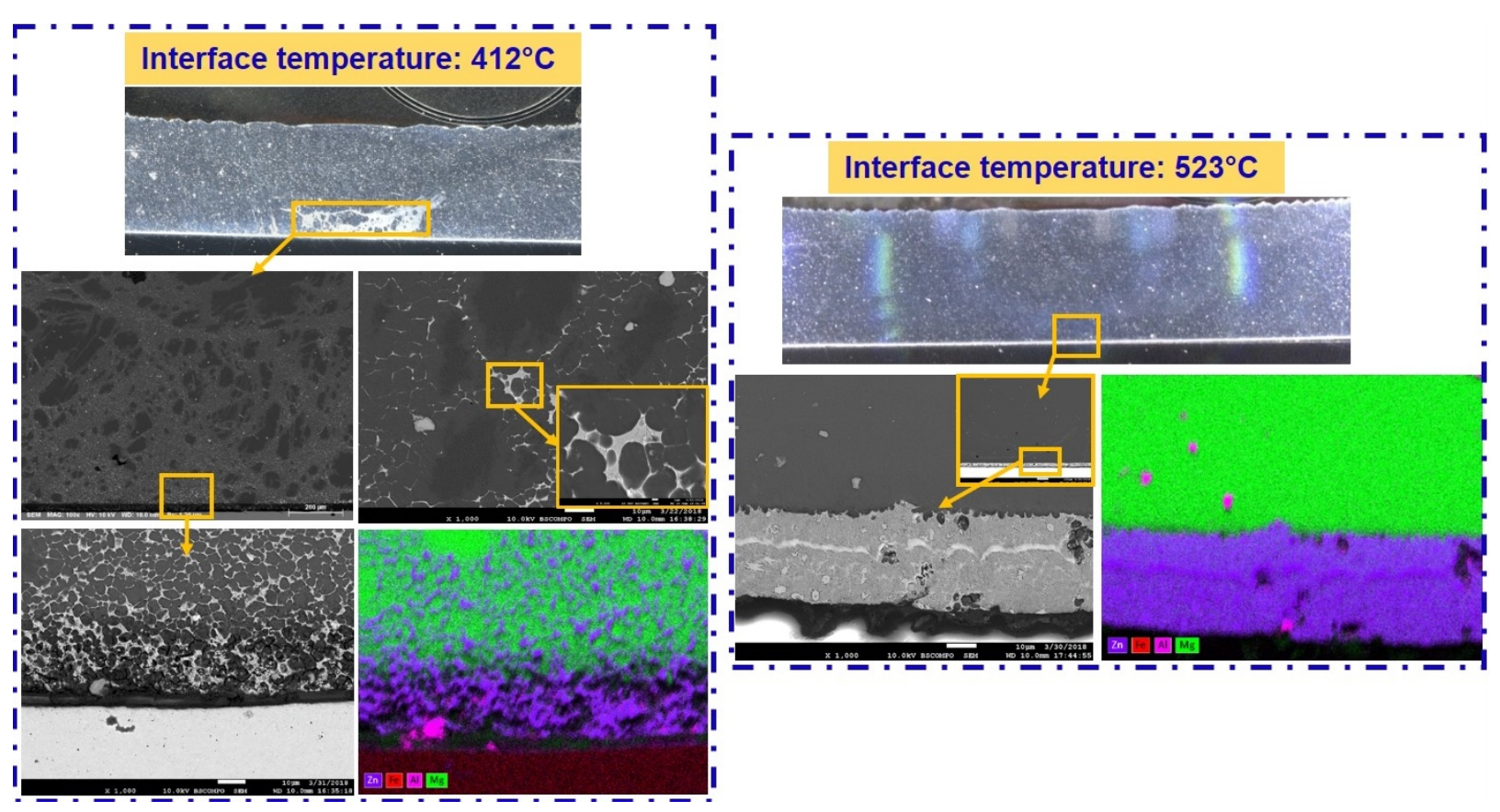

Figure 41 SEM with EDS mapping at the joint interface for two different temperature conditions (Source: PNNL)

Figure 41 shows the results from welding trials with conventional FSW tool without the scribe cutter. Macrograph for two different combination of parameters resulting in a peak temperature of $\sim 412^{\circ} \mathrm{C}$ and $\sim 523^{\circ} \mathrm{C}$ are shown. High magnification SEM image (Figure 41) and EDS mapping (Figure 41$)$ indicates that for weld performed at lower temperature $\left(\sim 412^{\circ} \mathrm{C}\right) \mathrm{Zn}$ from steel coating diffused towards the $\mathrm{Mg}$ nugget decorating the $\mathrm{Mg}$ grain boundaries. Whereas, for weld run at higher temperature $\sim 523^{\circ} \mathrm{C}$, this diffusion was not observed. Instead, a thick Mg-Zn eutectic at was observed. Moreover, in both the welding cases $\mathrm{Zn}$ diffusion to the $\mathrm{Mg}$ side is also noticed away from the joint line as shown in Figure 42 . Owing to a low melting point of $\mathrm{Zn}\left(420^{\circ} \mathrm{C}\right)$ and high interface pressure, surface oxide films ruptured at the interface resulting in liquid $\mathrm{Zn}$ extrusion with a broken oxide film, spreading along the interface between the two sheets. This diffusion of $\mathrm{Zn}$ on the Mg surface away from the interface may also act as a protective layer against general corrosion of $\mathrm{Mg}$.

While there was some difference in the interfacial compositions for high and low welding temperature, the general conclusion of this experimental runs was that high pressure and temperature alone did not result in significant joint strength, despite the formation of $\mathrm{Mg}-\mathrm{Zn}$ eutectic. For an average $\mathrm{Zn}$ coating thickness of $20 \mu \mathrm{m}$ and $10 \mu \mathrm{m}$, no viable joint strength was achieved with conventional FSW runs. While some bonding occurred via the presence of $\mathrm{Zn} / \mathrm{Mg}$ eutectic, a simple hand peeling resulted in interfacial fracture. 
PNNL-30945

ORNL/SPR-2021/1836

ANL-21/07

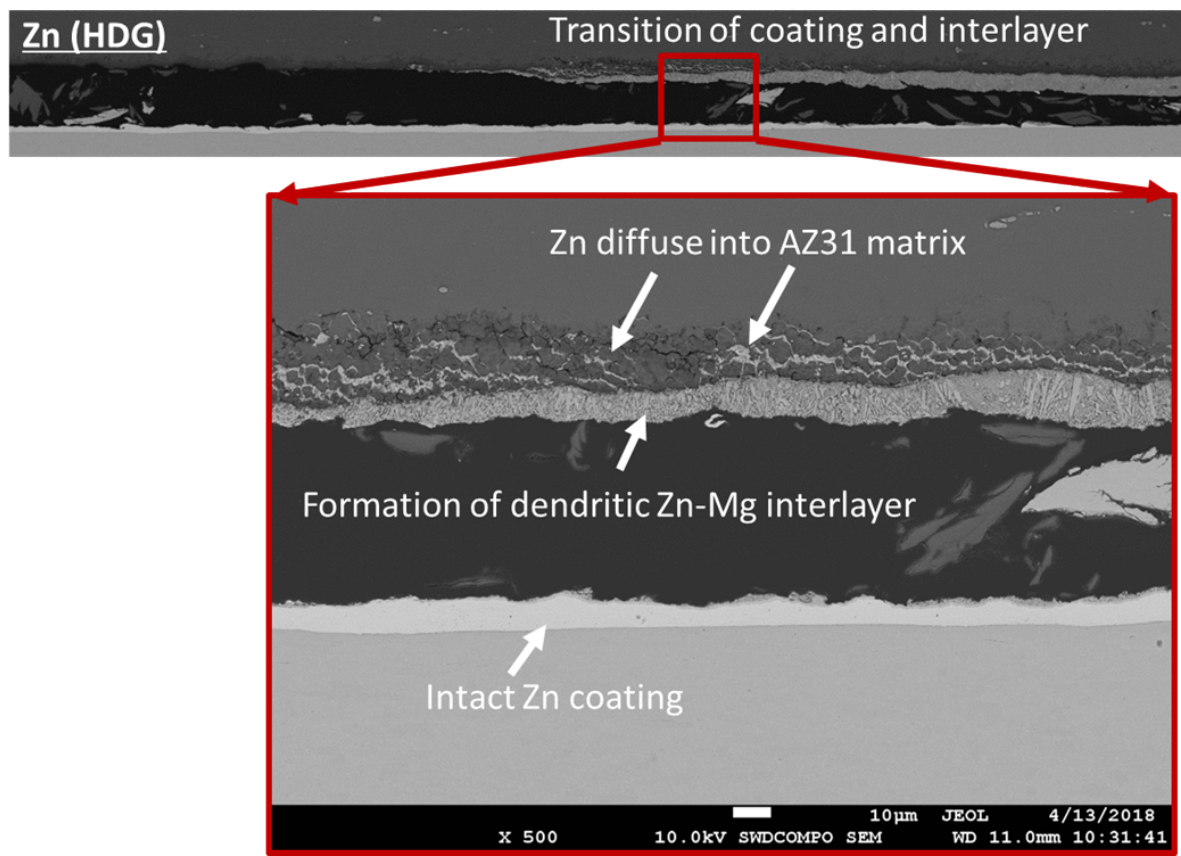

Figure 42 Zn diffusion away from the joint line (Source: PNNL)

2.2.1.2 Interface characterization of AZ31- Zn coated and uncoated DP 590 steel weld with FaST and USW
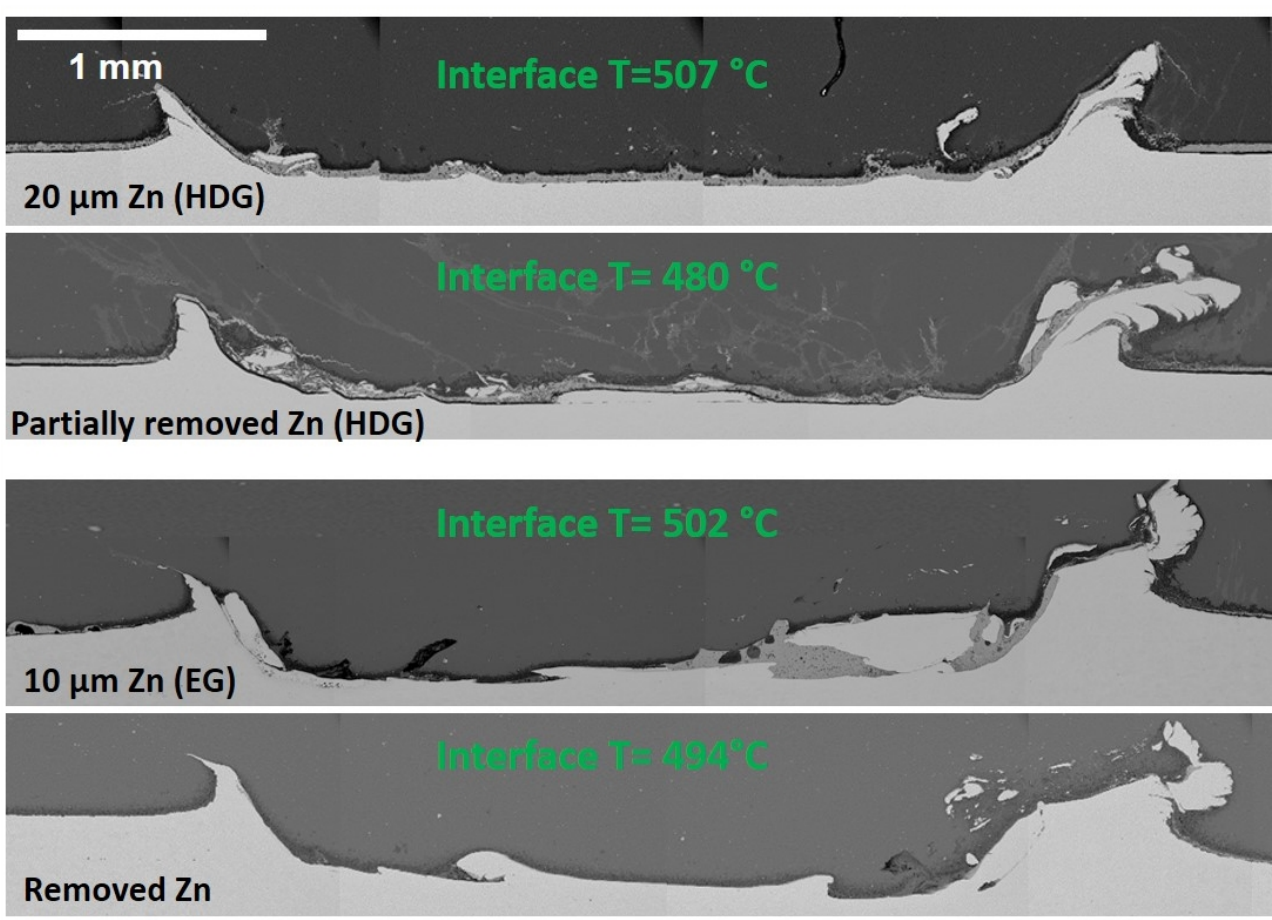

Figure 43 FaST processed AZ31 Mg to coated and uncoated DP 590 steel at different temperature (Source: PNNL) 


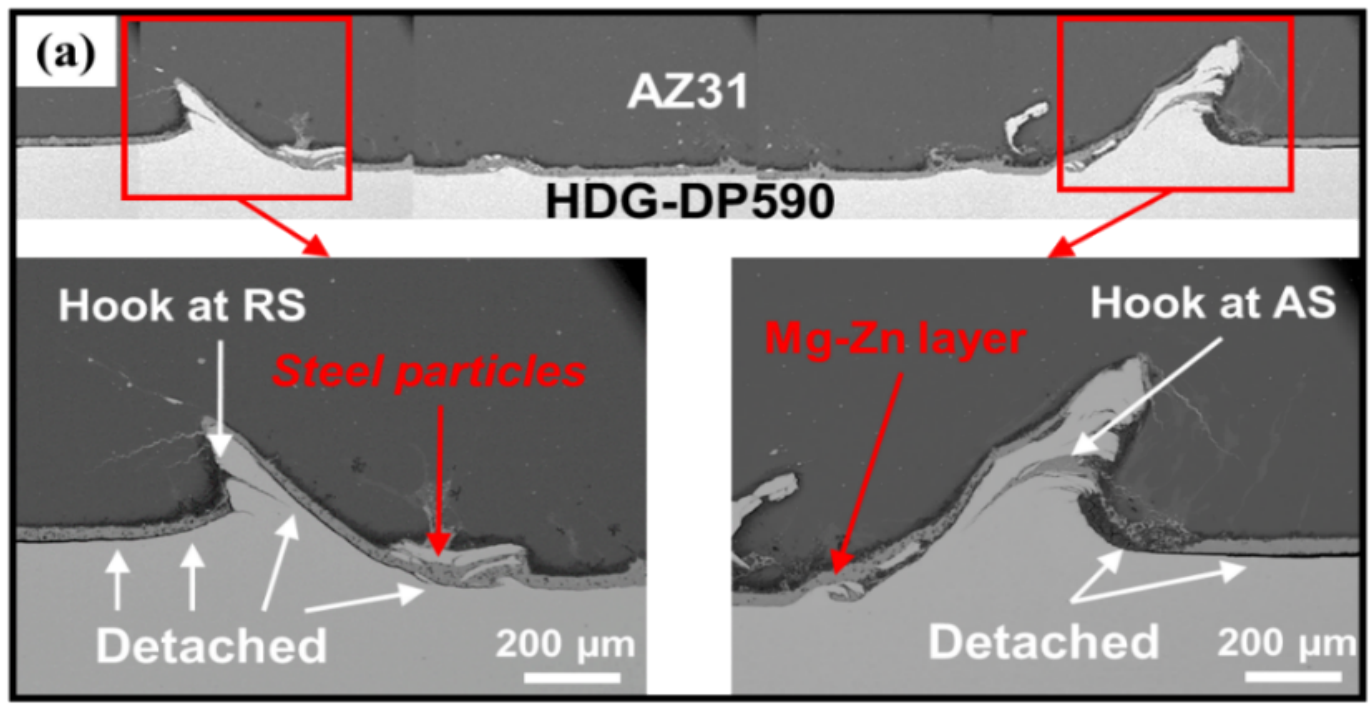

ANL-21/07

Figure 44 SEM images of the cross-sections of AZ31/HDG-DP590 (Source: PNNL)

Macro-cross section of FaST joints, typical hook formation and corresponding peak temperature for different set of materials are shown in Figure 43. Characteristic hook like features were obtained on the either side of the joint. Tool temperature measurements allows for liquidation of $\mathrm{Mg}-\mathrm{Zn}$ solid solution and a formation of $\mathrm{Mg}-\mathrm{Zn}$ eutectic structure during solidification after welding.

SEM micrographs showing cross sections of welded specimens of AZ31-HDG DP 590 and AZ31bare MS270 are summarized in Figure 44 and Figure 46. As shown in Figure 44(a), the Zn coating on base DP590 reacted with AZ31 forming a continuous Mg-Zn eutectic layer at the interface. Eutectic reaction between $\mathrm{Mg} / \mathrm{Zn}$ occurred as the interface temperature $\left(\sim 477-507^{\circ} \mathrm{C}\right)$ was measured. The IMC layer is well bonded to both $\mathrm{Mg}$ and steel side right under the tool. On either side of the hook region where deformation and pressure is reduced, the IMC appears to be detached from the steel side. (enlarged picture in Figure 44(a)). It is typical to observe a "crack" like noise right after the welding is complete which is associated with detachment of $\mathrm{Mg} / \mathrm{Zn}$ eutectic layer from steel sheet outside the hook region. The top $\mathrm{Mg}$ sheet expanded under high heat during welding and the subsequent sheet contraction upon cooling may have led to enough stress resulting in the detachment. In case of, AZ31 - bare MS 270 shown in Error! Reference source not found.(b) where the $\mathrm{Zn}$ coating layer was removed from the steel, a $\mathrm{Mg}$ oxide layer is observed at the welded $\mathrm{Mg} /$ steel interface.

EDS analysis on selected regions in Figure 44(a) were conducted and the results are shown in Figure 45. Welded interface between AZ31 and HDG-DP590 consists of-the MgO layer (white double side arrows) and the $\mathrm{Mg}-\mathrm{Zn}$ eutectic layer (blue double side arrows). Some stray steel particles (yellow arrows) exist at the interface region, which were created by the scribe machining. In addition, some $\mathrm{MgO}$ particles (red arrows) are present in the Mg-Zn eutectic layer, which were peeled off during welding from preexisting $\mathrm{MgO}$ layer on the $\mathrm{Mg}$ base metal. It is also worth noting that the Mg-Zn eutectic layer is well connected well with the base steel as shown in Figure 45(b). The result of EDS analysis on selected regions shown in Figure 46. Without $\mathrm{Zn}$ coating between the two sheets, a Mg-Fe-O layer is present between the steel and the MgO layer (Figure 46 (b)), which is confirmed by the EDS analysis (Figure $46\left(b_{1-4}\right)$ ). EDS linear scan along Mg-Fe-O layer as marked in Figure 46(b $\left.b_{1}\right)$ is shown in Figure 46(c). It displays that content of $\mathrm{Mg}$ and Fe are fluctuating in an opposite direction, which implies that $\mathrm{Mg}-\mathrm{Fe}-\mathrm{O}$ layer are formed due to mechanical mixing between Mg layer and Fe layer. 


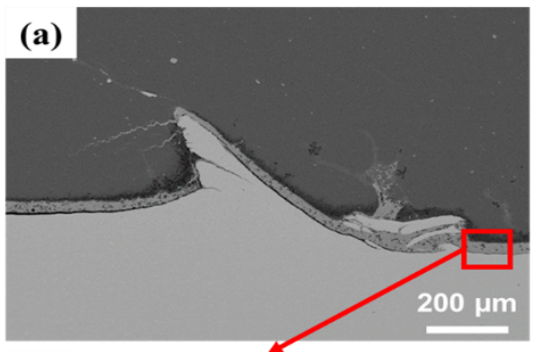

$\left(\mathbf{b}_{1}\right)$

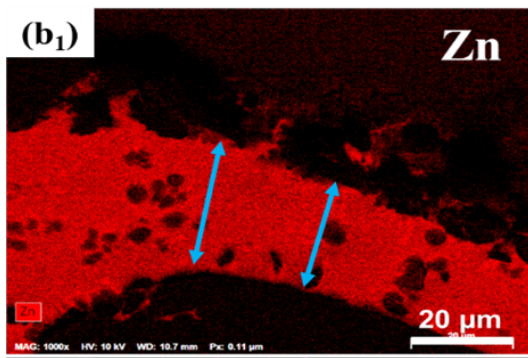

(b)

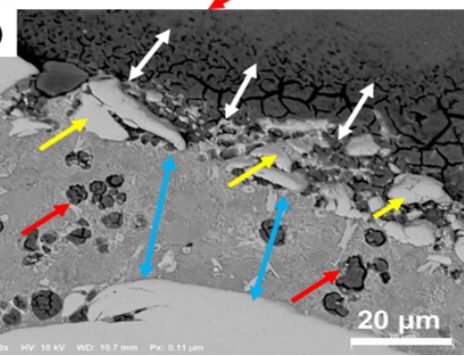

$\left(\mathbf{b}_{3}\right)$

Fe

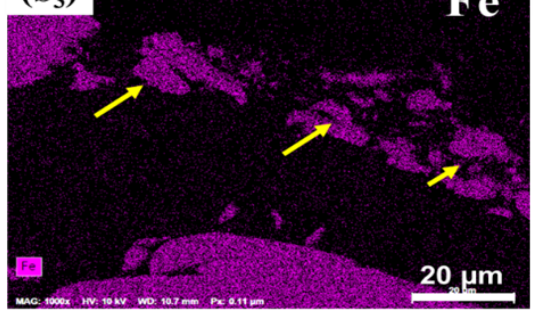

$\left(\mathbf{b}_{2}\right)$
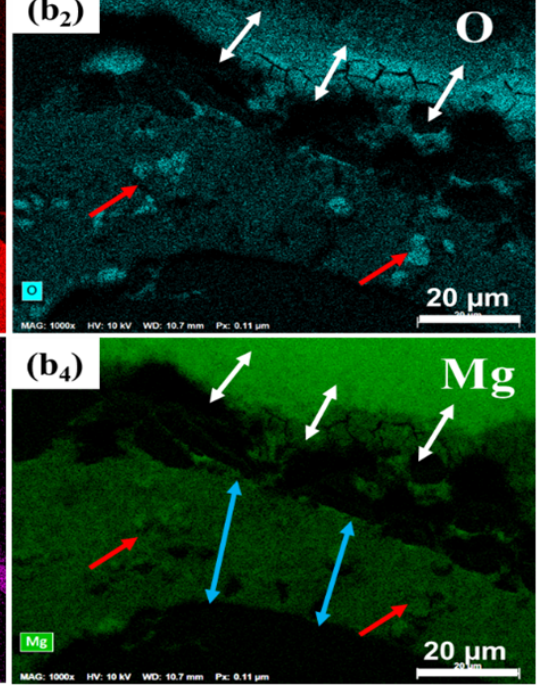

Figure 45 EDS analysis on interface of AZ31/HDG-DP590 conducted via FAST: (a) SEM of interface of run 1, (b) SEM of selected region with red rectangle in (a), (b1-4) EDS mapping analysis on region shown in (b). Note that $\mathrm{MgO}$ layer is marked with white double side (Source: PNNL)
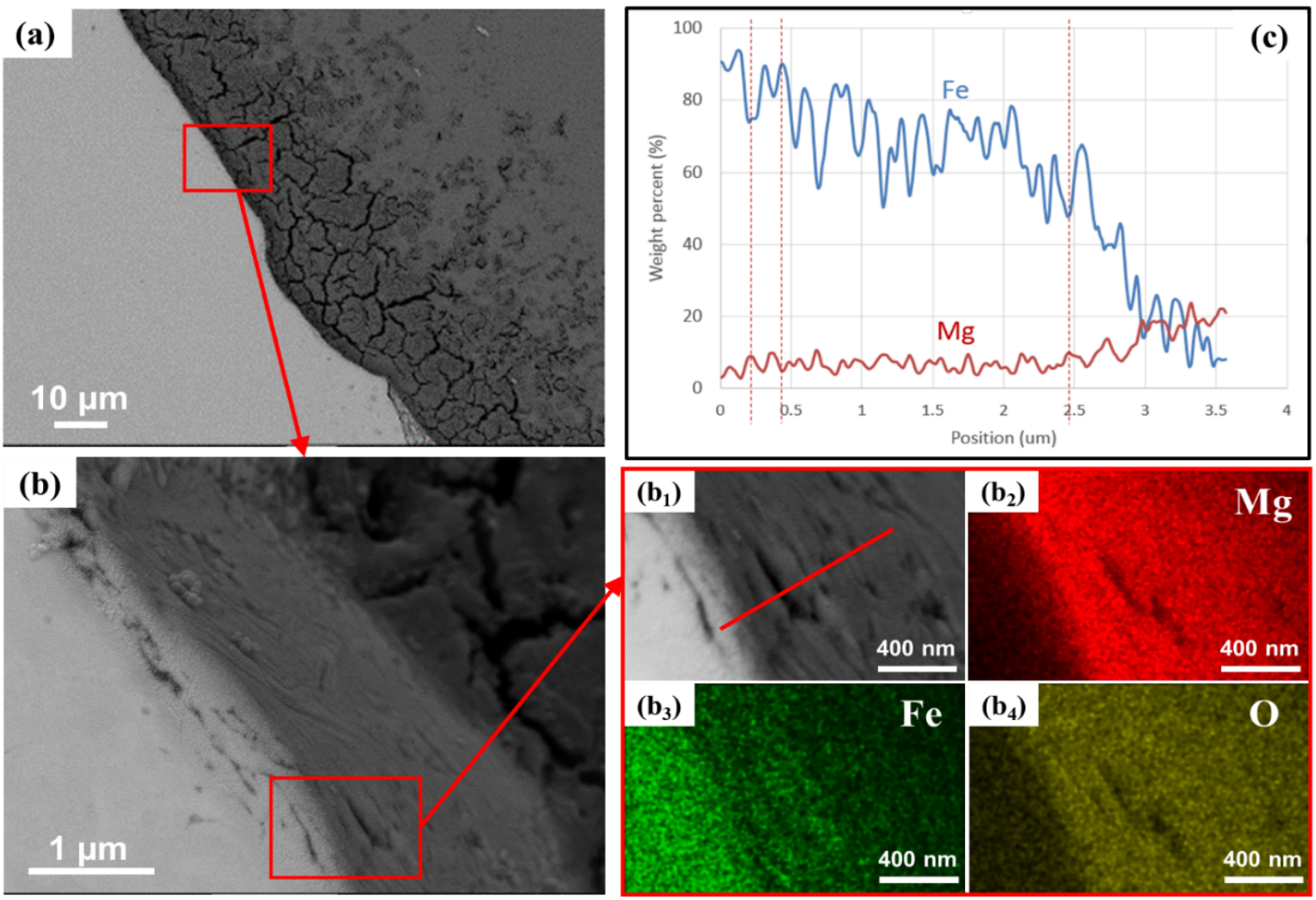

Figure 46 EDS analysis on the interface of AZ31/bare MS270 conducted via FAST: (a) SEM of interface of run 4, (b) SEM of selected region with red rectangle in (a), (b1-4) EDS mapping analysis on region shown in (b), (c) EDS linear scan analysis on red line (Source: PNNL) 


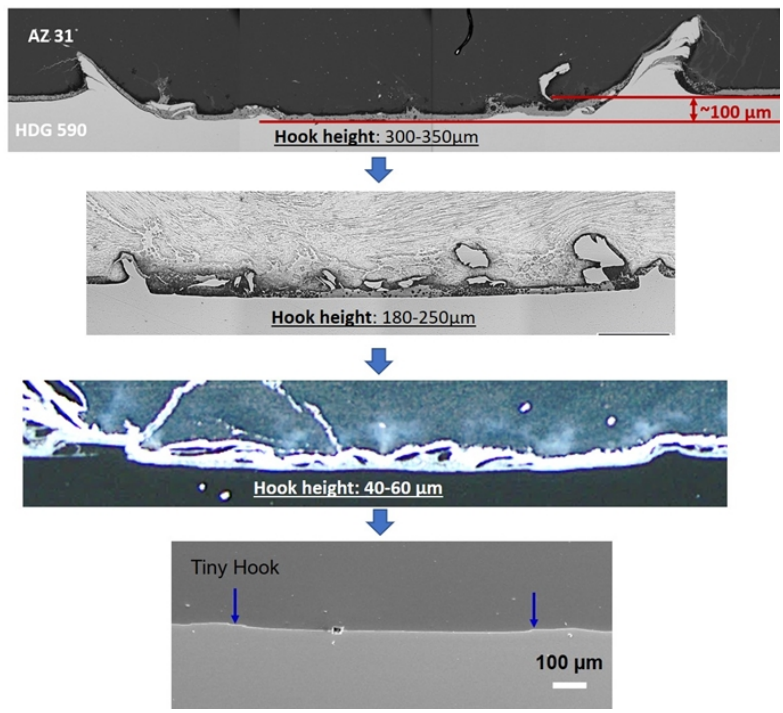

Figure 47 Progressively smaller hook size due to reduced scribe engagement (Source: PNNL)

In this project over time, the hook size was gradually reduced to understand its effects on the joint strength. To achieve this, scribe length was reduced from $(0.4-0.35) \mathrm{mm}$ to $(0.3-0.25 \mathrm{~mm})$ resulting interlocking hook feature height also decreased from $\sim 350 \mu \mathrm{m}$ to $<40 \mu \mathrm{m}$ as shown in Figure 47.
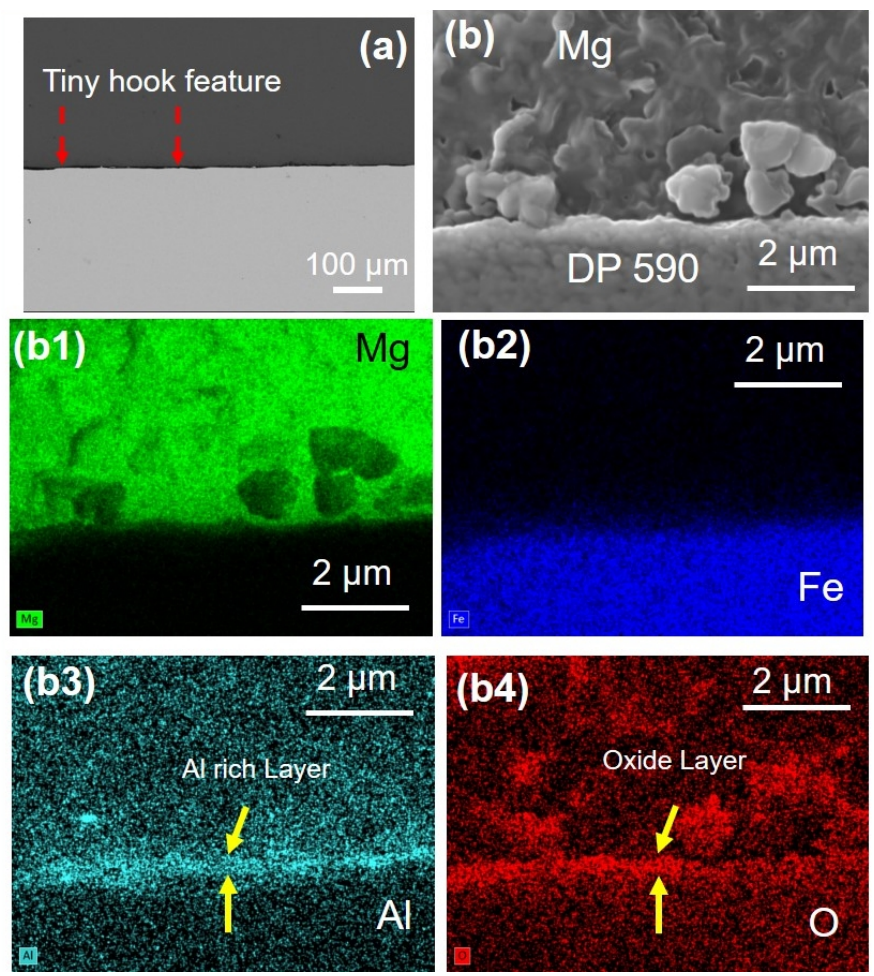

Figure 48 SEM with EDS of AZ31Mg-uncoated DP 590 joint. (a) Joint interface, EDS mapping of (b) $\mathrm{Mg}$, (b1) Fe, (b2) Al; (b3) O. (Source: PNNL)

To understand this effect, AZ31Mg - uncoated DP 590 steel was joined by FaST process with $0.3 \mathrm{~mm}$ scribe length and less scribe engagement in the steel side. The $\mathrm{Zn}$ layer was chemically 
removed from the as-received DP 590 to avoid $\mathrm{Mg} / \mathrm{Zn}$ interaction and eutectic formation at the interface. It is seen from Figure 48 (a) that due to low depth of penetration and less engagement of scribe in the steel side the hook feature is not prominent. Nevertheless, an appreciable amount of joint strength was observed as is reported in the following section. This observation meant that the joint strength in FaST is derived from 1) Mechanical interlocking hook and 2) Metallurgical bonding facilitated by interfacial phenomena with or without the presence of $\mathrm{Zn}$. SEM-EDS elemental mapping analysis indicates some aluminum (Al) layer with some probable oxide layer at the interface (Figure 48 (b3) and (b4)). Al-rich interlayer is also found at the interface which may be acting as a coupling layer. An appreciable amount of $O$ was also observed, especially towards the $\mathrm{Mg}$ side and the interface region. A complex $\mathrm{Al} / \mathrm{Mg}$ oxide layer is also formed at the interface. Detailed TEM with APT results are discussed in next few sections that sheds more light on the interface and joining mechanisms are found in sections below.

The Zn-coated DP590-AZ31B USW joints produced using the dual-head welding machine at $1000 \mathrm{~W}$ for $0.5 \mathrm{~s}$ welding time was analyzed. The SEM image in Figure 49 a shows the morphology of the cross-section at the center of the joint interface.
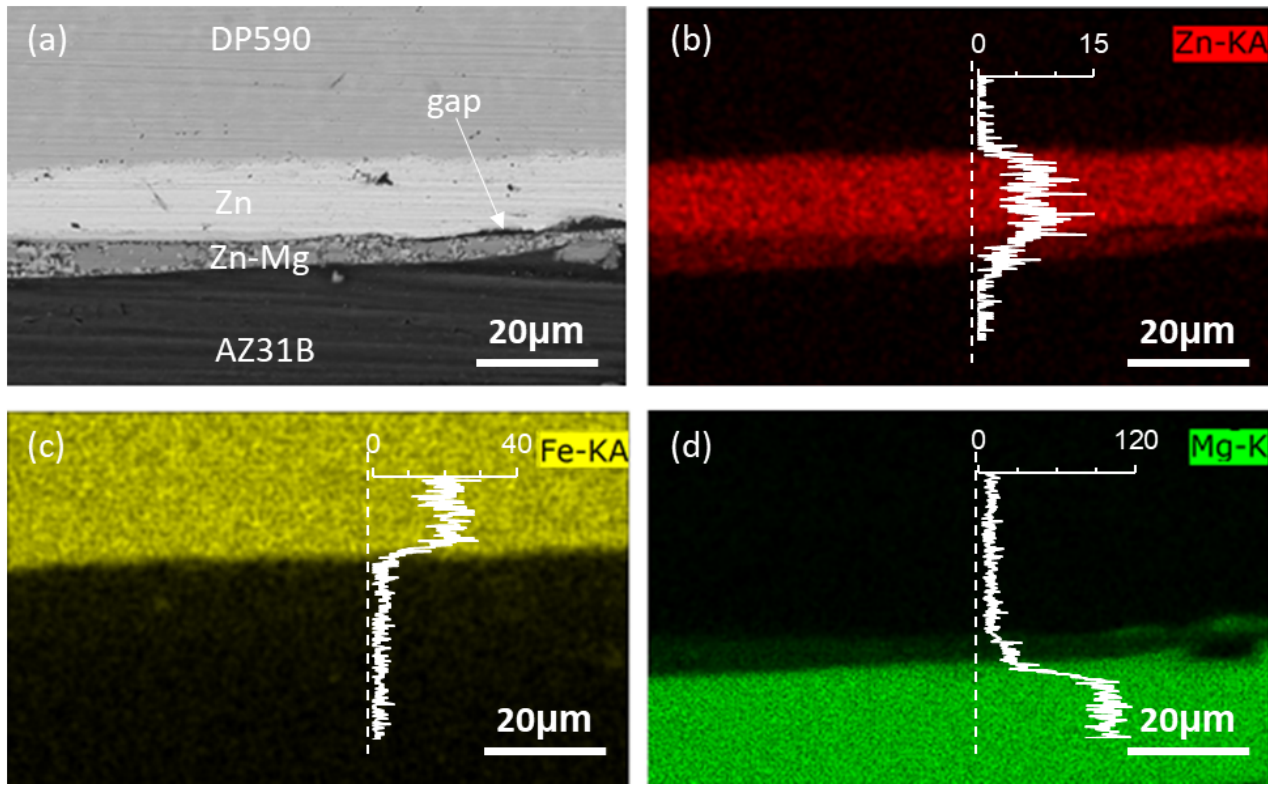

Figure 49 Morphology and chemical composition at the center of the joint interface on Zn-coated DP590-AZ31B welds produced with low welding energy (1000W for $0.5 \mathrm{~s}$ using the dual-head machine). The inserted line plots represent the quantification of each composition (Source: ORNL)

The distribution of the major chemical composition ( $\mathrm{Zn}, \mathrm{Fe}$ and $\mathrm{Mg}$ ) in the same area is shown in Figure 49 (b), (c) and (Error! Reference source not found.d) respectively. Considering the maximum temperature at $275^{\circ} \mathrm{C}$ was measured by the infrared camera at the edge of the stacked sheets during the welding experiment, the internal temperature would be higher than $275^{\circ} \mathrm{C}$ and close to the $\mathrm{Mg}-\mathrm{Zn}$ eutectic reaction temperature at $341^{\circ} \mathrm{C}$, suggesting the formation of a $\mathrm{Zn}-\mathrm{Mg}$ reaction layer (22). Hence, a layer of $Z n-M g$ region with a thickness of $5 \mu \mathrm{m}$ was observed between $\mathrm{Mg}$ and $\mathrm{Zn}$ as shown in Figure 49 (a). The total thickness of the Mg-Zn reaction layer and the remaining $\mathrm{Zn}$ layer was $20 \mu \mathrm{m}$, much less than the as-received $\mathrm{Zn}$ coating thickness (ranging from 
$50 \mu \mathrm{m}$ to $70 \mu \mathrm{m})$. The reduction of the thickness was a result of the vibrational shear motion at the interface which squeezed a portion of the $\mathrm{Zn}$ out of the faying surface.

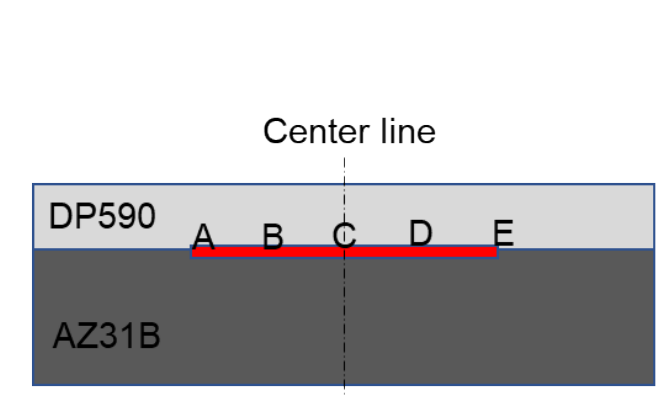

Schematic of a USW cross section
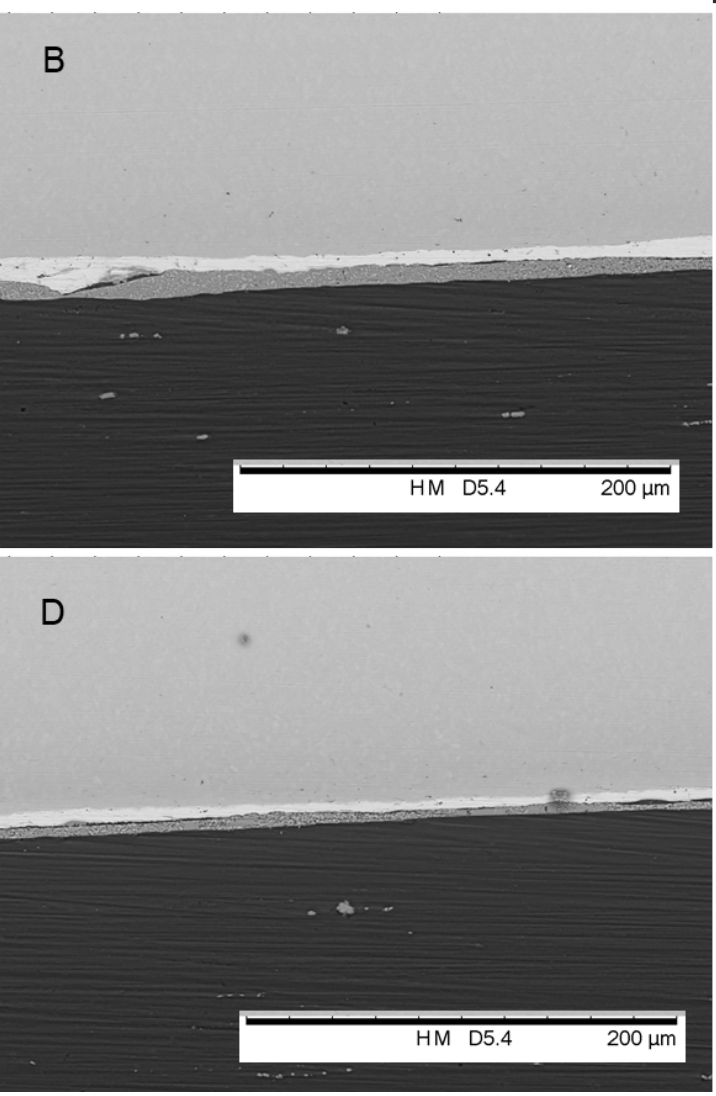
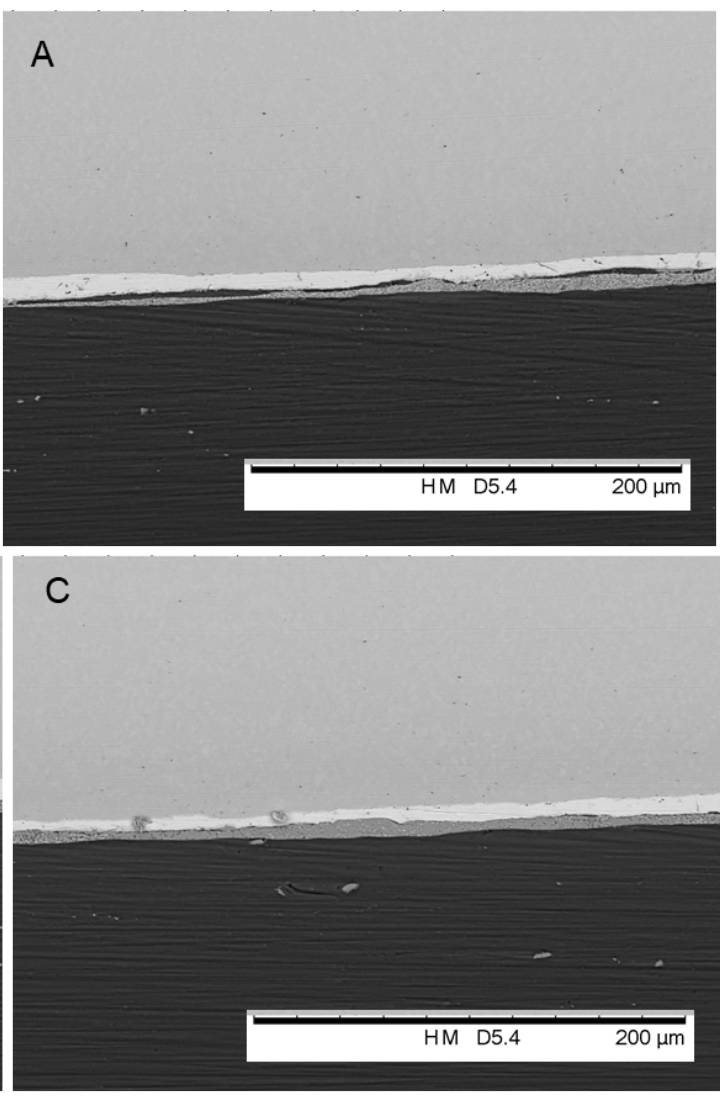

$\mathrm{E}$

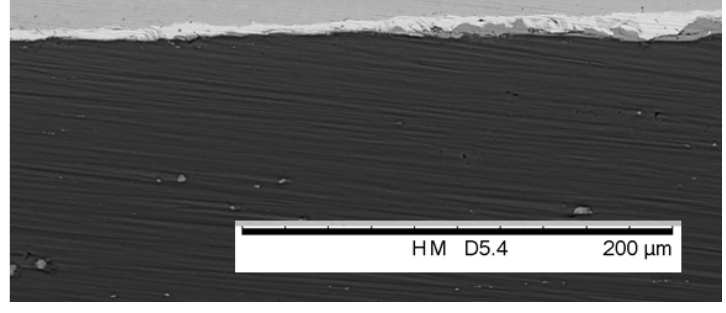

Figure 50 Interfacial morphology though the joint line of the Zn-coated DP590-AZ31B welds produced with low welding energy (1000W for $0.5 \mathrm{~s}$ using the dual-head machine). (Source: ORNL)

The presence of a gap between the $\mathrm{Zn}$ layer and the $\mathrm{Zn}-\mathrm{Mg}$ reaction layer indicates that an overall strong bond has not formed, which gave rise to the sliding motion (high amplitude of the relative interfacial velocity) at the DP590 - AZ31B faying interface towards the end of the welding process as shown in Figure 19. Figure 50 shows a series of SEM images taken through the entire joint line. At most of the joint interface, there was a mix of $\mathrm{Zn}$ and $\mathrm{Zn}-\mathrm{Mg}$ reaction layer like those 
shown in Error! Reference source not found.. Towards the edge of the USW joint, less Zn-Mg was observed.

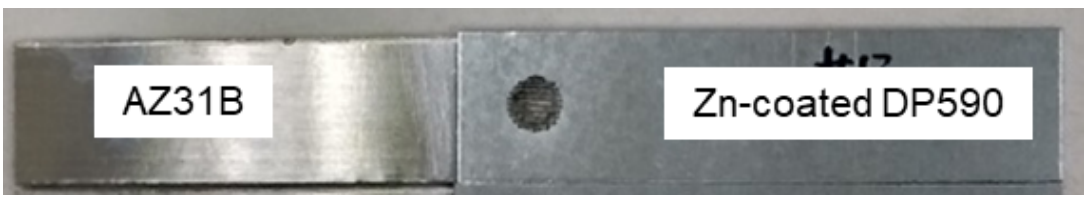

Figure 51 A typical Zn-coated DP590-AZ31B USW lap shear coupon (produced with the singlehead machine at $3500 \mathrm{~W}$ for 4 s) (Source: ORNL)
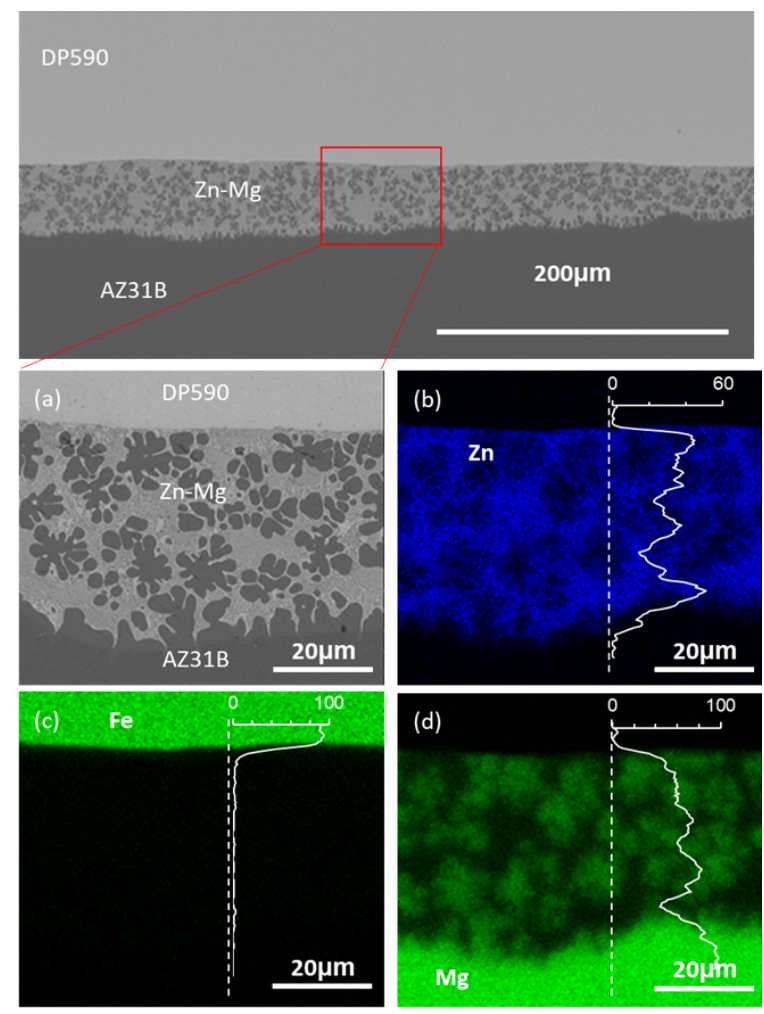

Figure 52 Morphology and chemical composition at the center of the joint interface on $\mathrm{Zn}$-coated DP590-AZ31B welds produced with high welding energy (3500W for $4 \mathrm{~s}$ using the single-head machine). The inserted line plots represent the quantification of each composition along the dashed line. The unit of the horizontal axis is in count. (Source: ORNL)

Zn-coated DP590-AZ31B USW joints (lap shear configuration) were also produced using a much higher energy input (3500W for $4 \mathrm{~s}$ ) with the single-head machine. The dimension of steel and $\mathrm{Mg}$ sheets were both 1 -inch wide and 4-inch long, with 1-inch by 1-inch overlap area. The USW weld was located at the center of the overlap region. Figure 51 shows an example of such a joint coupon. The SEM and EDS analysis are shown in Figure 52. Since the interface was expected to experience a much higher temperature for a much longer period, the original $\mathrm{Zn}$ coating layer has completely transformed to a $\mathrm{Zn}-\mathrm{Mg}$ reaction layer at the center of the joint as shown in Figure 52. The total thickness of this layer was $30 \mu \mathrm{m}$ that was also much less than the as-received $\mathrm{Zn}$

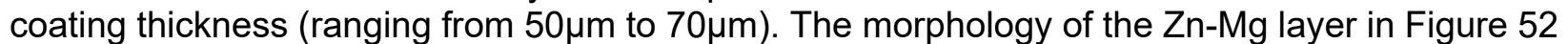
(high welding energy) was different from that in Figure 49 (low welding energy). The line scan data along the dashed line in Figure 52 shows that the $\mathrm{Zn}$ counts within the $\mathrm{Zn}$-Mg reaction layer varied from 15 to 50 and the $\mathrm{Mg}$ counts varied from 50 to 55 . No gap was observed at the joint 
interface, suggesting the formation of a stronger bond. Figure 52 shows the morphology near the edge of the same USW joint. A thin slice of the joint section in this area was extracted by focused ion beam (FIB) to analyze the chemical composition as shown in Figure 53. Different from the center region where the $\mathrm{Zn}$ completely transformed to $\mathrm{Zn}-\mathrm{Mg}$ reaction layer, the edge region had a mixed layer of $\mathrm{Zn}$ and $\mathrm{Zn}-\mathrm{Mg}$. This is because the joint edge underwent a low temperature, resulting in a partially dissolved $\mathrm{Zn}$ layer. The observation and comparison of the $\mathrm{Mg}-\mathrm{Zn}$ intermetallic layers in the joints produced with the low and the high energy input (Figure 49 and Figure 52 respectively) suggests that the formation of such an layer is critical to form a strong bond between steel and $\mathrm{Mg}$ with presence of $\mathrm{Zn}$ coating.

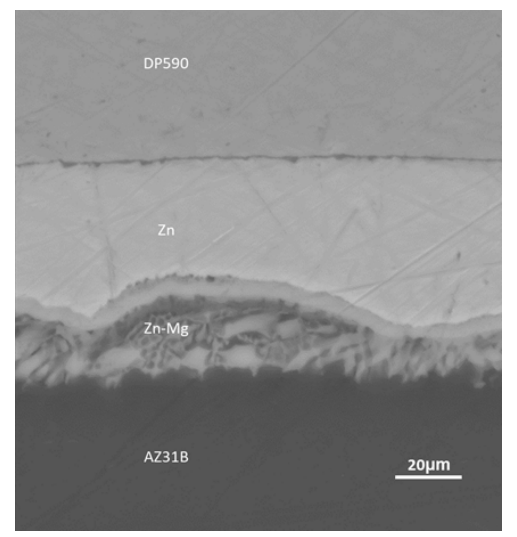

Figure 53. Morphology near the edge of the joint interface on Zn-coated DP590-AZ31B welds produced with high welding energy (3500W for $4 \mathrm{~s}$ using the single-head machine). (Source: ORNL)

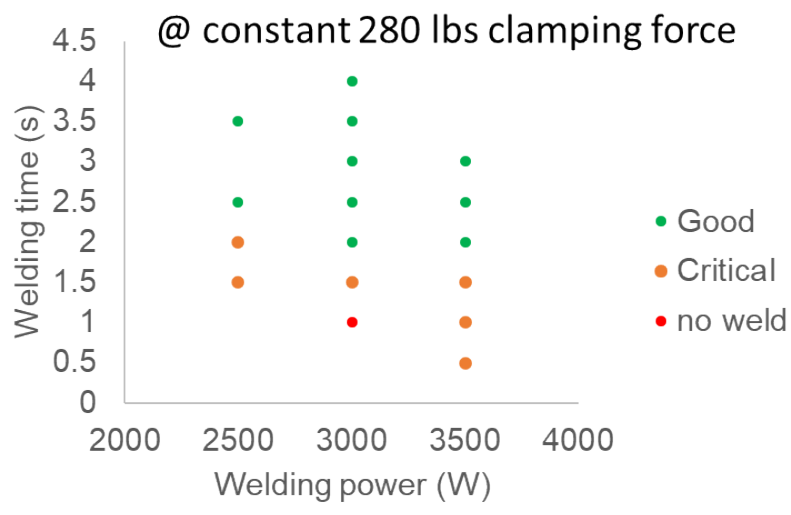

Figure 54 Joining bare DP590-AZ31B pairs with varying welding power and time at a constant 280lbs clamping force, and the resultant joint integrity. (Source: ORNL)

Since no joint formed between bare DP590 and AZ31B using a relatively low welding energy input (1000W for $0.5 \mathrm{~s}$ using a dual-head machine), a comprehensive investigation on the process parameters with varying welding power, time and clamping force was conducted on the same welding machine. Figure 54 and Figure 55 listed the parameters that have been used. The red dot indicates 'no weld was formed under the welding conditions specified in the figures. If no joint was formed. If a joint was formed, a dropping test $(1.5 \mathrm{~m}$ high) was then performed to evaluate the joint integrity. If the joint sample survived after dropping test, it is called 'good' joint in the figures. Otherwise, it is called a 'critical' weld. As can been seen in Figure 54 and Figure 55, 
conditions with large welding power, longer welding time and higher clamping force tend to produce better welds.

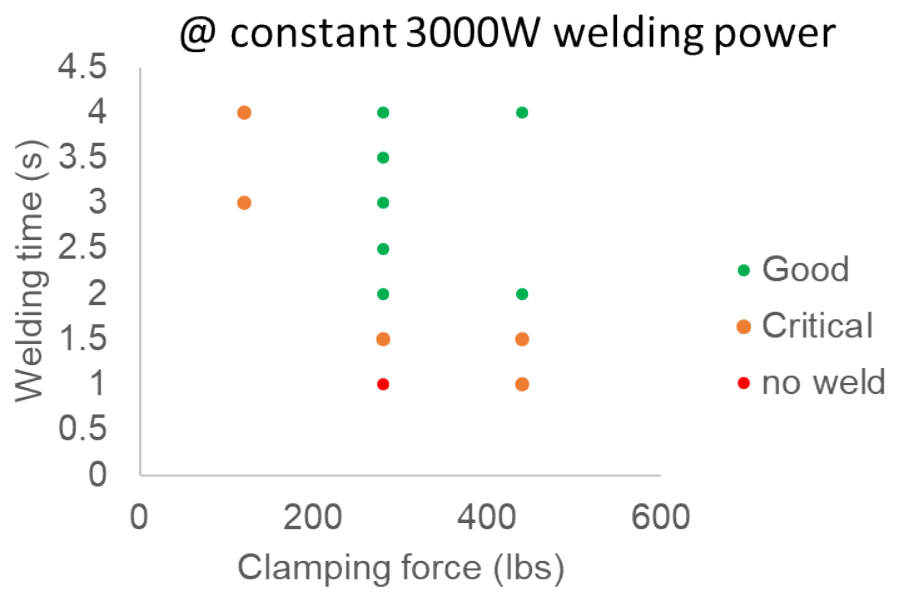

Figure 55 Joining bare DP590-AZ31B pairs with varying clamping force and welding time at a constant $3000 \mathrm{~W}$ welding power, and the resultant joint integrity. (Source: ORNL)

The influence of surface roughness on the joint strength was also studied as shown in Figure 56Error! Reference source not found.. All welds were made with a constant welding power at $3500 \mathrm{~W}$ using the single-head machine. With increase of the surface roughness on the bare steel surface, the peak lap shear strength for welds made with $2.5 \mathrm{~s}$ and $4 \mathrm{~s}$ welding time both increased.

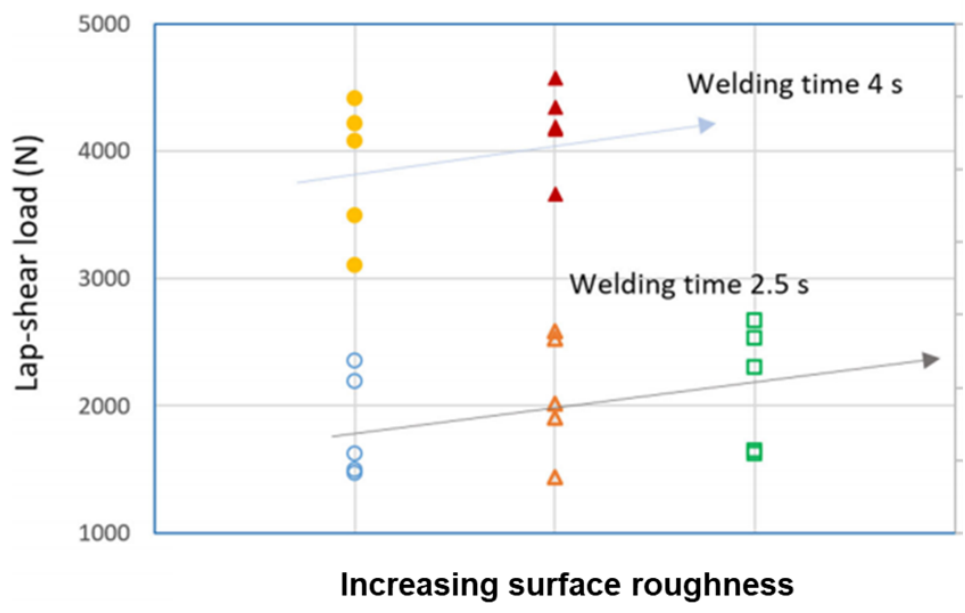

Figure 56 Joining bare DP590-AZ31B pairs with varying surface roughness and welding time at a constant $3500 \mathrm{~W}$ welding power, and the resultant lap shear strength. (Source: ORNL)

The welding trials with varying process conditions have demonstrated that strong metallurgical bonds could be formed between bare DP590 and AZ31B. An optimized set of process condition ( $3500 \mathrm{~W}$ for $4 \mathrm{~s}$ and $280 \mathrm{lbs}$. clamping force using the single-head machine) was applied to produce USW samples for the subsequent studies. Figure 57 shows a typical bare DP590-AZ31B USW lap shear coupon. 


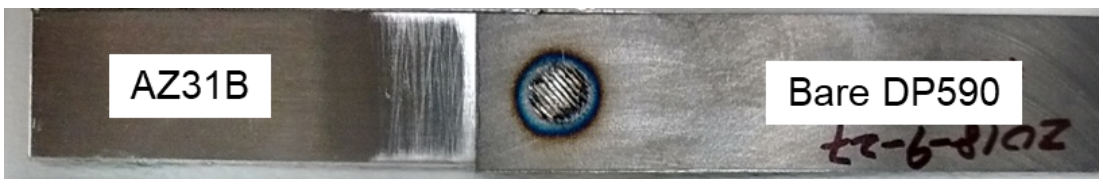

Figure 57 A typical bare DP590-AZ31B USW lap shear coupon (produced with the single-head machine at 3500W for 4s) (Source: ORNL)

Figure 58 shows the cross-section of the bare DP590-AZ31B USW joint cut from the weld center. Because of soft material property, the AZ31B sheet has much larger surface indentation than DP590. Slight bending can be observed along the width direction due to localized heat generation and pressure load. Prior to welding, the steel surface was grinded using a 120-grit sandpaper, creating scratches on the surface. This is can been observed in the SEM image. The SEM image also suggests that the morphology of the joint interface was much different from the morphology of Zn-coated DP590-AZ31B USW joints. No Zn or Zn-Mg reaction layer was present. The AZ31B magnesium alloy was conformed with the steel surface, filling in the cavities through plastic deformation.
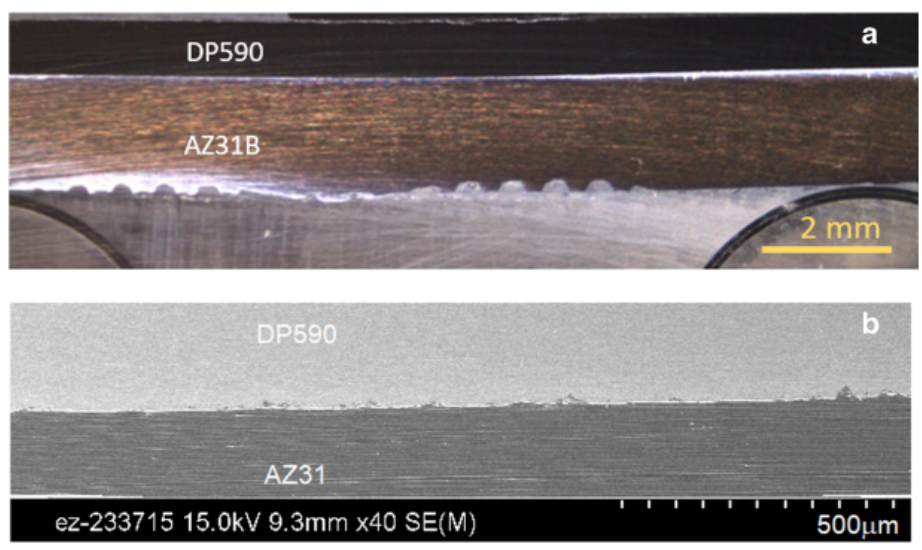

Figure 58 Cross-section of bare DP590-AZ31B USW joint (a) optical macrograph and (b) SEM image at the center of the joint interface (Source: ORNL)

\subsubsection{Interface characterization of Pure Mg- uncoated DP 590 steel joint with FaST and USW}

Pure Mg and Uncoated DP joints also made with FaST process to dig deeper into the joining mechanism. Commercially pure elemental $\mathrm{Mg}$ was used to avoid the effects of any alloying elements. SEM-EDS elemental mapping shows oxide layer at the interface (Figure 59). An appreciable amount of $\mathrm{O}$ was also observed, on the $\mathrm{Mg}$ side indicating $\mathrm{MgO}$ formation. TEM work in section below provides more treatment on Oxide layer.

To separate the role of alloy elements (Al, Zn, etc.) in the joint formation between bare DP590 and AZ31B, additional USW joint samples were produced using bare DP590 and pure Mg. Without the presence of the alloy elements in $\mathrm{Mg}$, a metallurgical bond was also formed as shown in Figure 60. 

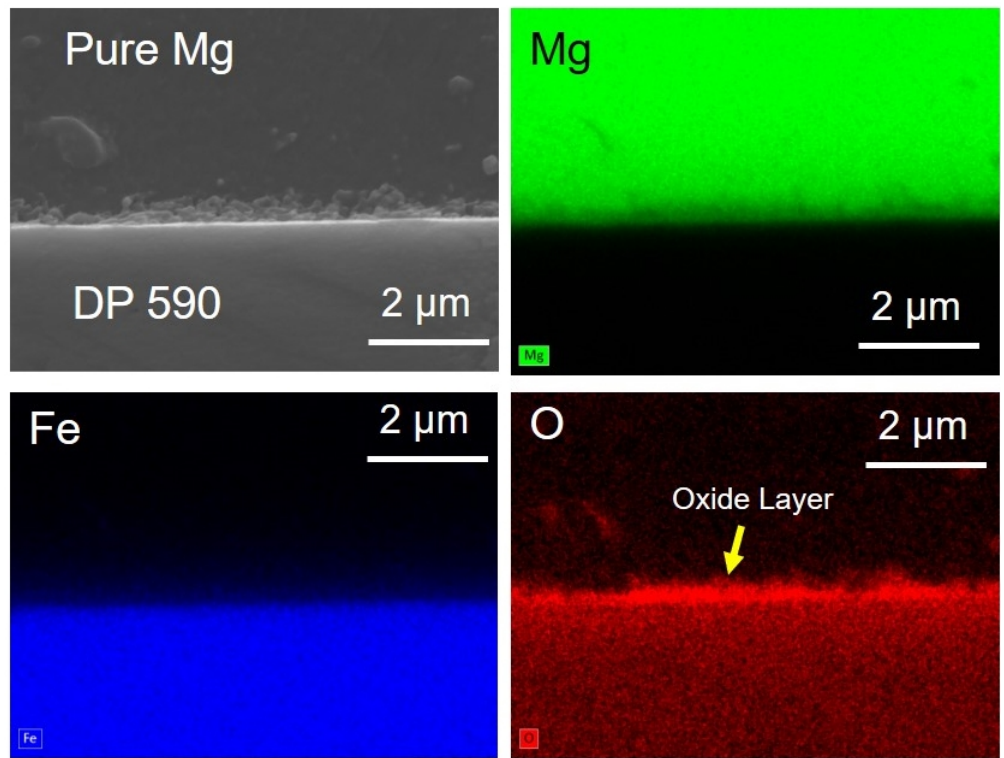

Figure 59 SEM with EDS of Pure Mg-uncoated DP 590 joint. (a) Joint interface, EDS mapping of $\mathrm{Mg}, \mathrm{Fe}$ and O. (Source: PNNL)

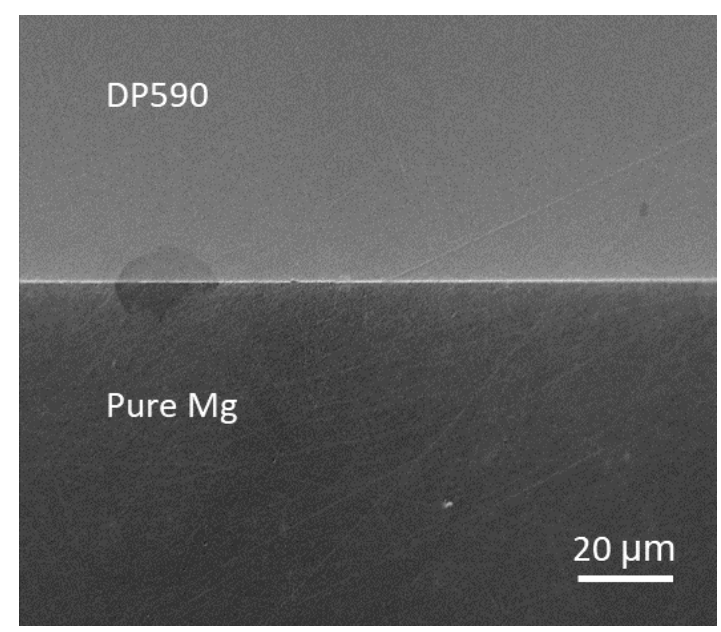

Figure 60 SEM image showing morphology at the center of a bare DP590-pure Mg USW joint (produced with the single-head machine at 3500W for 4s) (Source: ORNL)

\subsubsection{Synchrotron X- Ray Diffraction and Tomography}

\subsubsection{AZ31 - Coated DP 590 steel Joints by FaST}

Computed tomography and high-energy diffraction were performed at Advanced Photon Source (APS) Argonne National Laboratory. As Figure 61 and Figure 62 show the fine line scan of diffraction measurements, Mg-steel interface without and with $\mathrm{Zn}$ coating layer demonstrate different phase structure. In the None-Zn coating condition of Figure 61, there is no intermetallic phase forming at the Mg-steel interface. A sharp transition from steel side to $\mathrm{Mg}$ side is detected from the intensity evolution of principal peaks. One interesting thing is that there is intensity difference amongst the three principal peaks (Mg HCP-100, 002 and 101 crystalline 
planes) at the Mg-steel interface, which suggests crystalline orientation changes from interface to deep $\mathrm{Mg}$ side. In the $\mathrm{Zn}$-coating condition of Figure 62, there are additional peaks that correspond to low-symmetry phases found at the interface. The intensity of principal Fe peaks decay to background level rapidly at the interface because $\mathrm{Zn}$ has large solubility in $\mathrm{Fe}$, but $\mathrm{Mg}$ has no solubility in Fe. There is a reaction regime about $40 \mu \mathrm{m}$ in thickness at the $\mathrm{Mg}$ side. The low-symmetry phases in the reaction regime can be the Mg-Zn intermetallic compounds that are rich in the Mg-Zn phase diagram. Similar case of intensity difference of HCP-002 peak across the interface to the $\mathrm{Mg}$ side is found in the $\mathrm{Zn}$-coating condition.
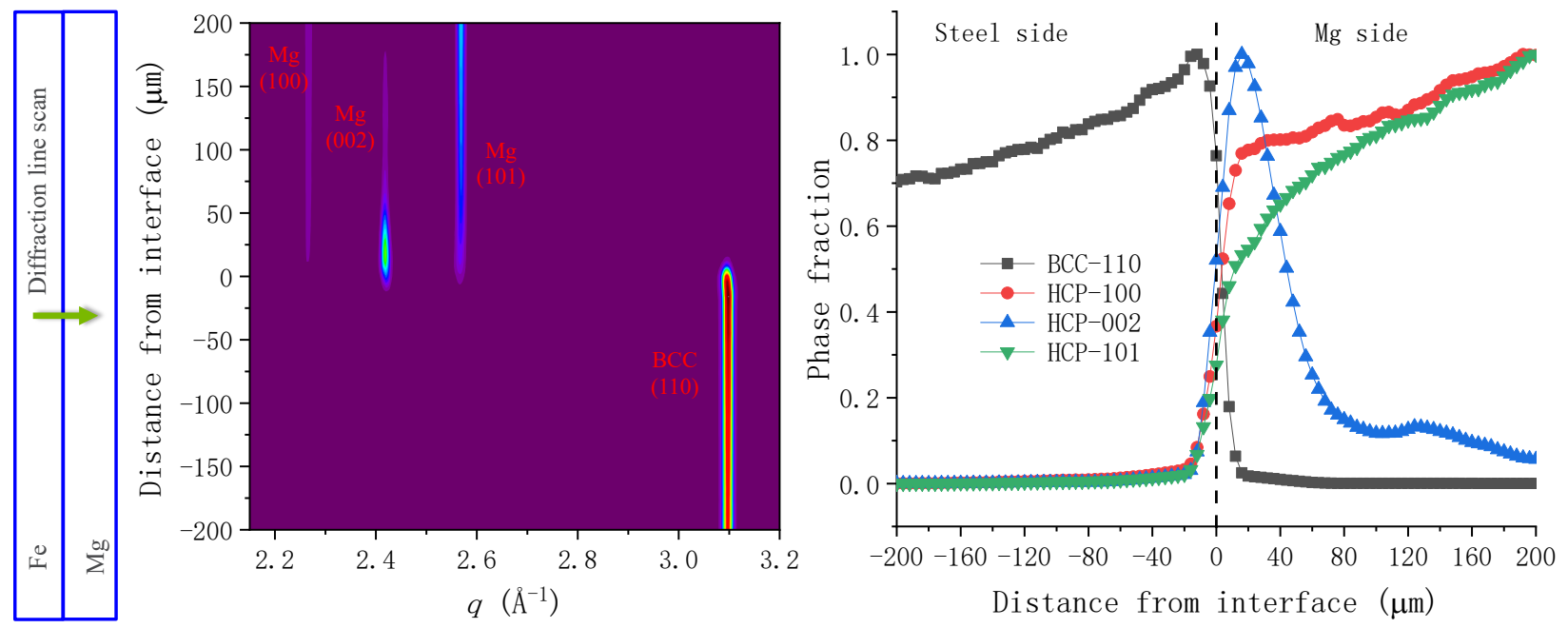

Figure 61 Diffraction line scan across Mg-steel interface without Zn coating layer. Left, schematic illustration of diffraction line scan. Middle, contour plot of diffraction patterns. Right, principal peaks of diffraction patterns evolve across the interface. (Source: ANL)
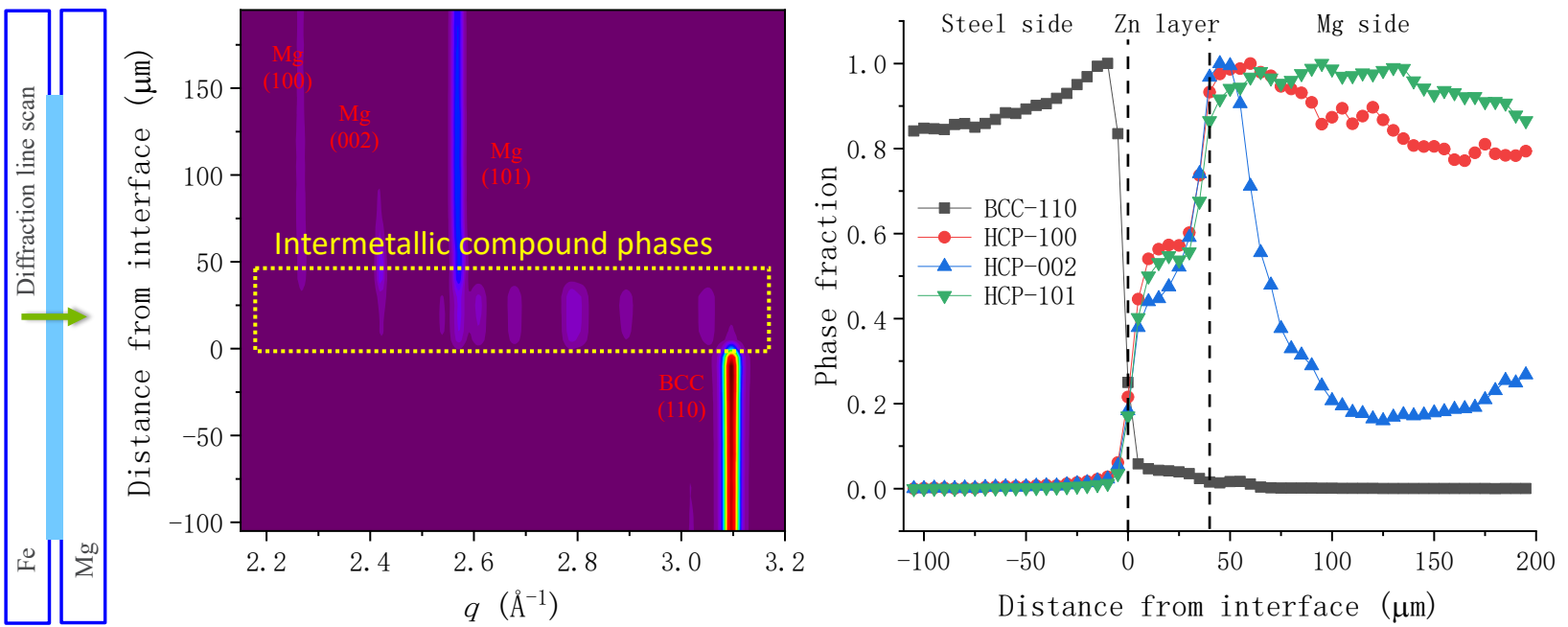

Figure 62 Diffraction line scan across Mg-steel interface with Zn coating layer. Left, schematic illustration of diffraction line scan. Middle, contour plot of diffraction patterns. Right, principal peaks of diffraction patterns evolve across the interface. (Source: ANL) 
Two major intermetallic compound phases, $\mathrm{MgZn}_{2}$ and $\mathrm{Mg}_{51} \mathrm{Zn}_{20}$, are highlighted after careful comparison to the standard powder diffraction files (PDFs) amongst Mg-Zn system (Figure 63). The phase fraction of each crystalline phases is quantified by Rietveld refinement. Intermetallic compound phases, $\mathrm{MgZn}_{2}$ and $\mathrm{Mg}_{51} \mathrm{Zn}_{20}$, account for large fraction in the reaction regime (about $40 \mu \mathrm{m}$ in width) while only $\mathrm{Fe}$ is present in steel side and sole $\mathrm{Mg}$ exists in $\mathrm{Mg}$ side. The formation of intermetallic compound phases might be caused by the localized heat generation in the friction stir welding process that melts the low-temperature $\mathrm{Zn}$ coating layer. The melted $\mathrm{Zn}$ reacts with $\mathrm{Mg}$ side and some high-temperature phases remain in the further rapid cooling process.
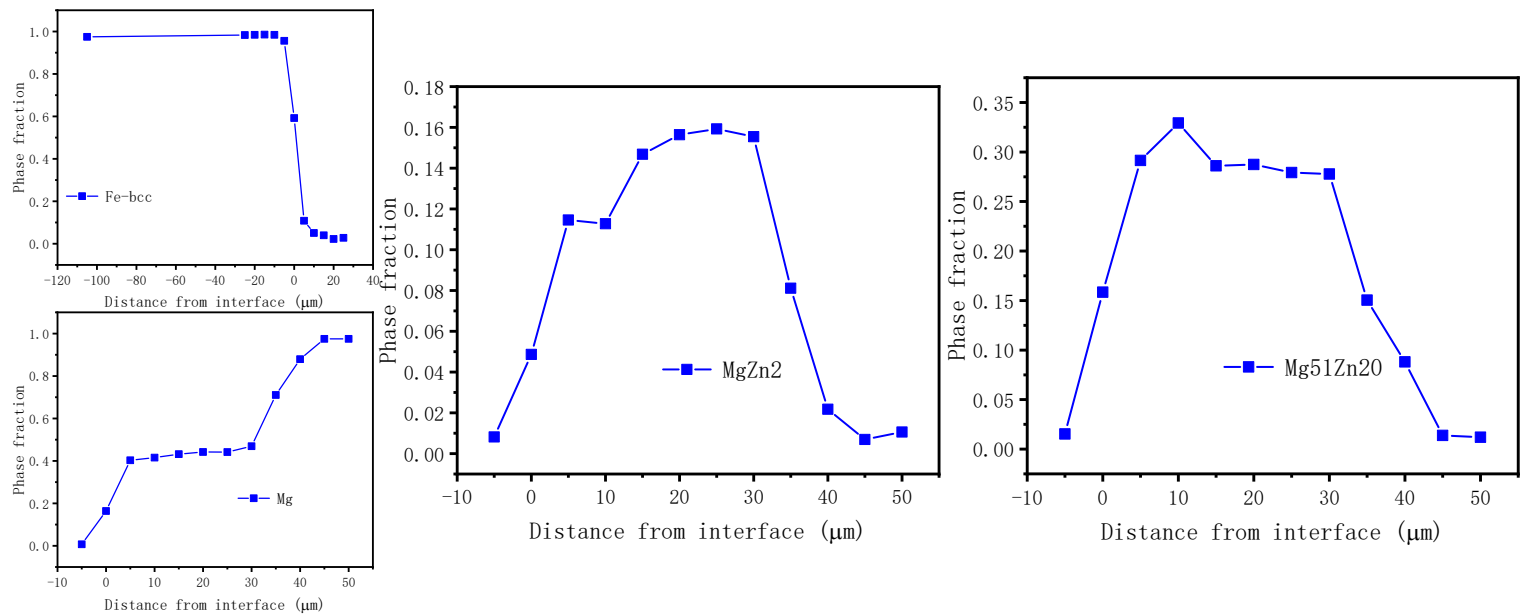

Figure 63 Evolution of intermetallic compound phases across Mg-steel interface. Steel side labels in negative value to the interface while $\mathrm{Mg}$ side is in positive value. Two major phases of $\mathrm{MgZn}_{2}$ and $\mathrm{Mg}_{51} \mathrm{Zn}_{20}$ are highlighted and phase fraction is tracked by Rietveld refinement (Source: ANL)

Bonded Mg-steel interface without and with $\mathrm{Zn}$ coating layer was characterized by synchrotron $\mathrm{x}$ ray computed tomography, as shown in Figure 64. Fe-rich particles deep (up to $\sim 200 \mu \mathrm{m}$ ) in the $\mathrm{Mg}$ side are found both in the non-Zn and $\mathrm{Zn}$-coating conditions. Pores can be seen in the $\mathrm{Zn}$ coating layer (Figure 64). Cracks are found near the Mg-steel interface or in Mg side.

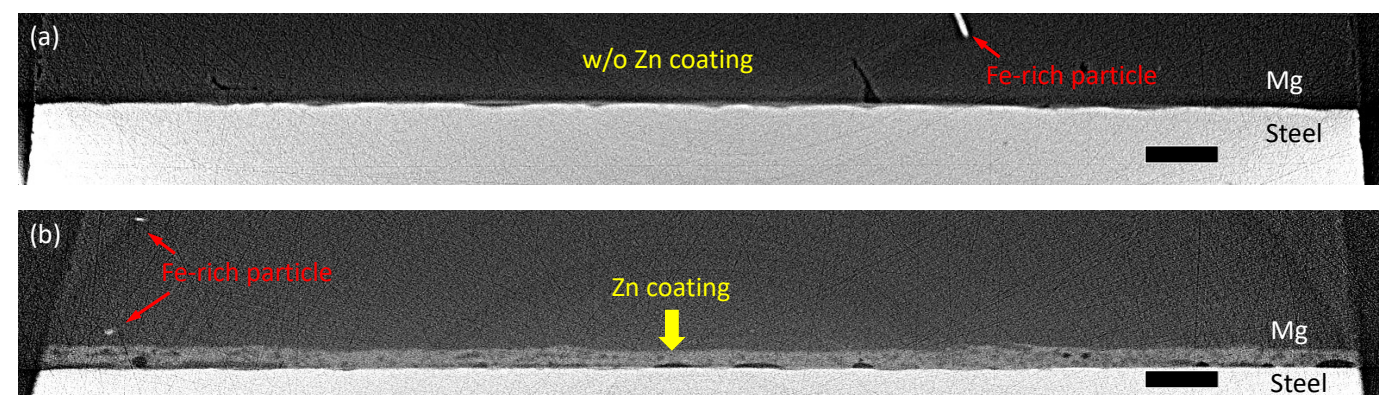

Figure 64 Bonded Mg-steel joint without and with Zn coating. Fe-rich particles can be found deep in $\mathrm{Mg}$ side. Crack is susceptible to initiate at the interface and propagate into Mg side. Scale bars are $100 \mathrm{~mm}$ (Source: ANL)

To see the effect of MgO layer at the Mg-steel interface, two kinds of joint were made: $\mathrm{MgO}$ removed AZ31-Coated DP 590 and as-received AZ31-coated DP 590. MgO layer was clearly identified at the as-received AZ31 Mg-coated DP590 joint, as shown in Figure 65. 

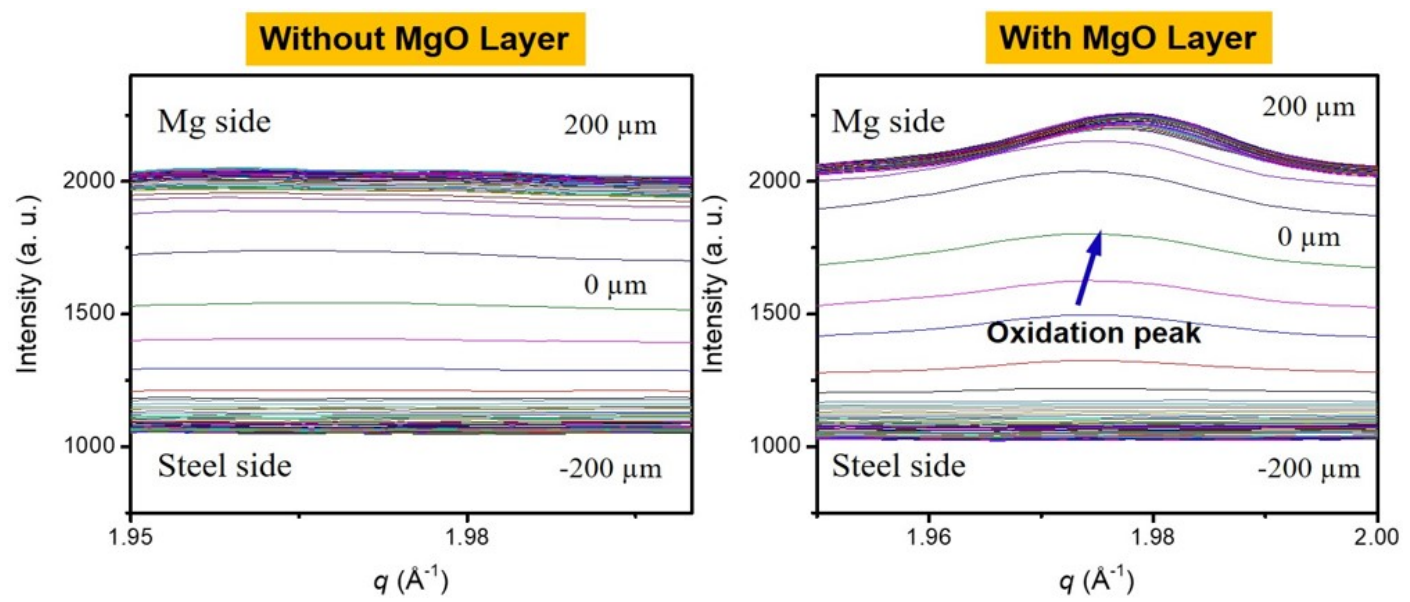

Figure 65 Diffraction patterns of Mg-steel interface under two conditions: without and with $\mathrm{MgO}$ layer. The oxidation peak is identified at the condition with $\mathrm{MgO}$ layer. (Source: $\mathrm{ANL}$ )

\subsubsection{Pure Mg - Uncoated DP 590 steel Joints by USW}

Synchrotron high-energy $\mathrm{x}$-ray diffraction was conducted to better understand the microstructure evolution of the dissimilar metal joining interface manufactured by ultrasonic welding method.

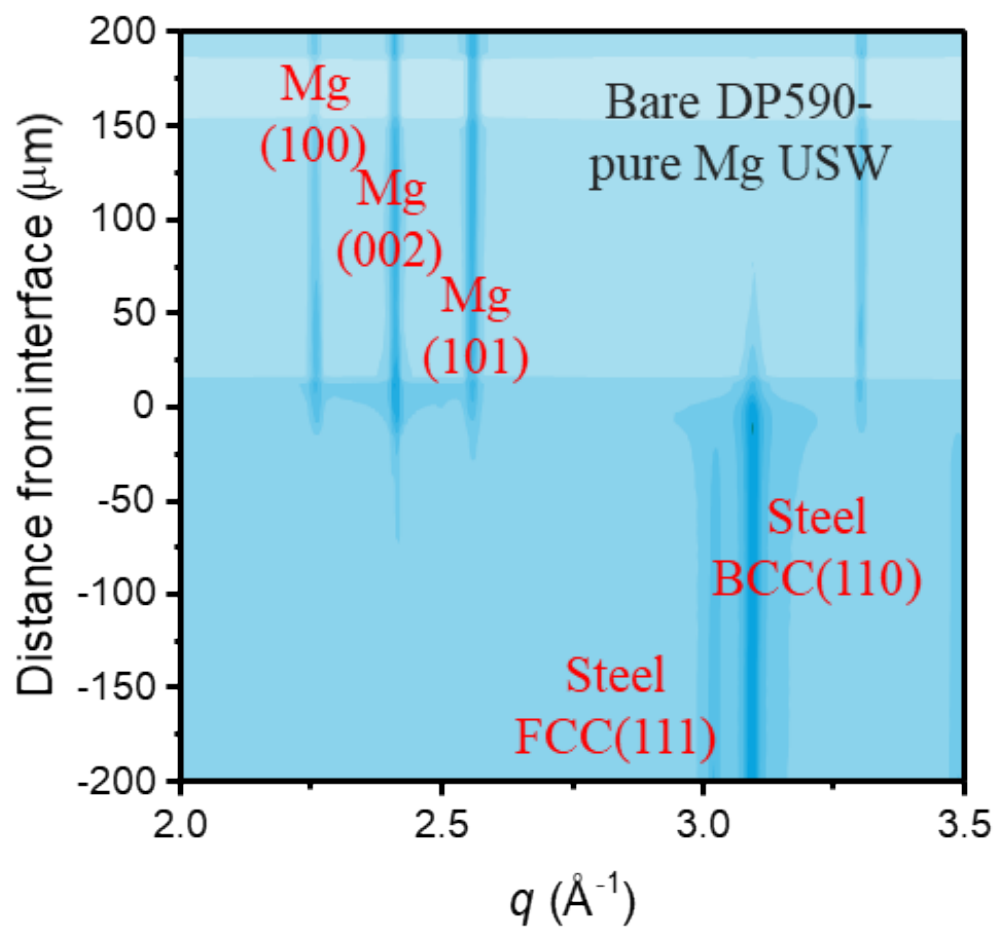

Figure 66 Series of line-scan diffraction data across bare DP590-pure Mg joint interface. The reciprocal lattice vector $q\left(\AA^{-1}\right)$ is on the $\mathrm{x}$-axis and the distance from interface at which each diffraction pattern recorded is on the $y$-axis. The position of the interface is defined as 0 , where positive direction is magnesium and negative direction is steel. (Source: ANL) 
PNNL-30945

ORNL/SPR-2021/1836

ANL-21/07

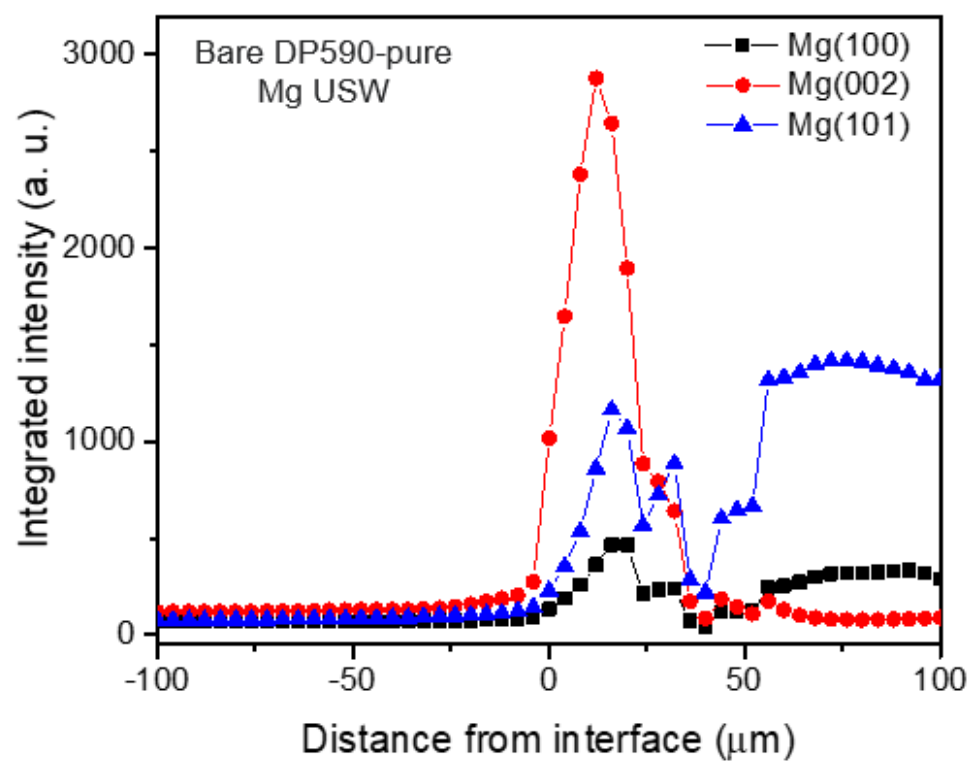

Figure 67. Evolution of integrated intensity of Mg-HCP peaks along the distance from bare DP590pure Mg USW joint interface. Intensity of magnesium phase, HCP-100, HCP-002 and HCP-101 peaks, is integrated and plotted against the depth at which the diffraction pattern was recorded (Source: ANL)

Figure 66 is the fine line scan of diffraction measurements at the bare DP590-pure Mg joint interface. The diffraction line scan starts at the center of joint interface $(0 \mathrm{~mm}$ on $y$-axis $)$ and reaches $200 \mu \mathrm{m}$ depth from the interface to magnesium and steel sides, respectively.

In the region far away from the interface $(>100 \mu \mathrm{m})$, only magnesium phase is seen in magnesium side (HCP-100, HCP-002, HCP-101 peaks) whilst only iron phases are seen in steel side (BCC110 and FCC-111 peaks). No additional peaks were observed near the joint interface $( \pm 50 \mu \mathrm{m})$, suggesting no obvious formation of intermetallic compound phases at this resolution (a few micrometers). Figure 67 displays the evolution of integrated peak intensity of magnesium phase at different depth from the bare DP590-pure Mg joint interface. The integrated intensity of three principle peaks from $\mathrm{Mg} \mathrm{HCP}(100), \mathrm{HCP}(002)$ and $\mathrm{HCP}(101)$ crystalline planes has a sharp change at the location close to the interface, which suggests crystalline orientation transition from the interface to the $\mathrm{Mg}$ side. This local texture change might correspond to the localized melting of magnesium during ultrasonic welding processing.

\subsubsection{Pure Mg - Coated DP 590 steel Joints by USW}

Synchrotron high-energy x-ray diffraction was also conducted on Zn-coated DP590-pure Mg USW joints as shown in Figure 68. The phase structure near the interface is significantly different from what has been observed at the bare DP590-pure joint interface. With the presence of Zn coating, there are many additional peaks (different from magnesium and steel phases) in the recorded diffraction pattern, highlighted by the yellow rectangle in Figure 68. These additional peaks might correspond to low-symmetry phases because $\mathrm{Zn}$ actively react with magnesium and magnesium has no solubility in iron. The integrated magnesium phase at different depth from the $\mathrm{Zn}$ coated DP590-pure Mg joint interface is shown in Figure 69. The intensities of HCP-101 and HCP-002 peaks are different from the Mg-steel joint interface without Zn coating (Figure 67). 
PNNL-30945

ORNL/SPR-2021/1836

ANL-21/07

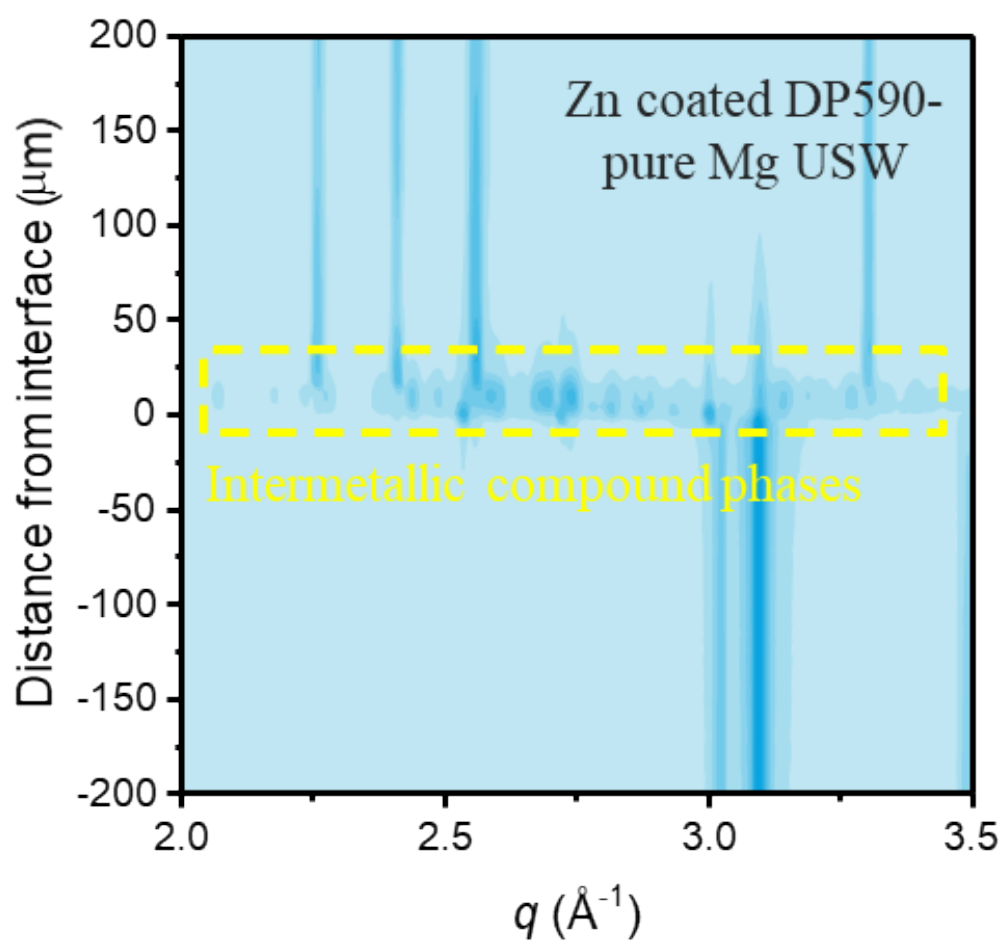

Figure 68 Series of line-scan diffraction data across Zn-coated DP590-pure Mg joint interface. The reciprocal lattice vector $q\left(\AA^{-1}\right)$ is on the $\mathrm{x}$-axis and the distance from interface at which each diffraction pattern recorded is on the $y$-axis. The position of the interface is defined as 0 , where positive direction is magnesium and negative direction is steel. (Source: ANL)

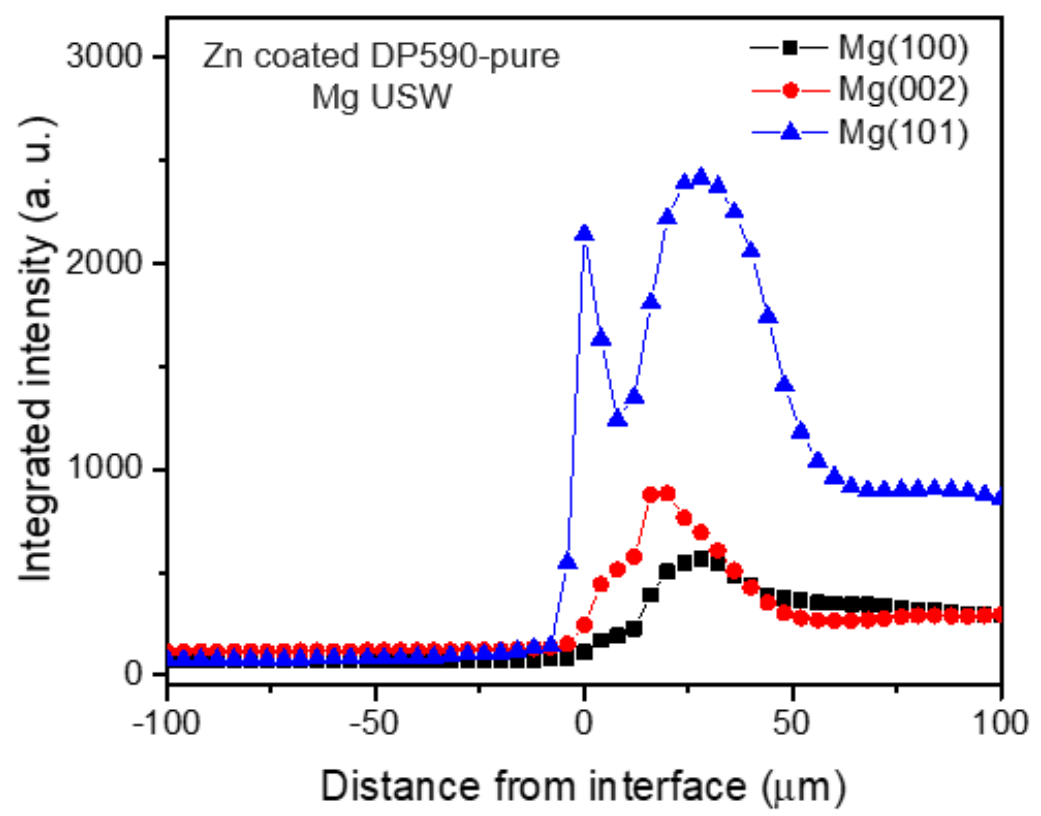

Figure 69 Evolution of integrated intensity of Mg-HCP peaks along the distance from $\mathrm{Zn}$ coated DP590-pure Mg USW joint interface. Intensity of magnesium phase, HCP-100, HCP-002 and HCP-101 peaks, is integrated and plotted against the depth at which the diffraction pattern was recorded (Source: ANL) 
PNNL-30945

ORNL/SPR-2021/1836

ANL-21/07
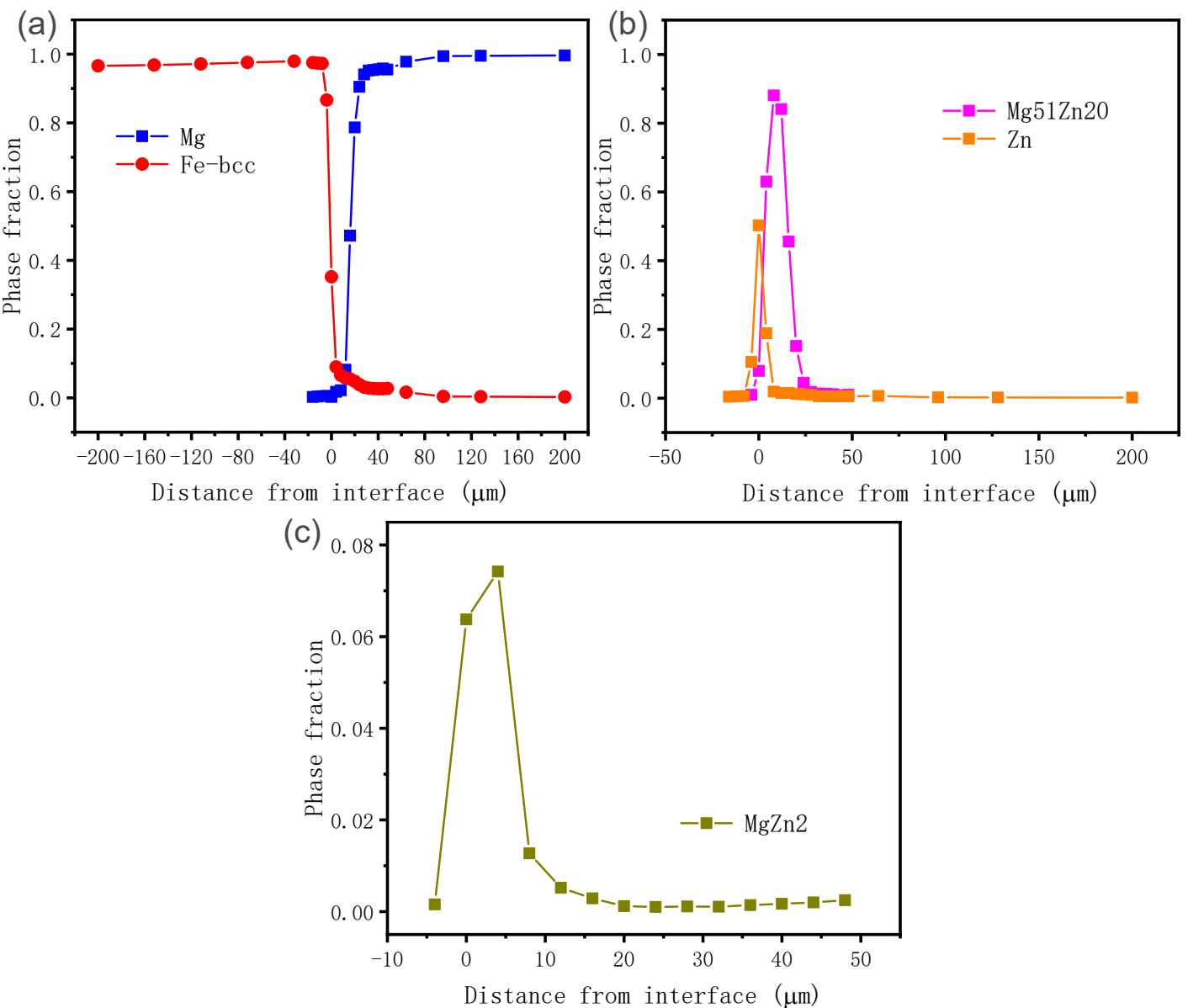

Figure 70 Phase fraction evolution of crystalline phases detected at different depth from recorded diffraction patterns (Zn coated DP590-pure Mg USW sample): (a) iron and magnesium phases; (b) $\mathrm{Zn}$ and $\mathrm{Mg}_{51} \mathrm{Zn}_{20}$; (c) MgZn $\mathrm{n}_{2}$ (Source: $\mathrm{ANL}$ )

As shown in Figure 70, two major intermetallic compound phases, $M g Z n_{2}$ and $M_{51} Z_{20}$, are highlighted after carefully compared to the standard powder diffraction database amongst Mg-Zn system. The phase fraction of each crystalline phases is quantified using Rietveld refinement method. Figure 70 (a) demonstrates the complex phase structures near the interface $( \pm 50 \mu \mathrm{m})$ but the phases at two sides far away from the interface are solely magnesium and steel, respectively. The eutectic phase $\mathrm{Mg}_{51} \mathrm{Zn}_{20}$ of Figure 70 (b) accounts for larger phase fraction as compared to the other intermetallic compound $\mathrm{MgZn}_{2}$ phase of Figure 70 (c). Pure Zn phase of Figure $70(\mathrm{~b})$ is also found in the coating layer. The formation of intermetallic compound phases might be caused by the localized heat generation in the ultrasonic welding process that melts the low-temperature $\mathrm{Zn}$ coating layer; and then the melted $\mathrm{Zn}$ reacts with $\mathrm{Mg}$ side and some hightemperature phases remain in the further rapid cooling process. 


\subsubsection{EBSD of Pure Mg-Pure Fe joint by FaST}

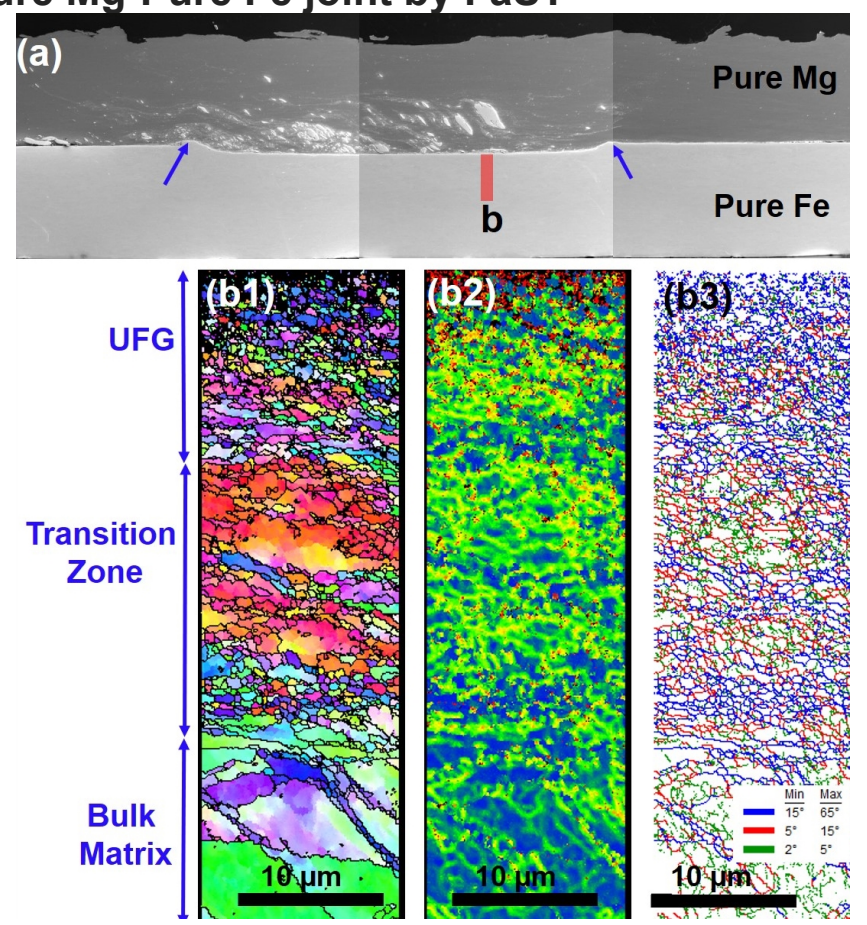

Figure 71 Macro-cross section and EBSD. (a) SEM macro for joint interface (b: red rectangular section for EBSD), (b1) IPF map, (b2) KAM and (b3) grain boundary orientation map. (Source: PNNL)

Kernel average misorientation (KAM) (Figure 71(b2)) shows an overall view of grain morphology of bonded Fe from the interface to the bulk matrix. The microstructure regime can be divided into three overall categories- 1) Ultra fine grain zones with a grain sizes in sub-micron scale 2) Transition zone with grain sizes from 1-6 $\mu \mathrm{m}$ and 3 ) bulk matrix. The first two zones contain grains with higher lattice distortion and dislocation density. Figure 71 (b3) also shows that that UFG regime consists of higher fraction of high angle grain boundaries. However, EBSD technique was not able to properly index the grains near the interface owing to low grain size. TEM work was done to reveal the grain structure in this region.

\subsubsection{XPS of Pure Mg-Pure Fe joint by USW}

Welding trials to join pure $\mathrm{Fe}$ and pure $\mathrm{Mg}$ were conducted in three different gas environments: (1) air, (2) oxygen rich $\left(\mathrm{O}_{2}>99 \mathrm{vol} \%\right)$ and (3) nitrogen as a shielding gas $\left(\mathrm{O}_{2}<1\right.$ vol\%). Metallurgical bonds were formed in all these conditions. Two sets of joint samples were produced for joint interface characterization using different techniques including XPS, STEM/EDS and APT.

For XPS analysis, prior to putting the sample into the XPS instrument, the welded samples were separated using a flat blade screwdriver. As soon as they were separated, the separated Fe and Mg parts were both attached to the XPS sample holder using metal clips, placed into the XPS load lock, and the load lock was evacuated. Total time that the separated parts before evacuation was less than 2 minutes. After the Fe and Mg parts were transferred into the analysis chamber XPS analysis were performed at the center and the edge of the joint on each part. Depth profiles are presented as composition versus sputter etch time (in sec). The ion gun parameters used for the depth profiles was previously calibrated as $\sim 11 \mathrm{~nm} / \mathrm{min}$. The diameter of ion beam was $700 \mu \mathrm{m}$. 
Figure 72 plots the XPS compositional depth profile of the pure Fe-pure Mg welded in ambient condition. In the center area of the Mg side, as sputtering was initiated, the $\mathrm{O} 1 \mathrm{~s}$, and Mg-oxide signals immediately decline and are essentially zero by $100 \mathrm{sec}$. The point at which the Mg-oxide goes to $\sim 0$ was $75 \mathrm{sec}$ of etching, which corresponds to a maximum thickness of $\sim 10-14 \mathrm{~nm}$. In the edge area of the $\mathrm{Mg}$ side, the depth profile shows a plateau region between 0 and $\sim 100 \mathrm{sec}$ for the $\mathrm{O}, \mathrm{Mg}$-oxide, and Mg-metal signals. Beyond $100 \mathrm{sec}$, the Mg-metal increases to its final amount of $\sim 90$ at.\% by the end of the profile. The profile on the Mg side suggests that when separation occurred the surface was primarily $\mathrm{Mg}$ metal and during the brief exposure to lab air a thin mixed oxide/carbonate layer form. The edge area showed a slightly thicker oxide layer. This may be due to a greater exposure of air in the edge region of the weld during the welding process. In the center area of the $\mathrm{Fe}$ side, the $\mathrm{C}$ profile dips with initial sputtering while the $\mathrm{O}$ profile jumps up.
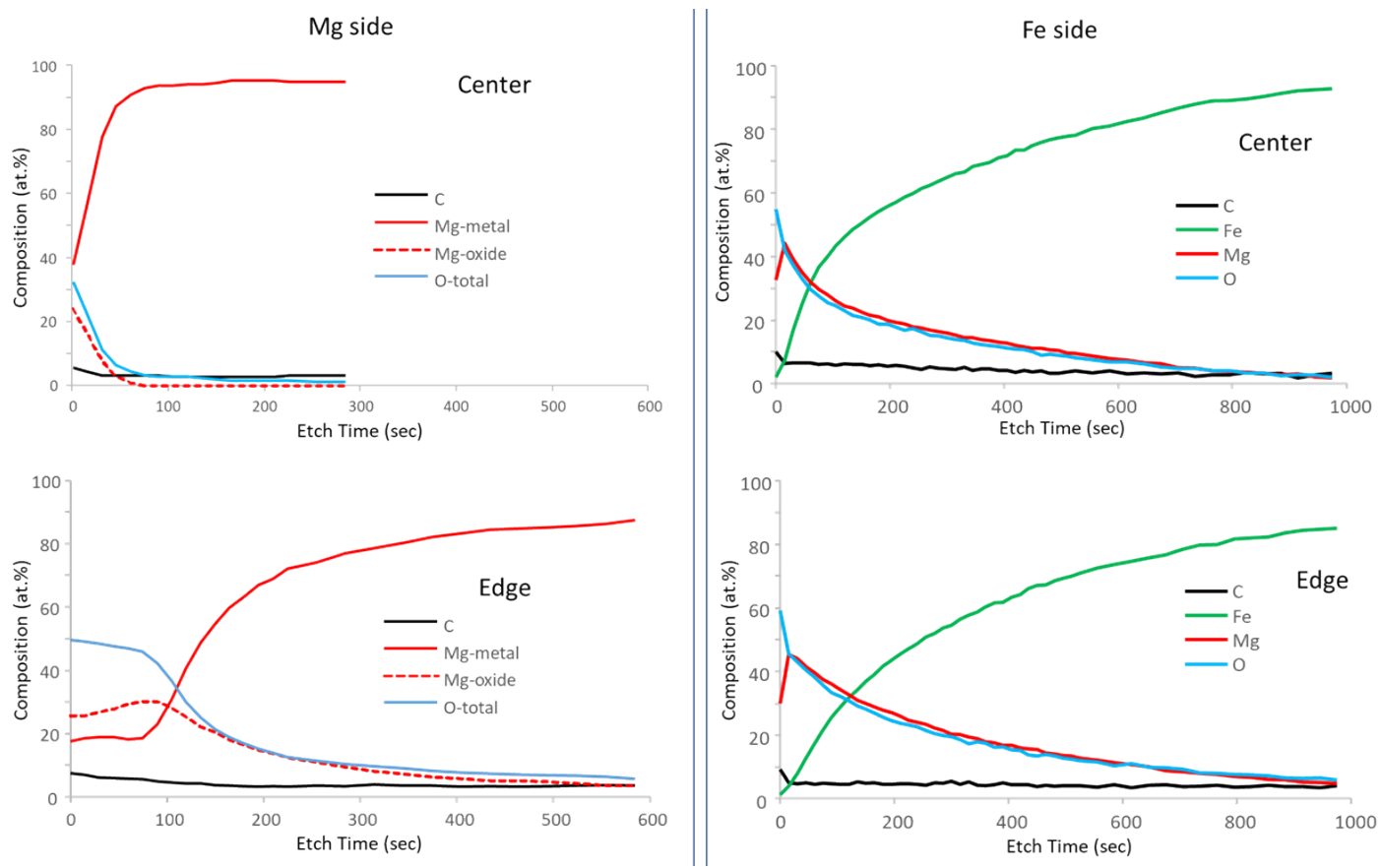

Figure 72 XPS depth profile of a pure Fe-pure Mg joint welded in air (Source: ORNL)

This is due to the removal of the thin carbonate layer that reveals the Mg-oxide material below. After this initial change, the $\mathrm{O}$ and $\mathrm{Mg}$ profiles decrease together as sputtering proceeds. At the same time, the Fe signal (primarily Fe-metal) increases. In the edge area of the Fe side, the depth profile of the edge area is like that of the center region for most of the part. The primary difference is that the $\mathrm{Mg}$ and $\mathrm{O}$ profiles for the edge area decrease more slowly compared to the center area. Likewise, the Fe signal rises a little more slowly compared to the center area. This would indicate that the oxide overlayer in the edge area is a little thicker. The data for the Fe side of the welded couple showed that a Mg-oxide layer was present on the surface. The depth profiles showed that the $\mathrm{Mg}$ and $\mathrm{O}$ persisted to at least $800 \mathrm{sec}$ of etching ( 150 nm deep). However, Fe metal was present during the entire $800 \mathrm{sec}$ of sputtering. This would indicate that the Mg-oxide and Fe-metal exists together in a mixed layer covering the Fe substrate. Combining profile data on both $\mathrm{Mg}$ and Fe sides, the picture that emerges is during the welding process, a Mg-oxide layer is formed and mixes with the Fe metal. When separated, the failure occurs at the Mgmetal/mixed Fe-metal + Mg-oxide layer. 
Figure 73 and Figure 74 shows the XPS depth profile measured on the pure Fe-pure Mg USW joints that were welded in oxygen and nitrogen respectively. The profiles are like what is presented in Figure 72.
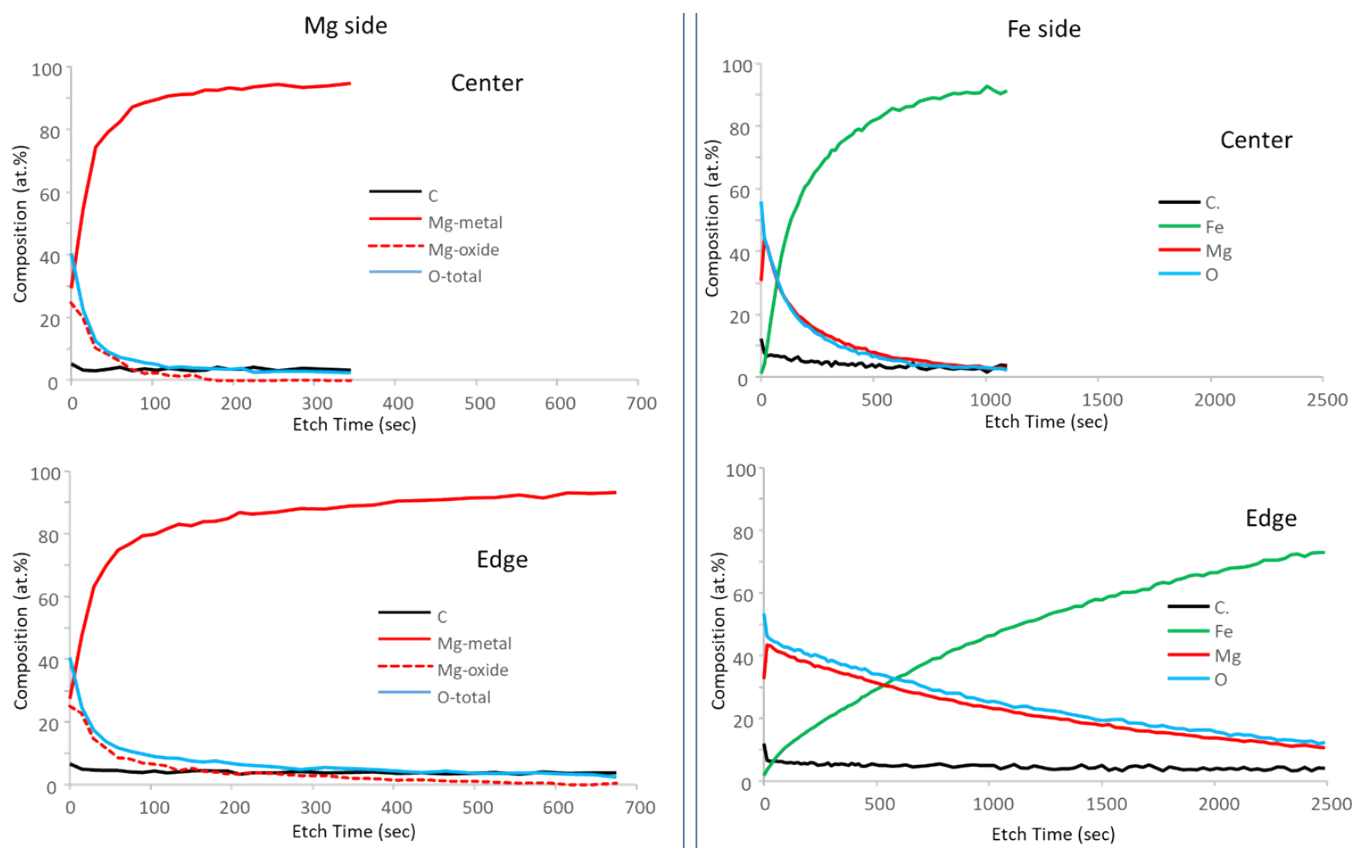

Figure 73 XPS depth profile of a pure Fe-pure Mg joint welded in oxygen (Source: ORNL)
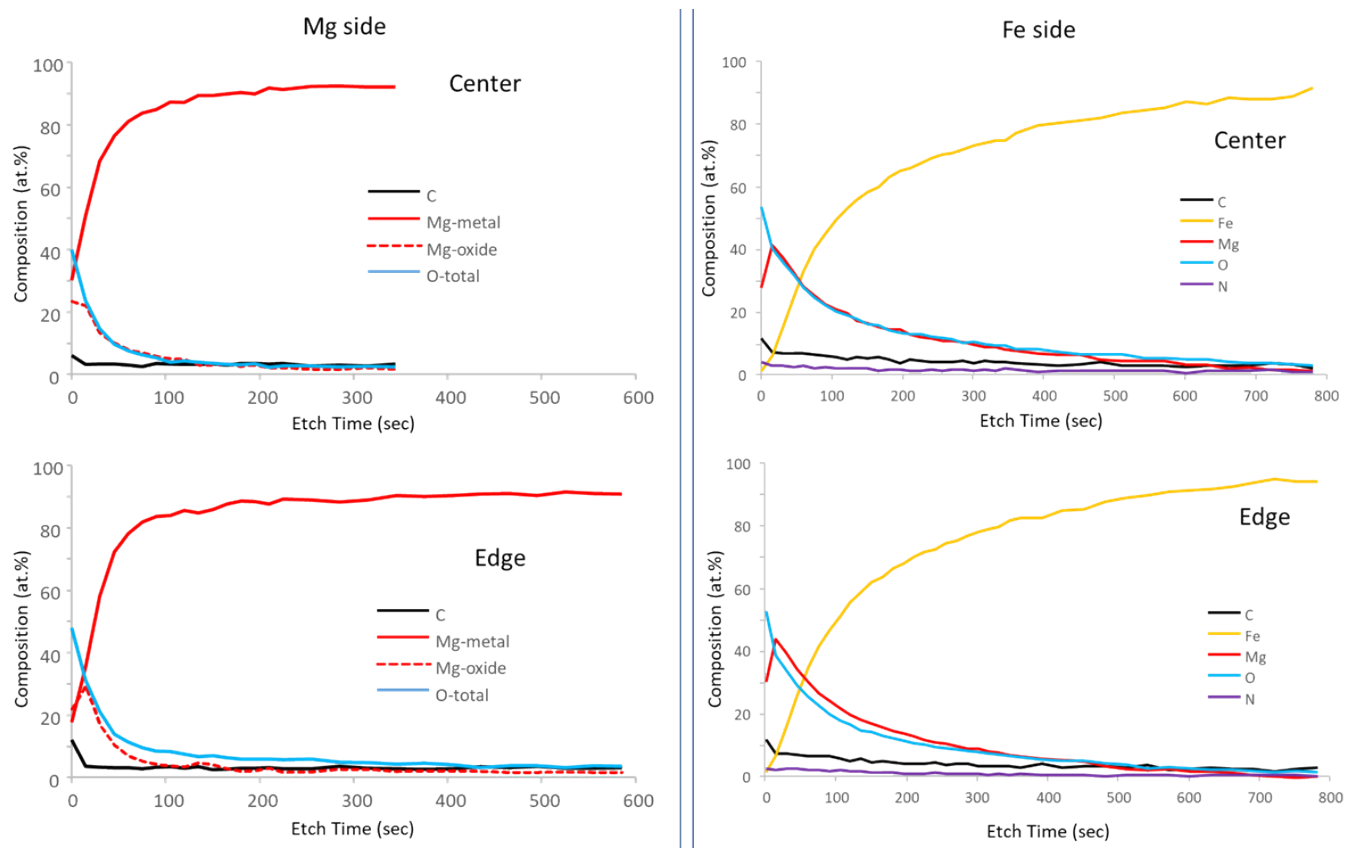

Figure 74 XPS depth profile of a pure Fe-pure Mg joint welded in nitrogen (Source: ORNL) 


\subsubsection{Transmission Electron Microscopy}

\subsubsection{TEM analysis at the interfaces of AZ31 - Zn coated DP 590 steel joint and pure Mg-DP 590 steel joint with FaST}

The TEM bright-field micrographs of joint interfaces and the steel side for AZ31-DP 590 steel and pure Mg-DP 590 steel welds are presented in Figure $75(a, b)$ and Figure $76(a, b)$, respectively. Owing to severe plastic deformation (SPD) from the scribe cutting on the steel surface, ultrafine grains (UFGs) were formed on the steel side next to the welded interface. Grains of steel were significantly refined from $8 \pm 5 \mu \mathrm{m}$ (base steel) to $200 \pm 100 \mathrm{~nm}$ in the AZ31-DP 590 joint and to $70 \pm 15 \mathrm{~nm}$ for the pure Mg-DP 590 steel joint. The grain size appears to gradually increase with distance from the interface. Nevertheless, the refined grains span $37 \pm 3 \mu \mathrm{m}$ away from the interface, indicating the extent of the plastic deformation in steel beyond the observed scribe engagement.

Mg side, where conventional FSW occurred also contained recrystallized and refined grains. The extent of grain refinement was much less than on the steel side. The grain size was reduced from $20 \pm 10 \mu \mathrm{m}$ to $3 \pm 2 \mu \mathrm{m}$. This could be associated with the comparatively high processing temperature in $\mathrm{Mg}$, resulting in greater grain growth after recrystallization than in steel. Scanning transmission electron microscopy (S/TEM) and EDS elemental maps at the interface and surrounding area are shown in Figure 75 (c-c3). An iron-rich particle of $\sim 100 \mathrm{~nm}$ size was observed about $400 \mathrm{~nm}$ away from the interface on the $\mathrm{Mg}$ side. This is a result of the scribing operation, like what has been routinely observed in macro cross sections in previous FaST work [12]. Nevertheless, this is a first observation of nano sized stray steel particles in FaST welding. At the interface, a continuous, nanosized, Al-rich layer $(\sim 40 \mathrm{~nm})$ was found (see the high magnification inset in Figure 75 (c2)). This suggests formation of an IMC, which has been previously reported in butt welding of $\mathrm{Mg} / \mathrm{steel}$ [7]. Al-rich chemistry around the stray steel particle on the $\mathrm{Mg}$ side shows that conditions are favorable for the formation of Al/Fe IMC layer. Fe- and Al-rich peaks also matched well (line scan d2) indicating formation of an AI-Fe IMC at the interface [7]. An appreciable amount of $\mathrm{O}$ was also observed, especially towards the $\mathrm{Mg}$ side and the interface region. From line scan d1 and d2 (Fig. 2d), the elemental gradient of $\mathrm{Mg}$ and $\mathrm{O}$ suggests the presence of $\mathrm{MgO}$ layer at the interface.

S/TEM with EDS elemental mapping of pure Mg and DP 590 steel is presented in Figure 76 (cc2). In the absence of Al, the interface layer has a distinct composition. An O-rich interfacial layer with profuse nanosized lumps (Figure $76 \mathrm{c}$ ) was identified close to the interface on the Mg side. A high-contrast view at the interface further reveals the interface with nanosized lumps (seen as darker spots, marked with yellow arrows in the Figure 76 (a) inset). This layer is $\sim 35 \pm 5 \mathrm{~nm}$ thick and is present across the interface view field (see the high magnification inset in Figure 76 (c2)). An EDS line scan also suggests the formation of a nanosized MgO layer (Figure 76 (d1)).

A good grasp of interfacial phenomena is critical for understanding the joint chemistry and controlling them for optimum joint performance. The following paragraphs describe our attempts to understand the interface chemistry based on the presented results. 

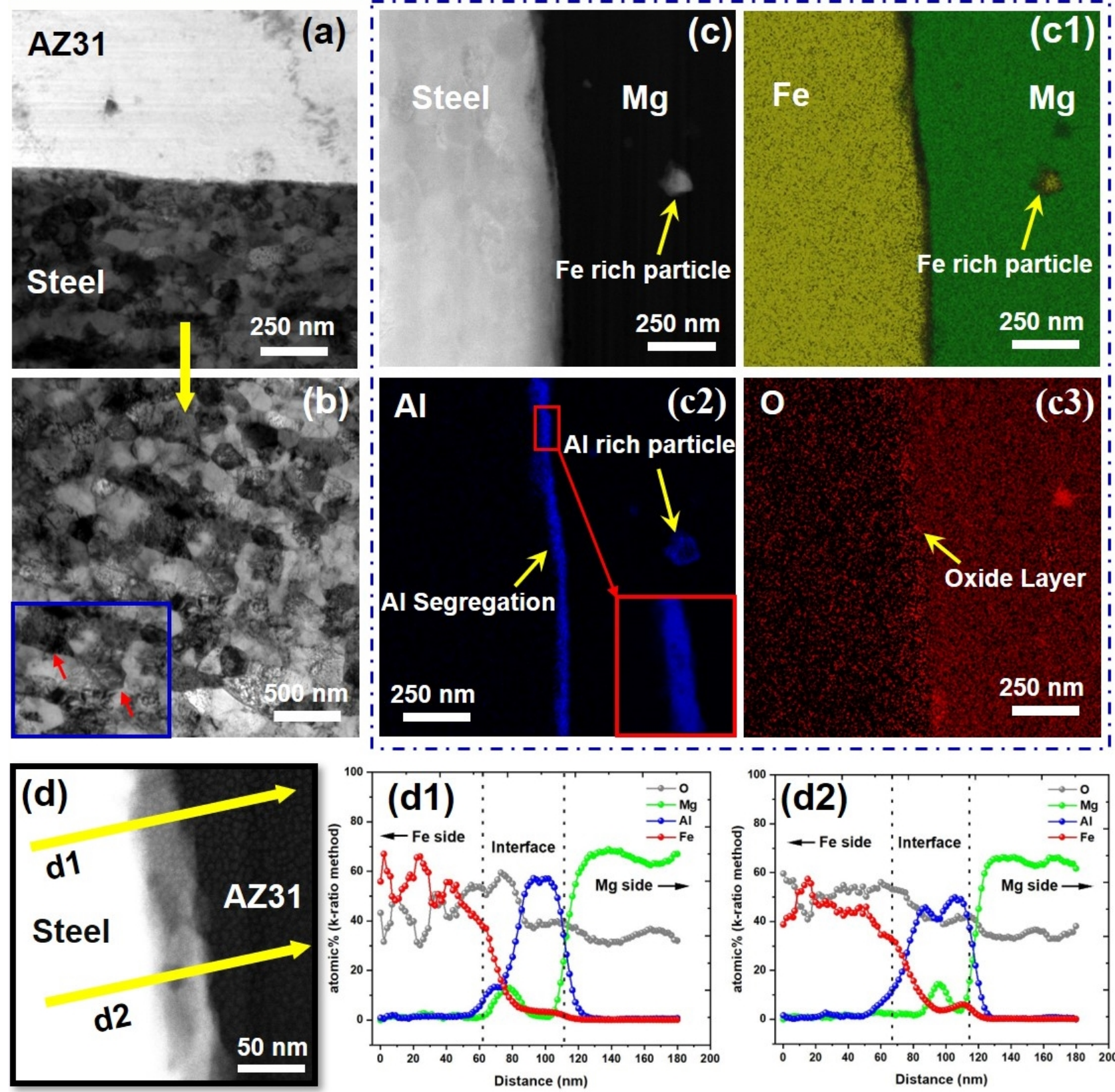

Figure 75 TEM with EDS of AZ31Mg-DP 590 joint. (a) Joint interface; (b) nano steel grains (inset: dislocations marked by red arrows); (c) S/TEM image, EDS mapping of (c1) Fe and Mg, (c2) Al (inset: high magnification view), (c3) O; (d) location of two EDS line scans; EDS line scan elemental analysis plots (d1) and (d2), for AZ31Mg-DP 590. (Source: PNNL)

Materials combination and lattice matching are the decisive factors that determine coherence or lack thereof between two phases or across an interface. For any metallurgical bonding, local temperature is a critical factor for determining the interface characteristics. Measured peak temperature at the AZ31-DP 590 interface was around $550{ }^{\circ} \mathrm{C}$, which is enough to enhance the up-hill Al diffusion towards the interface (Al melting point $660^{\circ} \mathrm{C}$ ). While it is tempting to draw from the existing knowledge base for elemental diffusion across an interface at high temperature and pressure, the time scale of the welding process is a few orders of magnitude lower than in a typical diffusion experiment. For example, a $1 \mathrm{~mm}$ interface is directly exposed to the heat source for 
0.08 second. Also, the total sheet thickness is $3 \mathrm{~mm}$, so a much higher cooling rate would be expected. Therefore, the interfacial chemistry is a more localized phenomenon and could vary slightly with location as well. It is likely that Al diffused from the Mg side towards the interface in response to high temperature, pressure and to a negative heat of mixing with Fe. Owing to high welding speed, short diffusion time, and weak diffusion coupling of $\mathrm{Al}$ towards $\mathrm{Fe}$, a nanosized $\mathrm{Al}$ rich layer $(40 \pm 10 \mathrm{~nm})$ formed at the interface.
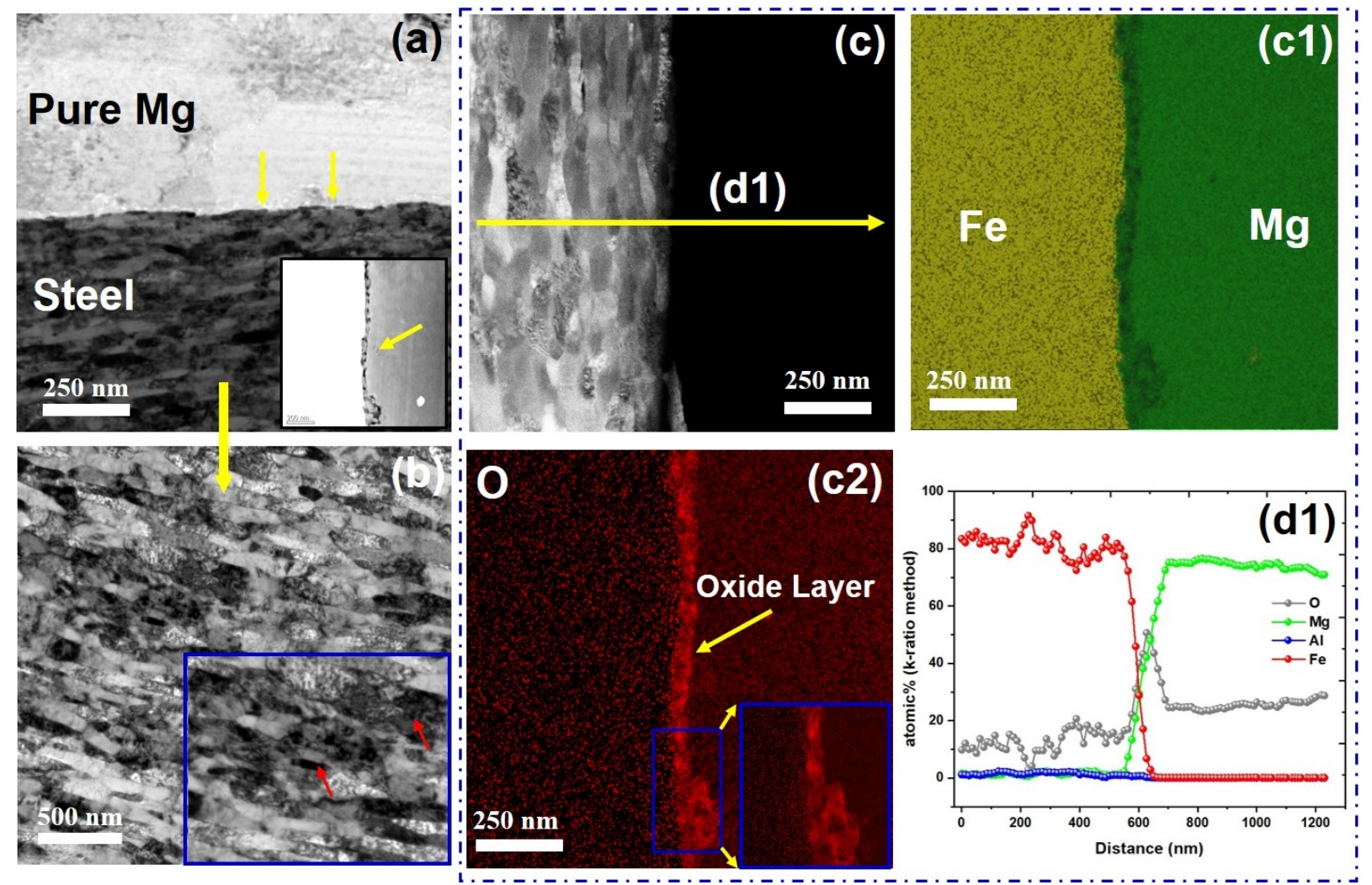

Figure 76 TEM with EDS of pure Mg-DP 590 joint. (a) Joint interface (inset: high-contrast, highangle annular dark field image with oxide layer at the interface); (b) nanosized steel grains (inset: dislocations, marked by red arrows), (c) S/TEM image with location of EDS line scan; EDS mapping of (c1) Fe and Mg, (c2) O (inset: high magnification view), (d1) line scan elemental analysis plot for pure Mg-DP 590. (Source: PNNL)

Al has excellent coherence with both $\mathrm{Mg}$ and steel intruded at the interface as a coupling layer. During development of dissimilar joining by FSW, researchers assumed that microscale to nanoscale interface layers always enhanced the joint strength, because the interface layer thickness correlates directly to the fracture path mechanism or failure mode.

It is well known that elemental magnesium is very unstable and prone to surface oxidation even at room temperature. Regardless of how clean the surface is, a small layer of oxide is bound to form in when exposed in air. Thus, it is valid to expect that just prior to joining the Mg surface contained a thin layer of $\mathrm{MgO}(\sim 30 \mathrm{~nm})$. This "prior" oxide layer however will not go undisturbed during the welding process as a significant amount of severe plastic deformation occurs at the interface due to the scribe cutting action. Additionally, a lot of material transport takes place around the interface. EDS elemental distribution (Figure 75 (d1) and (d2), Figure 76 (d1)) clearly indicates a significant saturation of oxygen at the interface compared to nearby processed zone. 
This cannot be explained by prior surface oxides/ hydroxides in the Mg side alone. We posit that oxygen saturation at the interface is a direct result of the joining process. Specifically, for pure Mg- DP590 case, in absence of Al (unlike the AZ31-DP590 case), we hypothesize that joining of Fe to Pure Mg may be mediated by lattice matching of a thin atomic layer of oxides. Given that no lattice plane matching exists for $\mathrm{Mg} / \mathrm{Fe}$ coupling according to the edge-to-edge matching model for the hexagonal closest packing/body centered cubic system. However, a considerable extent of lattice matching (with only a small lattice mismatch of $3.8 \%$ ) on a $45^{\circ}$ in-plane rotation can be found between $\mathrm{MgO}$ and $\mathrm{Fe}$, arising from strain misfit by dislocations. FaST induced Severe plastic deformation could introduce lattice mismatch between $\mathrm{Fe}$ and $\mathrm{MgO}$. Thus, the nanosized oxide layer may act as a coupling between two immiscible systems. Previous research work using impact welding have also shown higher oxygen concentration at the interface (Al-Steel joints) and also shows oxygen over saturation can take place at the interface.

For both AZ31-DP 590 and pure Mg-DP 590 joints, nanosized lath martensite formed (200 \pm 100 $\mathrm{nm}$ and $70 \pm 15 \mathrm{~nm}$, respectively) in a certain texture pattern close to the interface with accumulation of dislocations surrounding it, as shown in Figure 75 (b) and Figure 76 (b), respectively (dislocations are marked with red arrows). SPD induced by the scribe along with a FaST cooling rate transformed an island of martensite (DP 590 base metal microstructure) into nanosized laths (UFGs) with a highly strained grain boundary. This effect enhances the rapid dislocation pileup and interactions at the grain boundaries, as shown in Figure 75 (b) and Figure 76 (b). Because the relief of misfit strain by high energy nano laths enhances the grain boundary relaxation, activation energy for reaction is reduced. Previously researchers also observed nanolayer formation (Mg-Mn), and grain boundary relaxation phenomenon (Mg-Fe) acting as a coupling between two immiscible systems.

2.2.5.2 TEM analysis at the interfaces of AZ31- Zn coated DP 590 steel joint, AZ80uncoated DP 590 steel joint and Pure Mg - uncoated DP 590 steel joint by USW

Morphology and chemical composition of a FIB sample extracted near the edge of the joint interface on Zn-coated DP590-AZ31B welds produced with high welding energy (3500W for 4s using the single-head machine).

A thin slice of the joint section in this area was extracted by focused ion beam (FIB) to analyze the chemical composition as shown in Error! Reference source not found.. Different from the center region where the $\mathrm{Zn}$ completely transformed to $\mathrm{Zn}-\mathrm{Mg}$ reaction layer, the edge region had a mixed layer of $\mathrm{Zn}$ and $\mathrm{Zn}-\mathrm{Mg}$. This is because the joint edge was exposed to a lower temperature, resulting in a partially dissolved $\mathrm{Zn}$ layer. 


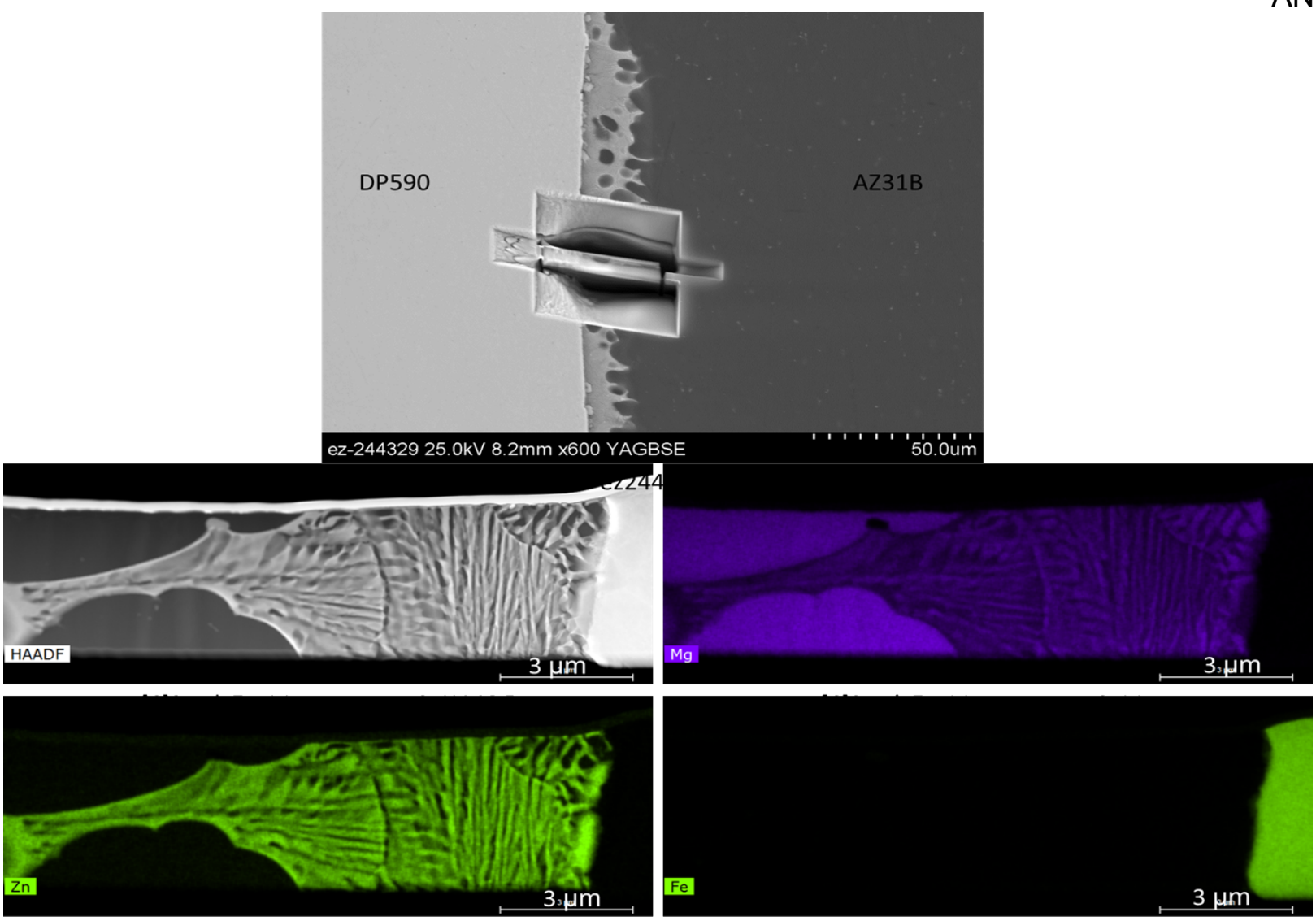

Figure 77 Morphology and chemical composition of a FIB sample extracted near the edge of the joint interface on Zn-coated DP590-AZ31B welds produced with high welding energy (3500W for 4 s using the single-head machine). (Source: ORNL)

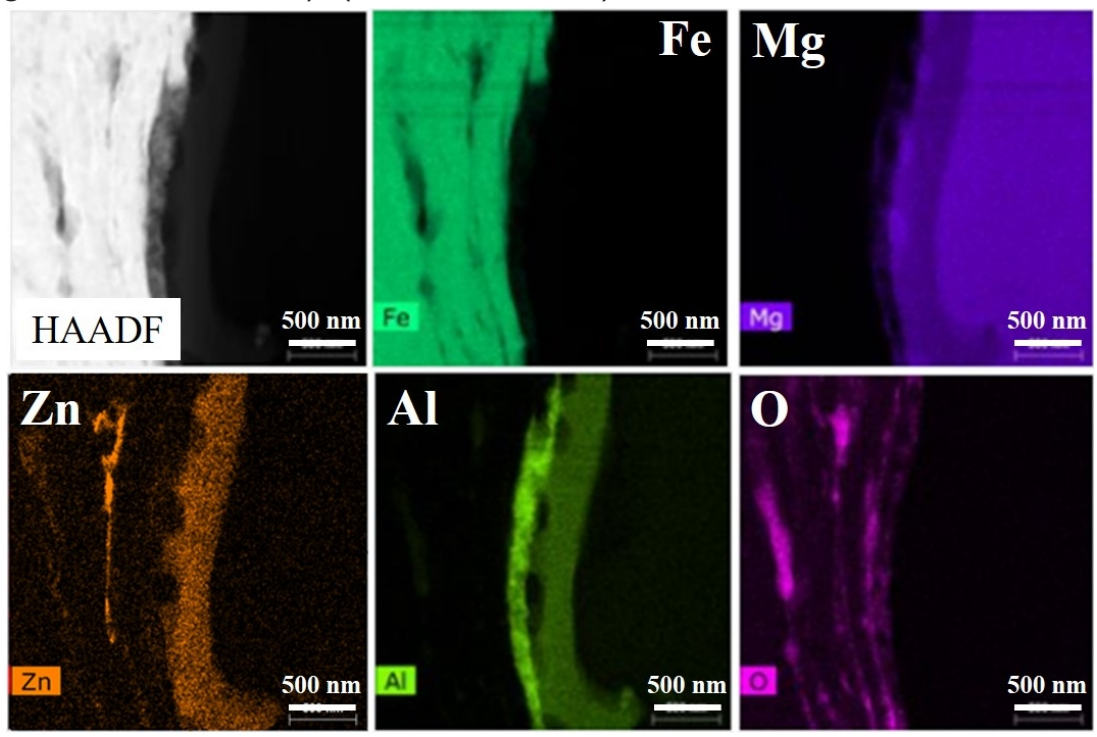

Figure 78 High-angle annular dark field (HAADF) image showing the interfacial morphology and EDS maps showing the chemical composition at the center of a bare DP590-AZ80 USW sample (produced with the single-head machine at 3500W for 4s) (Source: ORNL) 


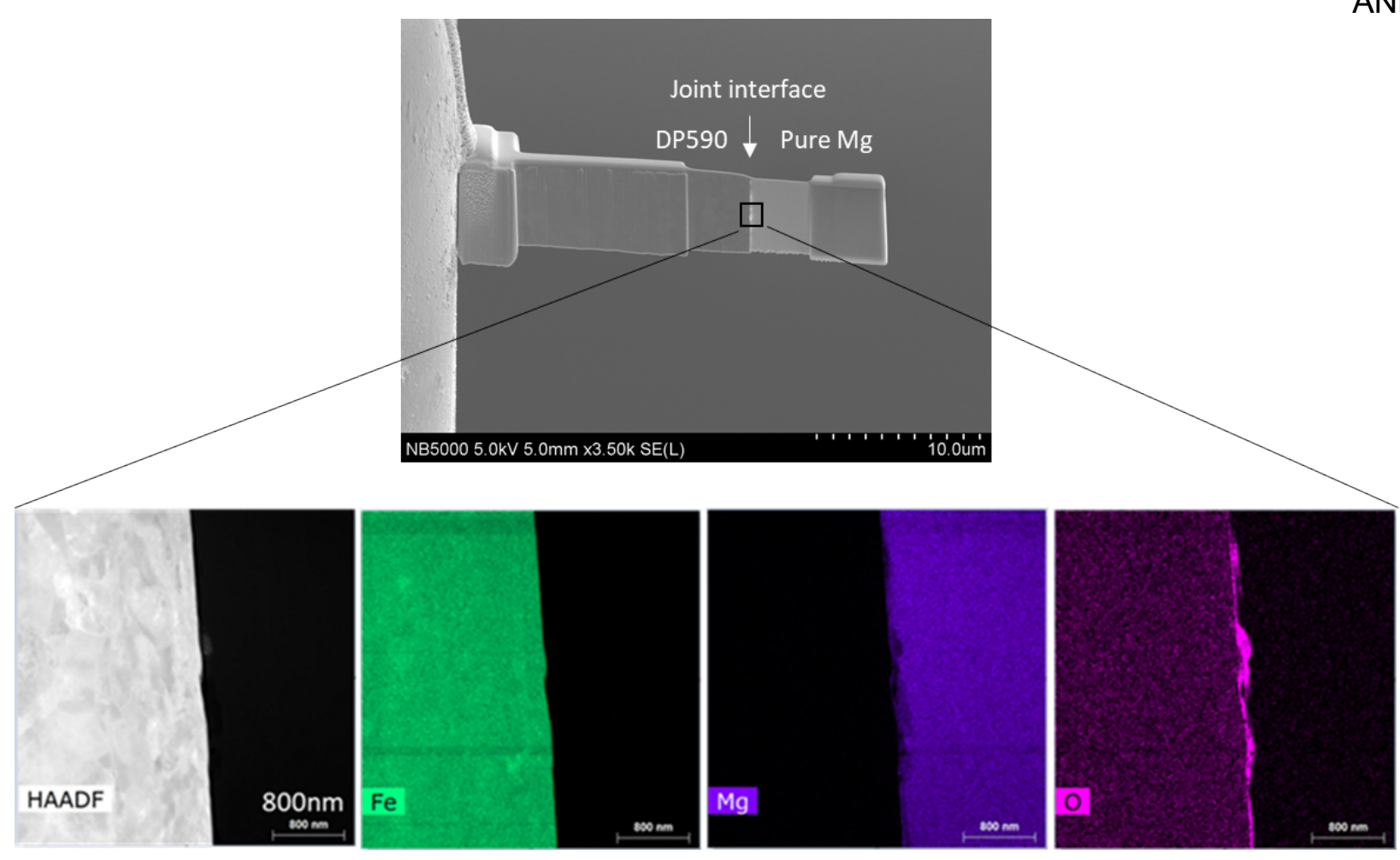

Figure 79 Chemical composition analysis on a FIB-lifted thin slice extracted from the center of the bare DP590-pure Mg USW joint (produced with the single-head machine at 3500W for 4s) (Source: ORNL)

Without the presence of the alloy elements in $\mathrm{Mg}$, a metallurgical bond was also formed as shown in Figure 78. The chemical analysis on the FIB-lifted thin sample (Figure 79) indicates that no concentration of $\mathrm{Al}$ or $\mathrm{Zn}$ was observed at the bare DP590-pure Mg joint interface. However, a layer of concentrated $O$ element (less than $100 \mathrm{~nm}$ ) was still present. This suggests that this layer of $\mathrm{O}$ could be responsible for the formation of joint between pure Mg and bare DP590.

\subsubsection{TEM analysis at the interfaces of Pure Mg - Pure Fe joint by FaST and USW}

TEM foils were extracted from the interface region using a focused ion beam (FIB) lift-out technique (details are provided in the Experimental Methods). The TEM bright-field micrographs of joint interface, Mg side with SADP and Fe side with SADP are presented in Figure 80 (a-a2) respectively. Due to severe plastic deformation (SPD) from the scribe cutting on the steel surface, ultrafine nano sized grains (UFGs) were formed on the steel side next to the welded interface confirming the EBSD observations in previous section. Grains of steel were significantly refined to $400 \pm 100 \mathrm{~nm}$ close to the interface. This is the probable reason behind poor indexing during EBSD close to the interface. Scanning transmission electron microscopy (S/TEM) and EDS elemental maps at the interface and surrounding area are shown in Figure 80 (b-b2). Nano sized iron-rich particles of size approximately $65 \pm 30 \mathrm{~nm}$ was observed close to the interface on the Mg side. This is a result of the scribing operation, similar to what has been routinely observed in macro cross sections in previous FaST work. Nevertheless, it is interesting that the machined off particle size can be nano scale. At the interface, a continuous, nanosized O-rich layer ( 40 \pm 10 $\mathrm{nm}$ ) was found (Figure 80 (b2)). Nano size Fe particle and corresponding EDS mapping shown in Figure 80. 
PNNL-30945

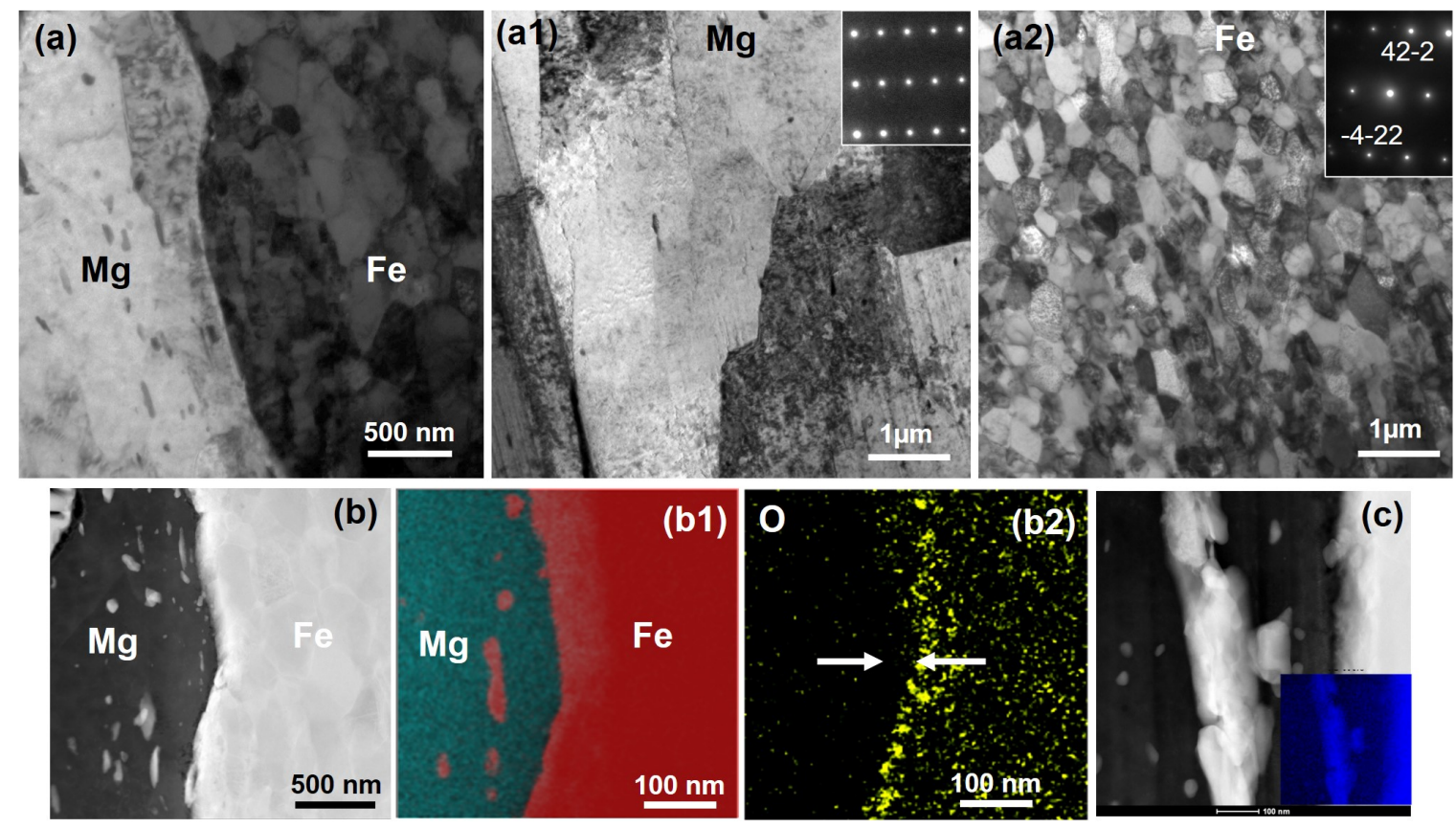

Figure 80 TEM analysis of Pure Mg-Pure Fe (Source: PNNL)
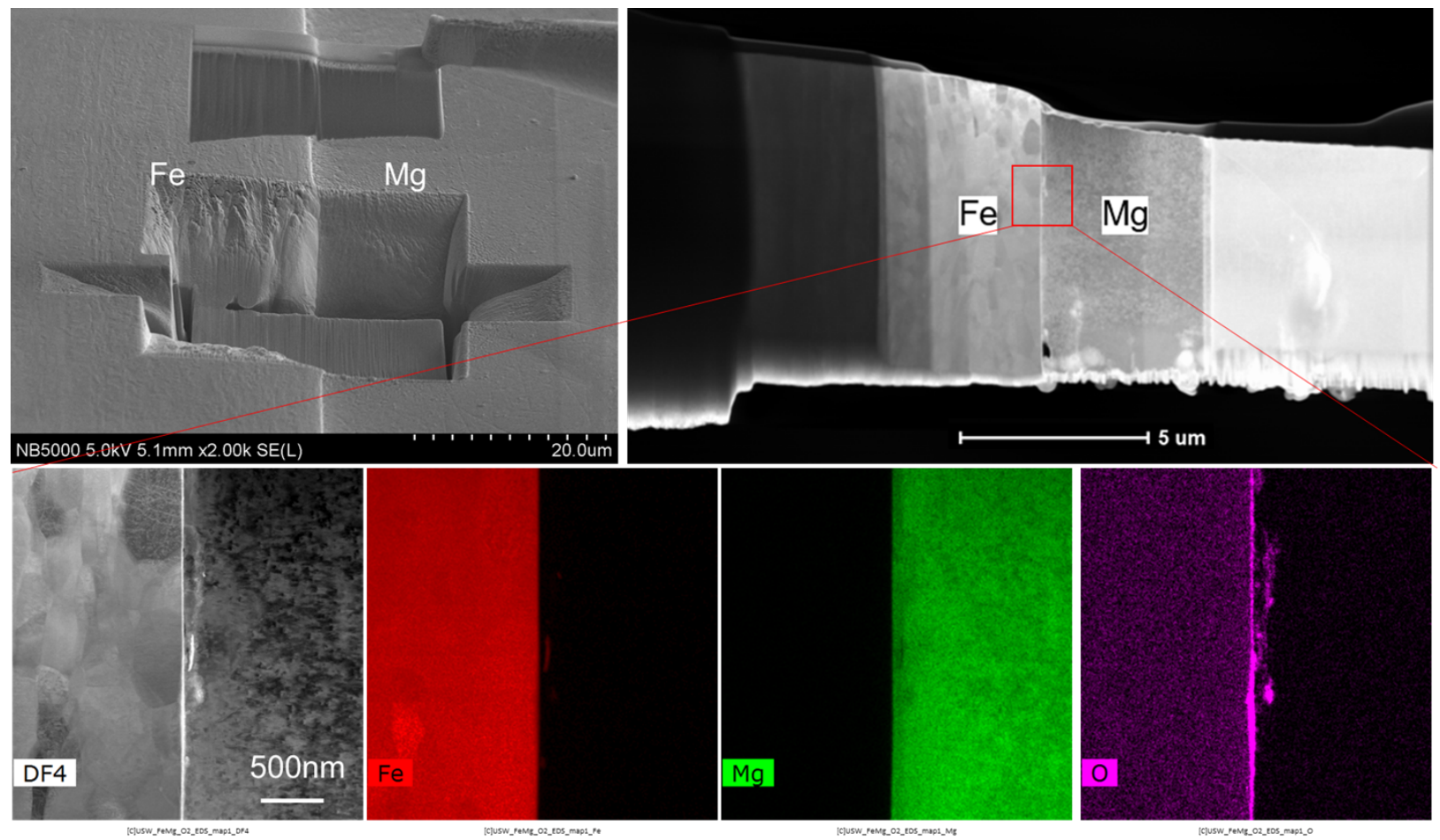

Figure 81. STEM/EDS analysis of USW joints made with pure Fe and pure Mg in oxygen rich environment (>99vol\% oxygen). (Source: ORNL) 
S/TEM with EDS elemental mapping corroborated nano-sized iron rich stray particles close to the interface as seen in Figure 80 (c-c2). Mg-enrichment in Fe particles and O-enrichment at the interface are evident from the line scan, as highlighted by the arrows in the figure. The local modulations in the composition are clearly captured in this plot due to the nano-layering of base metals. Enrichment of $\mathrm{Mg}$ concentration in Fe particles rationalized the fact of mechanical alloying induced by severe plastic deformation [35]. Scribing action to the steel side with high welding speed, short diffusion time, and lower processing temperature introducing high plastic strain.

Figure 81 shows the high magnification of STEM/EDS analysis of the USW sample welded in oxygen. A layer of $O(20 \sim 30 \mathrm{~nm})$ was observed at the joint interface. A needle-shaped specimen was extracted from the interface region for APT.

\subsubsection{Atom Probe Tomography}

\subsubsection{APT at the interface for AZ31-uncoated DP 590 steel joint by FaST}

For additional insight into the elemental diffusion mechanism, APT was performed at the interface of AZ31-DP 590 steel (Figure 82). The needle shaped specimens for APT analysis were made from the welded region such that a few needles captured the composition of the welded region on $\mathrm{Mg}$ side, interface, and Fe side, as shown in Figure 82 (a). Figure 82 (b) shows the reconstruction depicting the $\mathrm{Mg}$ ions (red) from the needle made from the AZ31 side ( $1 \mu \mathrm{m}$ away from the interface). A few discrete Fe-rich regions are evident in the reconstruction, as highlighted by the arrows in the figure. These regions were mechanically transferred to the $\mathrm{Mg}$ side by the scribe action during the FaST process. While micron sized stray steel particles in the Mg side has been reported previously, this is the first observation of nano-sized steel particles on the Mg side in FaST process.

(a)

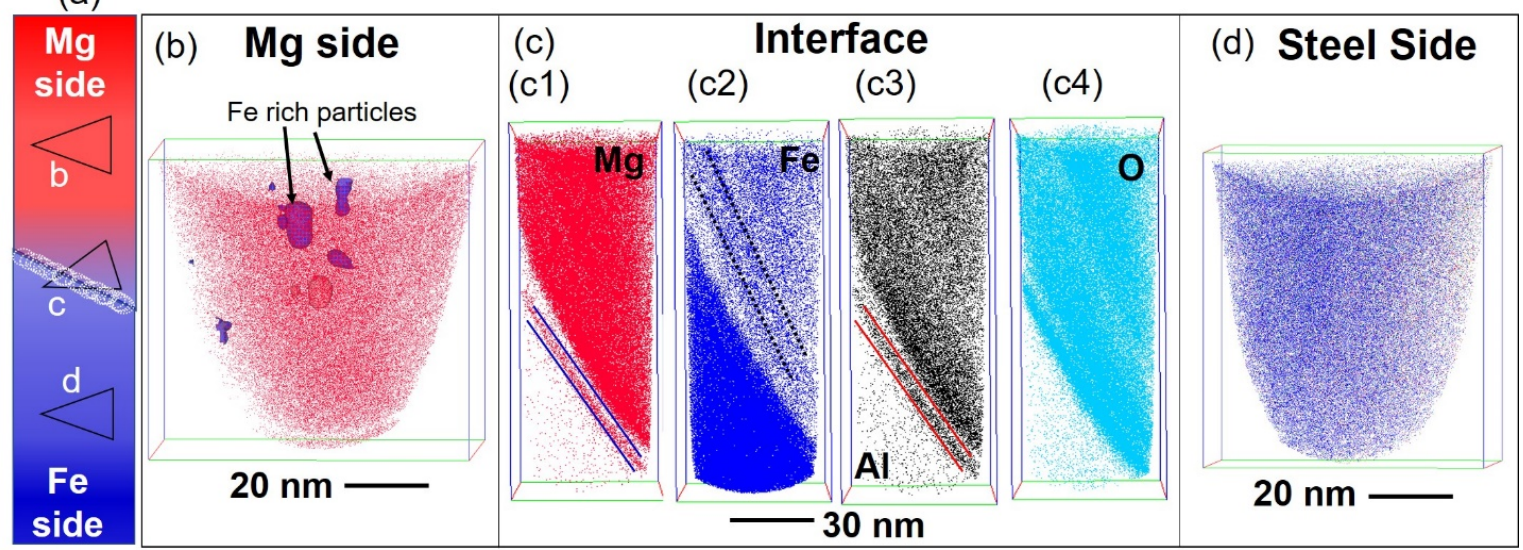

Figure 82 APT results from the interfacial region of the FaST joint between AZ31 and DP590. (a) schematic showing the region of interest for the APT analysis (notation b, $c$ and d indicates corresponding figures) ; (b) reconstruction showing the $\mathrm{Mg}$ ion map from $\mathrm{Mg}$ alloy side; (c) reconstructions showing the $\mathrm{Mg}, \mathrm{Fe}, \mathrm{Al}$, and $\mathrm{O}$ maps including the interface between the two alloys; (d) DP 590 steel side. (Source: PNNL) 

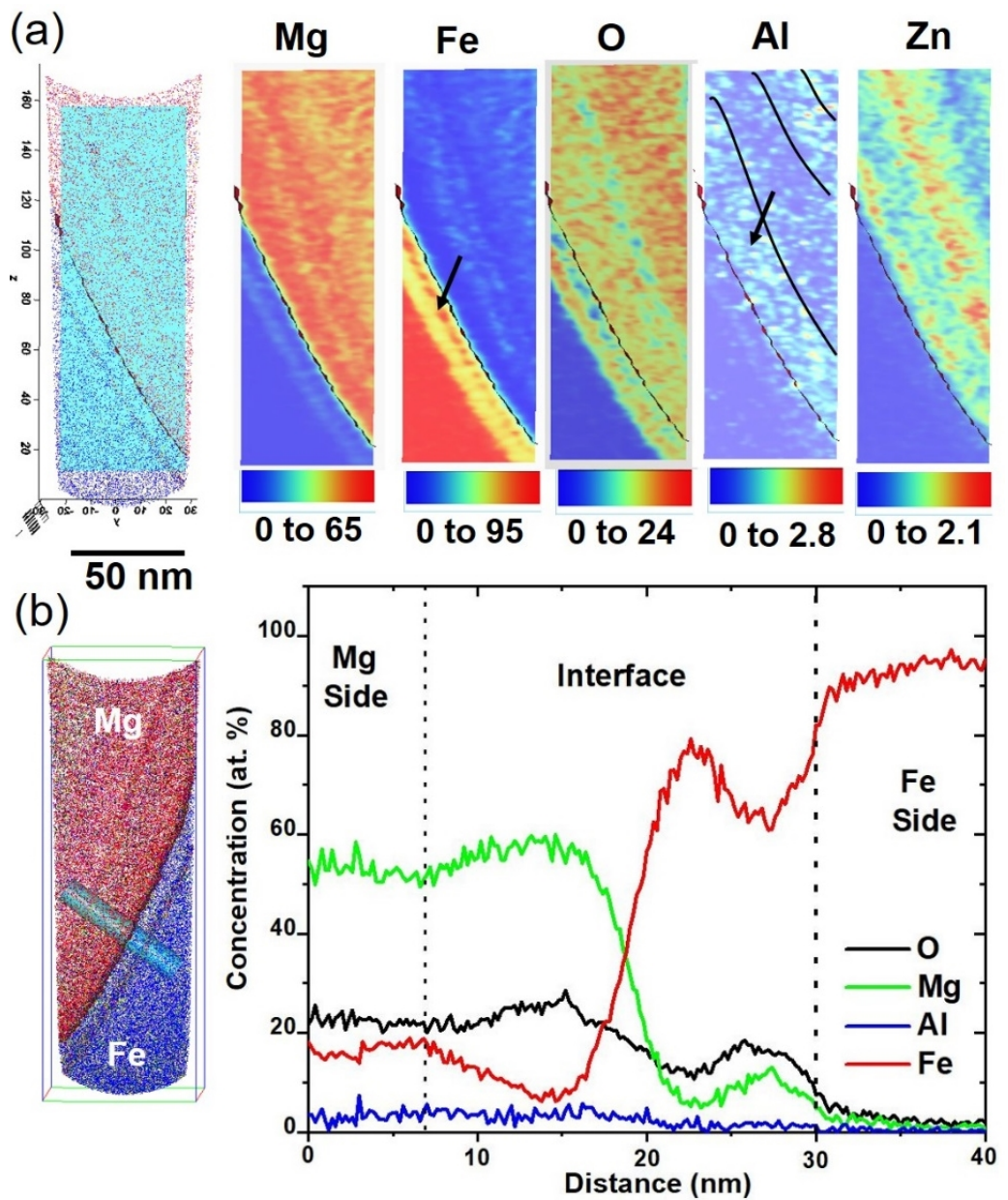

Figure 83 Elemental distribution across the interfacial region of the FaST joint between AZ31 and DP590. (a) Two-dimensional compositional map of the Fe, Mg, O, Al and Zn; (b) one-dimensional composition change along a cylinder $10 \mathrm{~nm}$ in diameter and $60 \mathrm{~nm}$ long. (Source: PNNL)

Additionally, the overall region on the $\mathrm{Mg}$ alloy side is enriched to $\sim 10$ at $\% \mathrm{Fe}$. The APT results from the interfacial region (Figure 82 (c1-c3)) confirmed the formation of a nanoscale Al-rich layer along with oxygen enrichment at the interface. Note that the reconstructions of $\mathrm{Mg}, \mathrm{Fe}, \mathrm{Al}$, and $\mathrm{O}$ in Figure 82 (c) show nanolayers of compositionally distinct regions, indicating mass transfer during welding. For example, note a layer rich in $\mathrm{Mg}, \mathrm{O}$, and $\mathrm{Al}$, highlighted by parallel blue lines in the Mg map, a Fe-rich layer and Al rich layer are highlighted by black dotted lines and red lines in respective Fe map and Al map. The quantitative assessment of the elemental gradient across the interface is presented in Figure 83. The reconstruction from the DP 590 steel side with the Fe ions in blue (Figure $82(\mathrm{~d})$ ) shows a homogeneous distribution of elements with a minimal $\mathrm{Mg}$ enrichment resulting from welding.

APT of a $5 \mathrm{~nm}$ slice of the needle excised from the interfacial region is given in Figure 83 (a). A rectangular area of $150 \mathrm{~nm} \times 50 \mathrm{~nm} \times 1 \mathrm{~nm}$ was selected to construct two-dimensional compositional maps of the $\mathrm{Fe}, \mathrm{Mg}, \mathrm{O}, \mathrm{Al}$, and $\mathrm{Zn}$ to examine their local distribution across the interface. APT compositional map at the interface shows no trace of leftover $\mathrm{Zn}$ on the Steel side. Interestingly, the $\mathrm{O}$ concentration is high (up to 24 at\%) throughout the alloy on the Mg alloy side. The Al-rich layer is delineated in the Al maps, where the local Al content reaches $\sim 2.4$ at $\%$, which 
is much lower than was observed in our TEM analysis. In the TEM analysis, we noticed that Al concentration can be as high as $\sim 40$ at\% in several locations. However, based on a combined assessment of TEM and APT results, it can be concluded that a complex oxide forms near the interface, with regions enriched in Al and Mg. It is likely that the FIB sample used for APT analysis contained Mg-enriched areas, while in TEM (at a larger scale) we observed the overall distribution of the $\mathrm{Al}-\mathrm{Mg}$ and $\mathrm{O}$ elements.

The oxygen concentration across the interface and on the $\mathrm{Mg}$ side is limited to $\sim 25$ at $\%$, which, however, can also be an underestimation. A one-dimensional composition change along a cylinder $10 \mathrm{~nm}$ in diameter and $60 \mathrm{~nm}$ long is plotted in Figure 83 (b). The local modulations in the composition are clearly captured in this plot because the base metal and the weld are nanolayered. Enrichment of $\mathrm{Fe}$ concentration towards the $\mathrm{Mg}$ side supported the concept of mechanical alloying or mixing induced by SPD. Hence, it is likely that high strain and shear during SPD enhances the abundant vacancies (point defects) and dislocations (line defects) so that a complex $\mathrm{MgO}$, (Mg-Al) $\mathrm{O}$ type oxide is formed at the interface. However, the lattice mismatch renders it difficult to form a homogeneous nanolayer throughout the interface. Rather, it is a more localized phenomenon and depends on the local atom and lattice misorientation. The structure of the oxide and structural changes at the interface can be confirmed using high resolution TEM.

\subsubsection{APT at the interface for Pure Mg-Pure Fe joint by USW in oxygen rich and $\mathrm{N}_{2}$ environment}
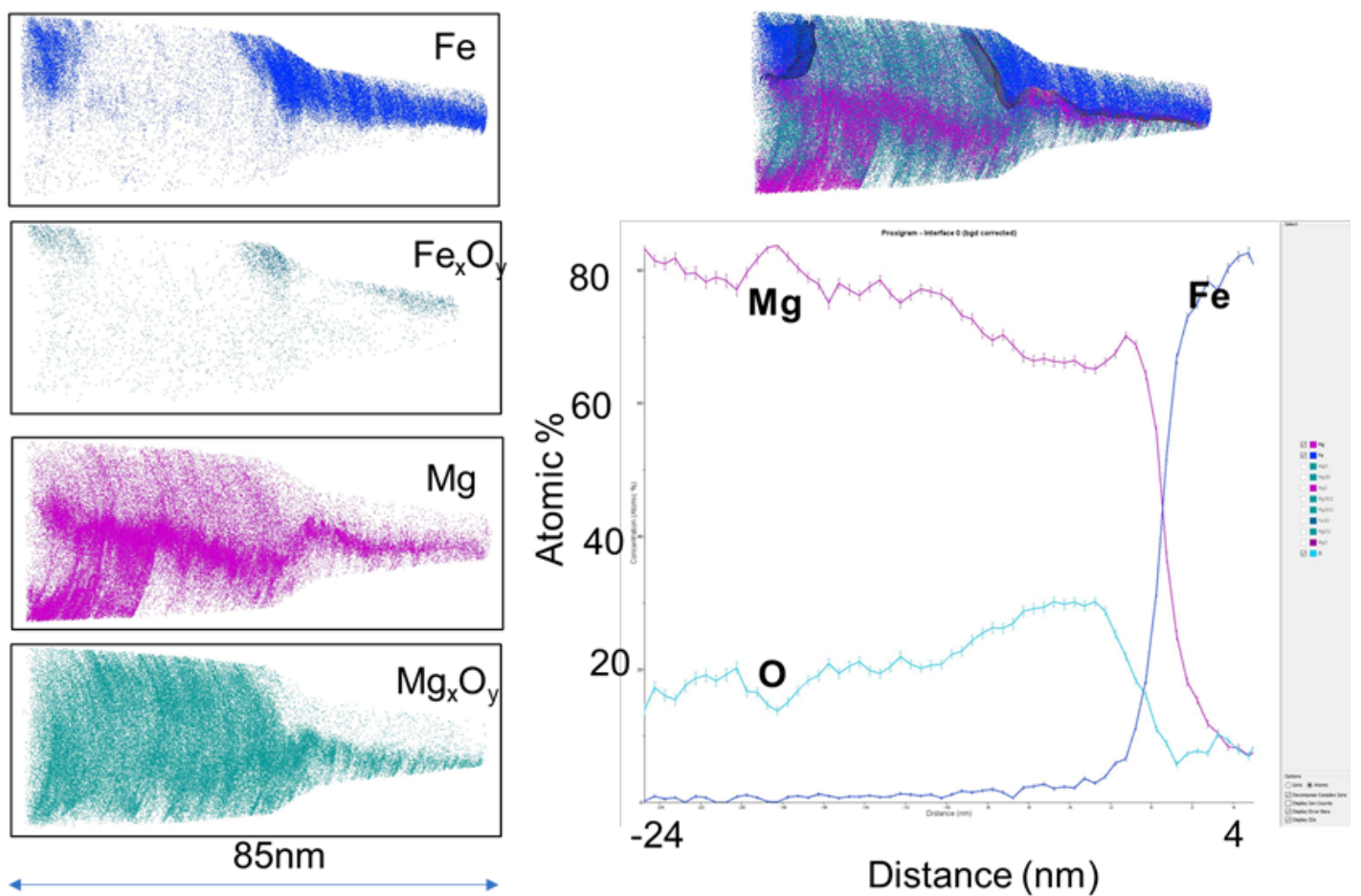

Figure 84. APT chemical analysis of USW joints made with pure Fe and pure Mg in oxygen rich environment (>99vol\% oxygen). (Source: ORNL) 

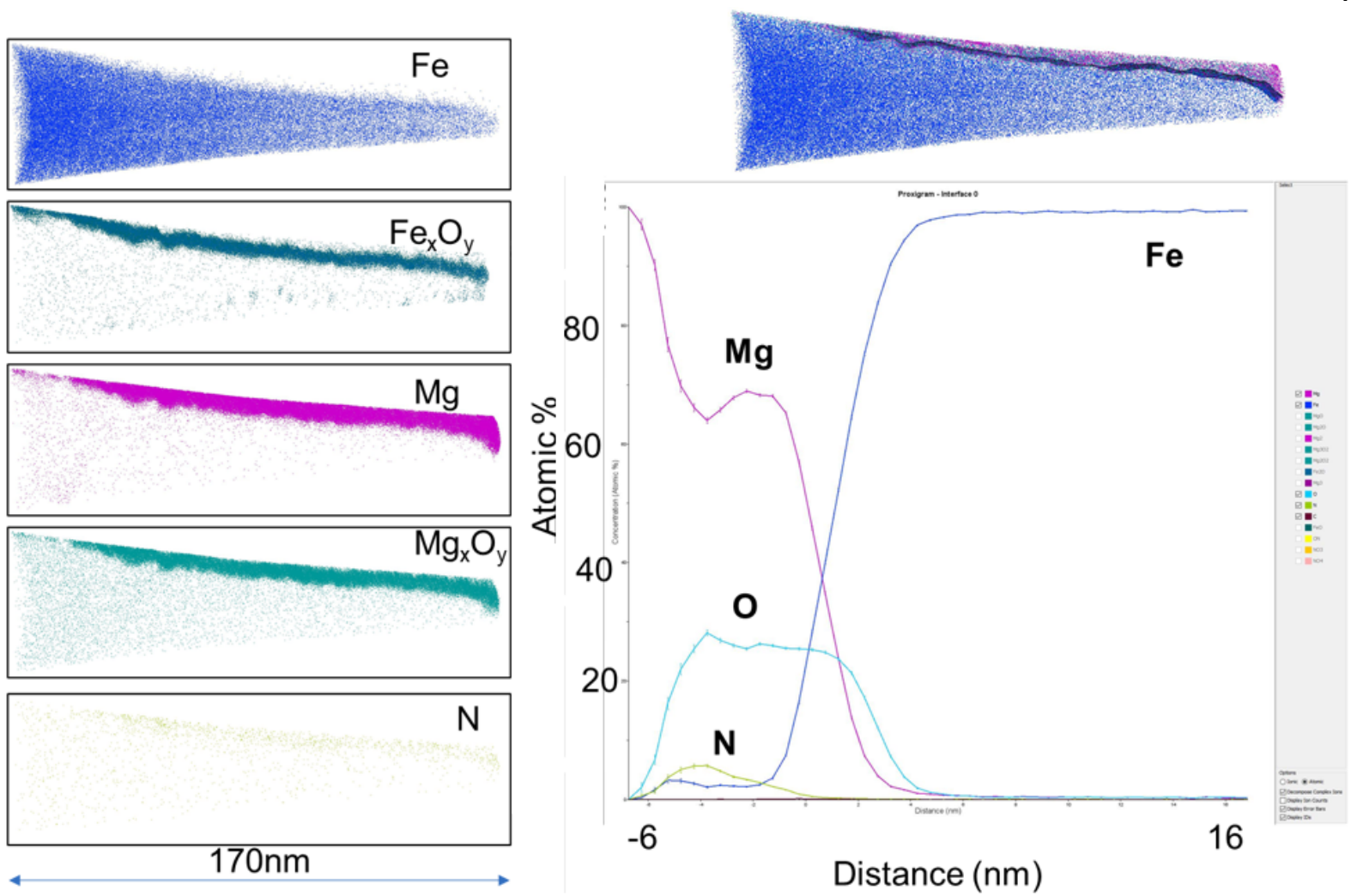

Figure 85. APT chemical analysis of USW joints made with pure Fe and pure Mg in in nitrogen shielding gas (<1vol\% oxygen). (Source: ORNL)

A needle-shaped specimen was also extracted from the interface region. Figure 84 shows needle reconstruction and elemental distribution for the USW joints made in oxygen. As can been seen in Figure 84, presence of the iron oxide and magnesium oxide at the joint interface bridges $\mathrm{Fe}$ metal and Mg metal. APT analysis was also performed on pure Fe-pure Mg USW sample welded in nitrogen. As shown in Figure 85, a layer of metal oxides is also present in the interface. The thickness of the oxide layer $(\sim 10 \mathrm{~nm})$ is thinner than that in the joint welded in oxygen.

\subsubsection{Micro and Nano Indentation}

Due to thermal and mechanical processing of material around the interface, joining process results in a significant modification of microstructure. A full field characterization of this microstructural change is necessary to accurately model the joint. For this purpose, micro hardness measurements were used in several sample set, and data set .

Figure 86 (a) and (b) show the micro hardness maps for Mg and Steel respectively. Using these maps, three different material zones were identified in the Mg sheet and two in the steel sheet. These representative material zones can be observed in

Figure 87. In

Figure $87(\mathrm{Mg})$, blue corresponds to the stir zone, green to the heat-affected zone (HAZ) and red to the base $\mathrm{Mg}$. In

Figure 87 (steel), cyan denotes the hardened steel and gray denotes the base steel. These data sets served as input into the structure-property model for interface by design (IbD) project. Representative plots with nano indentation locations shown in Figure 88. 
In order to validate the nano indentation techniques, we obtained nano indents on both the AZ31 nugget and scribed steel areas near the interface. The hardness values for both the material agreed with micro hardness methods Microhardness approach.

Figure 89 summarizes the results of the nano indentation measurements that were made specifically to characterize the $\mathrm{Mg} / \mathrm{Zn}$ eutectic. For IM layer, the base value refers to measurement obtained from IMC layer away from the weld region (outside the hook area). The IM layer found in between the hook region is significantly harder ( 3 times) and ductile ( 2 times) than the IM layer away from the hook region. While both the IM layer (inside and outside of the hook) are composed of $\mathrm{Zn} / \mathrm{Mg}$ eutectic layer, this indicates that the phases present in two cases are different. Greater ductility of the IM layer at the bonded interface can provide favorable joint performance. This dataset is provided to the $\mathrm{IbD}$ team for input into the model which allowed for better predictive capability towards specific joint characteristics including IM thickness layer, hook geometry etc.

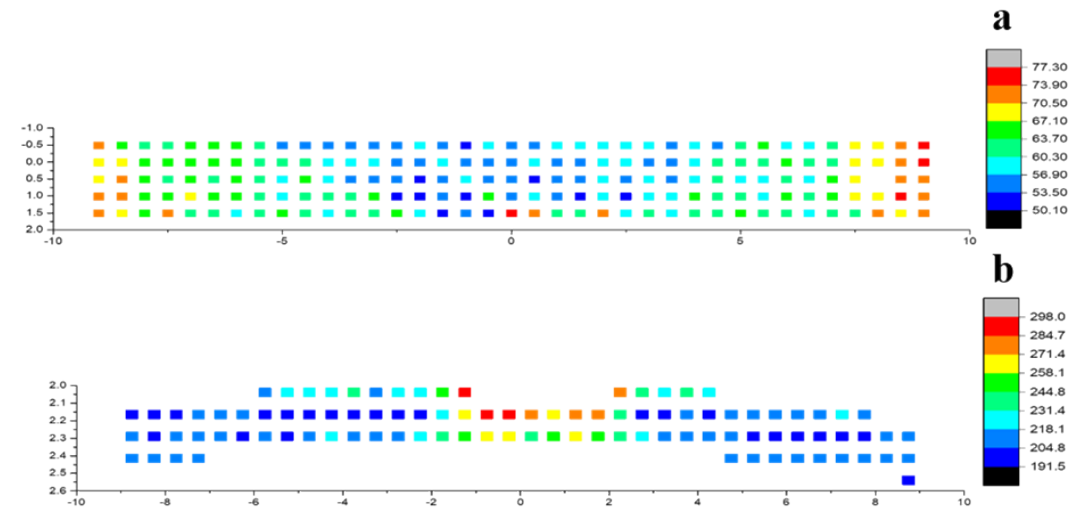

Figure 86. Vickers hardness distribution map of top Mg sheet (a), hardness distribution map of bottom steel (b) (Source: PNNL)

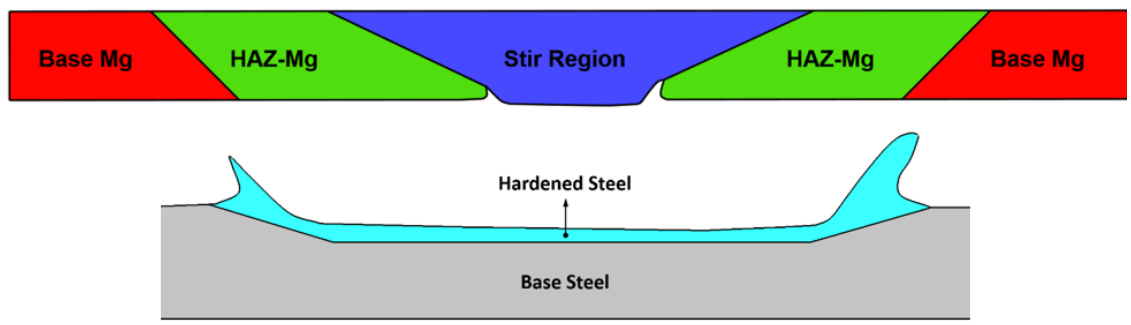

Figure 87. Discretized welded zones based on hardness measurements (Source: PNNL) 

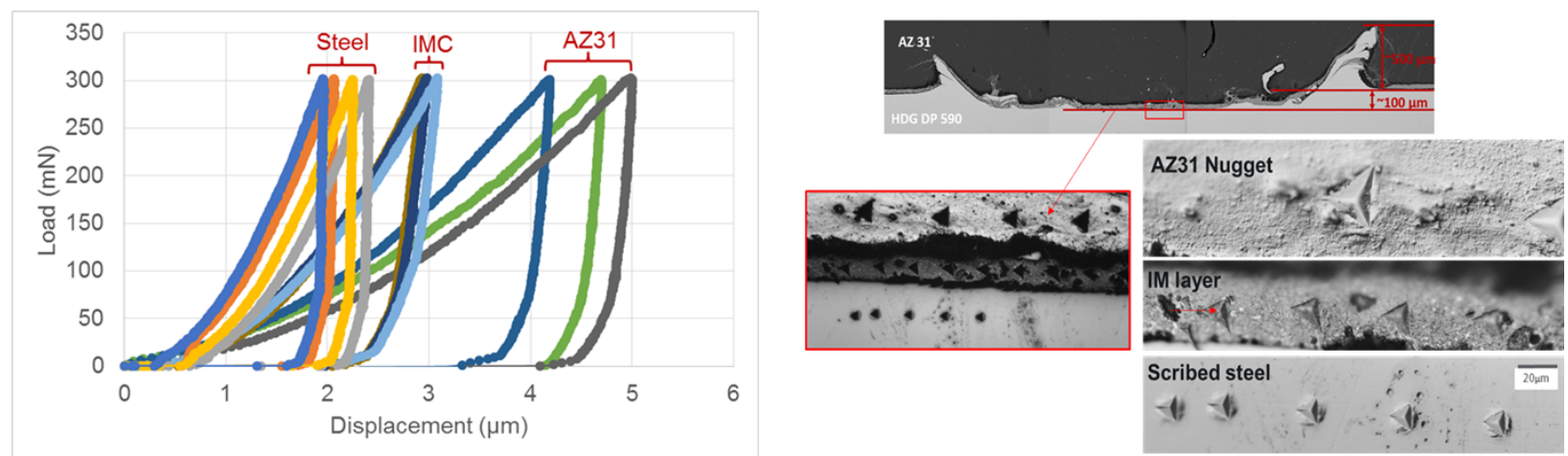

Figure 88 Representative load vs. displacement curves obtained during nano indentation weld interface (left). Snapshot of joint cross-section at various magnification shows nano indents at AZ31 weld nugget near the interface, IM layer at the interface and steel near the interface. (Source: PNNL)
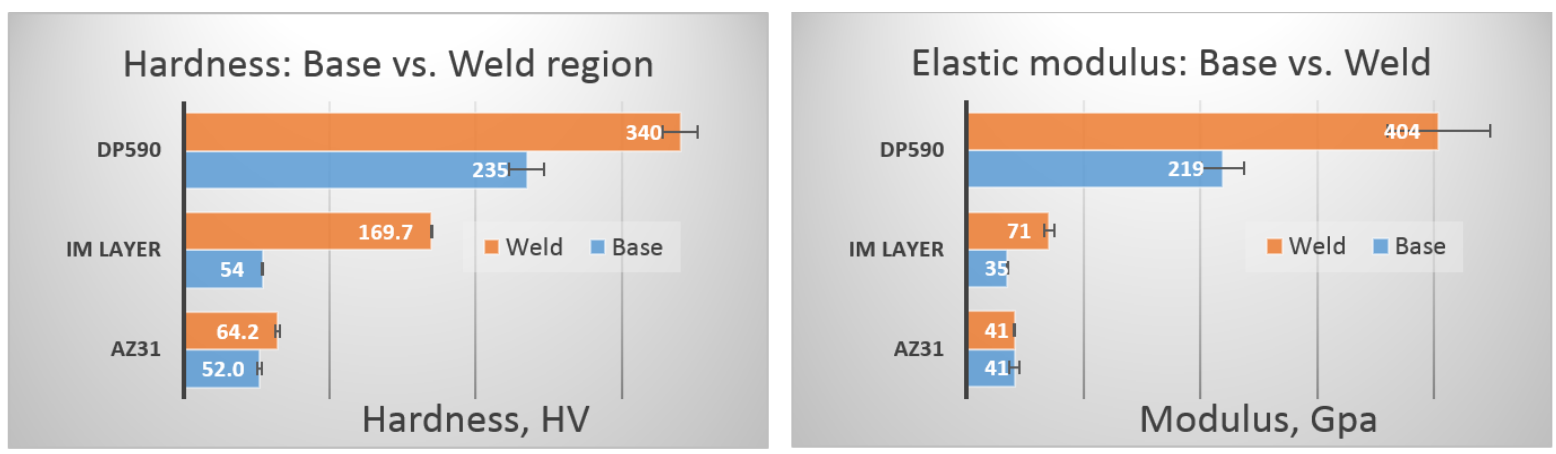

Figure 89 Comparison of hardness and elastic modulus calculated from nano indentation tests near the weld interface and base material. For IMC, the base represents IMC layer found outside of hooks. (Source: PNNL) 


\subsection{Mechanical Testing}

2.3.1 Lap shear testing for AZ31 - coated and uncoated DP 590 steel joint, Pure Mg - DP 590 steel joint and Pure Mg - Pure Fe joints by FaST

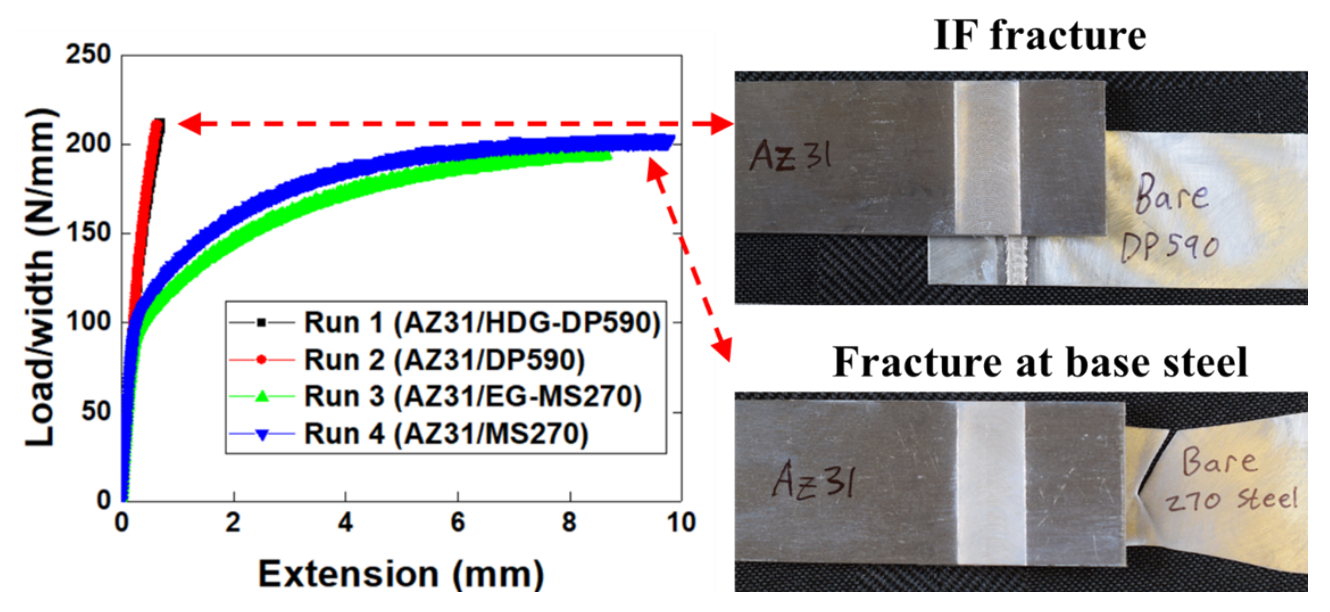

Figure 90 Lap shear tensile test results of welded AZ31/HDG-DP590, AZ31/bare DP590, AZ31/EG-MS270 and AZ31/bare MS270. Pictures of fractured AZ31/bare DP590 and AZ31/bare MS270 are also shown to display the difference in fracture mode: AZ31/HDG-DP590 and AZ31/EG-MS270 fractured at the base steel (Source: PNNL)

Lap shear tensile test results are shown in

Figure 90. For AZ31/bare DP590 and AZ31/HDG-DP590, joint strength reached $210 \mathrm{~N} / \mathrm{mm}$ and fracure occurred through the weld interface by crossing hooks. For AZ31/bare MS270 and AZ31/EG-MS270 shown in

Figure 90, the joint strength of the weled interface reached $200 \mathrm{~N} / \mathrm{mm}$ with a fracture occuring at the base steel. Difference in mechanical respsonse of different combinations came from the varying strengths in the base steels. Base MS270 has a lower yield strength and a tensile strength as compared to DP590. Due to that, during testing MS270 started yielding before crack crossed the hooks, and the final fracture locations were in base MS270 steel rather than the welded interface. 
PNNL-30945

ORNL/SPR-2021/1836

ANL-21/07

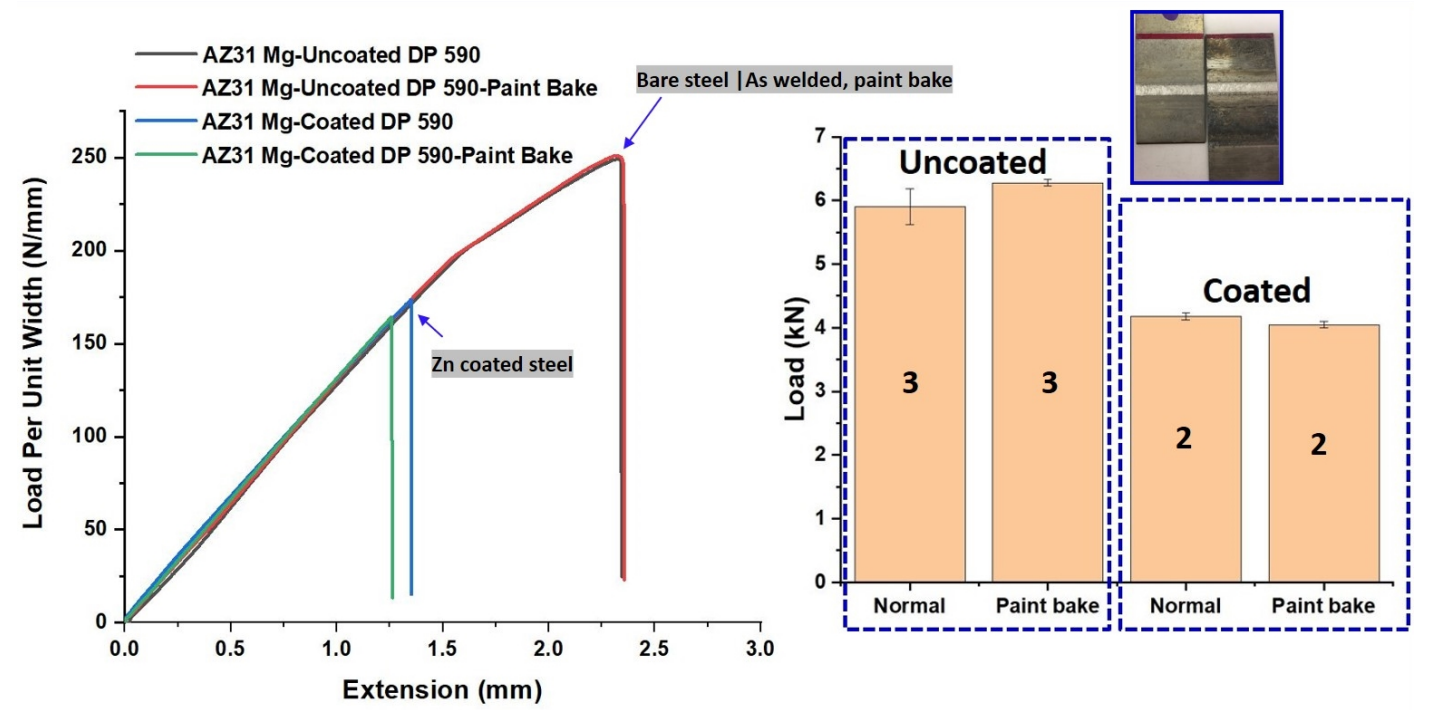

Figure 91 Paint Bake effect lap shear test for AZ341-Coated DP 590 and AZ31-uncoated DP 590 (Source: PNNL)

To understand the effect of scribe length $(0.3 \mathrm{~mm})$ and paint bake, another set of welds were made with AZ31-Zn Coated DP 590 and AZ31-Uncoated DP 590 steel. It is interesting to note that with reduced scribe length (compared to

Figure 90) load bearing capacity for AZ31-Coated DP 590 reduced while that for AZ31-uncoated DP increased. All the samples were fractured interfacially.

To understand the paint bake effect, lap shear samples were heat treated in a convention furnace at $180^{\circ} \mathrm{C}$ for 20 mins. Figure 91 shows that no meaningful change occurred post paint bake in most of joint cases. However, in case of AZ31-coated DP 590 steel, the lap shear strength was reduced slightly. All the samples fractured interfacially. Softening of the Mg-Zn eutectic at the interface during paint bake may be behind the reduced in lap shear strength for AZ31-coated DP 590 steel.

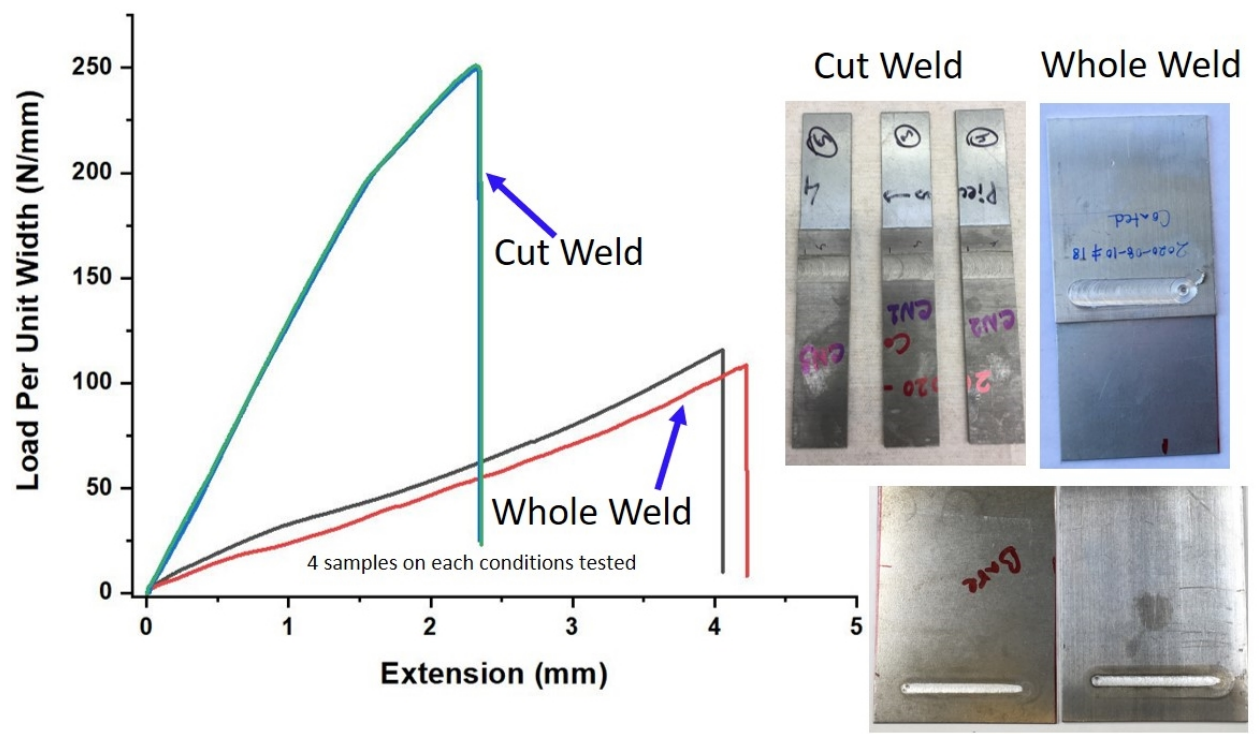

Figure 92 Lap shear Stitch Vs. Cut welds (Source: PNNL) 


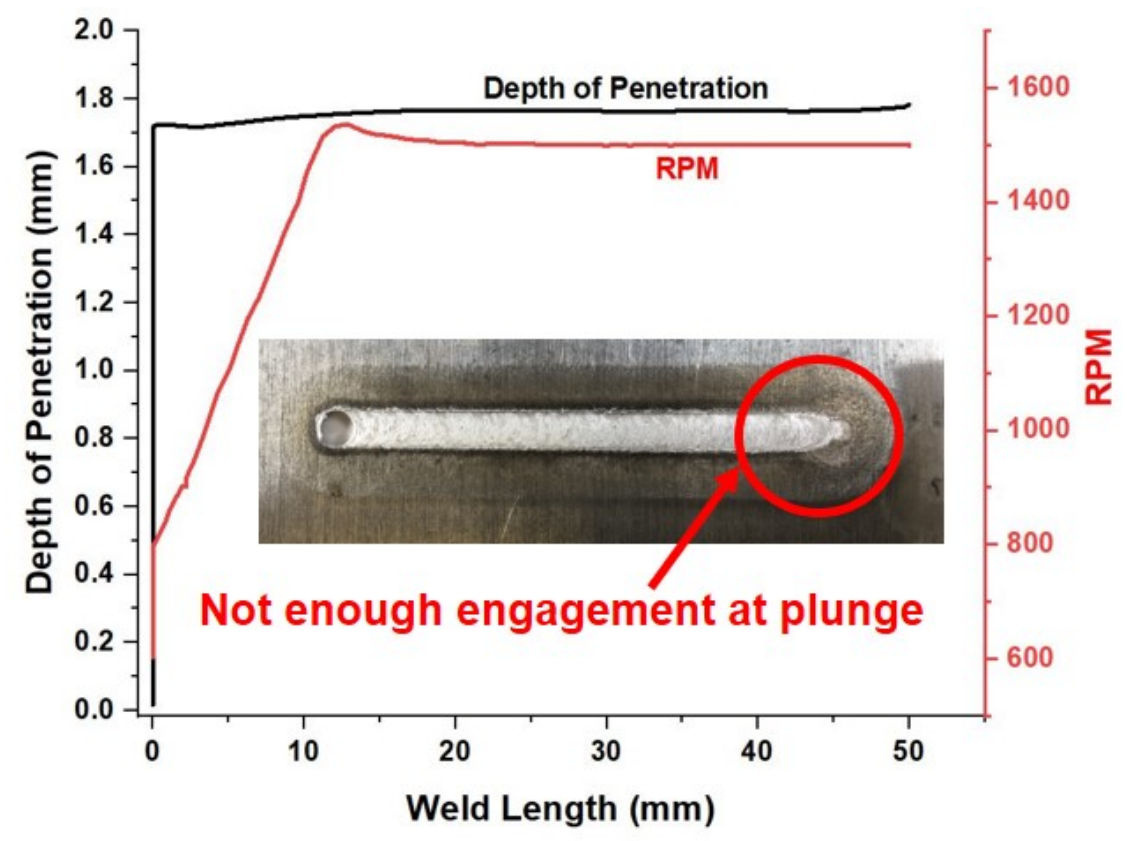

Figure 93 Process parameters and response during plunging for stitch welds (Source: PNNL)

Some weld runs were made such that whole weld including the weld start and weld exit can be tested to simulate a stitch weld case. Upon lap shear tests Stitch weld (whole weld) showed lower strength compared to cut welds (Figure 92). Generally, we ramp up the rpm to full speed during the start of the traversing for 20-25 mm's (Figure 93). Thus, rhea depth of scribe penetration may not be sufficient during the ramp up region to provide engagement that is observed in steady state welding case (Figure 93). Whereas, cut weld samples are made from long welds except that starting locations. Simple plunge-in parameter development can be used to increase the stitch joint strength.

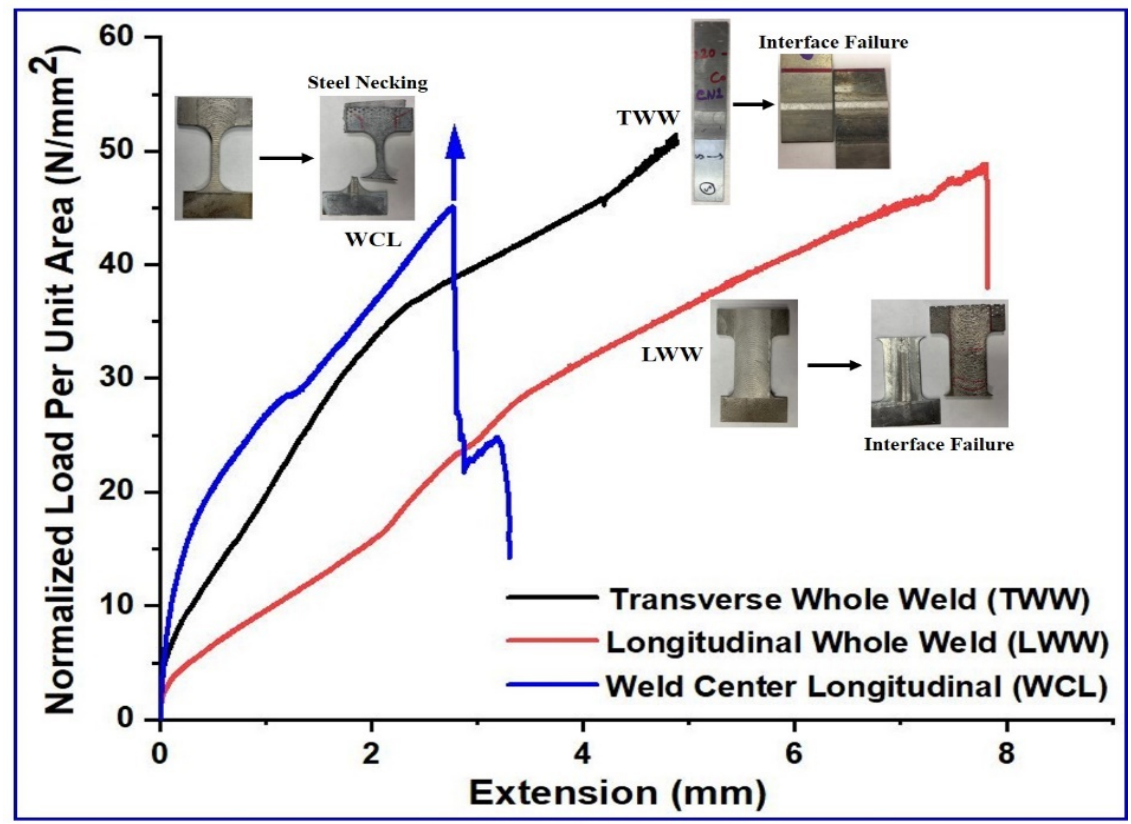

Figure 94 Lap shear strength comparison for longitudinal and transverse samples (Source: PNNL) 


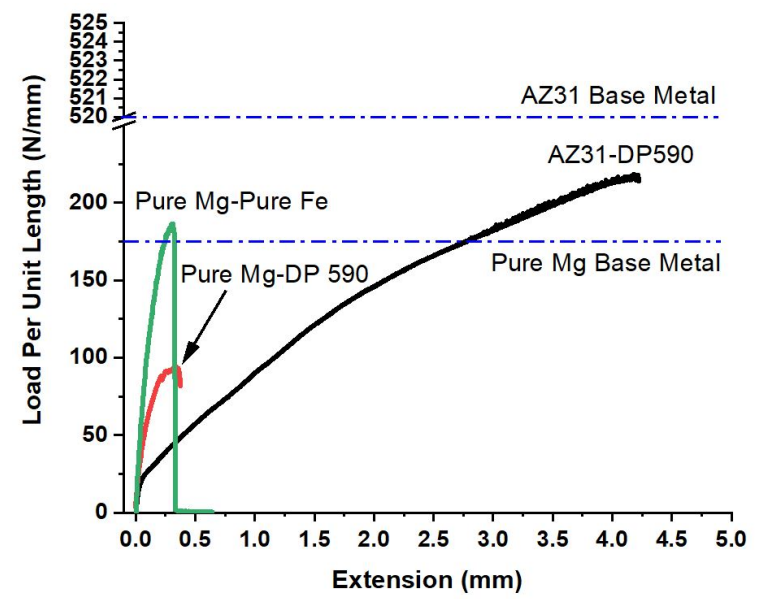

Figure 95 Comparison of lap shear strength for AZ31-uncoated DP 590 steel, Pure Mg-uncoated DP 590 steel and pure Mg-Pure Fe (Source: PNNL)

To understand the joint strength in the longitudinal direction different types of longitudinal shear tensile sample prepared as shown in Figure 94. Lap shear tensile test results for transverse whole ), and weld center longitudinal (WCL) samples are shown in Figure 94. It is intriguing to note that WCL (46 MPa) shows comparable normalized strength with LWW (47 MPa) and TWW (50 MPa), although the sample failed through the necking steel side. Both LWW and TWW failed through the weld

Lap shear strength for different joints are shown in Figure 95. All the joints fractured at the interface; thus, the weld strength is a direct measure of the weld's load bearing capacity expressed in terms of force per unit joint area. The data in Figure 95 indicates that the pure $\mathrm{Mg}$ joints are well bonded. The AZ31-DP 590 joint shows higher strength (50\% of that of AZ31 base metal), pure Mg-DP 590 and Pure Mg-Pure Fe joint also shows reasonable joint strength despite the poor strength of pure Mg base metal.

\subsubsection{Effect of swept radius on Lap Shear Strength for Az31-Coated DP 590 steel FaST joints}
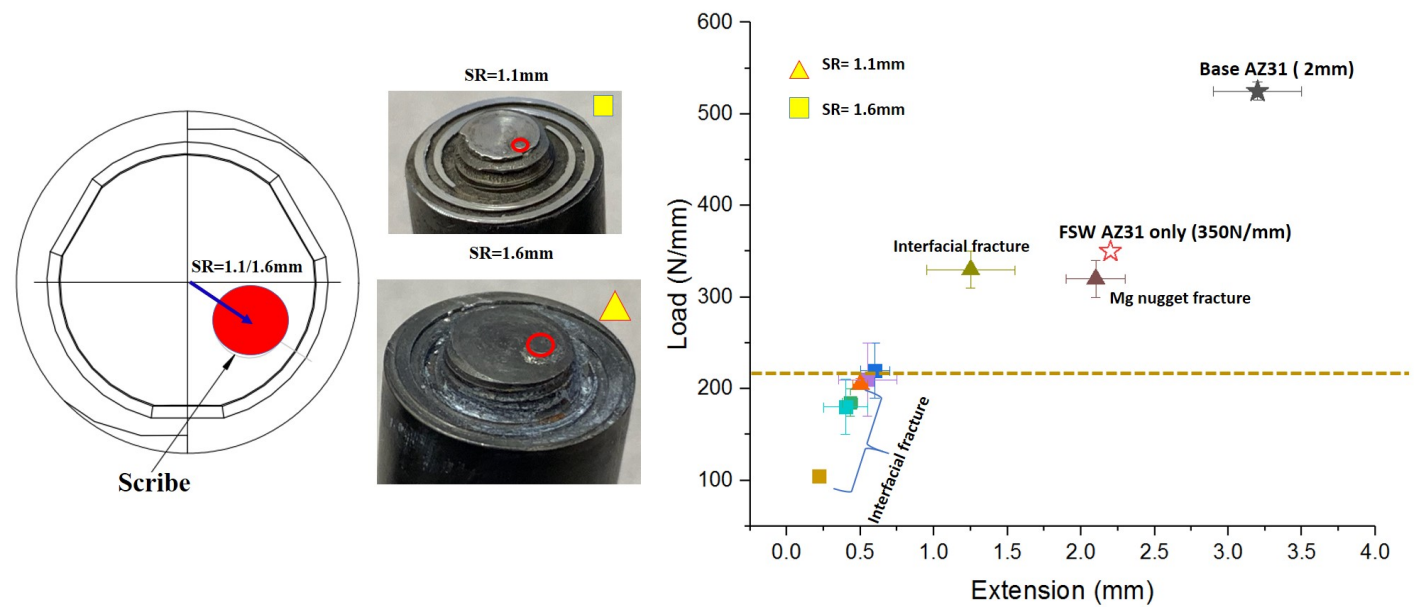

Figure 96 Different swept radius of scribe and effect on joint strength (Source: PNNL) 


\subsubsection{T Peel, Cross tension, and U Peel for FaST joints}
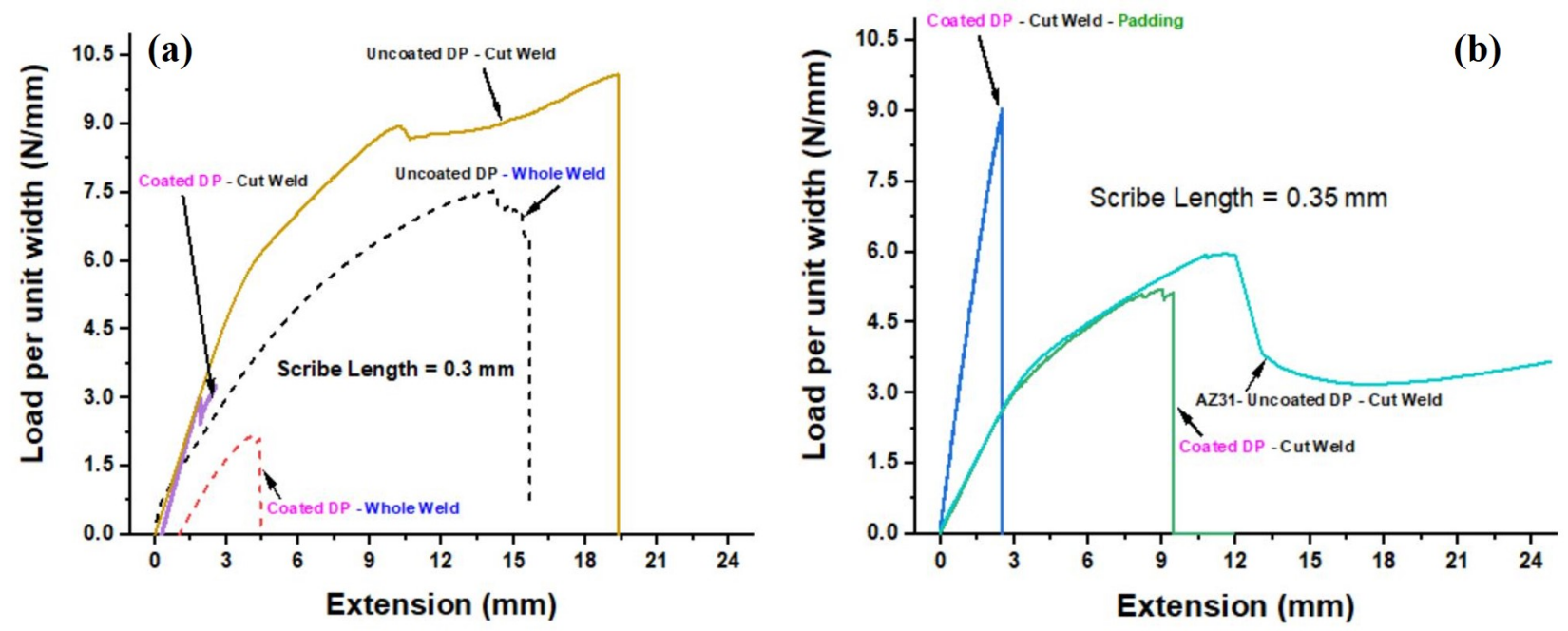

Figure $97 \mathrm{~T}$ peel strength for scribe length of (a) $0.3 \mathrm{~mm}$ and (b) $0.35 \mathrm{~mm}$ AZ31-coated DP 590 steel and AZ31-uncoated DP 590 steel (Source: PNNL)

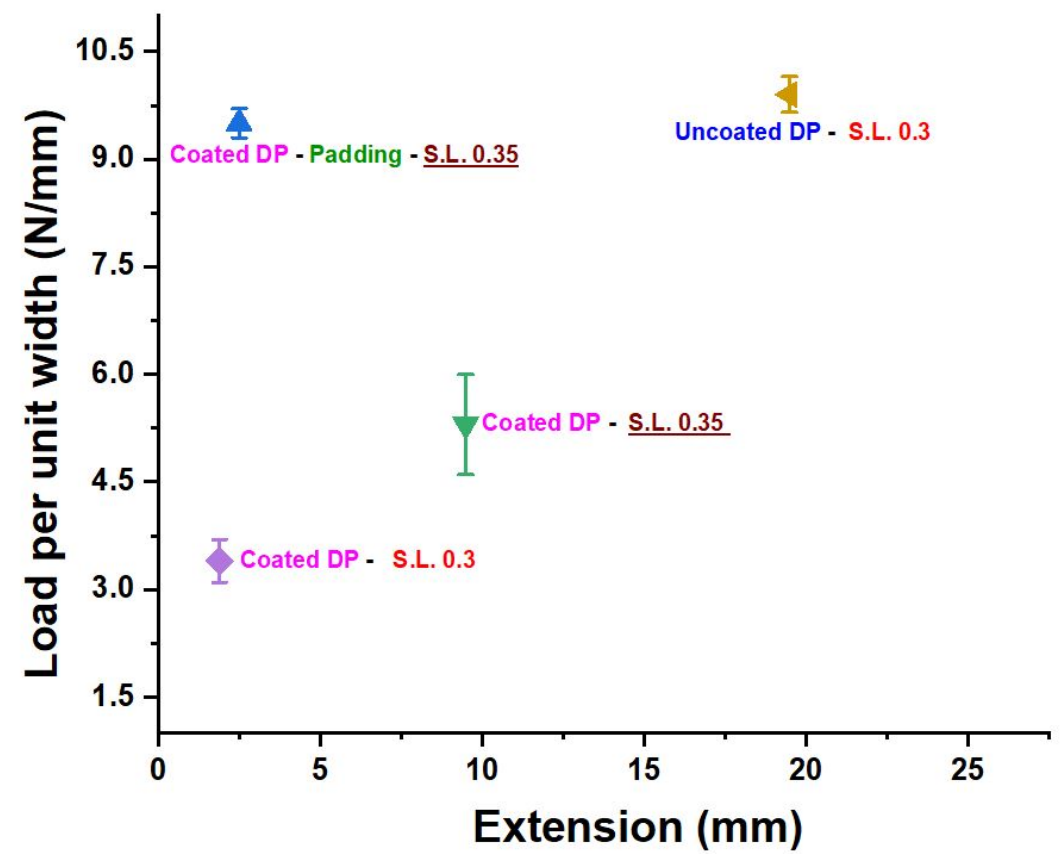

Figure $98 \mathrm{~T}$ peel results and summary for different conditions and different scribe length welds of AZ31-coated DP 590 steel and AZ31-uncoated DP 590 steel (Source: PNNL)

Presence of $\mathrm{Zn}$ at the interface (from the $\mathrm{Zn}$ coating in the steel) resulted in a marked reduction in load bearing capacity of $T$ peel and cross-tension loading. With scribe length of $0.3 \mathrm{~mm}$, removal of $\mathrm{Zn}$ coating from steel resulted in a 3.5-fold increase in T peel load bearing capacity (Figure 1left), while a 2-fold increase in cross tension loading (Figure 97 (a)). Four T peel samples were tested for each case while 8 samples were tested for cross tension testing. This effect of $\mathrm{Zn}$ coating on loading appears to interact with scribe length used. For instance, when the engagement was deeper, $(S L=0.35 \mathrm{~mm}$ ) removal of $Z n$ resulted in only $\sim 20 \%$ increase in T peel 
loading prior to fracture (Figure 97 (b)). In this case the fracture occurred via Mg sheet rather than interfacial. Thus, the overall load bearing capacity in $T$ peel also decreased with increased engagement. This is an important discovery, as this behavior is not readily observed in lap shear testing. The scribe engagement and thus hook height needs to be significantly greater before a $\mathrm{Mg}$ sheet fracture is observed. This suggests that in order to maximize T peel performance the scribe engagement should be kept lower (with $\mathrm{SL}=0.30 \mathrm{~mm}$ in this case). An overall picture of load bearing capacity in T peel loading obtained over the course of this project is summarized in (Figure 98) which provides various cases including different scribe lengths, with and without $\mathrm{Zn}$ coatings. A wide range of ductility and load bearing capacity has been observed. This data set along with existing lap shear data set can serve as a baseline for designing $\mathrm{Mg} / \mathrm{steel}$ joints for a prototype part.

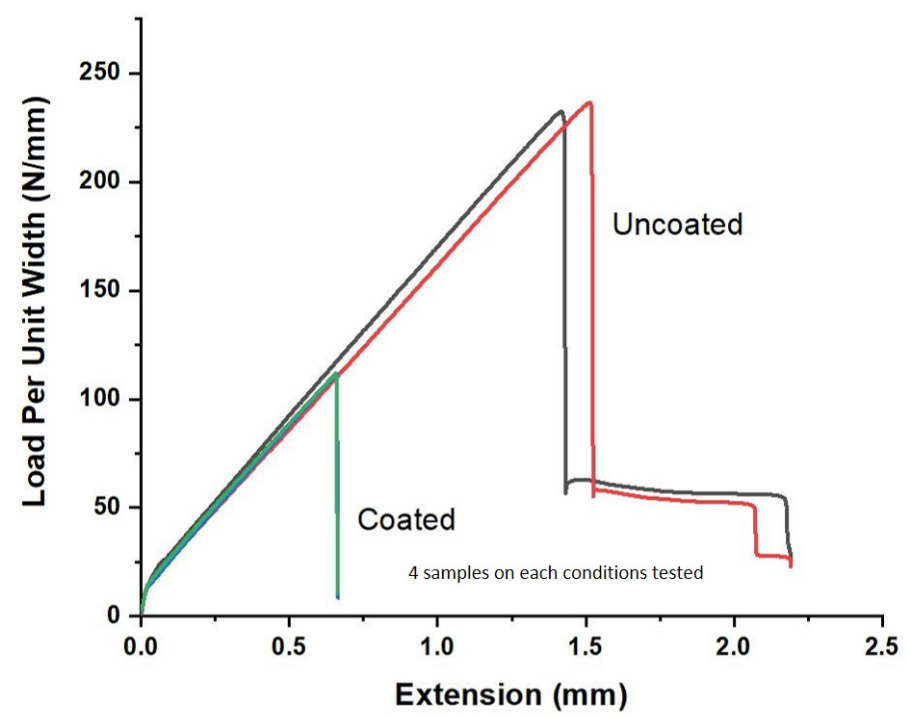

Figure 99 Cross tension result for AZ31-coated DP 590 steel and AZ31-uncoated DP 590 steel joints (Source: PNNL)

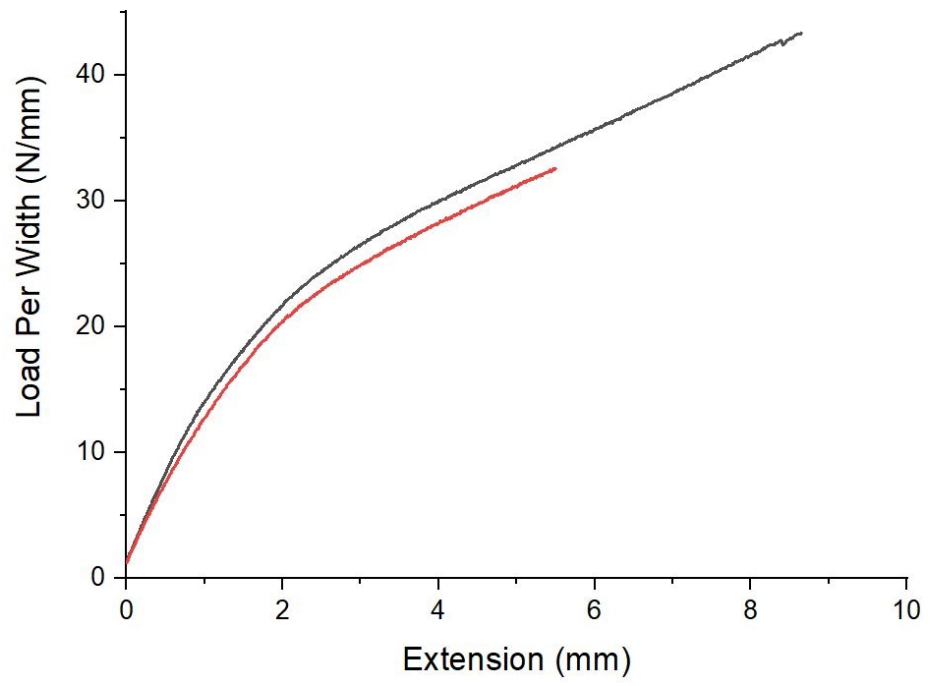

Figure 100 U Peel results for AZ31-Coated DP 590 steel (Source: PNNL) Cross-tension result shows that AZ31-Uncoated DP 590 has higher load bearing capacity than AZ31-Coated DP 590 steel (Figure 99). Figure 100 shows the U-Peel performance for AZ31Coated DP 590 steel joints. 


\section{- Lap shear and U-peel for USW samples}

Lap shear, fatigue, and U-peel tests were performed to evaluate the mechanical performance of the USW joints made with AZ31B and DP590 (both Zn coated and non-coated, welded with $3500 \mathrm{~W}$ for $4 \mathrm{~s}$ using the single-head machine). Figure 101 shows the lap shear and $\mathrm{U}$ peel test results. With $\mathrm{Zn}$ coating on the steel side, the lap shear strength reached around $7 \sim 8 \mathrm{kN}$. The result of U-peel strength scattered between $0.35 \mathrm{kN}$ and $0.65 \mathrm{kN}$. Without $\mathrm{Zn}$ coating, the lap shear strength was about $5 \mathrm{kN}$ and the U-peel strength was between $0.27 \mathrm{kN}$ and $0.5 \mathrm{kN}$, roughly $60 \sim 70 \%$ of the lap shear and the U-peel strengths compared with the USW joints made with Zn coating. Overall, the U-peel results had more scatter in comparison to lap shear tests. This is due to the pre-bent steel and $\mathrm{Mg}$ sheets undergoing relative displacement and rotation during ultrasonic vibration, resulting in slight misalignment of the U-peel joint coupons. The U-peel test was more sensitive to such misalignment. The fracture of all lap shear and $U$ peel joint coupons occurred at the joint interface.
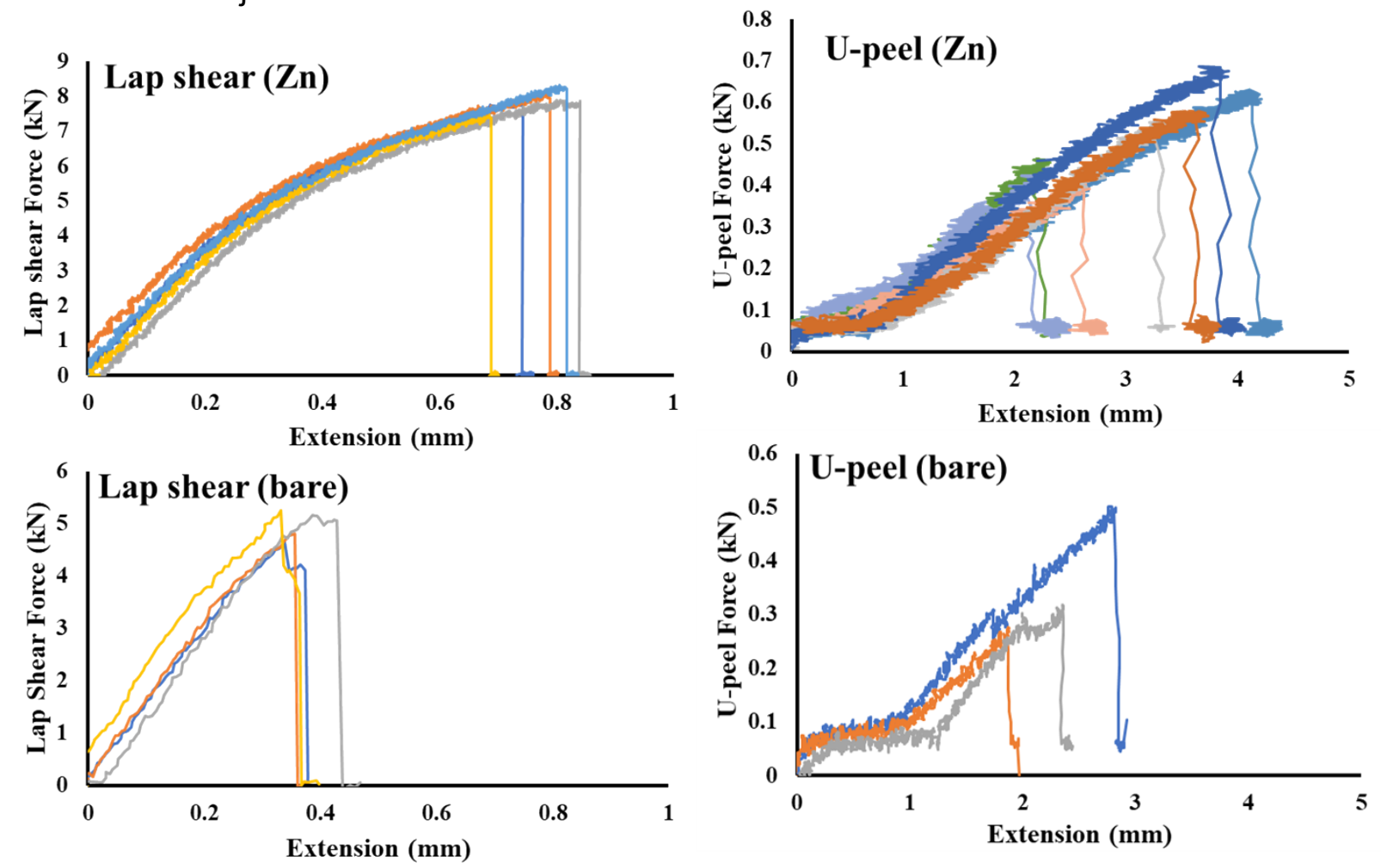

Figure 101. Lap shear and U-peel test results of USW joints made with AZ31B and DP590 (Zn coated versus non-coated, both welded with $3500 \mathrm{~W}$ for $4 \mathrm{~s}$ using the single-head machine) (Source: ORNL)

Figure 102 summarizes the lap shear strength of USW joints made of various Mg-Fe systems (e.g., 2-mm and 1-mm-thick, respectively) as well as other dissimilar metal pairs. All joints were produced with an identical USW process condition (i.e., 3500W for 4s using the single-head machine). For Mg-Fe systems, the USW joints with Zn coating on the DP590 steel sides had the highest average strength at around $8 \mathrm{kN}$ due to the formation of $\mathrm{Mg}-\mathrm{Zn}$ intermetallic compounds. Without Zn, the average lap shear strength of USW joints made of bare steel and different Mg alloys (i.e., AZ31B, AZ61, and AZ80) ranged from $3.5 \mathrm{kN}$ to $5 \mathrm{kN}$. The alloying elements (i.e., $\mathrm{Al}$ and $\mathrm{Zn}$ ) from the $\mathrm{Mg}$ alloy side, as well as the oxide layer at the interface, played a key role. For the USW joints made with bare steel and Pure Mg, the lap shear strength was only $1.8 \mathrm{kN}$ on the average. This lower strength was a result of an oxide layer that was observed at the interface. In 
addition, the same USW process condition was feasible to join other dissimilar metal pairs including DP980-AZ31B, DP590-Al5754, and AZ31B-AI5754.

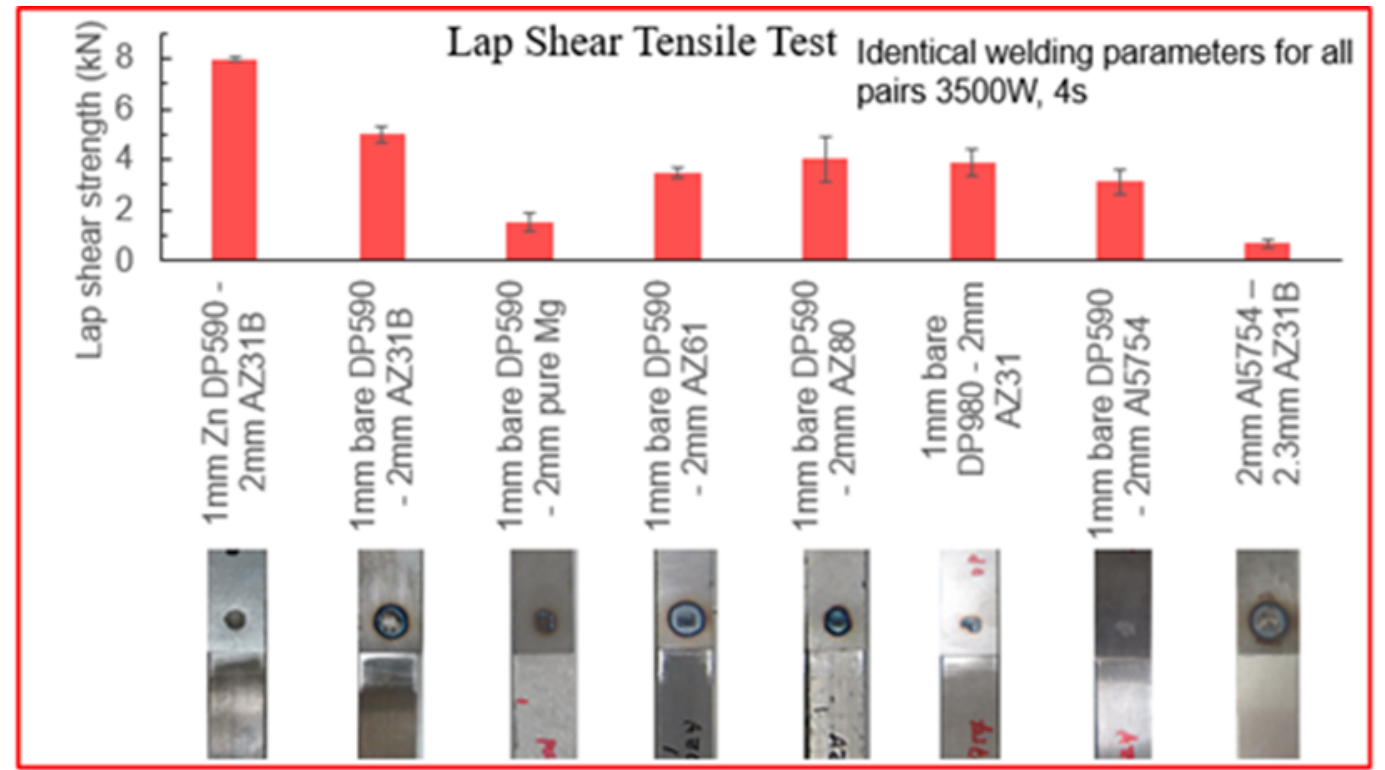

Figure 102. Lap shear and U-peel test results of USW joints made with AZ31B and DP590 (Zn coated versus uncoated) (Source: ORNL)

\subsubsection{Fatigue Testing for USW joints}

Fatigue testing was performed on DP590-AZ31B USW joints with and without the Zn coating. Figure 103 (a) shows the relationship between maximum lap shear tensile load and the number of cycles to failure during fatigue testing. The ratio of the minimum load and the maximum load or $\mathrm{R}$ ratio was 0.1 and the test frequency was $20 \mathrm{~Hz}$ in all the tests. Three maximum load conditions were performed corresponding to $20 \%, 40 \%$ and $60 \%$ of the average peak load obtained in the static lap shear tension tests for both USW coupon sets (with Zn coating versus without Zn coating). Overall, the fatigue life increased with decreasing maximum tensile load. Two fatigue failure modes occurred: interfacial fracture at the joint faying interface and parent AZ31B Mg fracture as shown in Figure 103 (b). The fatigue failure modes depended on the magnitude of applied load. With high maximum tensile loads, fracture occurred at the faying interface, similar to the fracture mode observed in lap shear tests. With low maximum tensile loads, fracture occurred in the parent $\mathrm{Mg}$ sheets.

To study the fracture propagation in the AZ31B Mg sheet during the fatigue testing with low maximum loads, the evolution of surface strain (along loading direction) on the Mg side was recorded using DIC technique as illustrated in Figure 104. Figure 105 shows the evolution of the strain during a fatigue testing on a Zn coated DP590-AZ31B joint using $20 \%$ of the load amplitude as shown in Figure 103 (a). The final fracture occurred in Mg sheet and the total number of cycles till failure was 164,348. As shown in Figure 105, at the initial fatigue stage (1\% of total cycles), a compressive strain (purple color) was observed in the lower part of the image, which was a result of bending under tensile load as illustrated in Figure 104. The similar strain distribution pattern didn't change much until $78 \%$ loading cycles were reached. The compressive strain zone started to concentrate to the lower edge of the joint, indicating cracks may have formed beneath the 
surface (Point B near the edge of the joint as illustrated in Figure 104). When 99\% fatigue cycles reached, the narrow band of the compressive zone propagated to both edges of the Mg sheet, suggesting a long crack has formed. The final fracture path occurred in the Mg sheet ("Mg fracture" as shown in Figure $103 \mathrm{~b}$ ).

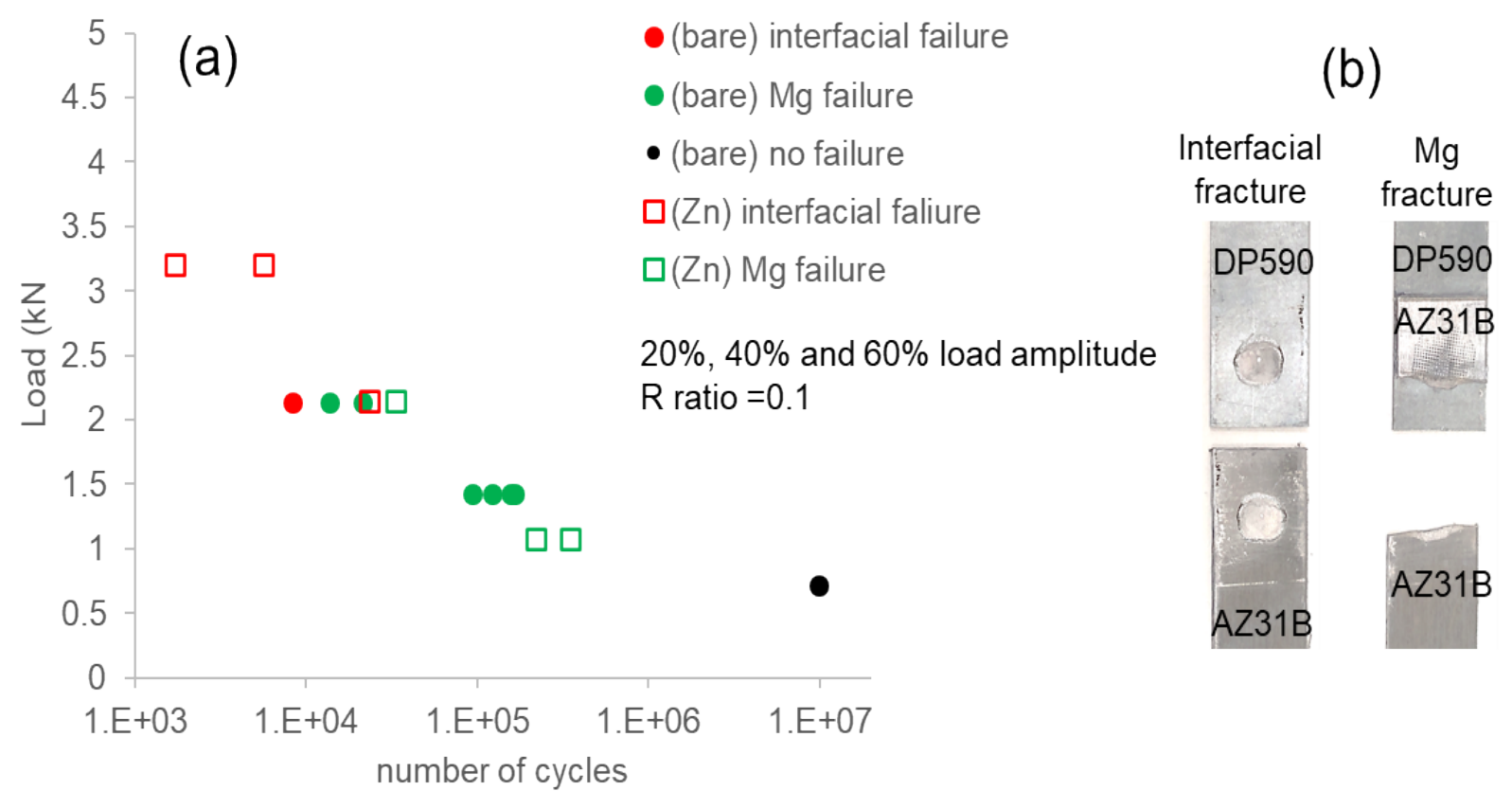

Figure 103. (a) Results of high cycle fatigue testing on Mg-Steel USW samples with fracture modes and test samples illustrating an interfacial fracture and a Mg fracture (Source: ORNL)

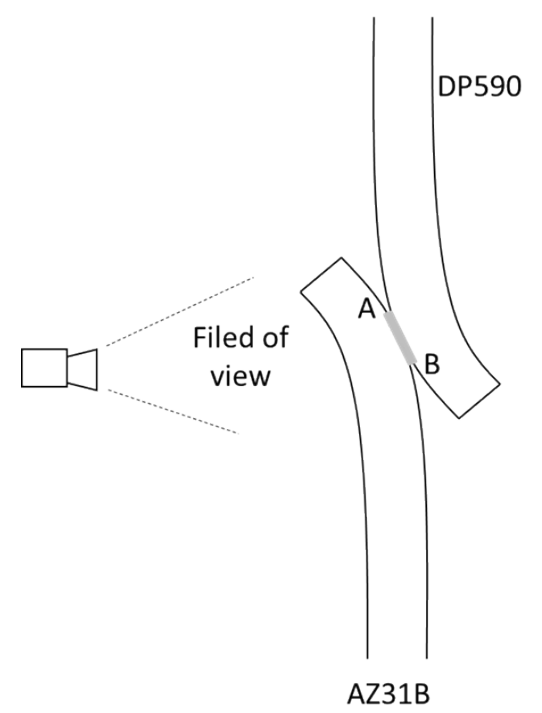

Figure 104. Schematic of DIC strain measurement during fatigue testing (Source: ORNL) 
PNNL-30945

ORNL/SPR-2021/1836
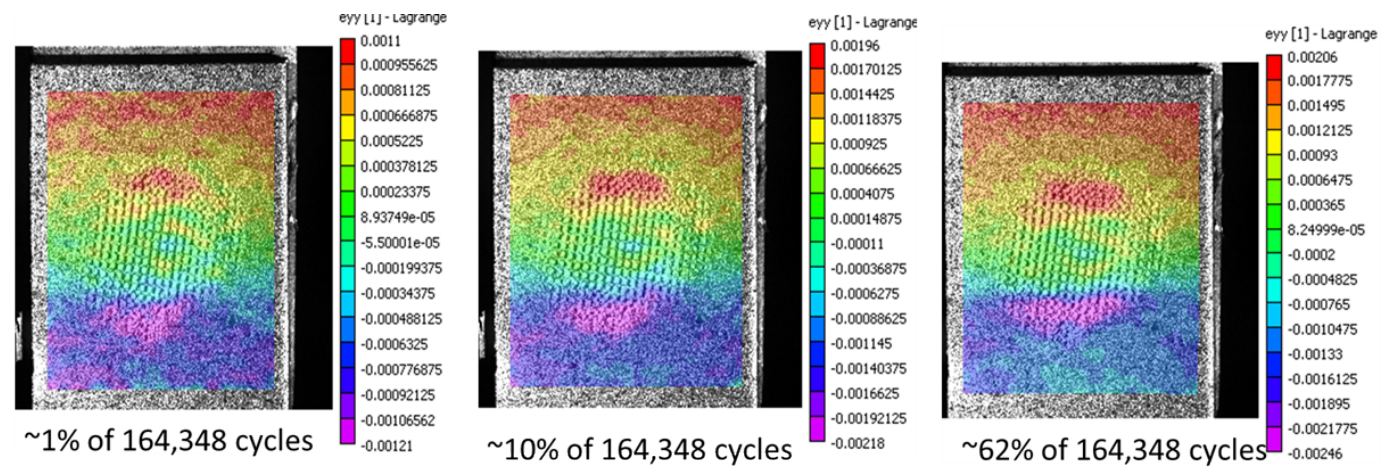

ANL-21/07
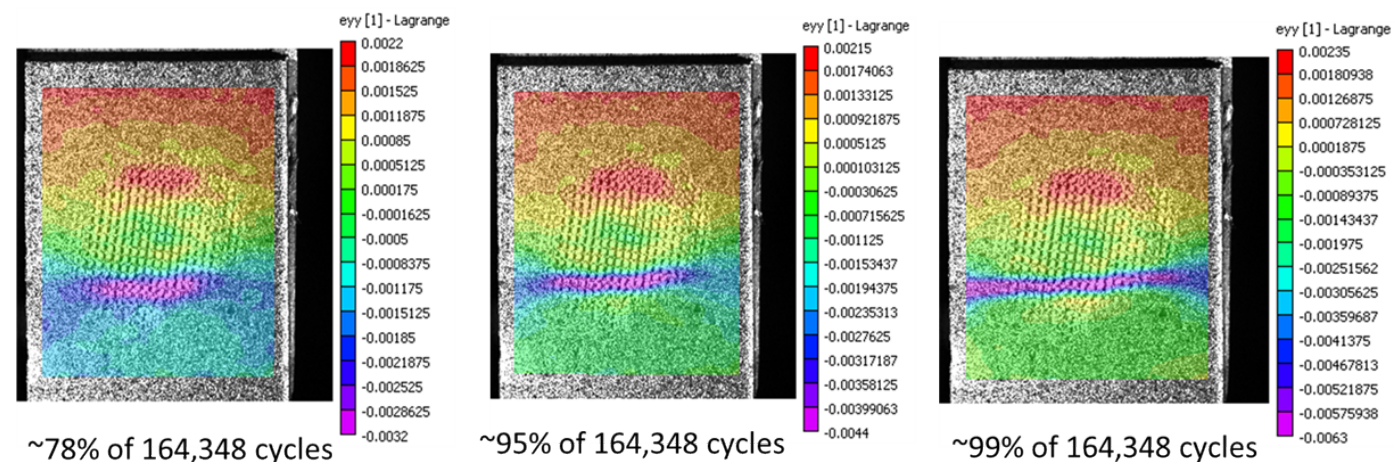

Figure 105. Strain evolution (AZ31B) side during fatigue testing (Source: ORNL)

\subsubsection{Fractography}
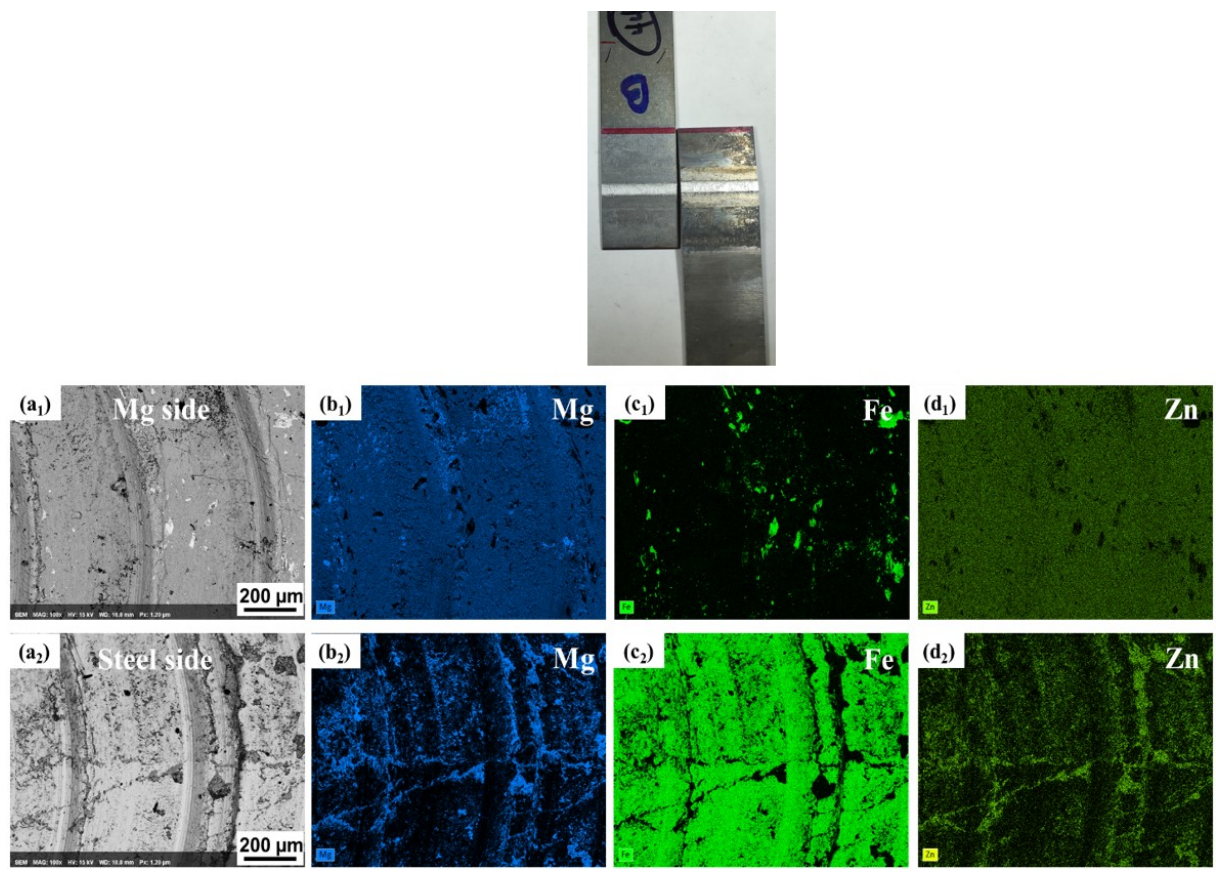

Figure 106 Fractography of broken AZ31/HDG-DP590: (a1) SEM of fractured Mg side and (b1, c1, d1) EDS analysis of Mg side shown in (a1); (b1) SEM of fractured steel side and (b2, c2, d2) EDS analysis of steel side shown in (a2) (Source: PNNL) 
Fractography with EDS maps are shown in Figure 106. Figure 106 (a1-d1) show the Mg side fracture surface that contain Mg-Zn eutectic layer at weld interface. Note that some steel particles exist at the fractography of $\mathrm{Mg}$ side. Some trace $\mathrm{Mg}-\mathrm{Zn}$ eutectic stayed on the steel side, especially within the grooves created by the scribe. Cross-section of the fractured sample is shown in Figure 107. EDS (Figure 107) mapping shows fracture occurs at the interface of the $\mathrm{Mg}-\mathrm{Zn}$ eutectic layer and steel. This observation is true for both FaST and USW samples made with $\mathrm{Zn}$ coated steels indicating that the bonding between steel and $\mathrm{Mg}-\mathrm{Zn}$ eutectic is the weakest upon mechanical testing.

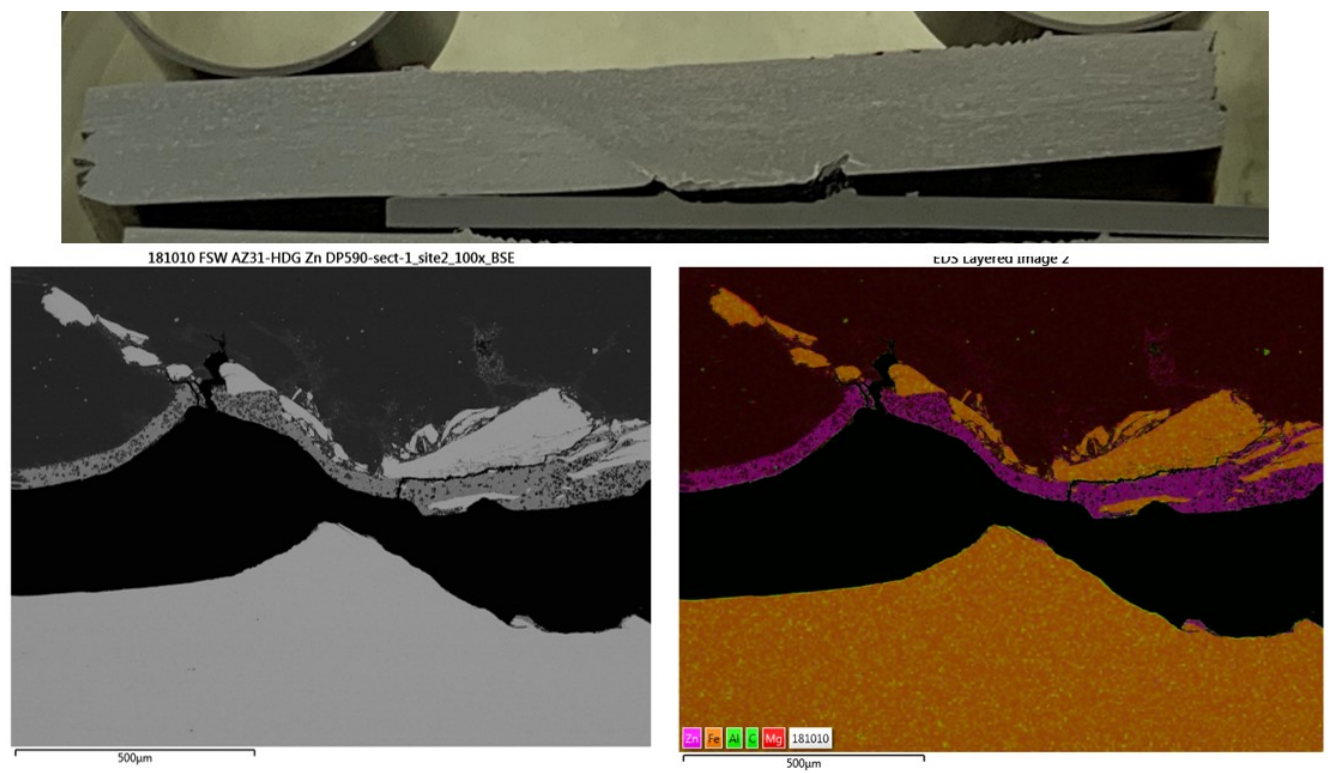

Figure 107 Fracture location with EDS analysis (Source: PNNL)

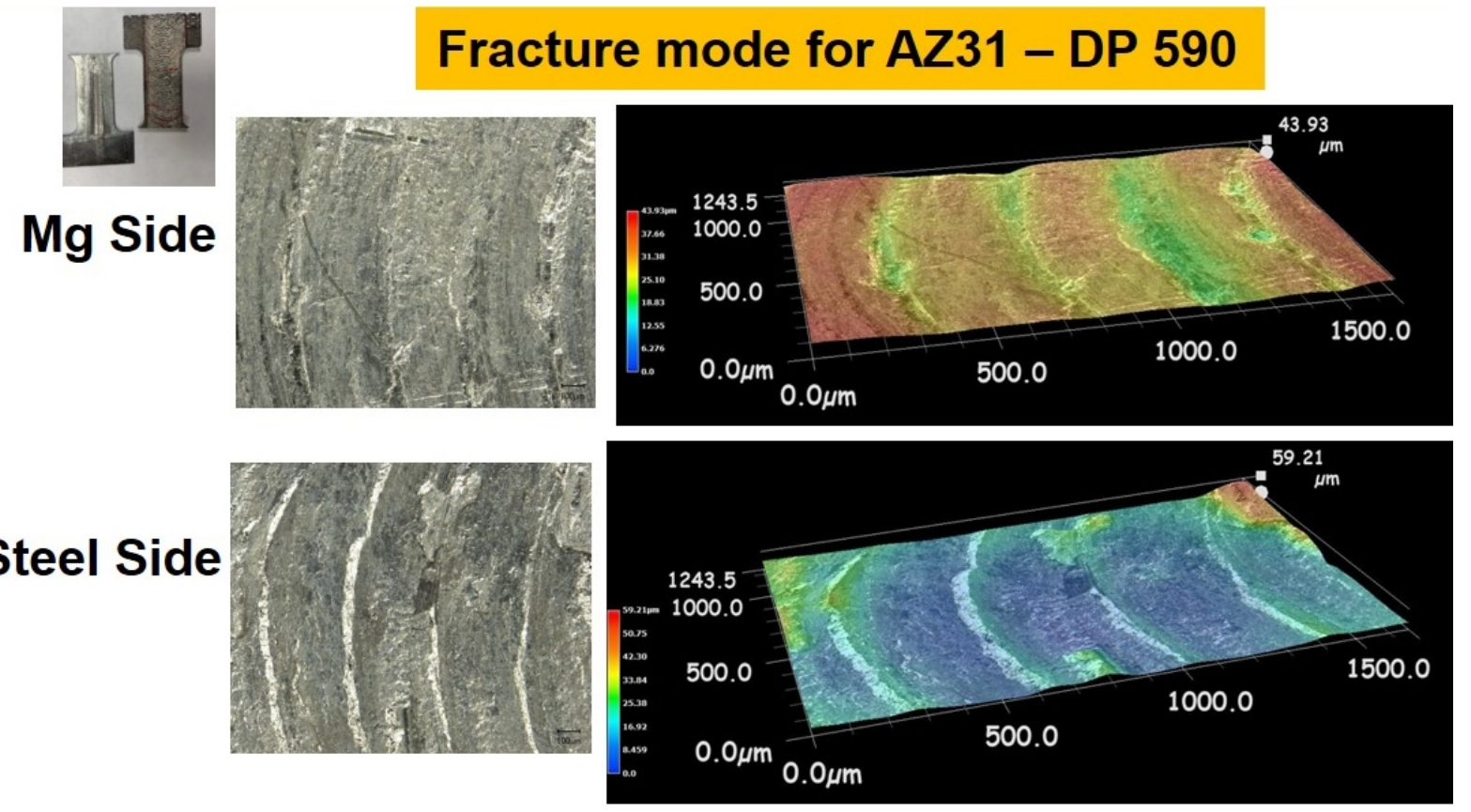

Figure 108 Fractographs of longitudinal lap shear samples for AZ31-Uncoated DP 590 (Source: PNNL) 
Figure 108 shows the Keyence scope imaging with surface roughness measurements of the fracture surface of welds testing in longitudinal direction. The wavy pattern associated with scribe engagement on the steel is apparent. Interfacial fracture observed during T Peel testing as shown in Figure 109.

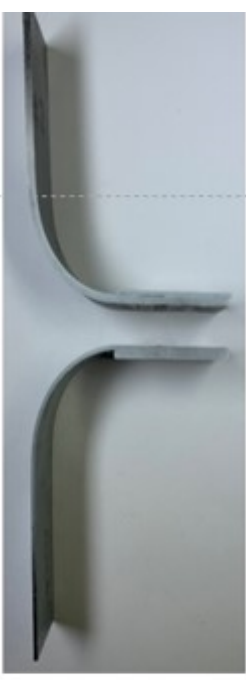

Partial padding
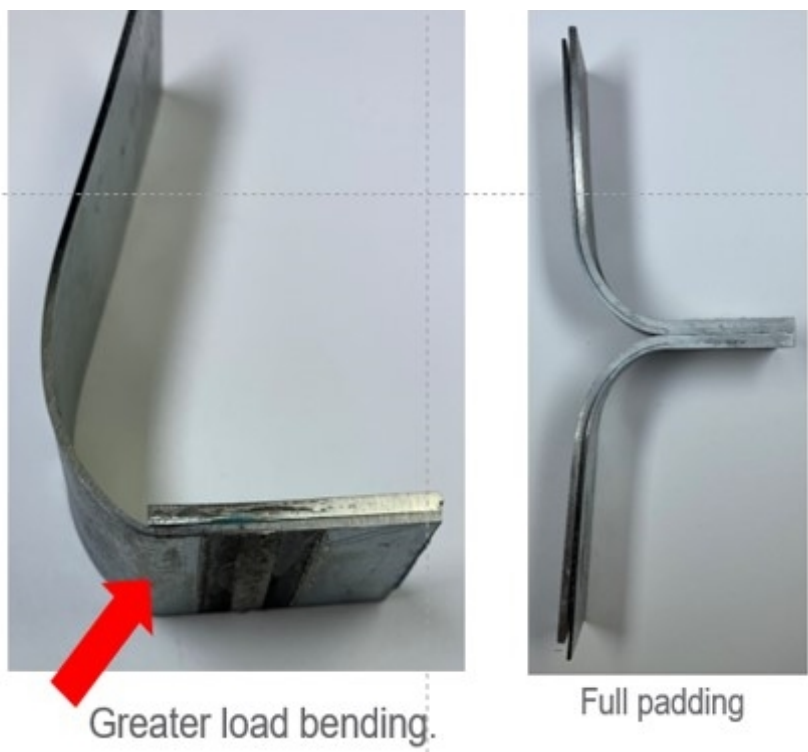

Full padding

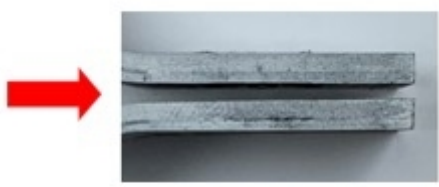

Interfacial fracture

Figure 109 Interfacial Fracture after T Peel test (Source: PNNL)

\subsection{Analysis and Discussions}

\subsubsection{Abnormal Zn flow during FaST process}

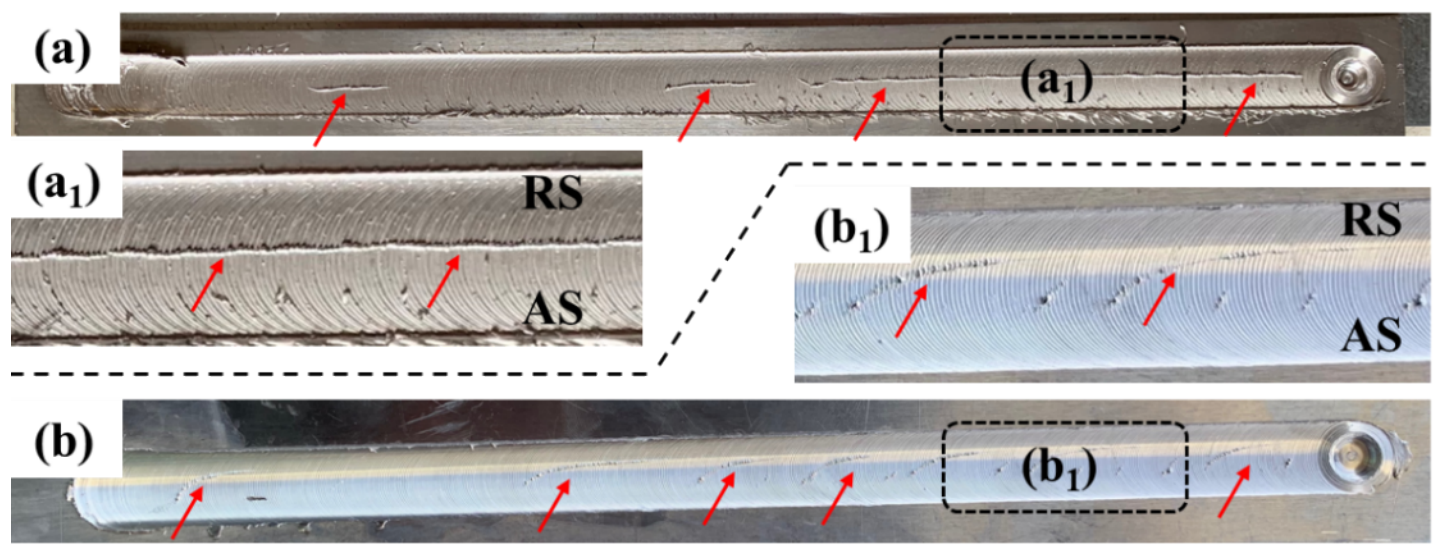

Figure 110 Surface pictures of different welds. Zinc diffusing upward to top magnesium surface are labelled by red arrows. (Source: PNNL)

In some select welding trials specifically made with concave shoulder, a peculiar observation was made. The weld crown surface contained a streak of metallic bubble (Figure 110). In many cases the streaks were discontinuous, appearing and disappearing. Upon further investigation and characterization of the joint interface, it was found that the bubble consisted of $\mathrm{Mg}$ and $\mathrm{Zn}$ eutectic that was transported from the interface to the weld crown through the Mg sheet thickness. Figure 111 (a) and (b) shows weld cross sections containing two representative types of the unusual Mg- 
$\mathrm{Zn}$ transport. For both the cases, a trail of Mg-Zn eutectic connects the Mg-steel interface to the Mg weld crown.
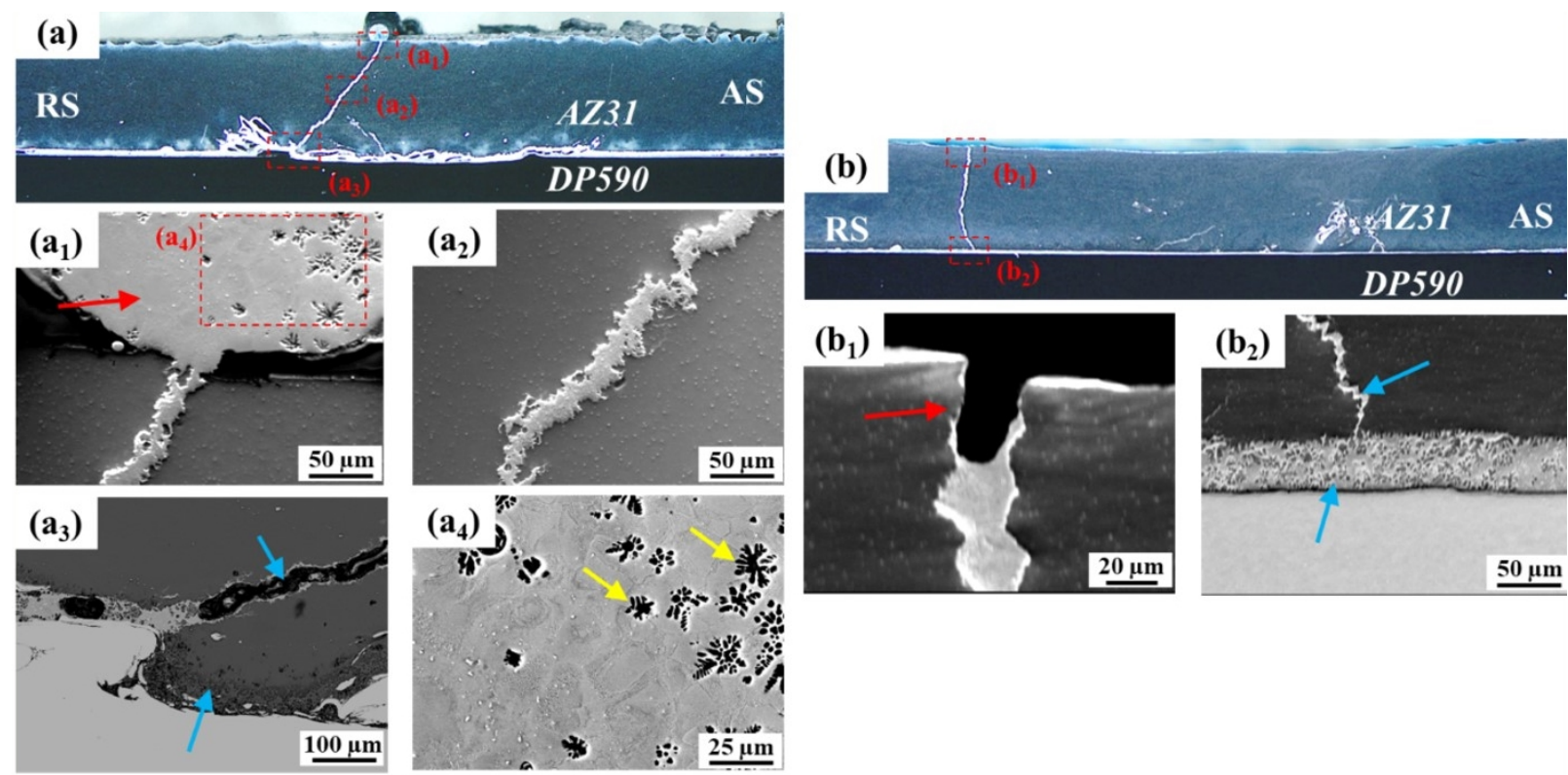

AZ31

AS
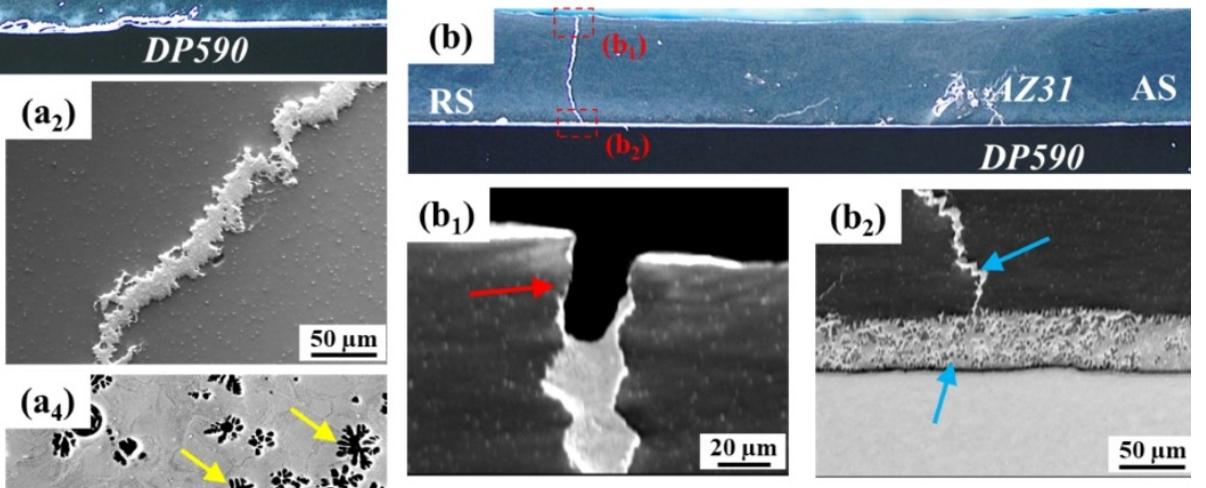

Figure $111 \mathrm{OM}$ and SEM of cross-sections (Source: PNNL)

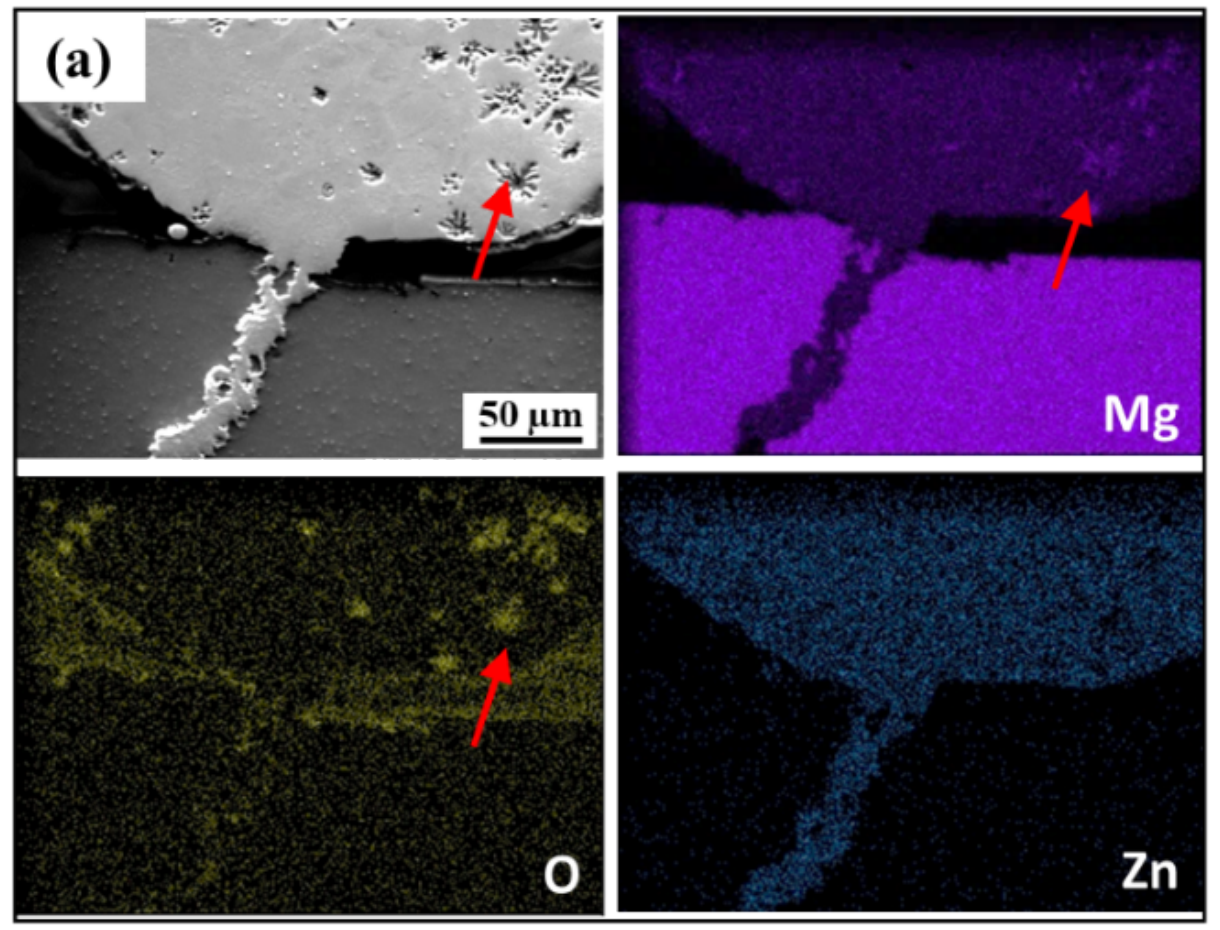

Figure 112 EDS mapping for Zn flow (Source: PNNL)

For weld \#1 the trail appears to begin at retreating side hook and ends up in the form of bubble 300 um in diameter. A closer inspection of the interface region indicate voids around the interface, suggesting lack of $\mathrm{Mg}-\mathrm{Zn}$ eutectic in the surrounding region (Figure 112). In contrast to weld \#1, weld \#2, shows no bubble formation at the surface. Instead, the trail terminates just 
below the Mg nugget creating a notch like feature that is more susceptible to premature fracture during mechanical loading (See Figure 112). Nevertheless, the characteristic Mg/Zn eutectic streak is visible across the through thickness of $\mathrm{Mg}$ sheet. Given the comparatively smaller volume of the eutectic, sufficient interfacial IMC is retained at the interface.

The $\mathrm{Mg} / \mathrm{Zn}$ eutectic layer is replete with oxide layer in dendritic form indicative of solidification microstructure as shown by red arrows in SEM and EDS mapping. Since the temperature during FaST welding can range from $470^{\circ} \mathrm{C}-520^{\circ} \mathrm{C}$, the constitutional liquidation of $\mathrm{Mg}-\mathrm{Zn}$ eutectic is not surprising. This phenomenon occurred much more readily in concave tool design. Unlike, conventional flat scrolled shoulder, the concave shoulder carries a reservoir of plasticized material on the back of the tool. As the tool rotated and translated forward, the cavity around the shoulder results in higher negative hydrostatic pressure. While the constitutional liquidation occurring in the stir zone or the heat affected zone during friction stir welding is not new, this is a first observation in FaST joining. It is puzzling that the Mg-Zn eutectic flow is a straight line connecting the interface to the crown. (of course, the routes are different) this indicates that $\mathrm{Mg}-\mathrm{Zn}$ flow did not participate in the flow bulk matrix friction stir welding which is characterized by onion ring/circular flow. around and under the shoulder. One explanation for this, could be that the Mg$\mathrm{Zn}$ liquid flow from interface to the crown occurred after the bulk FSW process for a given volume of the material. The temperature and pressure condition becomes most amenable right after the tool pin is past the volume. At this point, the $\mathrm{Mg}-\mathrm{Zn}$ in a liquid state a transport through the "still hot" nugget material.

Upon lap shear testing, many of the samples containing this abnormal Mg-Zn flow resulted in much reduced load bearing capacity due to fracture occurring at the $\mathrm{Mg}$ sheet around the $\mathrm{Zn}$ flow. A journal article is currently being prepared to report on this phenomenon.

\subsubsection{DIC Analysis}

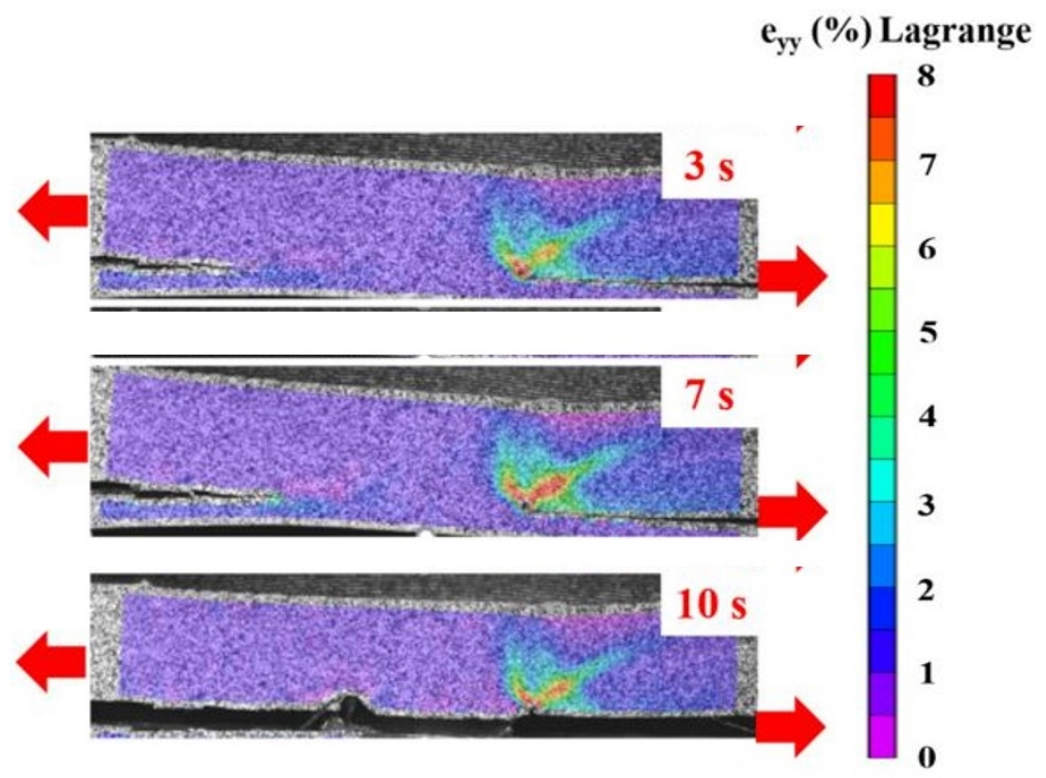

Figure 113 DIC analysis snapshots showing the fracture process of AZ31-HDG DP 590 (Source: PNNL) 
DIC analysis on testing of AZ31-HDG DP 590 is shown in Figure 113. Strain concentrated in AZ31 was observed above the AS hook from the beginning of the test, and crack propagated through the whole welded interface quickly after crossing the AS hook. There is no difference in the fracture behavior.

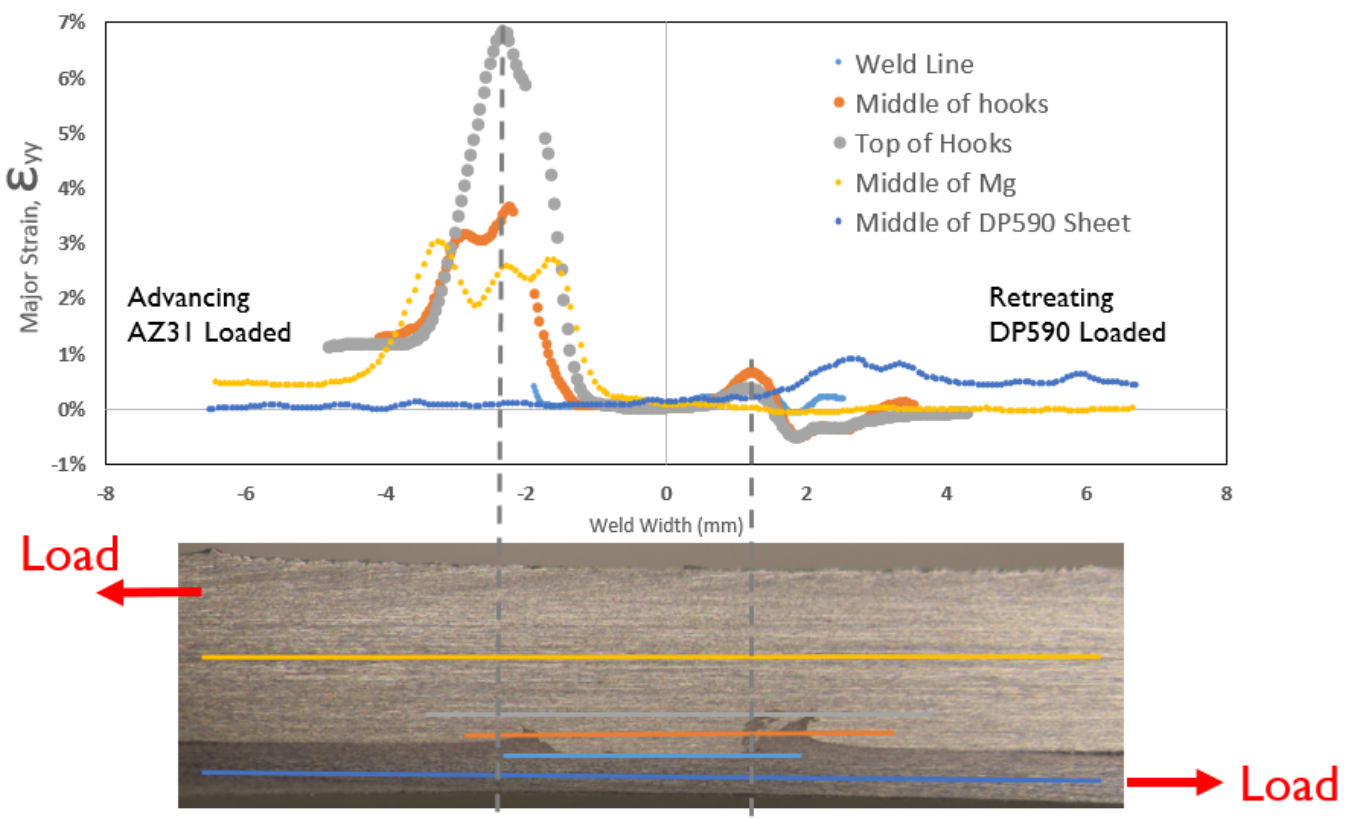

Figure 114 Strain distribution analysis through the section from DIC (Source: PNNL)

Strain distribution through the AZ31-DP 590 steel interface extrapolated from DIC are shown in Figure 114. Fracture mode during lap shear test for longitudinal whole weld (LWW) and weld center longitudinal (WCL) samples are shown in Figure 115. LWW fractured through the interface whereas WCL fractured by necking.

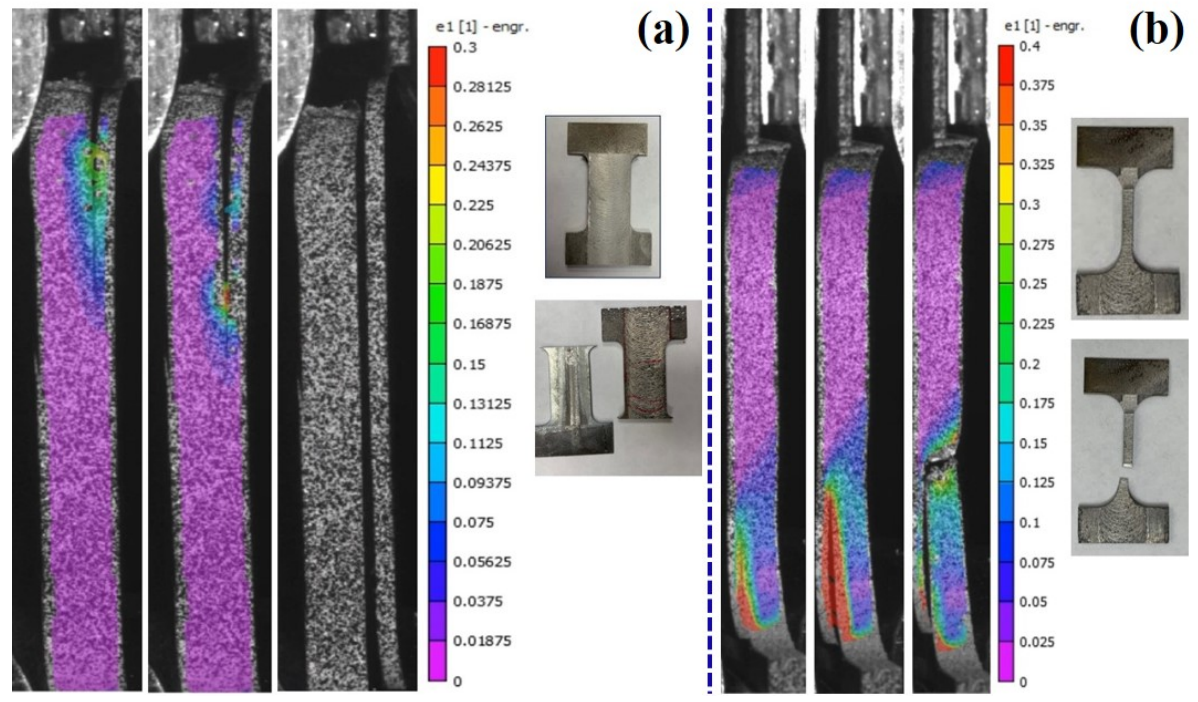

Figure 115 Fracture mode through DIC for (a) Longitudinal Whole Weld, (b) Weld Centre Longitudinal (Source: PNNL) 

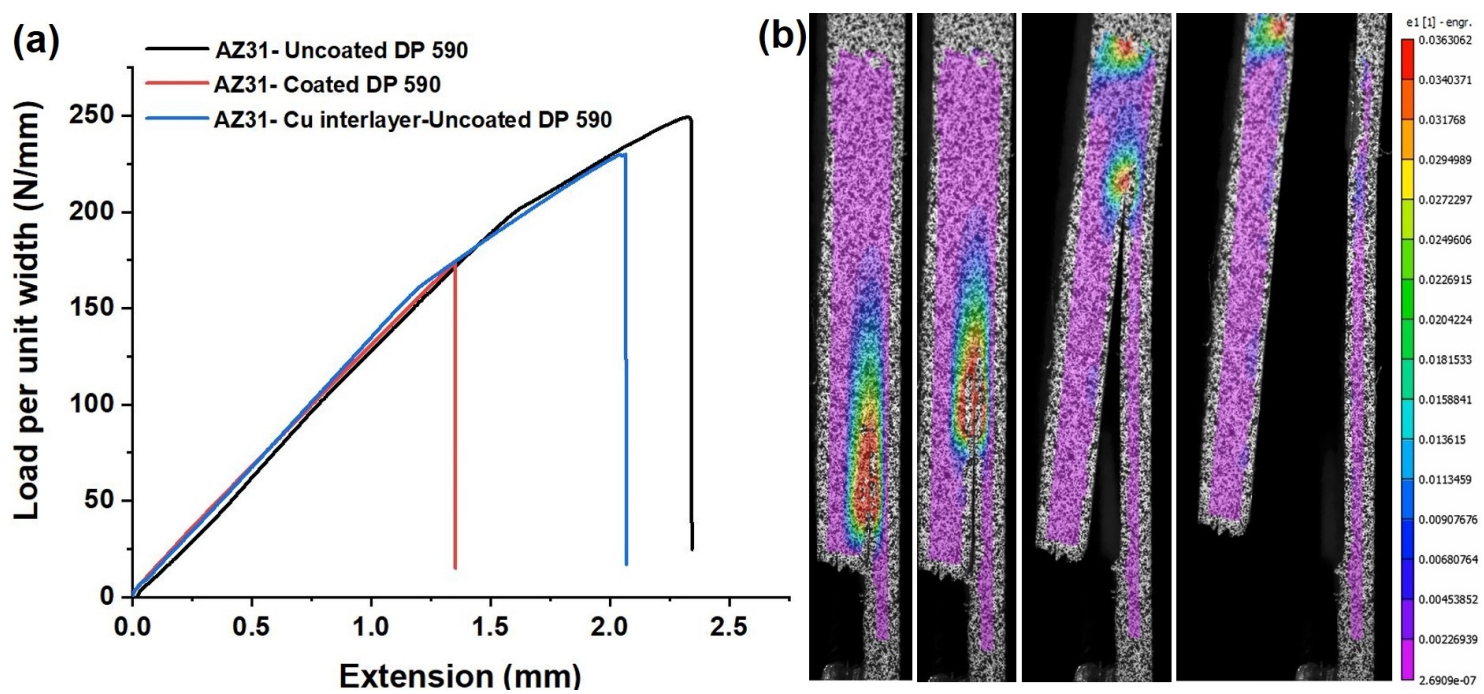

Figure 116 Comparison of lap shear tests for Az31-uncoated DP 590, AZ31-coated DP 590, AZ31-cu interlayer-uncoated DP 590 (Source: PNNL)

Figure 116 presents comparison of load bearing capacity for 3 different kind of joints. Joint strength increments in this order: AZ31-Zn coated DP $590<$ AZ31-Cu interlayer-uncoated DP 590 $<A Z 31$-uncoated DP 590. It clearly indicates that $\mathrm{Cu}$ interlayer enhance the joint strength compared to $\mathrm{Zn}$ coating. Mg-Cu eutectic has higher hardness compared to $\mathrm{Mg}$-Zn eutectic and this is the probable reason behind that.

\subsubsection{Preliminary corrosion test of joined samples}

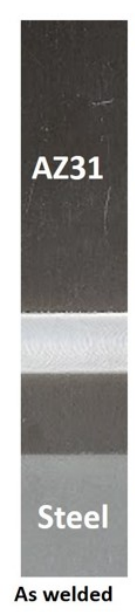

\section{(a)}

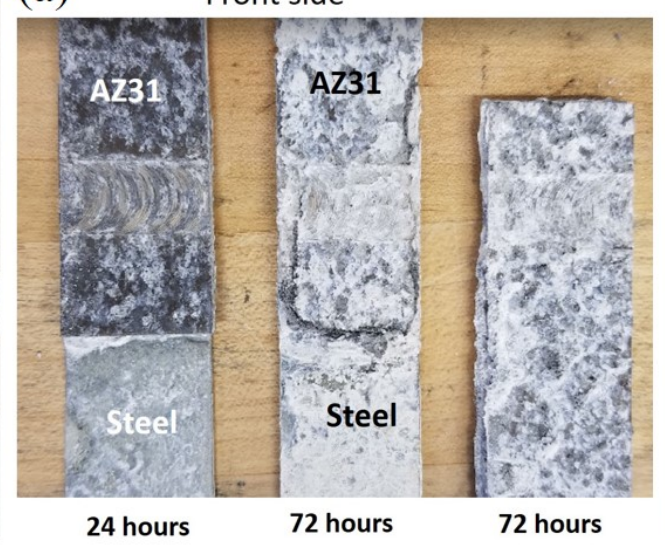

(b)

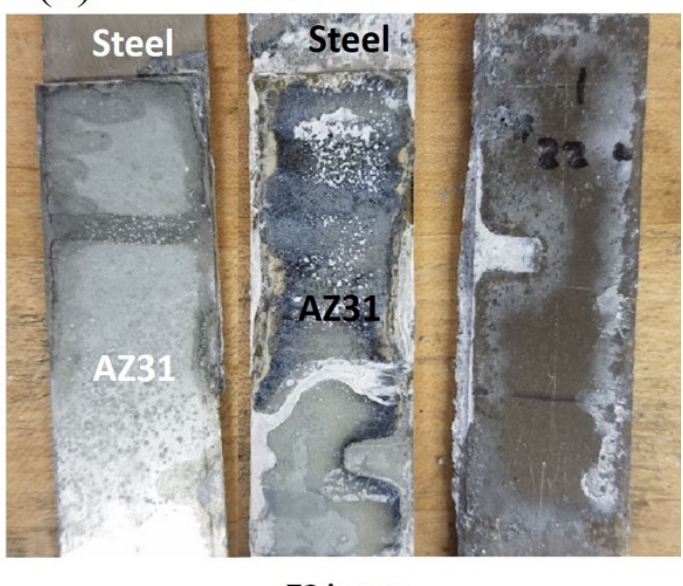

72 hours

Figure 117 AZ31-Zn coated DP 590 steel joint by FaST; After Salt-fog corrosion: front and back side of the joints after $24 \mathrm{hrs}$., $48 \mathrm{hrs}$. and $72 \mathrm{hrs}$. (Source: PNNL)

With increment in time from $24 \mathrm{hrs}$. to $72 \mathrm{hrs}$. test regime the top side corrodes severely though more pits observed in Mg side as shown in Figure 117 (a). Whereas, the back-side corrosion is not as prominent even after 72 hours (Figure 117 (b)). After 24 hours of exposure the lap shear strength did not reduce significantly $(209 \mathrm{~N} / \mathrm{mm}$ to $198 \mathrm{~N} / \mathrm{mm})$. 


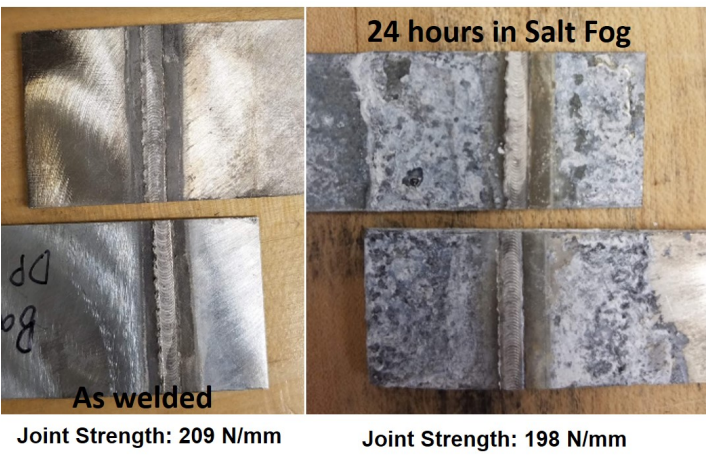

Figure 118 Lap shear samples before and after fog test AZ31-Zn coated DP 590 steel joint by FaST (Source: PNNL)

Preliminary corrosion testing was performed on Zn coated DP590-AZ31B joint coupons (welding condition: $3500 \mathrm{~W}$ for $4 \mathrm{~s}$ using single-head machine). After exposing the samples in the salt spray chamber for 24, 100 and 200 hours, they were taken out for subsequent lap shear testing. The fracture surfaces and the post-corrosion laps hear failure load as a function of salt-exposure time are shown in Figure 119. With 24 hour exposure in the salt spray, corrosion attack to the edge of the joint already occurred, resulting in a reduced failure load of $5.3 \mathrm{kN}$ compared to the base line failure load of 7 8kN as shown in Figure 120. With 100-hour exposure in salt, the post-corrosion lap shear failure further reduced to $2.4 \mathrm{kN}$. significant mass loss in $\mathrm{Mg}$ occurred as can been seen at the edge of the Mg sheet. With 200-hour salt exposure, Mg base metal broke due to galvanic corrosion.

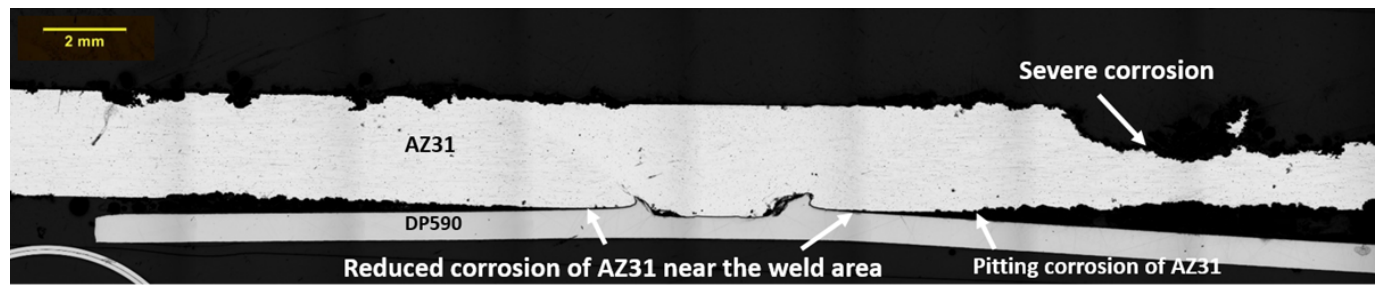

Figure $119 \mathrm{Mg} / \mathrm{Zn}$ coated steel FaST joint cross-section that was exposed to 72 hours inside a salt fog chamber per ASTM B117 showing areas with different extents of corrosion. (Source: PNNL)

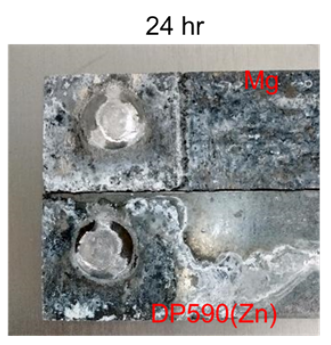

Lap shear failure load: $5.3 \mathrm{kN}$

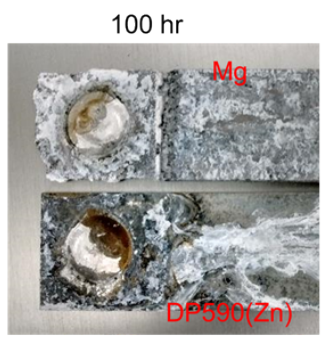

$2.4 \mathrm{kN}$
$200 \mathrm{hr}$

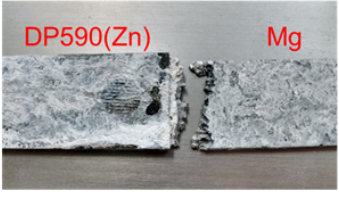

Not available*

* Sample broke at Mg base material due to severe corrosion

Figure 120 Fracture surface and post-corrosion lap shear failure load as a function of saltexposure time for AZ31-Zn coated DP 590 joints by USW (Source: ORNL) 
More comprehensive and detailed corrosion tests can be found in a separate report under Phase 1 of JCP.

\subsubsection{Cu interface layer reaction for AZ31 - uncoated DP 590 joint by FaST}

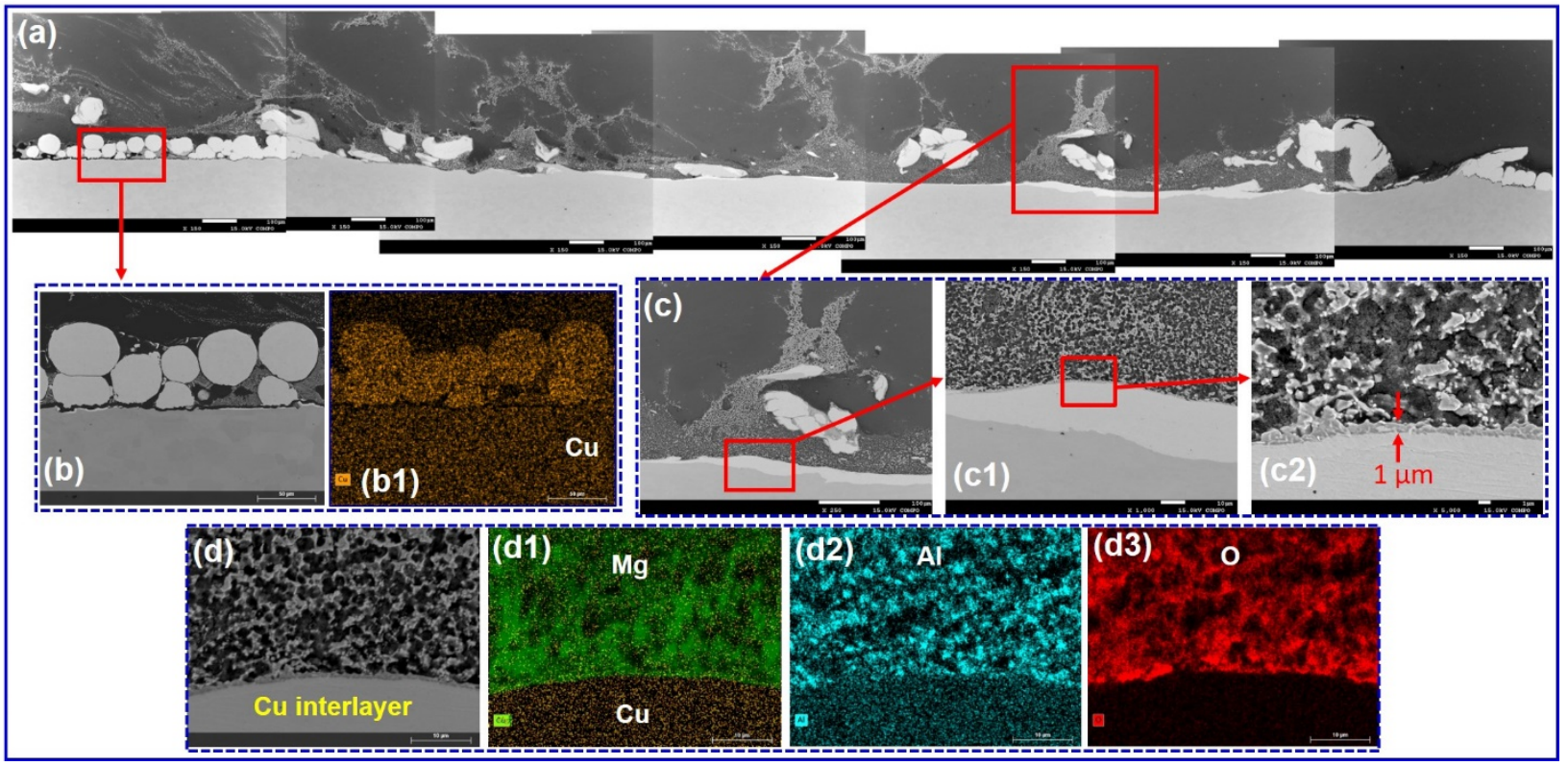

Figure 121 (a) SEM Cross section of AZ31-Uncoated DP 590 steel joint with Cu interlayer, Cu particles outside the joint regions (b) and EDS mapping (b1); Different magnification images close to the interface (c)-(c2), (d) Cu layer and Mg side with a thin interlayer at the interface, EDS elemental mapping of section d, (d1) $\mathrm{Mg}$ and $\mathrm{Cu}$, (d2) Al, (d3) O.

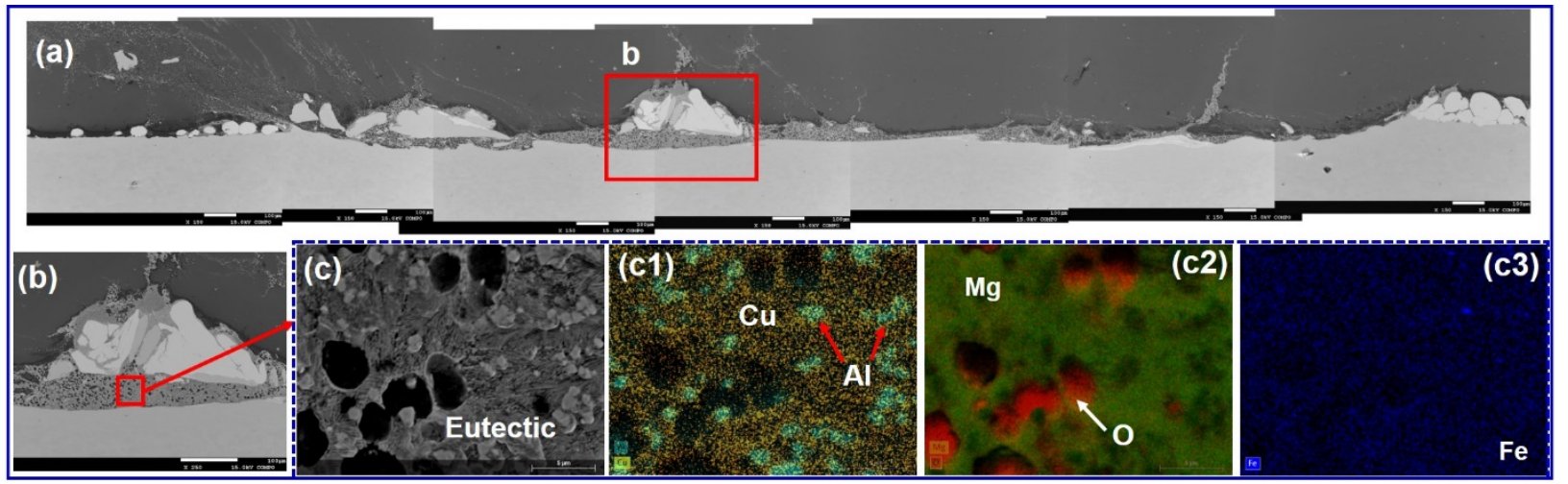

Figure 122 (a) SEM Cross section of another location of AZ31-Uncoated DP 590 steel, (b) high mag. image of section $b$ (marked red in (a)), (c) Eutectic formation at the interface, EDS elemental mapping at section $\mathrm{c},(\mathrm{c} 1) \mathrm{Cu}$ and $\mathrm{Al},(\mathrm{c} 2) \mathrm{Mg}$ and $\mathrm{O}$, (c3) Fe. 

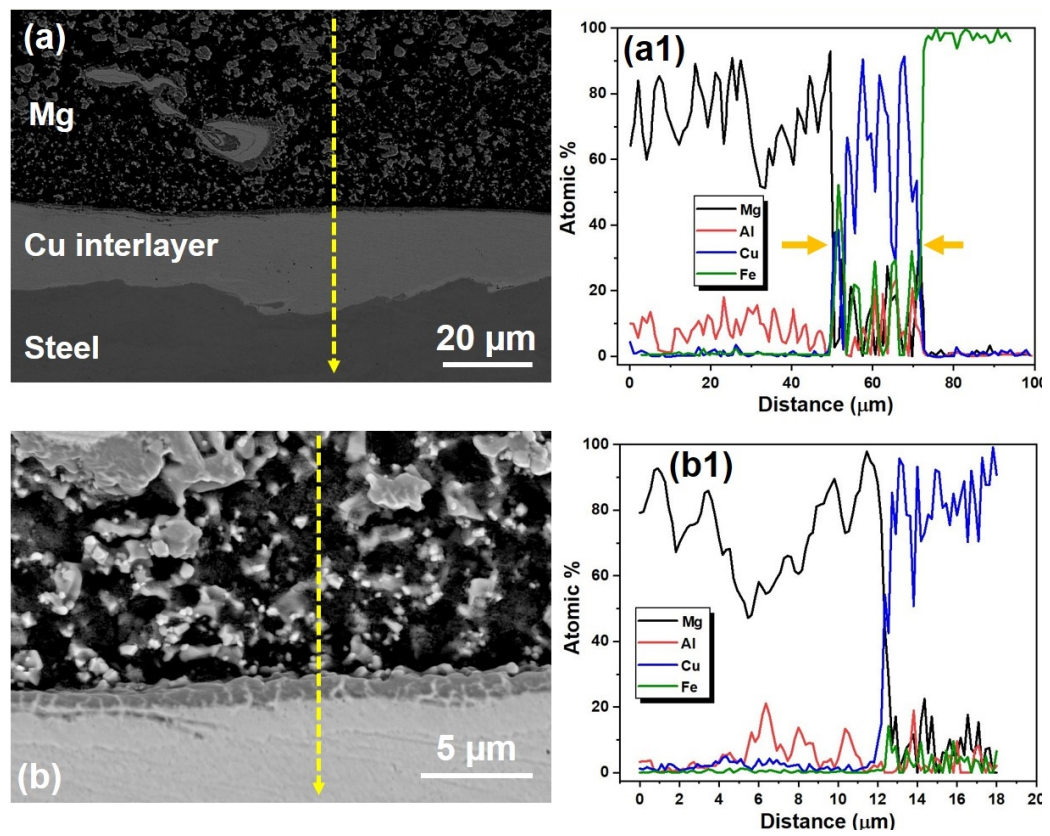

Figure 123 (a) SEM image showing line scan through Mg-Cu interlayer and Steel, (b) EDS line scan elemental profile.

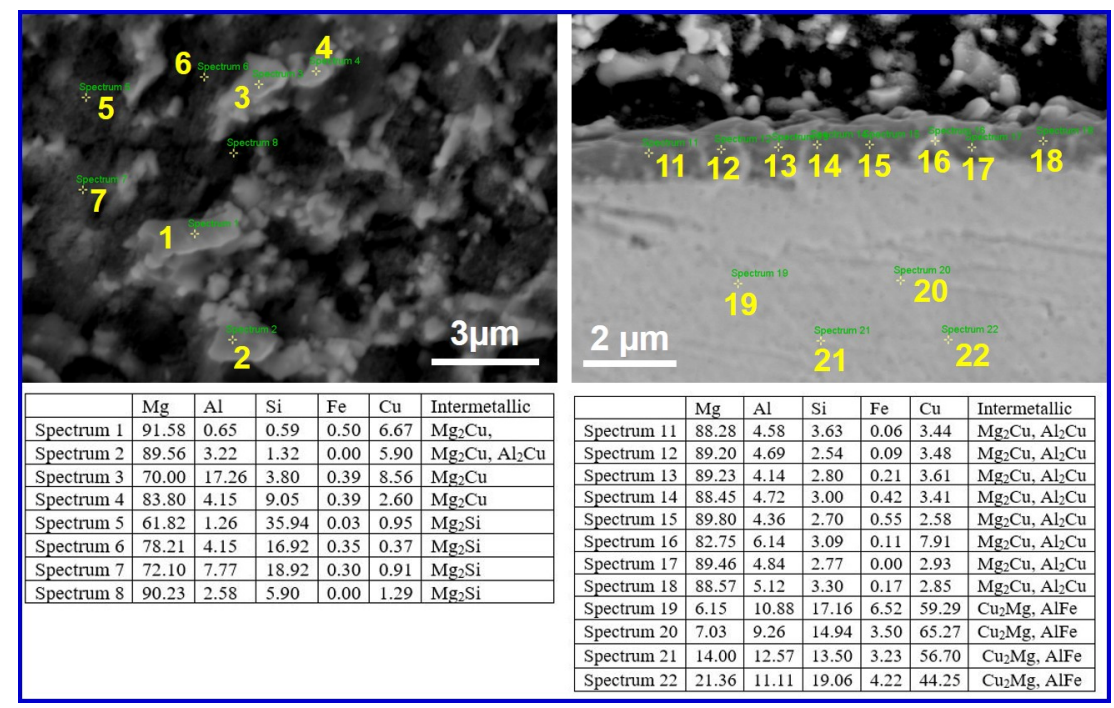

Figure 124 EDS point analysis at different locations towards the Mg side and at the interface (corresponding formation of probable IMC's mentioned in the table)

Magnesium and steel have been successfully joined by FAST without any macroscopic defects as shown in Figure 121(a) and Figure 122(a) (cross-sections of 2 different locations from a single weld). SEM micrograph shows the distribution of copper particles throughout the Mg/Steel interface. Moreover, the movement of copper particles from the interface towards the magnesium side is manifested as shown in Figure 121(a) and Figure 122(a). SEM and EDS analysis of the unprocessed copper particle $(55 \pm 25 \mu \mathrm{m})$ outside the hook is shown in Figure 121(b) and (b1). Whereas, after FAST, coarse Cu particles fragmented into fine particles $(4 \mu \mathrm{m}$ to $500 \mathrm{~nm})$ inside 
the hook. It indicates that high strain rate with severe plastic deformation and aggressive stirring at the interface during welding leading towards the refinement of copper particle size even submicron level. Some steel particle islands surrounded by fine $\mathrm{Cu}$ particles into the $\mathrm{Mg}$ side. It is obvious as some steel particle moving towards the Mg side during FAST. EDS mapping corroborated the formation of $\mathrm{Mg} / \mathrm{Cu}$ eutectic layer at the interface (Figure 122(c)-(c3)). Distinct interlayer of $1 \mu \mathrm{m}$ identifies between the $\mathrm{Mg} / \mathrm{Cu}$ interface. To understand the diffusion phenomenon line scanning been performed at the interface as shown in Figure 123. Figure 123 (a1) confirms the formation of $\mathrm{Cu}$ interlayer $(18 \pm 5 \mu \mathrm{m})$ at the $\mathrm{Mg} /$ steel interface (marked with red arrows). Concentration profile map (CPM) also shows that the interface consists of $\mathrm{Mg}, \mathrm{Al}$ and $\mathrm{Fe}$ as well (Figure 123 (a1)). Diffusion layer between Mg/Cu interface can be inferred from CPM. EDS assisted point analysis was performed at the interface and different layers to predict the formation of intermetallic (Figure $124 \mathrm{a}$ and b). The particles are mostly $\mathrm{Mg}_{2} \mathrm{Cu}$ and $\mathrm{Al}_{2} \mathrm{Cu}$ whereas the matrix consist of $\mathrm{Mg}$ and $\mathrm{Mg}_{2} \mathrm{Si}$. Interface also consists of $\mathrm{Mg}_{2} \mathrm{Cu}$ and $\mathrm{Al}_{2} \mathrm{Cu}$ intermetallic. Interestingly, the copper rich interlayer consists of $\mathrm{Cu}_{2} \mathrm{Mg}$ and $\mathrm{Al}-\mathrm{Fe}$ which is different $\mathrm{Zn}$ interlayer case. These point analyses data match well with concentration profile map in Figure $123 \mathrm{a}$ and $\mathrm{b}$. 


\subsection{Conclusion}

As a part of a multiyear, multi-lab collaborative effort to address key technical gaps in complex joining problems relevant to automotive sector, this project studied interfacial chemistry and established process-structure-property relationship in solid state dissimilar joining of Mg alloy to steel. Two solid state joining technologies namely Friction stir Assisted Scribe Technology and Ultra sonic welding were investigated. Variety of welded samples were tested and characterized to understand the relationship between welding conditions and joints microstructure and mechanical properties.

The knowledgebase on process development, in-situ and ex-situ characterization and structure to property relationship established in this project enables us to pursue developmental work on specific dissimilar joining problems faced by the automotive industry towards vehicle light weighting. 


\subsection{References}

1. FSLW of Mg alloy to steel: A preliminary investigation. Jana, S., Y. Hovanski, and G. J. Grant. 2010, Metall. Mater. Trans. A, pp. 3173-3182.

2. Formation of zinc interlayer texture during dissimilar ultrasonic spot welding of $\mathrm{Mg}$ and highstrength low alloy steel. Patel, V. K., S. D. Bhole, and D. L. Chen. 2013, Mater. Des., pp. 236240.

3. Friction stir scribe welding technique for dissimilar joining of $A l$ and galvanized steel. Wang, T., H. Sidhar, R. S. Mishra, Y. Hovanski, P. Upadhyay, and B. Carlson. 2017, Sci. Technol. Weld. Joi., pp. 249-255.

4. Joining of dissimilar materials. K. Martinsen, S.J. Hu, B.E. Carlson. 2015, CIRP Annals, pp. 679-699.

5. Method of connecting a metallic bolt to a plastic workpiece. S.T. Amancio-Filho, M. Beyer, J.F. dos Santos. 2005, German Patent DE102005056606.5.

6. Ensuring the integrity in clinching process. Varis, J. 2006, J. Mater. Process. Technol., pp. 277-285.

7. A new one-sided joining process for aluminum alloys: friction stir blind riveting. D. Gao, U. Ersoy, R. Stevenson, P.C. Wang. 2009, J. Manuf. Sci. Eng., p. 061002.

8. Plastic joining of ultra high strength steel and aluminum alloy sheets by self piercing rivet. $\mathrm{K}$. Mori, T. Kato, Y. Abe, Y. Ravshanbek. 2006, CIRP Annals, pp. 283-286.

9. Roller hemming apparatus and method. J.E. Carsley, W.W. Cai, G.A. Kruger, P.E. Krajewski, Y.T. Cheng. 2007, US Patent, p. 290.

10. Adhesion phenomena in bonded joints. Baldan, A. 2012, Int. J. Adhes. Adhes., p. 38.

11. A Review of Technologies for Welding Magnesium Alloys to Steels. Tianhao Wang, Piyush Upadhyay, Scott Whalen. 2020, International Journal of Precision Engineering and Manufacturing-Green Technology, pp. 1-16.

12. Interfacial structure of the joints between magnesium alloy and mild steel with nickel as interlayer by hybrid laser-TIG welding. X. Qi, G. Song. 2010, Mater. Design, pp. 605-609. 13. Microstructural characteristics of lap joint between magnesium alloy and mild steel with and without the addition of Sn element. L. Liu, X. Qi, Z. Wu. 2010, Materials Letters, pp. 89-92. 14. CO2 laser welding-brazing characteristics of dissimilar metals AZ31B Mg alloy to Zn coated dual phase steel with Mg based filler. L. Li, C. Tan, Y. Chen, W. Guo, C. Mei. 2013, J. Mater. Process. Technol., p. 213.

15. Effect of gradient thermal distribution on butt joining of magnesium alloy to steel with $\mathrm{Cu}-\mathrm{Zn}$ alloy interlayer by hybrid laser-tungsten inert gas welding. G. Song, G. An, L. Liu. 2012, Mater. Design, pp. 323-329.

16. Effect of reactive alloy elements on friction stir welded butt joints of metallurgically immiscible magnesium alloys and steel. T. Wang, S. Shukla, B. Gwalani, M. Komarasamy, L. Reza-Nieto, R.S. Mishra. 2019, J. Manuf. Processes, pp. 138-145.

17. The mechanisms of resistance spot welding of magnesium to steel. Metall. Mater. Trans. A, 41(10) (2010), pp. 2651-2661. L. Liu, L. Xiao, J.C. Feng, Y.H. Tian, S.Q. Zhou, Y. Zhou. 2019, J. Manuf. Processes, pp. 138-145.

18. Joint formation in dissimilar Al alloy/steel and Mg alloy/steel friction stir spot welds. T. Liyanage, J. Kilbourne, A.P. Gerlich, T.H. North. 2009, Sci. Technol. Weld. Joining, pp. 500-508. 19. Formation of zinc interlayer texture during dissimilar ultrasonic spot welding of magnesium and high strength low alloy steel. V.K. Patel, S.D. Bhole, D.L. Chen. 2013, Mater. Design, pp. 236-240.

20. utectic bonding of austenitic stainless steel 316L to magnesium alloy AZ31 using copper interlayer. W.M. Elthalabawy, T.I. Khan. 2011, Int. J. Adv. Manuf. Technol., pp. 235-241. 
PNNL-30945

21. Friction Stir Scribe Process for Joining Dissimilar Materials.

https://www. youtube.com/watch?v=c5nM0CVYOil\&ab. [Online] 2017.

22. Microstructure, welding mechanism, and failure of Al/Cu ultrasonic welds. Wu, X., Liu, T. and Cai, W. 2015, J. Manuf. Process, pp. 321-331.

23. The formation of ultrasonic bonds between metals. Joshi, K.C. 1971, Weld. J., pp. 840-848.

24. Macrosonics in industry 2: Ultrasonic welding of metals. Hulst, A.P. 1972, Ultrasonics, pp.

252-261.

25. Daniels, H.P.C. 1965, Ultrasonics, p. 190.

26. $h$ ttps://www. youtube.com/watch? $v=c 5 n M 0 C V Y 0 i / \& a b$. [Online] 


\section{Appendix A -Publications and Presentations}

1. Upadhyay, P., Feng Z. 2018, "Solid-state joining of magnesium sheet to high-strength steel," Annual Merit Review Meeting, 20 $0^{\text {th }}$ June 2018, Arlington, VA, USA. https://www.energy.gov/eere/vehicles/annualmerit-review-presentations

2. Upadhyay, P. Feng Z., 2019, "Solid-state joining of magnesium sheet to high-strength steel," Annual Merit Review Meeting, 12 ${ }^{\text {th }}$ June 2019, Arlington, VA, USA. https://www.energy.gov/eere/vehicles/annualmerit-review-presentations

3. Upadhyay, P., Feng Z. 2020, "Solid-state joining of magnesium sheet to high-strength steel," Virtual Annual Merit Review Meeting, 1-4 June 2020. https://www.energy.gov/eere/vehicles/annual-meritreview-presentations

4. Das, H., Upadhyay, P., Wang, T. et al. Interfacial reaction during friction stir assisted scribe welding of immiscible Fe and Mg alloy system. Sci Rep 11, 1588 (2021).

5. Shank S Kulkarni, Varun Gupta, Angel Ortiz, Hrishikesh Das, Piyush Upadhyay, Erin Barker, Darrell Herling, Determining cohesive parameters for modeling interfacial fracture in dissimilar-metal friction stir welded joints, International Journal of Solids and Structures, In Press, https://www.sciencedirect.com/science/article/pii/S0020768321000317

6. Shank Kulkarni; Hrishikesh Das; Daniel Ramírez Tamayo; Xiaolong Ma; Tianhao Wang; Dalong Zhang; Piyush Upadhyay; Kyoo Sil Choi; Ayoub Soulami; Darrell Herling, Towards joining phenomenon of AZ31 magnesium to uncoated DP590 steel using FaST: Understanding the contributions of mechanical versus metallurgical bonding, submitted in International Journal of Advanced Manufacturing Technology.

7. Chen, J., Y. Lim, H. Huang, Z. Feng, and X. Sun, 2019, "Ultrasonic welding of AZ31B magnesium alloy," MRS Bulletin, Vol. 44, No. 8, pp. 630-636.

8. Chen, J., Y. Lim, H. Huang, Z. Feng, and X. Sun, 2018, “Ultrasonic joining of magnesium to steel," AWS Professional Program, 6-7 November 2018, Atlanta, GA, USA.

9. Wang, T., et al, 2020, "Effect of interfacial characteristics on the mechanical performance of magnesium to steel joint obtained using FaST," Materials \& Design Vol.192, pp108697.

10. Chen, J., Y. C. Lim, D. Leonard, H. Huang, Z. Feng, and X. Sun, 2020, "In-situ and post-mortem characterizations of ultrasonic spot welded AZ31B and coated dual phase 590 steel joints," Metals, Vol. 10, No. 7, Art. 899.

11. Huang, H., J. Chen, Y. C. Lim, X. Hu, J. Cheng, Z. Feng, and X. Sun, 2019, "Heat generation and deformation in ultrasonic welding of magnesium alloy AZ31," J. Mater. Process Technol., Vol. 272, pp. $125-136$

12. A Review of Technologies for Welding Magnesium Alloys to Steels. Tianhao Wang, Piyush Upadhyay, Scott Whalen. 2020, International Journal of Precision Engineering and Manufacturing-Green Technology, pp. $1-16$. 


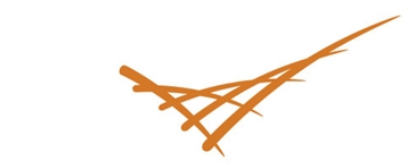

Pacific Northwest

U.S. DEPARTMENT OF ENERGY

Office of

ENERGY EFFICIENCY \& RENEWABLE ENERGY
Vehicle Technologies Office

JOINING CORE PROGRAM 